\section{Pacific Northwest}

National Laboratory

Operated by Battelle for the

U.S. Department of Energy

\title{
Plutonium Speciation in Support of Oxidative-Leaching Demonstration Test
}

SI Sinkov

October 2007

Prepared for the U.S. Department of Energy under Contract DE-AC05-76RL01830 


\title{
DISCLAIMER
}

This report was prepared as an account of work sponsored by an agency of the United States Government. Neither the United States Government nor any agency thereof, nor Battelle Memorial Institute, nor any of their employees, makes any warranty, express or implied, or assumes any legal liability or responsibility for the accuracy, completeness, or usefulness of any information, apparatus, product, or process disclosed, or represents that its use would not infringe privately owned rights. Reference herein to any specific commercial product, process, or service by trade name, trademark, manufacturer, or otherwise does not necessarily constitute or imply its endorsement, recommendation, or favoring by the United States Government or any agency thereof, or Battelle Memorial Institute. The views and opinions of authors expressed herein do not necessarily state or reflect those of the United States Government or any agency thereof.

\author{
PACIFIC NORTHWEST NATIONAL LABORATORY \\ operated by \\ BATTELLE \\ for the \\ UNITED STATES DEPARTMENT OF ENERGY \\ under Contract DE-AC05-76RL01830
}


PNNL-16844

WTP-RPT-165, Rev 0

\title{
Plutonium Speciation in Support of Oxidative-Leaching Demonstration Test
}

\author{
S. I. Sinkov
}

October 2007

Test specification: 24590-PTF-TSP-RT-06-002, Rev 0.

Test plan: TP-RPP-WTP-445

Test exceptions: none

R\&T focus area: Pretreatment

Test scoping statements(s): None

Pacific Northwest National Laboratory

Richland, Washington 99352 


\section{Completeness of Testing}

This report describes the results of work and testing specified by test plan TP-RPP$W T P-445$. The work and any associated testing followed the quality assurance requirements outlined in the test specification/plan. The descriptions provided in this test report are an accurate account of both the conduct of the work and the data collected. Test plan results are reported. Also reported are any unusual or anomalous occurrences that are different from expected results. The test results and this report have been reviewed and verified.

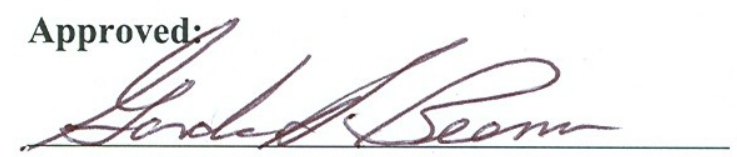

Gordon H. Beeman, Manager WTP R\&T Support Project

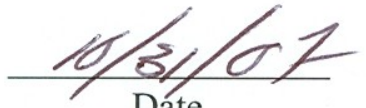

Date 


\section{Contents}

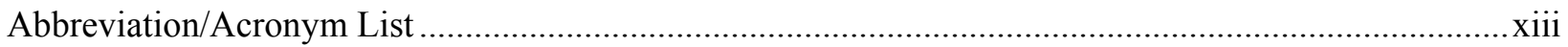

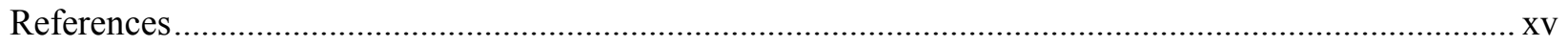

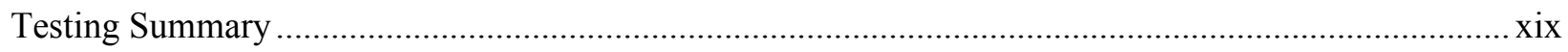

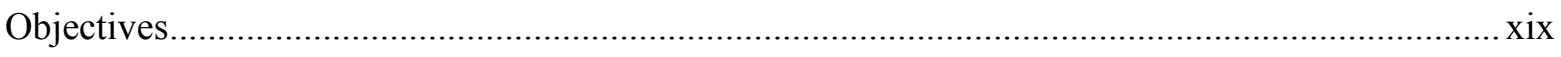

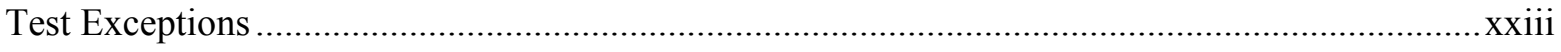

Results and Performance Against Success Criteria...........................................................................

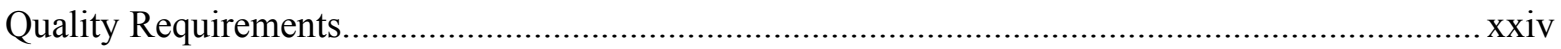

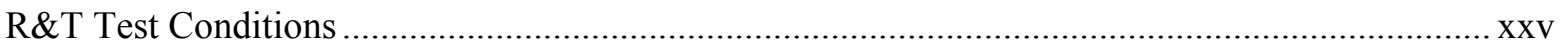

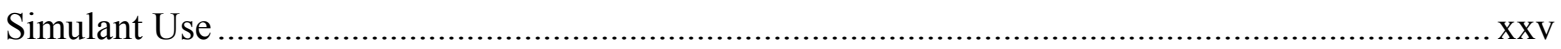

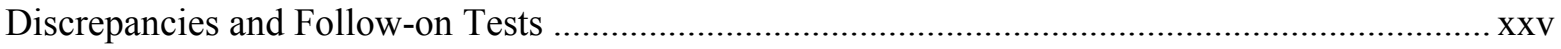

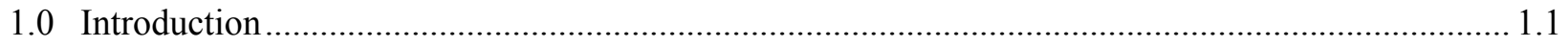

1.1 Oxidation States and Redox Stability of $\mathrm{Pu}(\mathrm{IV}, \mathrm{V}$, and V) in an Alkaline Medium................. 1.2

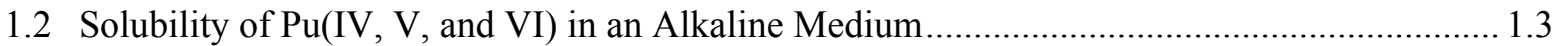

1.3 Controversy in Determination of Stability Fields of $\mathrm{Pu}(\mathrm{IV}), \mathrm{Pu}(\mathrm{V})$, and $\mathrm{Pu}(\mathrm{VI})$ Soluble

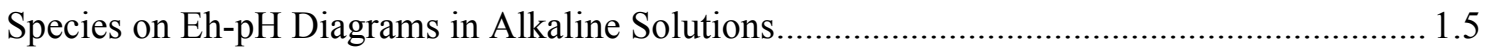

1.4 Direct Speciation of Pu at Low Micromolar Concentrations by Spectroscopic Techniques ..... 1.8

1.5 $\mathrm{Pu}$ Solubilization and Speciation in the Process of Oxidative Alkaline Leaching of

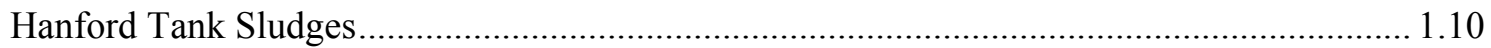

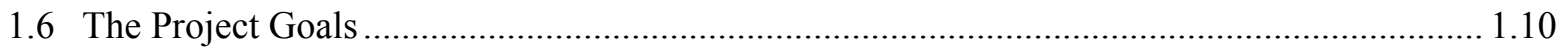

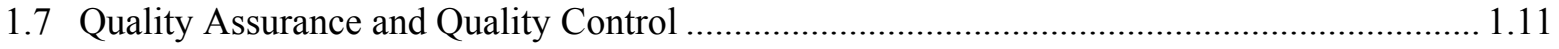

1.7.1 Application of RPP-WTP Quality Assurance Requirements..................................... 1.11

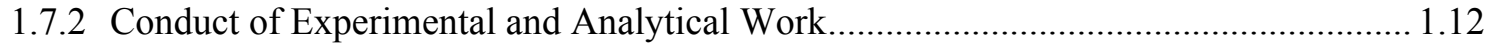

1.7.3 Internal Data Verification and Validation............................................................. 1.12

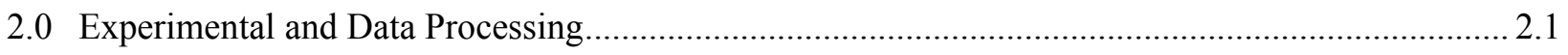

2.1 Reagents and Solvents Used in Calibration, Sludge Preparation, and Oxidative-Leaching

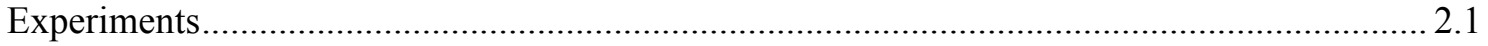

2.2 The Preparation, Purification, and Valence-State Adjustment of Pu Stock Solutions ............... 2.1

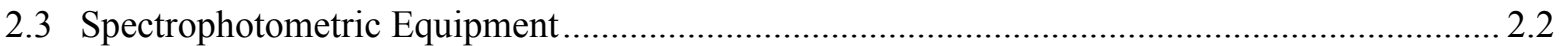

2.4 Calibration and Speciation Experiments with LWCC (cold testing and Pu calibrations)......... 2.3

2.5 Determination of Pu Concentration in Calibration Solutions and Leachates ........................... 2.3

2.6 Preparation of the $\mathrm{Fe}(\mathrm{OH})_{3} / \mathrm{Cr}(\mathrm{OH})_{3} / \mathrm{Pu}(\mathrm{OH})_{4}$ Sludge Simulant and Oxidative-Leaching Procedure. 
2.7 Measurements of Eh and $\mathrm{pH}$

2.8 Determination of $\mathrm{Cr}(\mathrm{VI}), \mathrm{Mn}(\mathrm{VII})$, and $\mathrm{Mn}(\mathrm{VI})$ Concentrations in the Course of Oxidative-Leaching Experiments

2.9 Baseline Subtraction and Net Peak Intensity Determination in $\mathrm{Nd}$ and $\mathrm{Pu}$ Calibration Experiments.

2.10 Simulation and Elimination of Waveform-Shaped Spectral Interference in LWCC Spectra

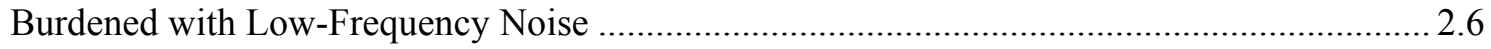

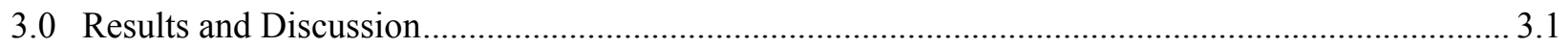

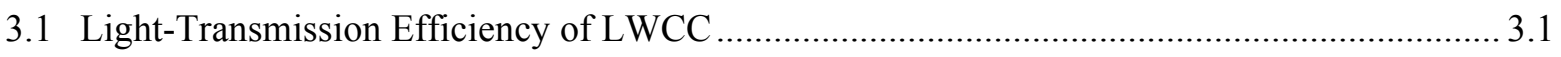

3.2 Demonstration of Identity of Spectral Features of $\mathrm{Nd}(\mathrm{III})$ in $\mathrm{H}_{2} \mathrm{O}$ and $\mathrm{D}_{2} \mathrm{O}$.............................. 3.4

3.3 Cold Testing of LWCC Using Nd(III) Complex with EDTA in $0.1 \mathrm{M} \mathrm{NaOH}$ and

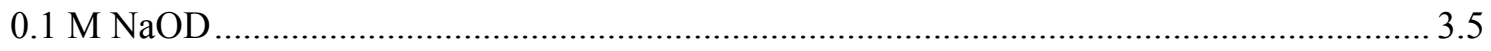

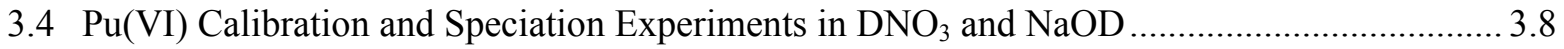

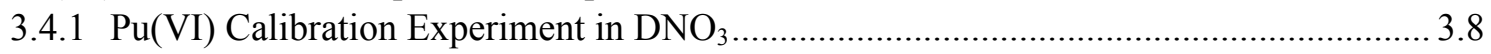

3.4.2 Pu(VI) Calibration Experiments in NaOD ............................................................. 3.10

3.4.3 Pu(VI) Spectra in the Presence of Carbonate at Constant Concentration of

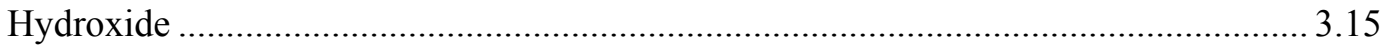

3.5 $\mathrm{Pu}(\mathrm{V})$ Calibration and Speciation Experiments in $\mathrm{NaOD}$........................................................ 3.17

3.5.1 Preparation and Characterization of $\mathrm{Pu}(\mathrm{V})$ Solution in $14 \mathrm{M}$ of $\mathrm{NaOD}$.......................... 3.17

3.5.2 $\mathrm{Pu}(\mathrm{V})$ Calibration and Speciation Experiments in $\mathrm{NaOD}$.......................................... 3.20

3.5.3 $\mathrm{Pu}(\mathrm{V})$ Spectra in the Presence of Carbonate at Constant Concentration of

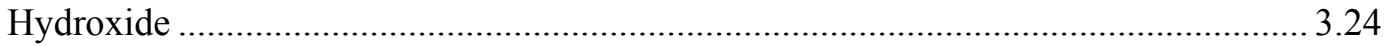

3.5.4 Pu(V) Redox Speciation After Acidification of Initially Alkaline Pu(V) Solution by $\mathrm{DNO}_{3}$ at a Low Micromolar Concentration of $\mathrm{Pu}(\mathrm{V})$............................................. 3.29

3.5.5 Determination of Formal Electrochemical Potential of $\mathrm{Pu}(\mathrm{VI}) / \mathrm{Pu}(\mathrm{V})$ Couple in 0.25 M to 1.0 M NaOD Using Direct Potentiometric Measurement with an ORP Electrode

$3.6 \mathrm{Pu}(\mathrm{IV})$ Spectral Measurements in $\mathrm{DNO}_{3}$ and $\mathrm{NaOD}$....................................................... 3.32

3.6.1 Verification of Identity of Spectral Features of $\mathrm{Pu}(\mathrm{IV})$ in $4 \mathrm{M}$ of $\mathrm{HNO}_{3}$ and

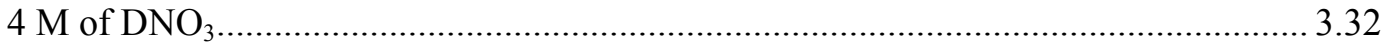

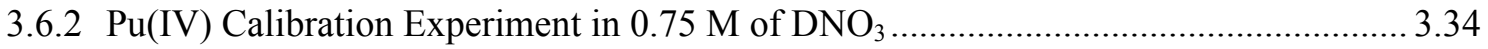

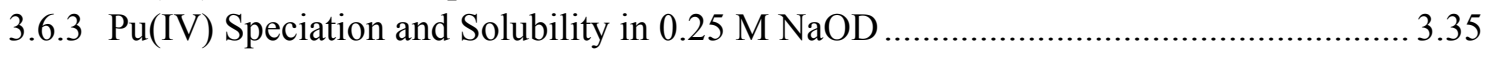

3.6.4 $\mathrm{Pu}(\mathrm{IV})$ Speciation and Solubility in $0.25 \mathrm{M} \mathrm{NaOD}$ in the Presence of Carbonate ........ 3.37

3.7 Oxidative Dissolution of Pu(IV) Hydroxide Suspension by Permanganate and Manganate

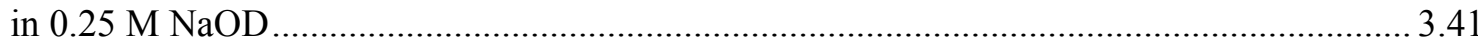

3.7.1 Oxidative Dissolution of $\mathrm{Pu}^{\mathrm{IV}}(\mathrm{OH})_{4}$ Suspension by $\mathrm{NaMnO}_{4}$ in $0.25 \mathrm{M} \mathrm{NaOD}^{2 . . . . . . . . . . ~} 3.41$

3.7.2 Oxidative Dissolution of $\mathrm{Pu}^{\mathrm{IV}}(\mathrm{OH})_{4}$ Suspension by Sodium Manganate in

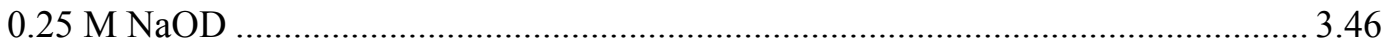

3.8 Oxidation of $\mathrm{Pu}(\mathrm{IV})$ by Permanganate in Acidic Solution.................................................. 3.48

3.8.1 Oxidative Dissolution of Pu(IV) Hydroxide Suspension by Permanganate in $1 \mathrm{M} \mathrm{DNO}_{3}$ 3.48 
3.8.2 Oxidation of Ionic $\mathrm{Pu}(\mathrm{IV})$ by Permanganate in $1 \mathrm{M} \mathrm{DNO}_{3}$ and the Effect of Dichromate on the Kinetics of this Process

3.9 Interaction of $\mathrm{Pu}(\mathrm{V})$ with Low Levels of Manganate in $0.25 \mathrm{M} \mathrm{NaOD}$

3.9.1 ORP Measurements in Manganate-Containing Solutions and Manganate-

Permanganate Mixtures in NaOD Solutions.

3.9.2 Instability of Permanganate and Manganate in 0.25 M NaOD at Low Micromolar Concentration of Initially Added Mn(VII) by Spectral Measurements with LWCC..... 3.52

3.9.3 Oxidation of $\mathrm{Pu}(\mathrm{V})$ by Manganate in $0.25 \mathrm{M} \mathrm{NaOD}$ Monitored by LWCC

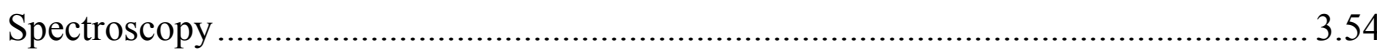

3.10 Oxidative Leaching of $\mathrm{Fe}(\mathrm{OH})_{3} / \mathrm{Cr}(\mathrm{OH})_{3} / \mathrm{Pu}(\mathrm{OH})_{4}$ Sludge Simulant with Permanganate ...... 3.55

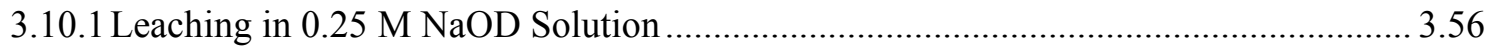

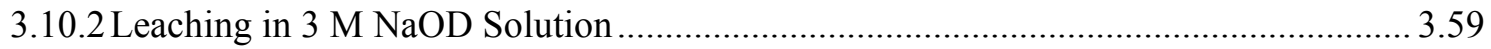

3.10.3 Quenching of Excessive Manganate in the Leachates with Weakly Acidic Solution

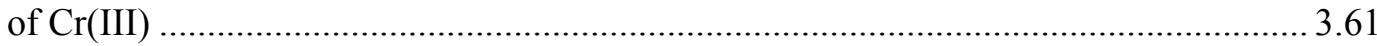

3.10.4 Comparison of Oxidative Alkaline Leaching of Pu from Sludge Simulant with

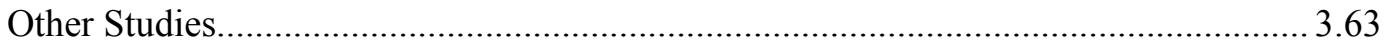

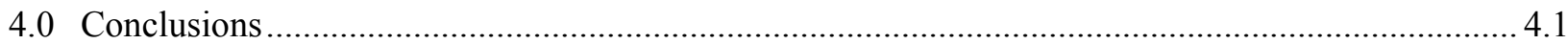

4.1 Summary of Dissolution of $\mathrm{Pu}(\mathrm{OH})_{4}$ (solid) in Alkaline Permanganate and Manganate

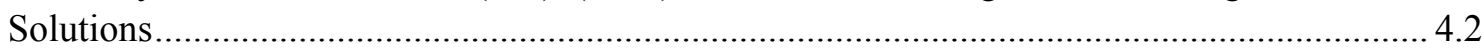

4.2 Summary of Oxidative Leaching of $\mathrm{Fe}(\mathrm{OH})_{3}+\mathrm{Cr}(\mathrm{OH})_{3}+\mathrm{Pu}(\mathrm{OH})_{4}$ Sludge Simulant ............... 4.2 


\section{Figures}

1.1. Formal Potentials of Various $\mathrm{Pu}$ Couples as a Function of $\mathrm{NaOH}$ Concentrations ......................... 1.3

1.2. Solubility Curves of $\mathrm{Pu}(\mathrm{IV}), \mathrm{Pu}(\mathrm{V})$ and $\mathrm{Pu}(\mathrm{VI})$ as a Function of $\mathrm{NaOH}$ Concentration................. 1.4

1.3. Eh-pH Diagram for Plutonium Based on Standard Redox Potentials and Hydrolysis Reactions

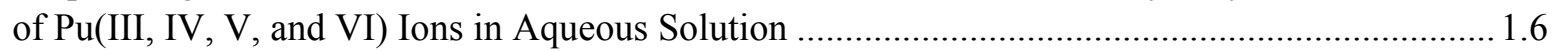

1.4. Eh-pH Diagram for Plutonium in Groundwater Containing Hydroxide, Carbonate, and Fluoride Ions

1.5. Eh-pH Diagram for Plutonium in Groundwater at $25^{\circ} \mathrm{C}$ Under Conditions Representative of J-13 Water Found Near the Proposed Yucca Mountain Nuclear Waste Repository .................... 1.8

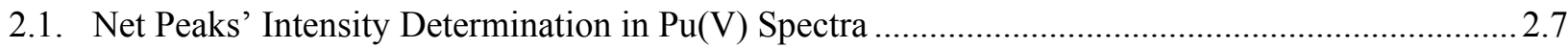

2.2. Manganate Reduction After Adding $\mathrm{Pu}(\mathrm{V})$. Initial $\mathrm{Mn}(\mathrm{VI})$ and $\mathrm{Pu}(\mathrm{V})$ concentrations are

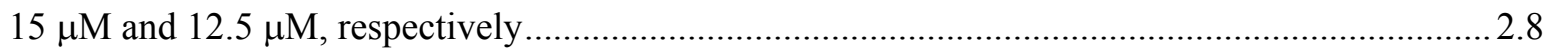

3.1. Light Intensity Spectra After Exiting a 5-m LWCC Filled with 99.8\% $\mathrm{D}_{2} \mathrm{O}$................................ 3.2

3.2. Light-Intensity Spectra After Passing Through a 1-cm Quartz Cell Filled with $99.8 \% \mathrm{D}_{2} \mathrm{O} \ldots \ldots \ldots . . .3 .2$

3.3. Light-Intensity Spectra with Direct Light Coupling to the Spectrophotometer............................... 3.3

3.4. Spectra of $0.2 \mathrm{mM} \mathrm{Nd}\left(\mathrm{NO}_{3}\right)_{3}$ Solution in $\mathrm{D}_{2} \mathrm{O}$ and $\mathrm{H}_{2} \mathrm{O}$ in $0.015 \% \mathrm{HNO}_{3}$ and $\mathrm{DNO}_{3}$,

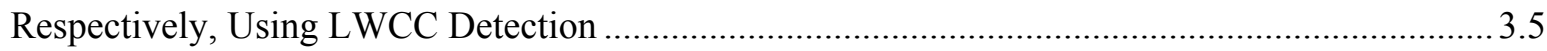

3.5. Spectra of $\mathrm{Na}_{2} \mathrm{CrO}_{4}$ Solution in $\mathrm{D}_{2} \mathrm{O}$ at $4 \mathrm{mM}$ and $40 \mathrm{mM}$ of $\mathrm{Cr}(\mathrm{VI})$.........................................

3.6. Calibration of LWCC Using Nd(III) Solution in the Presence of $0.25 \mathrm{M}$ of $\mathrm{Na}_{4}$ EDTA in $0.1 \mathrm{M}$ of Sodium Hydroxide: a) $\mathrm{NaOH} / \mathrm{H}_{2} \mathrm{O}$ no chromate b) $\mathrm{NaOD} / \mathrm{D}_{2} \mathrm{O}$ no chromate c) $\mathrm{NaOH} / \mathrm{H}_{2} \mathrm{O}+50 \mathrm{mM}$ of $\mathrm{Na}_{2} \mathrm{CrO}_{4}$ d) $\mathrm{NaOD} / \mathrm{D}_{2} \mathrm{O}+50 \mathrm{mM}$ of $\mathrm{Na}_{2} \mathrm{CrO}_{4}$

3.7. $\mathrm{Pu}(\mathrm{VI})$ Acidic Stock Solution Spectra in $0.5 \mathrm{M}$ of $\mathrm{HNO}_{3}$ [a) and b)] and $0.5 \mathrm{M}$ of $\mathrm{DNO}_{3}$ [c) and d)].

3.8. Calibration Experiment with $\mathrm{Pu}(\mathrm{VI})$ in $0.1 \mathrm{M}$ of $\mathrm{DNO}_{3}$ Using $500 \mathrm{~cm} \mathrm{LWCC}$

3.9. Calibration Experiments with $\mathrm{Pu}(\mathrm{VI})$ in $0.1 \mathrm{M}$ of $\mathrm{NaOD}$

3.10. Calibration Experiments with $\mathrm{Pu}(\mathrm{VI})$ in $1 \mathrm{M} \mathrm{NaOD}$

3.11. Spectral Evidence of Partial Reduction of $\mathrm{Pu}(\mathrm{VI})$ to $\mathrm{Pu}(\mathrm{V})$ in $1 \mathrm{M} \mathrm{NaOD}$ with Time

3.12. $\mathrm{Pu}(\mathrm{VI})$ Spectra in $0.1 \mathrm{M} \mathrm{NaOD}$ a), $0.25 \mathrm{M} \mathrm{NaOD}$ b), and $1 \mathrm{M} \mathrm{NaOD} \mathrm{c}$ ) in the Presence of Carbonate. 
3.13. Literature Data on $\mathrm{Pu}(\mathrm{V})$ Spectra in Concentrated Sodium Hydroxide.

3.14. Pu Spectra in $14 \mathrm{M}$ NaOD 20 Days After Adding Acidic Pu(IV) (red trace) and $\mathrm{Pu}(\mathrm{VI})$ (black trace) to an Excess of $14.9 \mathrm{M} \mathrm{NaOD}$

3.15. Comparison of the Stock Solution of $0.811 \mathrm{mM} \mathrm{Pu}(\mathrm{V})$ in $14 \mathrm{M} \mathrm{NaOD}$ Measured with

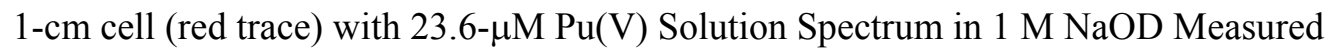
by LWCC (blue trace).

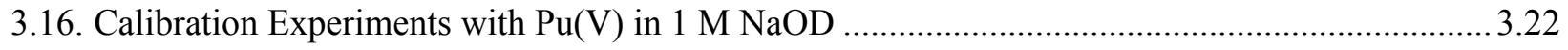

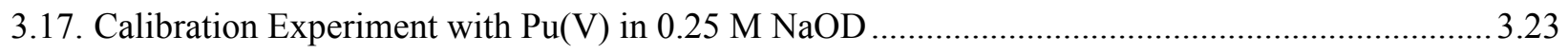

3.18. Calibration Experiments with $\mathrm{Pu}(\mathrm{V})$ in $1 \mathrm{M} \mathrm{NaOD}$ in the Presence of $50 \mathrm{mM}$ Chromate............. 3.25

3.19. Calibration Experiments with $\mathrm{Pu}(\mathrm{V})$ in $0.25 \mathrm{M} \mathrm{NaOD}$ in the Presence of $50 \mathrm{mM}$ Chromate........ 3.26

3.20. $\mathrm{Pu}(\mathrm{V})$ Spectra in $0.25 \mathrm{M} \mathrm{NaOD}$ a), and $1 \mathrm{M} \mathrm{NaOD} \mathrm{b})$ in the Presence of Carbonate.....................3.28

3.21. Spectra of $\mathrm{Pu}(\mathrm{V})$ After Acidic Strike of Small Amount of $\mathrm{Pu}(\mathrm{V})$ Stock in $14 \mathrm{M} \mathrm{NaOD}$ with a Slight Molar Excess of $0.4 \mathrm{M} \mathrm{DNO}_{3}$ Solution.....

3.22. Spectra of $\mathrm{Pu}(\mathrm{V})$ After Acidic Strike of Tiny Amount of $\mathrm{Pu}(\mathrm{V})$ Stock in $14 \mathrm{M}$ NaOD into a Slight Molar Excess of $0.4 \mathrm{M} \mathrm{DNO}_{3}$ Containing $5 \mathrm{mM}$ of Chromate (physically present as $2.5 \mathrm{mM}$ dichromate)

3.23. Spectra of $\mathrm{Pu}(\mathrm{VI})+\mathrm{Pu}(\mathrm{V})$ Solutions in $\mathrm{NaOD}$ Solutions at Total Concentration of $\mathrm{Pu}$ at $20 \mu \mathrm{M}$.

3.24. Optical Absorbance Spectra of $18 \mathrm{mM} \mathrm{Pu}(\mathrm{IV})$ in $4.0 \mathrm{M} \mathrm{HNO}_{3}$ (black trace) and 4.0 $\mathrm{M} \mathrm{DNO}_{3}$ (red trace)

3.25. Calibration Experiment with $\mathrm{Pu}(\mathrm{IV})$ in $0.75 \mathrm{M}_{\text {of }} \mathrm{DNO}_{3}$ Using a 500-cm LWCC.

3.26. Pu(IV) Spectra in $0.25 \mathrm{M} \mathrm{NaOD}$ for Freshly Spiked (bold black trace, $0.027 \mu \mathrm{M}$ of total $\mathrm{Pu}$ ) and 3-Day-Old Solution (bold red trace; $0.016 \mu \mathrm{M}$ of total $\mathrm{Pu}$ )....

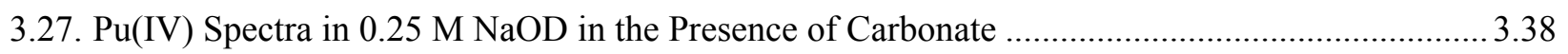

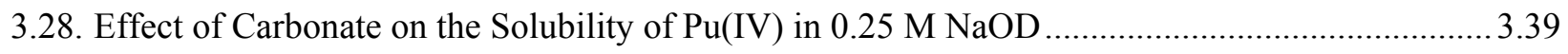

3.29. Spectral Monitoring over Mn(VII) Conversion to $\mathrm{Mn}(\mathrm{VI})$ in the Presence of Added $\mathrm{Pu}(\mathrm{OH})_{4} \ldots .3 .42$

3.30. Spectral Monitoring over Mn(VII) Conversion to Mn(VI) in the Presence of in situ Generated $\mathrm{Pu}(\mathrm{OH})_{4}$ in Alkaline Solution of $\mathrm{Mn}(\mathrm{VII})$.

3.31. The Kinetics of Oxidative Dissolution of $\mathrm{Pu}^{\mathrm{IV}}(\mathrm{OH})_{4}$ Suspension in a Series of $\mathrm{NaMnO}_{4}$ Solutions in $0.25 \mathrm{M}$ of $\mathrm{NaOD} / \mathrm{D}_{2} \mathrm{O}$ at Three Levels of Permanganate 
3.32. The Effect of Carbonate Concentration on the Kinetics of Oxidative Dissolution of $\mathrm{Pu}^{\mathrm{IV}}(\mathrm{OH})_{4}$ Suspension in a Series of $\mathrm{NaMnO}_{4}$ Solutions in $0.25 \mathrm{M} \mathrm{NaOD} / \mathrm{D}_{2} \mathrm{O}$ at $0.75 \mathrm{mM}$ of Permanganate

3.33. Spectral Monitoring over Mn(VI) Consumption in the Presence of Oxidative Alkaline Leaching of $\mathrm{Pu}(\mathrm{OH})_{4}$ in $0.25 \mathrm{M} \mathrm{NaOD}$

3.34. The Kinetics of Dissolution of $\mathrm{Pu}(\mathrm{OH})_{4}$ by $\mathrm{Mn}(\mathrm{VII})$ in $1 \mathrm{M} \mathrm{DNO}_{3}$

3.35. The Kinetics of the Oxidation of Monomeric $\mathrm{Pu}(\mathrm{IV})$ by $\mathrm{Mn}(\mathrm{VII}), \mathrm{Cr}(\mathrm{VI})$, and Their Mixture in $1 \mathrm{M} \mathrm{HNO}_{3}$

3.36. Evidence of $\mathrm{Mn}(\mathrm{VII})$ and $\mathrm{Mn}(\mathrm{VI})$ Reduction in $0.25 \mathrm{M}$ NaOD Using LWCC Detection

3.37. Red Trace Spectrum from 2.2 After Application of the Waveform Suppression Treatment and Spectral Smoothing.....

3.38. Oxidative Leaching of $\mathrm{Fe}(\mathrm{OH})_{3} / \mathrm{Cr}(\mathrm{OH})_{3} / \mathrm{Pu}(\mathrm{OH})_{4}$ Sludge Simulant with a Substoichiometric to Stoichiometric Amount of Permanganate in $0.25 \mathrm{M} \mathrm{NaOH}$

3.39. Oxidative Leaching of $\mathrm{Fe}(\mathrm{OH})_{3} / \mathrm{Cr}(\mathrm{OH})_{3} / \mathrm{Pu}(\mathrm{OH})_{4}$ Sludge Simulant with Excessive Amount of Permanganate

3.40. The Kinetics of Oxidative Leaching of $\mathrm{Fe}(\mathrm{OH})_{3} / \mathrm{Cr}(\mathrm{OH})_{3} / \mathrm{Pu}(\mathrm{OH})_{4}$ Sludge Simulant with Excessive Amount of Permanganate ....

3.41. Cold Experiment on Stepwise Reduction of Manganate by $\mathrm{Cr}(\mathrm{OH})_{4}{ }^{-}$in $2.5 \mathrm{M} \mathrm{NaOD}$

3.42. Quenching of Excessive Mn(VI) with Soluble $\mathrm{Cr}$ (III) Nitrate in $3 \mathrm{M} \mathrm{NaOD}$ Leachate 6 Days After Oxidative Treatment of $\mathrm{Fe}(\mathrm{OH})_{3} / \mathrm{Cr}(\mathrm{OH})_{3} / \mathrm{Pu}(\mathrm{OH})_{4}$ Sludge Simulant with $15 \%$ Molar Excess of Mn(VI): a) Mn(VI) peak intensity decrease with increasing amount of $\mathrm{Cr}(\mathrm{III})$ added; b) concentration profile of soluble plutonium at various stages of elimination of $\mathrm{Mn}(\mathrm{VI})$ from solution. 


\section{Tables}

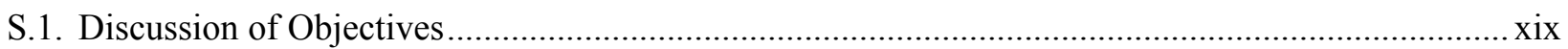

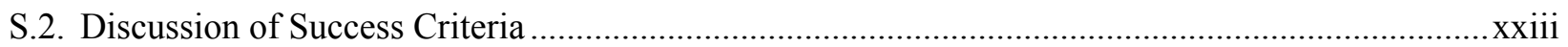

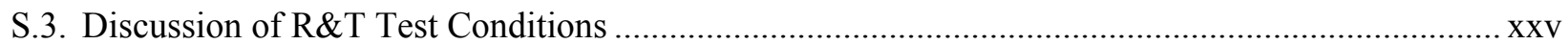

1.1. Standard Potentials for Plutonium for the Hypothetical Condition of Zero Ionic Strength............. 1.2

3.1. Summary of Calibration Experiments with 5-m LWCC Using Nd-EDTA Complex in $\mathrm{NaOH}$

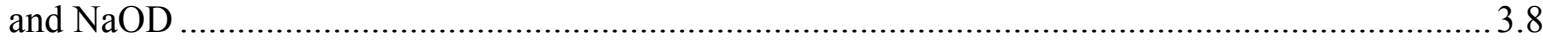

3.2. Summary of Calibration Experiments with $\mathrm{Pu}(\mathrm{VI})$ in $0.1 \mathrm{M}$ of $\mathrm{DNO}_{3}, 0.1 \mathrm{M}$ and $1 \mathrm{M}$ of $\mathrm{NaOD}$

3.3. Summary of Calibration Experiments with $\mathrm{Pu}(\mathrm{V})$ in $0.25 \mathrm{M}$ and $1 \mathrm{M} \mathrm{NaOD}$

3.4. Calculation of Formal Potentials of the $\mathrm{Pu}(\mathrm{VI}) / \mathrm{Pu}(\mathrm{V})$ Couple in NaOD Solution

3.5. Comparison of Experimentally Determined Solubilities of $\mathrm{Pu}$ in Mixed Hydroxy-Carbonate Medium at Constant Level of $0.25 \mathrm{M} \mathrm{NaOD} / \mathrm{D}_{2} \mathrm{O}$ with Predictions of the SRNL $\mathrm{Pu}$ Solubility Model

3.6. Oxidation Reduction Potentials of Manganate Solutions and Permanganate-Manganate Mixtures in $\mathrm{NaOD}$

3.7. Concentrations of $\mathrm{Cr}(\mathrm{VI})$ and Soluble $\mathrm{Pu}$ in the $3 \mathrm{M} \mathrm{NaOD}$ Leachates with Substoichiometric to Stoichiometric Addition of Mn(VII). 



\section{Abbreviation/Acronym List}

\begin{tabular}{|c|c|}
\hline ASO & Analytical Service Organization \\
\hline $\mathrm{BNI}$ & Bechtel National, Incorporated \\
\hline $\mathrm{D}_{2} \mathrm{O}$ & Deuterated (heavy) Water \\
\hline DOE & U.S. Department of Energy \\
\hline EDTA & EthyleneDiamineTetraacetic Acid \\
\hline Eh & Oxidation Potential \\
\hline FWHM & $\begin{array}{l}\text { Full Width at Half Maximum. Characteristic of absorbance peak sharpness and resolution } \\
\text { in Optical Absorbance Spectroscopy. Typically expressed in nm. }\end{array}$ \\
\hline IR & Infrared (region of optical spectrum) \\
\hline LIPAS & Laser-Induced Photoacoustic Spectroscopy \\
\hline LSC & Liquid Scintillation Counting \\
\hline LWCC & Liquid Waveguide Capillary Cell \\
\hline M & Molar; concentration in moles per liter \\
\hline $\mathrm{M} \& \mathrm{TE}$ & Measuring and Test Equipment \\
\hline $\mathrm{NaOD}$ & Deuterated Sodium Hydroxide \\
\hline OAS & Optical Absorbance Spectroscopy (synonym: Spectrophotometry) \\
\hline Orion & Combination Redox/ORP Electrode \\
\hline ORP & Oxidation-Reduction Potential \\
\hline $\mathrm{pH}$ & Solution Acidity \\
\hline PNNL & Pacific Northwest National Laboratory \\
\hline PNWD & Battelle-Pacific Northwest Division \\
\hline PUREX & Plutonium-URanium EXtraction (solvent extraction process) \\
\hline QAP & Quality Assurance Program \\
\hline QAPjP & Quality Assurance Project Plan \\
\hline QARD & Quality Assurance Requirements and Descriptions \\
\hline redox & $\begin{array}{l}\text { reduction-oxidation (pertaining to oxidation-reduction reactions or oxidation-reduction } \\
\text { electrical potentials) }\end{array}$ \\
\hline REDOX & REDuction-OXidation (solvent extraction process) \\
\hline RPL & Radiochemical Processing Laboratory \\
\hline SBMS & Standards-Based Management System \\
\hline SOW & Statement of Work \\
\hline
\end{tabular}


SRNL Savannah River National laboratory

TRU Transuranic

UV Ultraviolet (region of optical spectrum)

VIS VISible (region of optical spectrum)

WTPSP Waste Treatment Plant Support Project

WTP Waste Treatment Plant

WPI World Precision Instruments

Molar Absorptivity (or molar extinction) of a light absorbing species in solution. Normally $\varepsilon$ is expressed in $\mathrm{M}^{-1} \mathrm{~cm}^{-1}$ units. Its physical meaning is the optical absorbance created by a $1 \mathrm{M}$ solution of a light-absorbing species in a 1-cm-thick layer of solution 


\section{References}

Allard B, H Kipatsi, and JO Liljenzin. 1980. "Expected Species of Uranium, Neptunium and Plutonium in Neutral Aqueous Solutions.” J. Inorg. Nucl. Chem. 42:1015-1027.

Altmaier M, V Neck, R Muller, Th Fanghänel. 2005. "Solubility of $\mathrm{ThO}_{2} \cdot \mathrm{xH}_{2} \mathrm{O}(\mathrm{am})$ in Carbonate Solution and the Formation of Ternary Th(IV) Hydroxide-Carbonate Complexes." Radiochimica Acta 93:83-92.

Barney GS, and CH Delegard. 1999. "Chemical Species of Plutonium in Hanford Site Radioactive Tank Wastes." In: Actinide Speciation in High Ionic Strength Media. DT Reed, SB Clark, and L Rao (Eds.). Kluwer Academic/Plenum Publishers.

Beitz JV, MM Boxtader, VA Maroni, S Okajima, and DT Reed. 1990. "High Sensitivity Photoacoustic Spectrometer for Variable Temperature Solution Studies.” Rev. Sci. Instrum. 61(5):1395-1403.

Bourges J. 1972. "Preparation et Identification du Plutonium a l'Etat d'Oxydation-V en Milieu Basique." Radiochem. Radioanal. Lett. 12:111.

Budantseva NA, IG Tananaev, AM Fedoseev, AA Bessonov, and CH Delegard. 1997. Investigation of the Behavior of $\mathrm{Pu}(\mathrm{V})$ in Alkaline Media. PNNL-11624, Richland, WA.

Byrne RH, X Liu, EA Kaltenbacher, K Sell. 2002. "Spectrophotometric Measurement of Total Inorganic Carbon in Aqueous Solutions Using A Liquid Core Waveguide" Anal. Chim. Acta. 451(2):221-229.

Carnall WT. 1979. "The Absorption and Fluorescence Spectra of Rare Earth Ions in Solution." Chapter 24 in Handbook on the Physics and Chemistry of Rare Earths (KA Gschneider, Jr and L Eyring, Eds.). Published by the Journal of Applied Crystallography.

Clark DL, DE Hobart, and MP Neu. 1995. "Actinide Carboante Complexes and Their Importance in Actinide Environmental Chemistry." Chemical Reviews 95(1):25-48.

Cohen D. 1961. The Absorption Spectra of Plutonium Ions in Perchloric Acid Solutions. J. Inorg. Nucl. Chem. 18, 211-218.

Delegard CH. 1987. "Solubility of $\mathrm{PuO}_{2} \cdot \mathrm{xH}_{2} \mathrm{O}$ in Alkaline Hanford High-Level Waste Solution." Radiochimica Acta 41:11-21.

Gelis AV, P Vanishek, MP Jensen, and KL Nash. 2001. "Electrochemical and Spectrophotometric Investigations of Neptunium in Alkaline Media.” Radiochimica Acta. 89:565-571.

Gmelin Handbuch der Anorganischen Chemie. 1975. Manganese and references therein, SpringerVerlag, Berlin-Heidelberg-New York, Vol. 56, Part C2.

Koltunov VS. 1974. Kinetics of Actinide Reactions [in Russian]. Atomizdat, Moscow. 
Krot NN, AA Bessonov, AV Gelis, VP Shilov, VP Perminov, and LN Astafurova. 1998.

"Coprecipitation of Transuranium Elements from Alkaline Solutions by the Method of Appearing

Reagents. I. Coprecipitation of Pu(VI,V) with Manganese Dioxide.” Radiochemistry 40(4):347-352.

Lierse Ch, and JI Kim. 1986. Chemical Behavior of Plutonium in Natural Aquatic Systems: Hydrolysis, Carbonate Complexation and Redox Reactions. RCM 02286, Institut fur Radiochemie der Technischen Universitet Munchen, Garching, Germany.

Nash KL, M Borkowski, M Hancock, and I Laszak. 2005. "Oxidative Leaching of Plutonium from Simulated Hanford Tank-Waste Sludges.” Separation Science and Technology 40:1497-1512.

Neck V, JI Kim, BS Seidel, CM Marquardt, K Dardenne, MP Jensen, and W Hauser. 2001. "A Spectroscopic Study of the Hydrolysis, Colloid Formation and Solubility of Np." Radiochimica Acta 89:439-446.

Neck V, M Altmaier, A Seibert, JI Kim, JI Jun, CM Marquardt, and Th Fanghänel. 2007. "Solubility and Redox Reactions of $\mathrm{Pu}(\mathrm{IV})$ Hydrous Oxide: Evidence for the Formation of $\mathrm{PuO}_{2+\mathrm{x}}$ (s, hyd)."

Radiochimica Acta 93:193-207.

Neu MP, DC Hoffman, KE Roberts, H Nitsche, and RJ Silva. 1994. “Comparison of Chemical extractions and Laser Photoacoustic Spectroscopy for Determination of Plutonium Species in Carbonate Solution.” Radiochimica Acta 66/67:251.

Peretrukhin VF, and VI Spitsyn. 1982. "Electrochemical Determination of the Oxidation Potentials and the Thermodynamic Stability of the Valence States of the Transuranium Elements in Aqueous Alkaline Media". Izv. Akad. Nauk SSSR, Ser. Khim, 4, 826-831.

Peretrukhin VF, SV Kryutchkov, VI Silin, and IG Tananaev. 1996. Determination of the Solubility of Np(IV-(VI), Pu(III)-(VI), Am(III)-(VI) and Tc(IV), (V) Hydroxo Compounds in 0.5 - $14 \mathrm{M} \mathrm{NaOH}$ solutions. WHC-EP-0987, Westinghouse Hanford Company. Richland, WA.

Perez-Bustamante JA. 1965. "Solubility Product of Tetravalent Plutonium Hydroxide and Study of the Amphoteric Character of Hexavalent Plutonium Hydroxide." Radiochimica Acta 4(1):67-75.

Rai D, NJ Hess, AR Felmy, DA Moore, M Yui, and P Vitorge. 1999. "A Thermodynamic Model for the Solubility of $\mathrm{PuO}_{2}(\mathrm{am})$ in the Aqueous $\mathrm{K}^{+}-\mathrm{HCO}_{3}{ }^{-}-\mathrm{CO}_{3}{ }^{2-}-\mathrm{OH}^{-}-\mathrm{H}_{2} \mathrm{O}$ System." Radiochimica Acta 86:89-99.

Rapko BM, JGH Geeting, SI Sinkov, and JD Vienna. 2004. Oxidative-Alkaline Leaching of Washed 241-SY-102 and 241-SX-101 Tank Sludges. WTP-RPT-117, Rev 0, Battelle-Pacific Northwest Division, Richland, WA.

Ray M, IC Pius, MM Charyvlu, and CK Sivaramakrishnandu. 1988. "Spectrophotometric Studies on the Behaviour of Plutonium in Basic Media. Preprint \# CT-36." In: Radiochemistry and Radiation Chemistry Symposium. Bombay, India, February 22-26, 1988.

Reilly SD, WK Myers, SA Stout, DM Smith, MA Ginder-Vogel, and MP Neu. 2003. "Plutonium(VI) Sorption to Manganese Dioxide." In: AIP Conference Proceedings, Vol. 673 (Plutonium Futures-The Science), pp. 375-376. 
Reilly SD, W Runde, and MP Neu. 2007. "Solubility of Pu(VI) Carbonate in Saline Solutions." Geochimica et Cosmochimica Acta 71:2672-2679.

Rudisill TS, DT Hobbs, and TB Edwards. 2004. Preliminary Results from Plutonium/Americium Solubility Studies Using Simulated Savannah River Site Waste Solutions. WSRC-TR-2004-00349, Westinghouse Savannah River Company, Aiken, SC.

Runde W. 2000. "The Chemical Interactions of Actinides in the Environment." In: Los Alamos Science. Number 26, Challenges in Plutonium Science, Volume II: pp. 392-411.

Spitsyn VI, AD Gelman, NN Krot, MP Mefodiyeva, FA Zakharova, Yu A Komkov, VP Shilov, and IV Smirnova. 1969. "Heptavalent State of Neptunium and Plutonium." J. Inorg. Nucl. Chem. 31:27332745.

Varlashkin PG, GM Begun, and JR Peterson. 1984a. "Electrochemical and Spectroscopic Studies of Neptunium in Concentrated Aqueous Carbonate and Carbonate-Hydroxide Solutions." Radiochimica Acta 35:91-96.

Varlashkin PG, GM Begun, and JR Peterson. 1984b. "Electrochemical and Spectroscopic Studies of Plutonium in Concentrated Aqueous Carbonate and Carbonate-Hydroxide Solutions." Radiochimica Acta 35:211-218.

Waterbury RD, W Yao, and RH Byrne. 1997. "Long Pathlength Absorbance Spectroscopy: Trace Analysis of Fe(II) using a 4.5 m Liquid Core Waveguide." Anal. Chim. Acta. 357(1-2):99-102.

Weigel F, JJ Katz, and GT Seaborg. 1986. "Plutonium." Chapter 7 in: The Chemistry of Actinide Elements. JJ Katz, GT Seaborg, LR Morse (Eds.). Volume I. Chapman and Hall.

Wilson RE, Y-J Hu, and H Nitsche. 2005. "Detection and Quantification of Pu(III, IV, V, and VI) using a 1.0-meter Liquid Core Waveguide.” Radiochimica Acta 93:203-206.

Yamaguchi T, Y Sakamoto, and T Ohnuki. 1994. "Effect of the Complexation on Solubility of Pu(IV) in Aqueous Carbonate System.” Radiochimica Acta 66/67:9-14. 



\section{Testing Summary}

\section{Objectives}

Bechtel National, Inc. (BNI) is evaluating the plutonium speciation in caustic solutions that reasonably represent the process streams from the oxidative-leaching demonstration test. Battelle-Pacific Northwest Division (PNWD) was contracted to develop a spectrophotometric method to measure plutonium speciation at submicromolar $\left(<10^{-6} \mathrm{M}\right)$ concentrations in alkaline solutions in the presence of chromate and carbonate. Data obtained from the testing will be used to identify the oxidation state of $\mathrm{Pu}(\mathrm{IV}), \mathrm{Pu}(\mathrm{V})$, and $\mathrm{Pu}(\mathrm{VI})$ species, which potentially could exist in caustic leachates. Work was initially conducted under contract number 24590-101-TSA-W000-00004 satisfying the needs defined in Appendix C of the Research and Technology Plan TSS A-219 to evaluate the speciation of chromium, plutonium, and manganese before and after oxidative leaching. In February 2007, the contract mechanism was switched to Pacific Northwest National Laboratory (PNNL) Operating Contract MOA: 24590-QL-HC9-WA49-00001.

Table S.1 discusses the specific objectives of the work described in this report:

Table S.1. Discussion of Objectives

\begin{tabular}{|c|c|c|}
\hline Test Objective & $\begin{array}{c}\text { Objective Met } \\
\text { (Y/N) }\end{array}$ & Discussion \\
\hline $\begin{array}{l}\text { 1. Develop a } \\
\text { spectrophotometric } \\
\text { method to measure } \\
\text { plutonium speciation at } \\
\text { submicromolar } \\
\left(<10^{-6} \mathrm{M}\right) \text { concentrations } \\
\text { of this element in } \\
\text { alkaline solutions }(0.1 \text { to } \\
1.0 \mathrm{M} \text { of } \mathrm{NaOH}) \text { in the } \\
\text { presence of chromate }(0 \\
\text { to } 0.05 \mathrm{M}) \text { and carbonate } \\
(0 \text { to } 0.1 \mathrm{M}) \text {. }\end{array}$ & Yes & $\begin{array}{l}\text { The applicability of a } 500 \text {-cm Liquid Waveguide Capillary } \\
\text { Cell (LWCC) for spectral measurements in alkaline } \\
\text { aqueous solution using cold simulants was verified. } \\
\text { Detection ranges in } \mathrm{H}_{2} \mathrm{O} \text { and in } \mathrm{D}_{2} \mathrm{O} \text { media were found to } \\
\text { be } 560 \text { to } 700 \mathrm{~nm} \text { and } 560 \text { to } 960 \mathrm{~nm} \text {, respectively. A } \\
\text { significant extension of a useable spectral range of } \\
\text { LWCC-based detection in deuterated aqueous medium to } \\
\text { the previously unexplored region was demonstrated. The } \\
\text { presence of chromate up to } 0.05 \mathrm{M} \text { concentration did not } \\
\text { deteriorate spectral measurements and did not narrow } \\
\text { these spectral ranges. The validity of the Beer law (linear } \\
\text { relationship between concentration of a light absorbing } \\
\text { species and magnitude of optical absorbance) was } \\
\text { demonstrated for all eight absorbance bands of } \\
\text { neodymium-ethylenediaminetetraacetic acid (Nd-EDTA) } \\
\text { complex in } 0.1 \mathrm{M} \text { NaOD/D } \mathrm{O} \text { medium in a wide range of } \\
\text { concentrations of this species. Detection limits achieved } \\
\text { were less than } 1 \times 10^{-6} \mathrm{M} \text { for a number of Nd-EDTA peaks } \\
\text { with molar absorptivities greater than } 6 \mathrm{M}^{-1} \mathrm{~cm}^{-1} \text {. } \\
\text { Successful demonstration of the LWCC performance with } \\
\text { cold simulants allowed experiments to be performed with } \\
\text { Pu(VI) and Pu(V) in deuterated alkaline media from } 0.1 \mathrm{M}\end{array}$ \\
\hline
\end{tabular}




\begin{tabular}{|c|c|c|}
\hline Test Objective & $\begin{array}{l}\text { Objective Met } \\
(\mathrm{Y} / \mathrm{N})\end{array}$ & Discussion \\
\hline & & $\begin{array}{l}\text { to } 1.0 \mathrm{M} \text { of } \mathrm{NaOD} \text { in pure hydroxide solutions and in } \\
\text { hydroxide-carbonate mixtures. }\end{array}$ \\
\hline $\begin{array}{l}\text { 2. Measure optical } \\
\text { absorbance spectra and } \\
\text { molar absorptivities of } \\
\mathrm{Pu}(\mathrm{IV}), \mathrm{Pu}(\mathrm{V}) \text {, and } \\
\mathrm{Pu}(\mathrm{VI}) \text { complexes with } \\
\text { hydroxide and mixed } \\
\text { complexes with } \\
\text { hydroxide and carbonate } \\
\text { in the presence of } \\
\text { chromate to identify the } \\
\text { oxidation state(s) of } \\
\text { plutonium in caustic } \\
\text { solution and determine } \\
\text { concentrations of these } \\
\text { oxidation states. }\end{array}$ & $\begin{array}{l}\text { Objective is } \\
\text { partially met } \\
\text { (two of the three } \\
\text { oxidation states } \\
\text { of plutonium in } \\
\text { alkaline solution } \\
\text { are spectrally } \\
\text { characterized; } \\
\text { Pu(IV) spectra } \\
\text { could not be } \\
\text { measured due to } \\
\text { solubility } \\
\text { problems). }\end{array}$ & 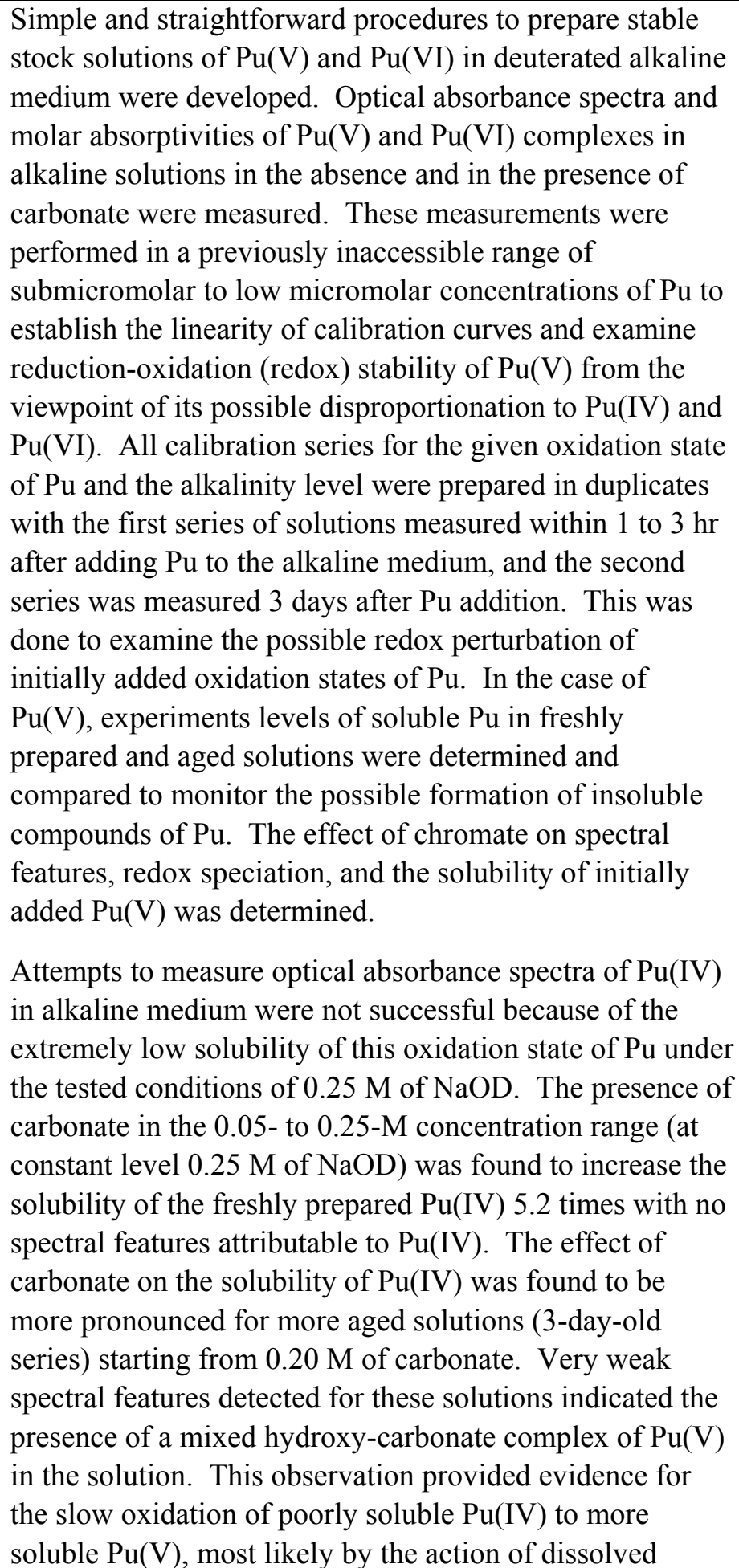 \\
\hline
\end{tabular}




\begin{tabular}{|c|c|c|}
\hline Test Objective & $\begin{array}{c}\text { Objective Met } \\
\text { (Y/N) }\end{array}$ & Discussion \\
\hline & & 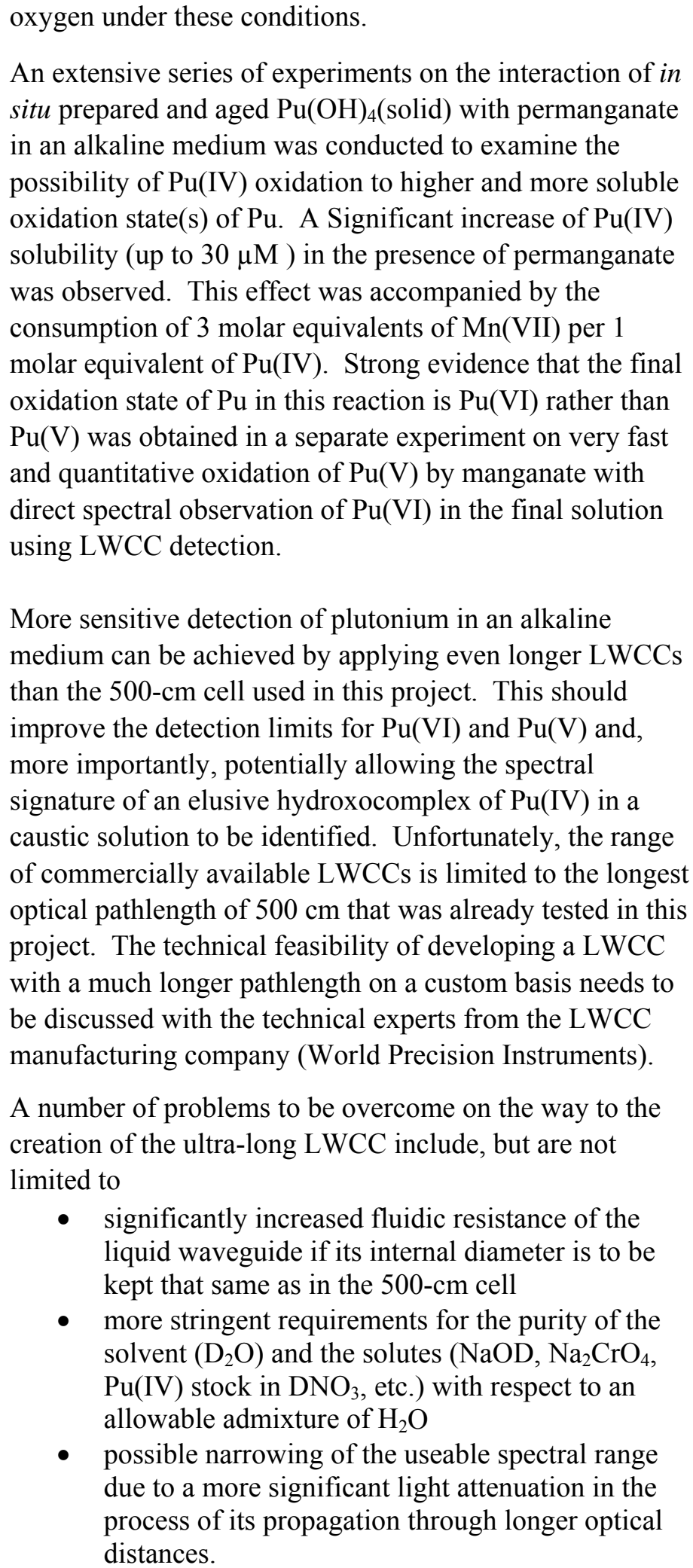 \\
\hline
\end{tabular}




\begin{tabular}{|c|c|c|}
\hline Test Objective & $\begin{array}{c}\text { Objective Met } \\
\text { (Y/N) }\end{array}$ & Discussion \\
\hline & & $\begin{array}{l}\text { Additionally, the possibility should be considered of } \\
\text { acquiring and using a better quality spectrophotometer } \\
\text { than the one used in the course of this project. Instruments } \\
\text { with a better resolution and with a higher signal-to-noise } \\
\text { ratio have appeared on the market since } 2003 \text {, when the } \\
\text { spectrophotometer employed in this project was } \\
\text { manufactured. }\end{array}$ \\
\hline $\begin{array}{l}\text { 3. Determine detection } \\
\text { limits for each oxidation } \\
\text { state of } \mathrm{Pu} \text { in alkaline } \\
\text { solution. }\end{array}$ & $\begin{array}{l}\text { Objective is } \\
\text { partially met } \\
\text { (detection limits } \\
\text { for two of the } \\
\text { three oxidation } \\
\text { states of } \\
\text { plutonium in } \\
\text { alkaline solution } \\
\text { are determined). }\end{array}$ & 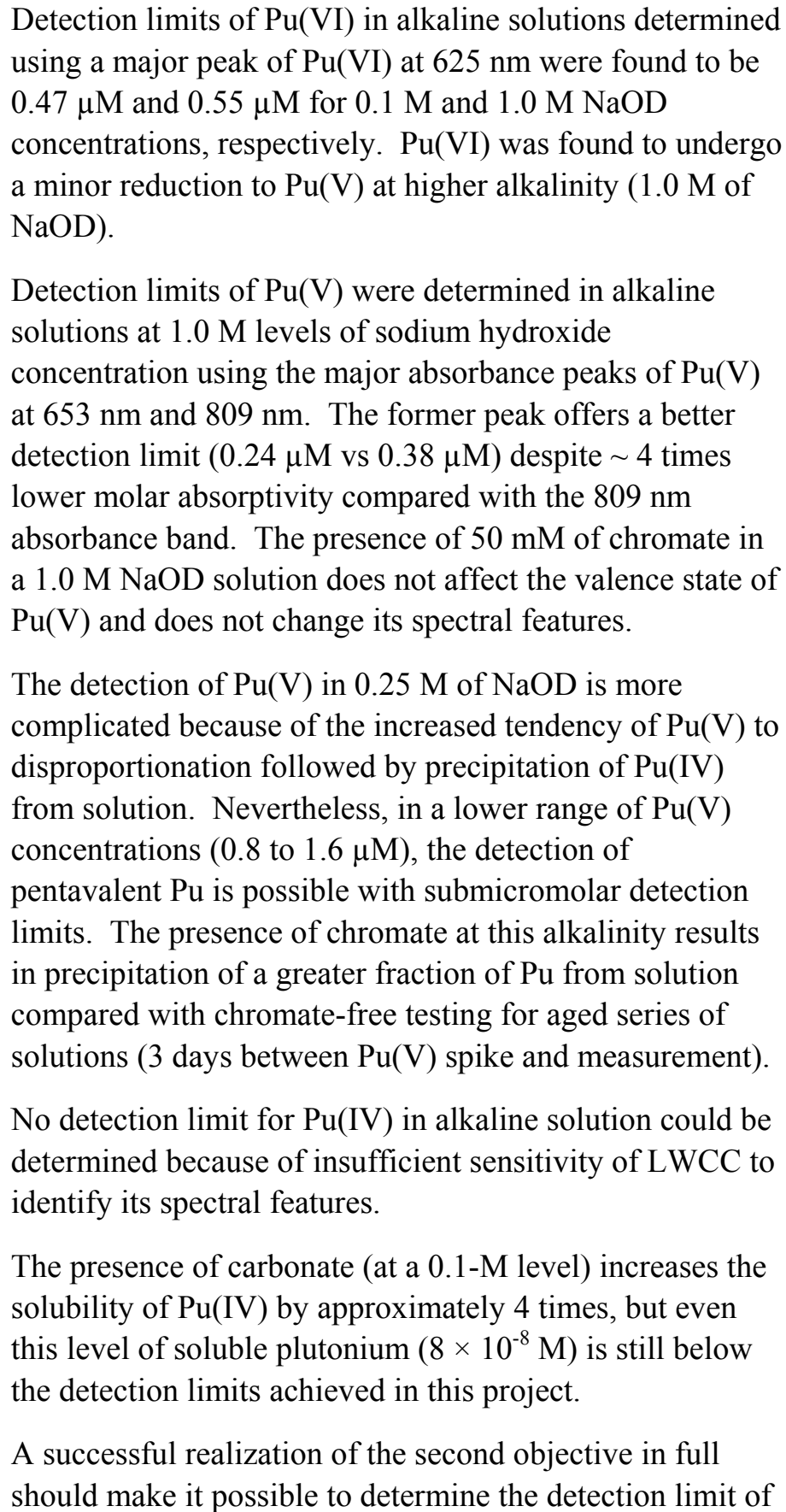 \\
\hline
\end{tabular}




\begin{tabular}{|l|c|l|}
\hline Test Objective & $\begin{array}{c}\text { Objective Met } \\
(\mathbf{Y} / \mathbf{N})\end{array}$ & Discussion \\
\hline & & $\mathrm{Pu}(\mathrm{IV})$ in an alkaline medium. \\
\hline
\end{tabular}

\section{Test Exceptions}

No test exceptions were generated during testing

\section{Results and Performance Against Success Criteria}

This task involved the development of a method to identify Pu speciation in caustic solutions that reasonably represent the process streams from anticipated plant flowsheet conditions. Specifically, the methods will identify the oxidation state of the $\mathrm{Pu}(\mathrm{IV}), \mathrm{Pu}(\mathrm{V})$, and $\mathrm{Pu}(\mathrm{VI})$ species that potentially could exist in caustic media ( 0.1 to $1.0 \mathrm{M}$ of $\mathrm{NaOH}, 0$ to $0.05 \mathrm{M}$ of $\mathrm{Na}_{2} \mathrm{CrO}_{4}$, and 0.01 to $0.1 \mathrm{M}$ of $\mathrm{Na}_{2} \mathrm{CO}_{3}$ ). The detection limit target is the greater of $5 \times 10^{-8} \mathrm{M}$ or a minimum $\mathrm{Pu}(\mathrm{IV})$ solubility in a given matrix (see Table S.2).

Table S.2. Discussion of Success Criteria

\begin{tabular}{|c|c|}
\hline List Success Criteria & $\begin{array}{l}\text { Explain How the Tests Did or Did } \\
\text { Not Meet the Success Criteria }\end{array}$ \\
\hline $\begin{array}{l}\text { 1. Development of a method to identify the } \\
\text { oxidation state of the } \mathrm{Pu}(\mathrm{IV}), \mathrm{Pu}(\mathrm{V}) \text {, and } \mathrm{Pu}(\mathrm{VI}) \\
\text { species in caustic solutions that reasonably } \\
\text { represent the process streams from anticipated plant } \\
\text { flowsheet conditions. }\end{array}$ & $\begin{array}{l}\text { Enhanced optical absorbance spectroscopy based } \\
\text { on application a } 500 \text {-cm pathlength LWCC is } \\
\text { demonstrated to be capable of identifying the } \\
\text { oxidation states of } \mathrm{Pu}(\mathrm{V}) \text { and } \mathrm{Pu}(\mathrm{VI}) \text { in } 0.1-\mathrm{M} \text { to } \\
1.0-\mathrm{M} \mathrm{NaOH} \text { solutions in the presence and absence } \\
\text { of chromate and carbonate with much greater } \\
\text { sensitivity than was possible before with } \\
\text { conventional spectrophotometry. } \mathrm{Pu}(\mathrm{IV}) \text { detection } \\
\text { with the current configuration of } \mathrm{LWCC} \text { is not } \\
\text { possible due to low solubility of this oxidation state } \\
\text { of } \mathrm{Pu}\left(\sim 2 \times 10^{-8} \mathrm{M} \text { in } 0.25 \mathrm{M} \text { sodium hydroxide). }\right. \\
\text { Detecting such low levels of } \mathrm{Pu}(\mathrm{IV}) \text { would require } \\
\text { LWCC with } 20 \text { to } 50 \text { times longer optical } \\
\text { pathlengths compared with the } 500 \text {-cm pathlength } \\
\text { employed in this project. }\end{array}$ \\
\hline $\begin{array}{l}\text { 2. The detection limit target is the greater of } \\
5 \times 10^{-8} \mathrm{M} \text { or a minimum } \mathrm{Pu} \text { (IV) solubility in a } \\
\text { given matrix }(0.1 \text { to } 1.0 \mathrm{M} \text { of } \mathrm{NaOH}, 0 \text { to } 0.05 \mathrm{M} \text { of } \\
\left.\mathrm{Na}_{2} \mathrm{CrO}_{4} \text {, and } 0.01 \text { to } 0.1 \mathrm{M} \text { of } \mathrm{Na}_{2} \mathrm{CO}_{3}\right) \text {. }\end{array}$ & $\begin{array}{l}\text { The detection limits for Pu species determined in } \\
\text { this project are as follows: } \\
\text { - } \mathrm{Pu}(\mathrm{VI}): 5.1 \pm 0.4 \times 10^{-7} \mathrm{M} \text { in } 0.1 \text { to } 1.0 \mathrm{M} \\
\mathrm{NaOD} \text { based on major absorbance band of } \\
\mathrm{Pu}(\mathrm{VI}) \text { at } 625 \mathrm{~nm} \\
\text { - } \mathrm{Pu}(\mathrm{V}): 0.22 \pm 0.03 \times 10^{-7} \mathrm{M}(653 \mathrm{~nm} \text { peak }) \\
\text { and } 0.36 \pm 0.03 \times 10^{-7} \mathrm{M}(809 \mathrm{~nm} \text { peak }) \text { in }\end{array}$ \\
\hline
\end{tabular}




\begin{tabular}{|c|c|}
\hline List Success Criteria & $\begin{array}{l}\text { Explain How the Tests Did or Did } \\
\text { Not Meet the Success Criteria }\end{array}$ \\
\hline & $\begin{array}{l}1 \mathrm{M} \mathrm{NaOD} \\
\text { - } \mathrm{Pu}(\mathrm{V}) 0.60 \pm 0.10 \times 10^{-7} \mathrm{M}(653 \mathrm{~nm} \text { peak }) \\
\text { and } 0.35 \pm 0.05 \times 10^{-7} \mathrm{M}(809 \mathrm{~nm} \text { peak }) \text { in } \\
0.25 \mathrm{M} \mathrm{NaOD} \\
\text { - } \mathrm{Pu}(\mathrm{IV}) \text { : no detection limit was determined } \\
\text { due to very low solubility }\left(2 \times 10^{-8} \mathrm{M}\right) \text { of } \\
\text { this oxidation state in } 0.25 \mathrm{M} \mathrm{NaOD} \text { and } \\
\text { insufficiently intense molar absorptivities } \\
\text { of absorbance bands of } \mathrm{Pu}(\mathrm{IV}) \text {. } \\
\text { The reason for these higher-than-targeted detection } \\
\text { limits is insufficiently intense absorbance peaks of } \\
\mathrm{Pu}(\mathrm{VI}) \text { and Pu(V) suitable for their detection. } \\
\mathrm{Acidification} \text { of initially alkaline } \mathrm{Pu}-\mathrm{containing} \\
\text { solutions with conversion of soluble } \mathrm{Pu}(\mathrm{V}) \text { and } \\
\mathrm{Pu}(\mathrm{VI}) \text { to their unhydrolyzed forms }\left(\mathrm{PuO}{ }^{+} \text {and }\right. \\
\mathrm{PuO}{ }_{2}^{2+} \text { respectively) is demonstrated as a possible } \\
\text { solution of this problem. This technique allows the } \\
\text { detection limit to be improved for } \mathrm{Pu}(\mathrm{V}) \text { by } \\
\sim 3 \text { times (estimated) and by } 100 \text { times for Pu(VI). } \\
\text { In the latter case, the experimentally measured } \\
\text { detection limit is found to be } 5.6 \times 10^{-9} \mathrm{M} \text { of } \\
\mathrm{Pu}(\mathrm{VI}) \text {. The detection limit for } \mathrm{Pu}(\mathrm{IV}) \text { under acidic } \\
\text { conditions was found to be } 2.7 \times 10^{-8} \mathrm{M} \text {, which is } \\
\text { still not sufficient to detect this species after } \\
\text { acidification of Pu(IV) containing alkaline } \\
\text { solutions with initial soluble levels of } \mathrm{Pu}(\mathrm{IV}) \text { below } \\
2 \times 10^{-8} \mathrm{M} \text {. }\end{array}$ \\
\hline
\end{tabular}

\section{Quality Requirements}

The data represented in this report will refer to PNWD (in support of Bechtel National, Inc. Support Project [BNI-SP] before February 12, 2007) or PNNL (in support of Waste Treatment Plant Support Program [RPP-WTP] following February 12, 2007). Work was performed for both of these projects to the same QA program.

PNNL implemented the RPP-WTP quality requirements by performing work in accordance with the River Protection Project-Waste Treatment Plant Support Program (RPP-WTP) Quality Assurance Plan (RPP-WTP-QA-001, QAP). Work was performed to the quality requirements of NQA-1-1989 Part I, Basic and Supplementary Requirements, NQA-2a-1990, Part 2.7, and DOE/RW-0333P, Rev 13, Quality Assurance Requirements and Descriptions (QARD). These quality requirements were implemented through the River Protection Project-Waste Treatment Plant Support Program (RPP-WTP) Quality Assurance Manual (RPP-WTP-QA-003, QAM). 
PNNL addressed internal verification and validation activities by conducting an Independent Technical Review of the final data report in accordance with PNNL's procedure QA-RPP-WTP-604. This review verifies that the reported results were traceable, inferences and conclusions were soundly based, and the reported work satisfied the Test Plan objectives.

\section{R\&T Test Conditions}

Table S.3 discusses R\&T test conditions implemented in a pertinent portion of the test specification.

Table S.3. Discussion of R\&T Test Conditions

\begin{tabular}{|l|l|}
\hline List R\&T Test Conditions & \multicolumn{1}{c|}{ Were Test Conditions Followed } \\
\hline $\begin{array}{l}\text { Battele shall prepare a test plan containing detailed } \\
\text { information needed to implement this test } \\
\text { specification. }\end{array}$ & $\begin{array}{l}\text { Yes, Test Plan TP-RPP-WTP-445 was prepared to } \\
\text { implement the plutonium speciation before and } \\
\text { after oxidative-leaching bench scale test portion of } \\
\text { the test specification. The client approved the test } \\
\text { plan on } 06 / 28 / 2006\end{array}$ \\
\hline
\end{tabular}

\section{Simulant Use}

The tests described in Section 3.10 of this report used a simplified Hanford tank sludge simulant comprised of homogeneously co-precipitated iron(III) hydroxide, chromium(III) hydroxide, and trace amounts of $\mathrm{Pu}(\mathrm{IV})$ hydroxide. Section 2.6 of the report provides a detailed description of the simulant composition and conditions used in its preparation. The simulant was used to generate oxidative alkaline leachates as result of its treatment with permanganate to convert insoluble chromium(III) to soluble chromium(VI). These leachates were selected at the final stage of the project to simulate feed materials for speciation analysis of plutonium.

\section{Discrepancies and Follow-on Tests}

Most experiments specified in the Test Plan were performed in accordance with the proposed procedures. A number of changes were introduced into the procedures that were initially suggested for preparing alkaline stock solutions of $\mathrm{Pu}(\mathrm{V})$ and $\mathrm{Pu}(\mathrm{IV})$. In the case of $\mathrm{Pu}(\mathrm{V})$, a simpler and safer way was found to prepare a stable solution of purely pentavalent $\mathrm{Pu}$ in concentrated alkali (see Section 2.2 for more details). The original procedure for preparing the relatively concentrated $\mathrm{Pu}(\mathrm{IV})$ solution in $10 \mathrm{M}$ sodium hydroxide was abandoned because of the impossibility of verifying its final oxidation state using liquid waveguide capillary cell spectroscopy in such a viscous medium. Instead, the working solutions of $\mathrm{Pu}(\mathrm{IV})$ in alkaline medium were generated by spiking small volumes of acidic $\mathrm{Pu}(\mathrm{IV})$ into a large excess of sodium hydroxide.

The results from this testing lead to the following recommendations for further study:

1) To obtain a direct proof of $\mathrm{Pu}(\mathrm{VI})$ being the only oxidation state in the oxidative-leaching simulants, the $\mathrm{Pu}(\mathrm{OD})_{4}$ oxidative-dissolution experiments need to be performed with 
substoichiometric additions of permanganate with respect to an amount of freshly generated $\mathrm{Pu}(\mathrm{OD})_{4}$, assuming 2:3 stoichiometry for the following reaction:

$$
2 \mathrm{MnO}_{4}{ }^{-}+3 \mathrm{Pu}^{\mathrm{IV}}(\mathrm{OD})_{4}+(3 \mathrm{n}-8) \mathrm{OD}^{-} \rightarrow 2 \mathrm{MnO}_{2}+3 \mathrm{Pu}^{\mathrm{VI}} \mathrm{O}_{2}(\mathrm{OD})_{\mathrm{n}}{ }^{(2-\mathrm{n})}+2 \mathrm{D}_{2} \mathrm{O} \text {. }
$$

This reaction should be studied first in a carbonate free medium with detection of $\mathrm{Pu}(\mathrm{VI})$ in solution using its major peak at $625 \mathrm{~nm}$.

2) It is desirable to repeat these experiments in a mixed deuterated hydroxy-carbonate medium to maximize the formation of the mixed $\mathrm{Pu}^{\mathrm{VI}} \mathrm{O}_{2}(\mathrm{OD})_{\mathrm{n}}\left(\mathrm{CO}_{3}\right)_{\mathrm{m}}{ }^{-(\mathrm{n}+2 \mathrm{~m}-2)}$ complex with a more-intense and better-defined absorbance peak of $\mathrm{Pu}(\mathrm{VI})$ with a maximum at $870 \mathrm{~nm}$. Detecting this peak and verifying its molar absorptivity should serve as an additional proof of existence of dissolved plutonium solely in the hexavalent form.

3) A series of the $\mathrm{Fe}(\mathrm{OH})_{3} / \mathrm{Cr}(\mathrm{OH})_{3} / \mathrm{Pu}(\mathrm{OH})_{4}$ sludge simulants with a variety of $\mathrm{Fe}(\mathrm{III})$ to $\mathrm{Cr}$ (III) to $\mathrm{Pu}(\mathrm{IV})$ molar ratios should be prepared and tested in alkaline oxidative-leaching experiments to understand better $\mathrm{Pu}$ leachability and post-leaching behavior as a function of the simulant composition and $\mathrm{Mn}$ (VII)-to-Cr(III) molar ratio.

4) This variation should include two simplified cases of only one macrocomponent present with homogeneous incorporation of $\mathrm{Pu}(\mathrm{IV})$ traces:

- $\mathrm{Fe}(\mathrm{III})+\mathrm{Pu}(\mathrm{IV})$ (with no $\mathrm{Cr}(\mathrm{III})$ present)

- $\mathrm{Cr}(\mathrm{III})+\mathrm{Pu}(\mathrm{IV})$ (with no Fe(III) present).

These simplified matrices are expected to elucidate the behavior of plutonium associated with the individual phases of $\mathrm{Fe}(\mathrm{OH})_{3}$ and $\mathrm{Cr}(\mathrm{OH})_{3}$ in the process of oxidative leaching.

5) Selective dissolution of the $\mathrm{MnO}_{2}$ phase generated in the oxidant-treated sludge simulant as a product of permanganate reduction by $\mathrm{Cr}(\mathrm{OH})_{3}$ should be tested (with determination of $\mathrm{Pu}$ leachability from $\mathrm{MnO}_{2}$ ) to understand the distribution of insoluble plutonium between the remaining $\mathrm{Fe}(\mathrm{OH})_{3}$ and the newly formed $\mathrm{MnO}_{2}$ in the metathesized sludge simulant. 


\subsection{Introduction}

Oxidative alkaline leaching of Hanford tank sludges using permanganate was shown to not only solubilize $\mathrm{Cr}$ (III) phases in the sludge, but to also increase the concentration of plutonium in the leachates. The extent of $\mathrm{Pu}$ solubilization is a sensitive function of the level of sodium hydroxide in the leachant, with a much higher percentage of $\mathrm{Pu}$ dissolution found in leachates at higher alkalinity ( $3 \mathrm{M} \mathrm{NaOH})$. All previous tests with real Hanford tank sludges did not provide any information regarding the oxidation state and the chemical form of the dissolved $\mathrm{Pu}$ in alkaline leachates containing chromate (and occasionally permanganate as excessive or not fully reacted oxidant). Knowledge of Pu speciation in the leachates is of crucial importance for understanding and predicting the behavior of this fissionable material at subsequent stages of treating process streams. This treatment includes removing ${ }^{137} \mathrm{Cs}$ and other fission products using an ion-exchange process based on the application of a resin with a significant reduction potential. This property of the resin is related to the abundance of organic moieties of a reductive nature in its polymeric framework. The interaction of $\mathrm{Pu}$ in its higher and more soluble oxidation states (penta- and/or hexavalent plutonium) with an excess of the ion-exchange resin may induce the reduction of $\mathrm{Pu}$ to its much less soluble tetravalent form. This process may be followed by the precipitation of poorly soluble $\mathrm{PuO}_{2} \cdot \mathrm{HH}_{2} \mathrm{O}$ and its retention on the surface of the resin beads, or by its uncontrolled accumulation in pipelines and solution storage vessels at the subsequent stages of the leachate treatment process.

On the other hand, the effect of the solubilization of Pu by the oxidative treatment of the sludge might be related to the formation of the more soluble $\mathrm{Pu}(\mathrm{IV})$ species [without their oxidation to $\mathrm{Pu}(\mathrm{V})$ or $\mathrm{Pu}(\mathrm{VI})$ ] due to increased temperature at the leaching stage or transformation of the hydrolyzed forms of $\mathrm{Pu}(\mathrm{IV})$ to its mixed hydroxy complexes with carbonate and, to a lesser extent, with chromate. The former agent is always present in the stock solutions of $\mathrm{NaOH}$ as a contaminant. Unlike $\mathrm{Pu}(\mathrm{V})$ or $\mathrm{Pu}(\mathrm{VI})$, these transformed species of $\mathrm{Pu}(\mathrm{IV})$ may interact with the resin beads in a completely different way.

The potential accumulation of significant amounts of the insoluble phase of $\mathrm{Pu}(\mathrm{IV})$ within the process equipment raises criticality safety concerns and calls for the development of a direct speciation analysis of $\mathrm{Pu}$ in the oxidative alkaline leachates before their treatment to remove fission products and other components from the post-leaching process streams.

Bechtel National, Inc. (BNI) is evaluating the plutonium speciation in caustic solutions that reasonably represent the process streams from oxidative-leaching demonstration test. Battelle-Pacific Northwest Division (PNWD) was contracted to develop a spectrophotometric method to measure plutonium speciation at submicromolar $\left(<10^{-6} \mathrm{M}\right)$ concentrations in alkaline solutions in the presence of chromate and carbonate. Data obtained from the testing will be used to identify the oxidation state of $\mathrm{Pu}(\mathrm{IV})$, $\mathrm{Pu}(\mathrm{V})$, and $\mathrm{Pu}(\mathrm{VI})$ species that potentially could exist in caustic leachates. Work was initially conducted under contract number 24590-101-TSA-W000-00004 satisfying the needs defined in Appendix C of the Research and Technology Plan TSS A-219 to evaluate the speciation of chromium, plutonium, and manganese before and after oxidative leaching. In February 2007, the contract mechanism was switched to Pacific Northwest National Laboratory (PNNL) Operating Contract DE-AC05-76RL01830. 
This section provides background information for the following areas: the oxidation states and reductionoxidation (redox) stability of $\mathrm{Pu}$ as well as the solubility of $\mathrm{Pu}$ in an alkaline medium; the controversy in determining the stability fields of Pu-soluble species on Eh-pH diagrams in alkaline solutions; the direct speciation of $\mathrm{Pu}$ at low micromolar concentrations; and $\mathrm{Pu}$ solubilization and speciation in the process of oxidative alkaline leaching. The goals of the project are also discussed.

\subsection{Oxidation States and Redox Stability of Pu(IV, V, and V) in an Alkaline Medium}

Plutonium has a very diverse redox and complexation chemistry in aqueous solution, depending on the $\mathrm{pH}$ and redox potential. While the oxidation states of $\mathrm{Pu}$ and the redox equilibria between them have been well established in acidic medium (Weigel et al. 1986), the alkaline chemistry of Pu has not been investigated as thoroughly. Among a number of difficulties associated with studies of Pu redox and complexation chemistry in alkaline solutions, the low solubility of $\mathrm{Pu}(\mathrm{IV}, \mathrm{V})$ and to a lesser extent of $\mathrm{Pu}(\mathrm{VI})$ should be mentioned as the major problem that makes it impossible in most cases to apply direct noninvasive techniques (such as Optical Absorbance Spectroscopy) for reliable identification of the oxidation states of $\mathrm{Pu}$ and possible interconversions between them.

The plutonium-reduction potentials for $1 \mathrm{M}$ hydroxide were projected based on the respective potentials in acid and the corresponding hydrolysis reactions (Allard et al. 1980). Table 1.1 shows the results of this calculation.

Table 1.1. Standard Potentials for Plutonium for the Hypothetical Condition of Zero Ionic Strength. Values at pH 14 were calculated using hydrolysis data and solubility products for respective oxidation states of $\mathrm{Pu}$.

\begin{tabular}{|c|c|c|c|}
\hline $\begin{array}{l}\text { Valence } \\
\text { Change }\end{array}$ & $\mathbf{p H}$ & Dominating Reaction & $\mathbf{E}^{\mathbf{0}}, \mathbf{V}$ \\
\hline \multirow{2}{*}{ VI-V } & 0 & $\mathrm{PuO}_{2}^{2+}+\mathrm{e}^{-}=\mathrm{PuO}_{2}^{+}$ & 0.933 \\
\hline & 14 & $\mathrm{PuO}_{2}(\mathrm{OH})_{3}^{-}+\mathrm{H}^{+}+\mathrm{e}^{-}=\mathrm{PuO}_{2}(\mathrm{OH})_{2}^{-}+\mathrm{H}_{2} \mathrm{O}$ & $0.16 \pm 0.24$ \\
\hline \multirow{2}{*}{ VI-IV } & 0 & $\mathrm{PuO}_{2}^{2+}+4 \mathrm{H}^{+}+2 \mathrm{e}^{-}=\mathrm{Pu}^{4+}+2 \mathrm{H}_{2} \mathrm{O}$ & 1.024 \\
\hline & 14 & $\mathrm{PuO}_{2}(\mathrm{OH})_{3}^{-}+2 \mathrm{H}^{+}+2 \mathrm{e}^{-}=\mathrm{Pu}(\mathrm{OH})_{5}^{-}$ & $0.34 \pm 0.12$ \\
\hline \multirow{2}{*}{ V-IV } & 0 & $\mathrm{PuO}_{2}^{+}+4 \mathrm{H}^{+}+\mathrm{e}^{-}=\mathrm{Pu}^{4+}+2 \mathrm{H}_{2} \mathrm{O}$ & 1.115 \\
\hline & 14 & $\mathrm{PuO}_{2}(\mathrm{OH})_{2}^{-}+\mathrm{H}^{+}+\mathrm{H}_{2} \mathrm{O}+\mathrm{e}^{-}=\mathrm{Pu}(\mathrm{OH})_{5}^{-}$ & $0.52 \pm 0.24$ \\
\hline \multirow{2}{*}{ IV-III } & 0 & $\mathrm{Pu}^{4+}+\mathrm{e}^{-}=\mathrm{Pu}^{3+}$ & 1.017 \\
\hline & 14 & $\mathrm{Pu}(\mathrm{OH})_{5}^{-}+\mathrm{H}^{+}+\mathrm{e}^{-}=\mathrm{Pu}(\mathrm{OH})_{4}^{-}+\mathrm{H}_{2} \mathrm{O}$ & $-1.04 \pm 0.24$ \\
\hline
\end{tabular}

The authors pointed out that the formation of polynuclear species and the probable dehydration of $\mathrm{Pu}(\mathrm{OH})_{4}$ to $\mathrm{PuO}_{2}$ with a decrease in solubility were not considered in their calculation. Therefore, they considered their description of aqueous plutonium chemistry in alkaline aqueous solution as partly qualitative with an emphasis on the need for accurate chemical data in this field.

Plutonium oxidation states in alkaline solution have been recently reviewed by Barney and Delegard (1999). $\mathrm{Pu}(\mathrm{III})$ and $\mathrm{Pu}(\mathrm{VII})$ were reported to be unstable in alkaline solutions at $\mathrm{NaOH}$ concentrations from $0.1 \mathrm{M}$ to $15 \mathrm{M}$. The $\mathrm{Pu}(\mathrm{VI}) / \mathrm{Pu}(\mathrm{V})$ couple was found to be reversible, which implies that the respective plutonium species have similar structures. On the other hand, the $\mathrm{Pu}(\mathrm{V}) / \mathrm{Pu}(\mathrm{IV})$ was found to be irreversible, indicating structural differences between these two oxidation states of plutonium. 
Dependence of the formal potentials of the $\mathrm{Pu}(\mathrm{VI}) / \mathrm{Pu}(\mathrm{V})$ and $\mathrm{Pu}(\mathrm{V}) / \mathrm{Pu}(\mathrm{IV})$ couples on the concentration of $\mathrm{NaOH}$ shows that the both dependences are linear functions of $\mathrm{NaOH}$ concentration over the ranges from $1 \mathrm{M}$ to $14 \mathrm{M}$ and $5 \mathrm{M}$ to $14 \mathrm{M}$ of $\mathrm{NaOH}$, respectively, with a much more significant downward slope for the V/IV line than for the VI/V one. The two plots (Figure 1.1) cross each other at approximately $9 \mathrm{M}$ of $\mathrm{NaOH}$. This indicates that $\mathrm{Pu}(\mathrm{V})$ is unstable to disproportionation at $\mathrm{NaOH}$ concentrations lower than the crossing point.
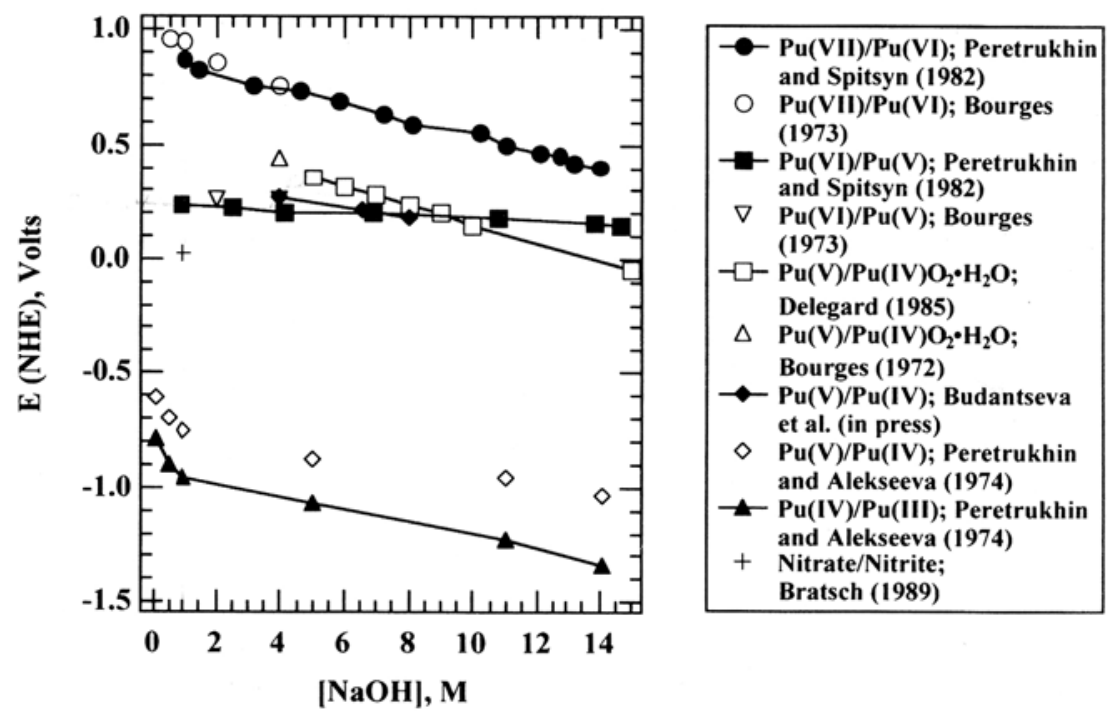

Figure 1.1. Formal Potentials of Various Pu Couples as a Function of $\mathrm{NaOH}$ Concentrations. Taken from (Barney and Delegard 1999).

Optical absorbance spectra of $\mathrm{Pu}(\mathrm{IV}), \mathrm{Pu}(\mathrm{V})$, and $\mathrm{Pu}(\mathrm{VI})$ in acidic aqueous solution are well established (see, for example, Table 7.96 [page 787] in [Weigel et al. 1986]). Their spectral features are sufficiently resolved both in the visible and near IR ranges of the spectrum to allow quantification of Pu speciation when two or more oxidation states coexist in the same solution. However, the alkaline chemistry of these oxidation states of plutonium is much less explored, and very few measurements of absorbance band positions and intensities are reported in the literature for $\mathrm{Pu}(\mathrm{V})$ and $\mathrm{Pu}(\mathrm{VI})$ (Budantseva et al. 1997) at $\mathrm{NaOH}$ concentrations from $2 \mathrm{M}$ to $8 \mathrm{M}$. Essentially, no data on optical absorbance spectra of $\mathrm{Pu}(\mathrm{VI})$ and $\mathrm{Pu}(\mathrm{V})$ at low-to-moderate concentrations of $\mathrm{NaOH}(0.1$ to $1 \mathrm{M})$ are reported. This lack of spectral measurements in the case of $\mathrm{Pu}(\mathrm{V})$ is attributed to a strong tendency of $\mathrm{Pu}(\mathrm{V})$ to disproportionation at low alkalinity (Budantseva et al. 1997). A spectrum of freshly prepared $\mathrm{Pu}(\mathrm{VI})$ in alkaline solution with a major peak position at $875 \pm 3 \mathrm{~nm}$ is reported to be unstable at an $\mathrm{NaOH}$ concentration of $<2 \mathrm{M}$ and at $\mathrm{Pu}(\mathrm{VI})>5 \times 10^{-4} \mathrm{M}$. No spectrum of $\mathrm{Pu}(\mathrm{IV})$ was reported at any concentration of $\mathrm{NaOH}$, presumably because of the very low solubility of this oxidation state of Pu in an alkaline medium and especially at a lower concentration of $\mathrm{NaOH}$.

\subsection{Solubility of Pu(IV, V, and VI) in an Alkaline Medium}

Plutonium-solution chemistry under alkaline conditions is dominated by the low solubility of amorphous hydroxide, $\mathrm{Pu}(\mathrm{OH})_{4}(\mathrm{am})$, or hydrous oxide, $\mathrm{PuO}_{2} x \mathrm{H}_{2} \mathrm{O}(\mathrm{s})$, where designation "s" may stand for fresh, $\mathrm{X}-$ 
ray amorphous precipitates ("am") or for aged precipitates including both amorphous and microcrystalline fractions (Neck et al. 2007 and references therein). The stabilization of higher oxidation states and an increasing solubility of plutonium compounds are observed with increasing hydroxide concentrations. Figure 1.2, which is based on a recent review of Pu chemistry in alkaline media (Barney and Delegard 1999) shows solubilities of $\mathrm{Pu}(\mathrm{IV}), \mathrm{Pu}(\mathrm{V})$, and $\mathrm{Pu}(\mathrm{VI})$ compounds as a function $\mathrm{NaOH}$ concentrations.

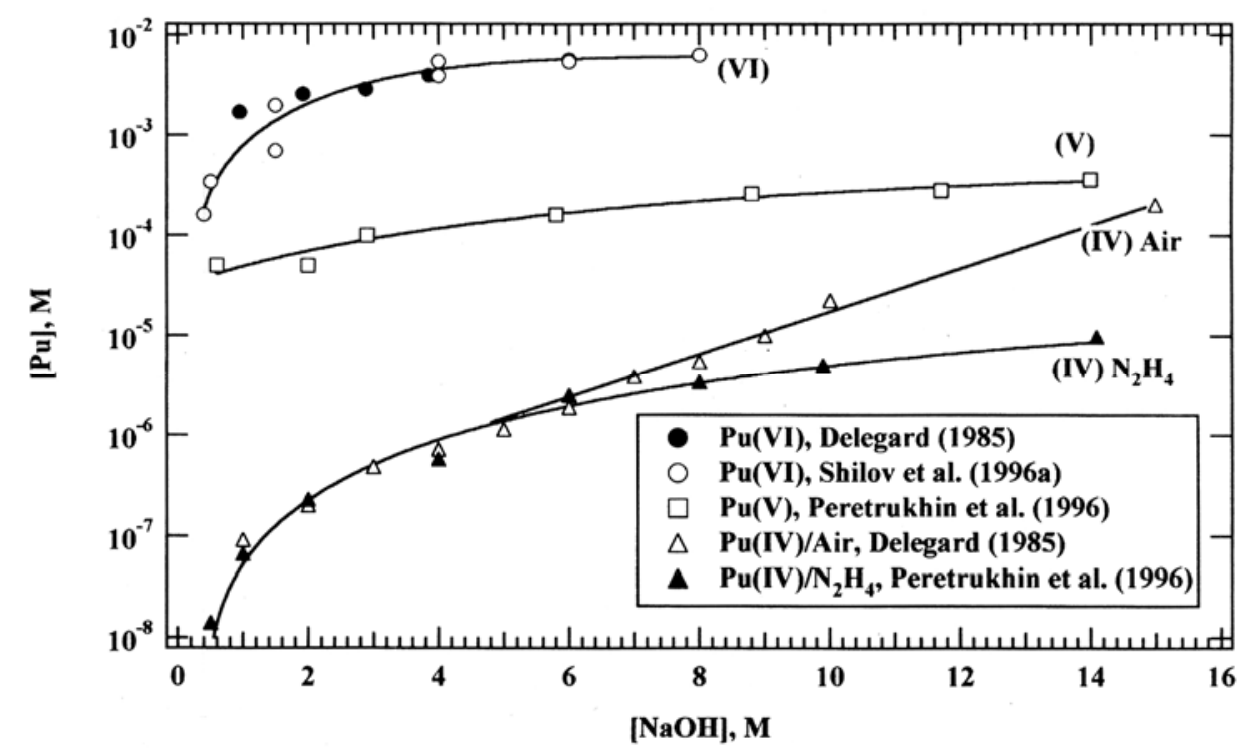

Figure 1.2. Solubility Curves of $\mathrm{Pu}(\mathrm{IV}), \mathrm{Pu}(\mathrm{V})$ and $\mathrm{Pu}(\mathrm{VI})$ as a Function of $\mathrm{NaOH}$ Concentration. Taken from Barney and Delegard's review (Barney et al. 1999).

It should be noted that at lower hydroxide concentration $(<1 \mathrm{M}$ of $\mathrm{NaOH})$, solubility data for $\mathrm{Pu}(\mathrm{V})$ and $\mathrm{Pu}(\mathrm{IV})$ cannot be considered reliable because the soluble species of $\mathrm{Pu}$ in equilibrium with respective salts or hydroxides of $\mathrm{Pu}(\mathrm{IV})$ and $\mathrm{Pu}(\mathrm{V})$ were never characterized by optical absorbance spectroscopy (OAS) to confirm that the final oxidation state of Pu corresponded to the initially added oxidation state. The perturbation of the initial oxidation state of Pu may occur through a number of Redox reactions (such as oxidation by dissolved oxygen or disproportionation reaction for intermediate oxidation states of $\mathrm{Pu}$ ). $\mathrm{Pu}(\mathrm{VI})$ solubility remains relatively high and constant in a broad range of $\mathrm{NaOH}$ concentrations from 1 to $15 \mathrm{M}$, but rapidly goes down by several orders of magnitude in the $1 \mathrm{M}$ to $0.4 \mathrm{M} \mathrm{NaOH}$ range. It appears that $\mathrm{Pu}(\mathrm{VI})$ solubility was not systematically measured in the $0.4 \mathrm{M}$ to $0.1 \mathrm{M}$ range of $\mathrm{NaOH}$ concentrations, and only one experimental point is available for $\mathrm{Pu}(\mathrm{VI})$ solubility at $0.11 \mathrm{M}$ of $\mathrm{NaOH}$ where $10.5 \mu \mathrm{M}$ of $\mathrm{Pu}(\mathrm{VI})$ was found in equilibrium with the solid phase of plutonyl hydroxide (PerezBustamante 1965).

$\mathrm{Pu}$ chemistry in alkaline solution becomes even more complex in the presence of a high concentration of multicharged anions capable of competing with hydroxide for coordination sites around a plutonium metal center. The effect of a number of inorganic and organic complexing agents on the solubility of $\mathrm{Pu}(\mathrm{OH})_{4}$ was studied in $1 \mathrm{M} \mathrm{NaOH}$ and $4 \mathrm{M} \mathrm{NaOH}$ solutions representing the conditions under which Hanford high level wastes are stored (Peretrukhin et al. 1996). In the absence of complexing agents, the solubility of $\mathrm{Pu}(\mathrm{IV})$ was found to be $0.067 \mu \mathrm{M}$ and $0.58 \mu \mathrm{M}$ in $1 \mathrm{M}$ and $4 \mathrm{M} \mathrm{NaOH}$ solutions, 
respectively. Among inorganic complexants tested (carbonate, phosphate, and fluoride), carbonate showed the most significant effect of solubility enhancement of $\mathrm{Pu}(\mathrm{IV}$ ) (from 5.2 to 16 times in $1 \mathrm{M}$ of $\mathrm{NaOH}$ in the carbonate concentration range of 0.05 to $0.5 \mathrm{M}$ ), illustrating the effect of a mixed complex formation with this ligand. In regard to organic chelators tested (glycolate, citrate, ethylenediaminetetraacetate [EDTA], and oxalate), the first three agents showed practically the same level of solubility increase ( 25 to 28 times in the ligands' concentration range from 0.03 to $0.5 \mathrm{M}$ ). At higher alkalinity ( $4 \mathrm{M}$ of $\mathrm{NaOH}$ ), the effect of all complex-forming reagents on the solubility of $\mathrm{Pu}(\mathrm{IV})$ hydroxide becomes $\sim 10$ to 15 times less significant for organic chelators and 2 to 3 times less in the case of carbonate.

In a recent series of tests at Savannah River National laboratory (SRNL), Pu(IV) in nitric acid was mixed with a large number of different simulated waste compositions (Rudisill et al. 2004). These simulants contained sodium salts of $\mathrm{NO}_{3}{ }^{-}, \mathrm{NO}_{2}{ }^{-}, \mathrm{OH}^{-}, \mathrm{CO}_{3}{ }^{2-}$, and $\mathrm{Al}(\mathrm{OH})_{4}{ }^{-}$anions. These solutions were mixed for 1 to 3 months, then sampled, filtered, and analyzed for total Pu concentration. It was determined that only $\mathrm{CO}_{3}{ }^{2-}$ and $\mathrm{OH}^{-}$were statistically significant factors in increasing $\mathrm{Pu}$ solubility. The analyses produced the following empirical model of $\mathrm{Pu}(\mathrm{IV})$ solubility (see Equation 1.1 below). The data also show that temperatures in the range 25 to $85^{\circ} \mathrm{C}$ do not have a statistically significant impact on $\mathrm{Pu}(\mathrm{IV})$ solubility.

$$
[\mathrm{Pu}]=-7.48 \times 10^{-8}+1.2 \times 10^{-6}\left[\mathrm{OH}^{-}\right]+4.9 \times 10^{-6}\left[\mathrm{CO}_{3}^{2-}\right]
$$

(The derived coefficients are valid for $\mathrm{OH}^{-}$and $\mathrm{CO}_{3}{ }^{2-}$ concentrations expressed in molar scale.)

Since the reference process for oxidative leaching involves leaching between $0.1 \mathrm{M}$ and $1.0 \mathrm{M}$ of $\mathrm{NaOH}$ (with minimal carbonate), a reasonable lower limit on the $\mathrm{Pu}(\mathrm{IV})$ solubility under expected Waste Treatment Plant (WTP) conditions is $5 \times 10^{-8} \mathrm{M}$. It is important to note that the calculated value of $\mathrm{Pu}(\mathrm{IV})$ solubility of $5 \times 10^{-8} \mathrm{M}$ is obtained by extrapolating the derived equation onto an unexplored range of alkalinity because the lowest hydroxide concentration tested in the SRNL study was $0.45 \mathrm{M}$ of $\mathrm{NaOH}$, and that solution also contained $0.073 \mathrm{M}$ of $\mathrm{Na}_{2} \mathrm{CO}_{3}$.

\subsection{Controversy in Determination of Stability Fields of $\mathrm{Pu}(\mathrm{IV}), \mathrm{Pu}(\mathrm{V})$, and Pu(VI) Soluble Species on Eh-pH Diagrams in Alkaline Solutions}

The Redox speciation of $\mathrm{Pu}$ as a function of solution acidity $(\mathrm{pH})$ and oxidation potential (Eh) can be conveniently expressed in the form of Eh-pH diagrams. In a carbonate-free medium, hydrolysis constants of $\mathrm{Pu}(\mathrm{III}),(\mathrm{IV}),(\mathrm{V})$, and (VI) should be taken into account to derive functional expressions describing the Redox potentials of $\mathrm{Pu}(\mathrm{IV}) / \mathrm{Pu}(\mathrm{III}), \mathrm{Pu}(\mathrm{V}) / \mathrm{Pu}(\mathrm{IV})$, and $\mathrm{Pu}(\mathrm{VI}) / \mathrm{Pu}(\mathrm{V})$ Redox couples as a function of acidity. One of the first attempts to construct $\mathrm{Eh}-\mathrm{pH}$ diagrams for $\mathrm{Pu}$ in carbonate-free aqueous solution was undertaken by Lierse and Kim (1986). Their diagram is reproduced here as Figure 1.3. According to their calculations, the region of stability of $\mathrm{Pu}(\mathrm{V})$ is limited not only by increasing acidity $(\mathrm{pH}>1.5)$, but also by relatively low hydroxide concentration $(\mathrm{pH}<10.2)$. At higher alkalinity, $\mathrm{Pu}(\mathrm{IV})$ exists in equilibrium with $\mathrm{Pu}(\mathrm{VI})$. This disappearance of $\mathrm{Pu}(\mathrm{V})$ from equilibrium with lower and higher oxidation states of $\mathrm{Pu}$, to our understanding, is based of the fact that calculated potential of the $\mathrm{Pu}(\mathrm{V}) / \mathrm{Pu}(\mathrm{IV})$ couple exceeds the oxidation potential of the $\mathrm{Pu}(\mathrm{VI}) / \mathrm{Pu}(\mathrm{V})$, which makes $\mathrm{Pu}(\mathrm{V})$ unstable at $\mathrm{pH}>10.2$ due to its disproportionation to $\mathrm{Pu}(\mathrm{VI})$ and $\mathrm{Pu}(\mathrm{IV})$. 


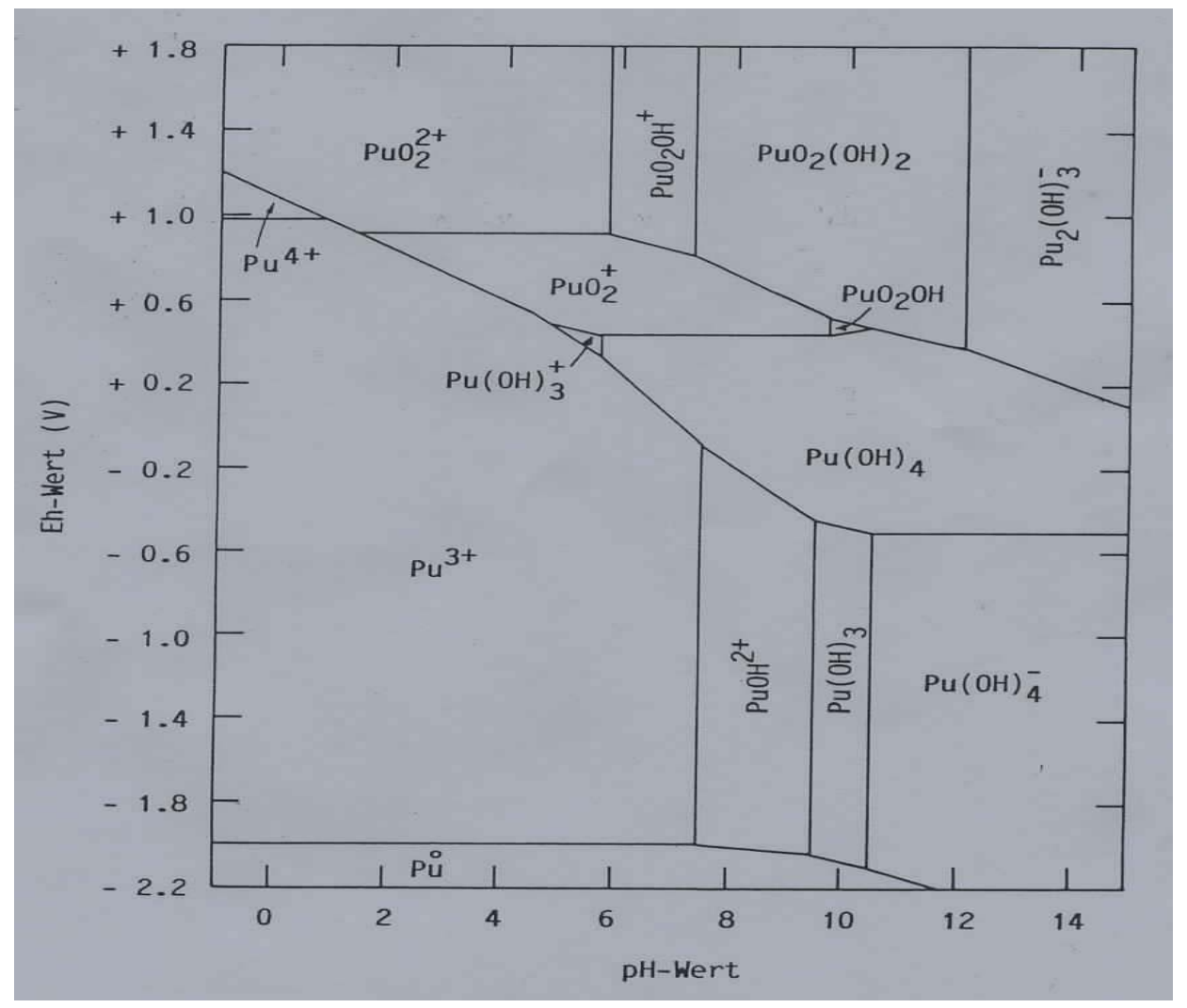

Figure 1.3. Eh-pH Diagram for Plutonium Based on Standard Redox Potentials and Hydrolysis Reactions of $\mathrm{Pu}(\mathrm{III}, \mathrm{IV}, \mathrm{V}$, and VI) Ions in Aqueous Solution. These are carbonate-free conditions (Lierse and Kim 1986).

More recently, Runde constructed the Eh-pH diagram for $\mathrm{Pu}$ in water containing hydroxide, carbonate, and fluoride with the ligands' concentrations comparable to those found in groundwater from well J-13 (Yucca Mountain, Nevada) (Runde 2000). This diagram is shown in Figure 1.4. In striking contrast with the previous figure, the alkaline side of this diagram shows a much larger stability field of $\mathrm{Pu}(\mathrm{V})$, extending all the way to a $1 \mathrm{M} \mathrm{NaOH}$ concentration $(\mathrm{pH}=14)$. In the $\mathrm{pH}$ range from 8 to $12.3 \mathrm{Pu}(\mathrm{V})$ is represented by a monocarbonate complex in equilibrium with bis- and tris-carbonate complexes of $\mathrm{Pu}(\mathrm{VI})$ at higher potentials. Complexation with carbonate and its effect on Redox potentials might be responsible for such prominent changes in the stability field of $\mathrm{Pu}(\mathrm{V})$ due to suppression of its disproportionation. However, starting from $\mathrm{pH} 12.3$ and higher, the carbonate complexation of both $\mathrm{Pu}(\mathrm{V})$ and $\mathrm{Pu}(\mathrm{VI})$ yields to a formation of hydroxy complexes, the most predominant of which, according to the previous diagram, should result in eliminating $\mathrm{Pu}(\mathrm{V})$ from the equilibrium. Yet, a stability field $\mathrm{Pu}(\mathrm{V})$ is present in Figure 1.4 all the way to $\mathrm{pH} 14$. This discrepancy between the Lierse's and Runde's calculations [both based on the similar values of hydrolysis constants of $\mathrm{Pu}(\mathrm{IV}), \mathrm{Pu}(\mathrm{V})$, and $\mathrm{Pu}(\mathrm{VI})]$ is difficult to understand.

Another attempt of Pu Redox speciation modeling in terms of the Eh-pH diagram was undertaken just a few months ago at Los Alamos National Laboratory by the same group of authors who did the calculation 7 years ago (Reilly et al. 2007). The new diagram is reproduced in Figure 1.5. Apparently, the same concentrations of fluoride and carbonate representative for the J-13 groundwater were used in both the calculations. It is amazing to see to what extent the alkaline portion of the diagram has been transformed 
for the same matrix composition. It appears now that carbonate complexes of both $\mathrm{Pu}(\mathrm{V})$ and $\mathrm{Pu}(\mathrm{VI})$ do not yield to hydrolysis and, instead, dominate the speciation of these higher oxidation states of $\mathrm{Pu}$ up to 1 $\mathrm{M} \mathrm{NaOH}$ concentration. The Redox potentials of $\mathrm{Pu}(\mathrm{V}) / \mathrm{Pu}(\mathrm{IV})$ and $\mathrm{Pu}(\mathrm{VI}) / \mathrm{Pu}(\mathrm{V})$ couples at $\mathrm{pH}=14$ dropped down from +0.21 and $+0.36 \mathrm{~V}$ (old diagram) to -0.04 and $0.22 \mathrm{~V}$ (new diagram), respectively. The respective numbers for $\mathrm{pH} 13.5(\sim 0.31 \mathrm{M}$ of $\mathrm{NaOH})$ changed from +0.23 and $+0.38 \mathrm{~V}$ to +0.02 and $+0.24 \mathrm{~V}$. To the best of our knowledge, the stability constants of hydroxide and carbonate complexes of $\mathrm{Pu}(\mathrm{IV}), \mathrm{Pu}(\mathrm{V})$, and $\mathrm{Pu}(\mathrm{VI})$ have not been remeasured or critically revised to any significant extent in the last 7 years, which would explain such significant changes in the positions of the stability fields of $\mathrm{Pu}(\mathrm{IV}), \mathrm{Pu}(\mathrm{V})$, and $\mathrm{Pu}(\mathrm{VI})$ as well as the drastic change between relative magnitudes of hydroxide and carbonate competition for the metal center.

Regardless of the controversy in the Redox field positions of soluble forms of $\mathrm{Pu}$, one valuable feature of the Eh-pH diagram shown in Figure 1.5 never presented before should be mentioned here. This diagram shows areas of stability fields of the solubility controlling phases of $\mathrm{Pu}(\mathrm{III})\left[\mathrm{Pu}(\mathrm{OH}) \mathrm{CO}_{3}(\mathrm{~s})\right], \mathrm{Pu}(\mathrm{IV})$ $\left[\mathrm{Pu}(\mathrm{OH})_{4}(\mathrm{~s})\right]$, and $\mathrm{Pu}(\mathrm{VI})\left[\mathrm{PuO}_{2}(\mathrm{OH})_{2}(\mathrm{~s})\right]$ in equilibrium with soluble species of $\mathrm{Pu}$. It is interesting to see that $\mathrm{Pu}(\mathrm{OH})_{4}(\mathrm{~s})$ controls the soluble levels of $\mathrm{Pu}$ at much higher potentials than those that define the stability field of $\mathrm{Pu}(\mathrm{OH})_{4}(\mathrm{aq})$. This feature helps to better understand $\mathrm{Pu}$ speciation and solubility in heterogeneous systems.

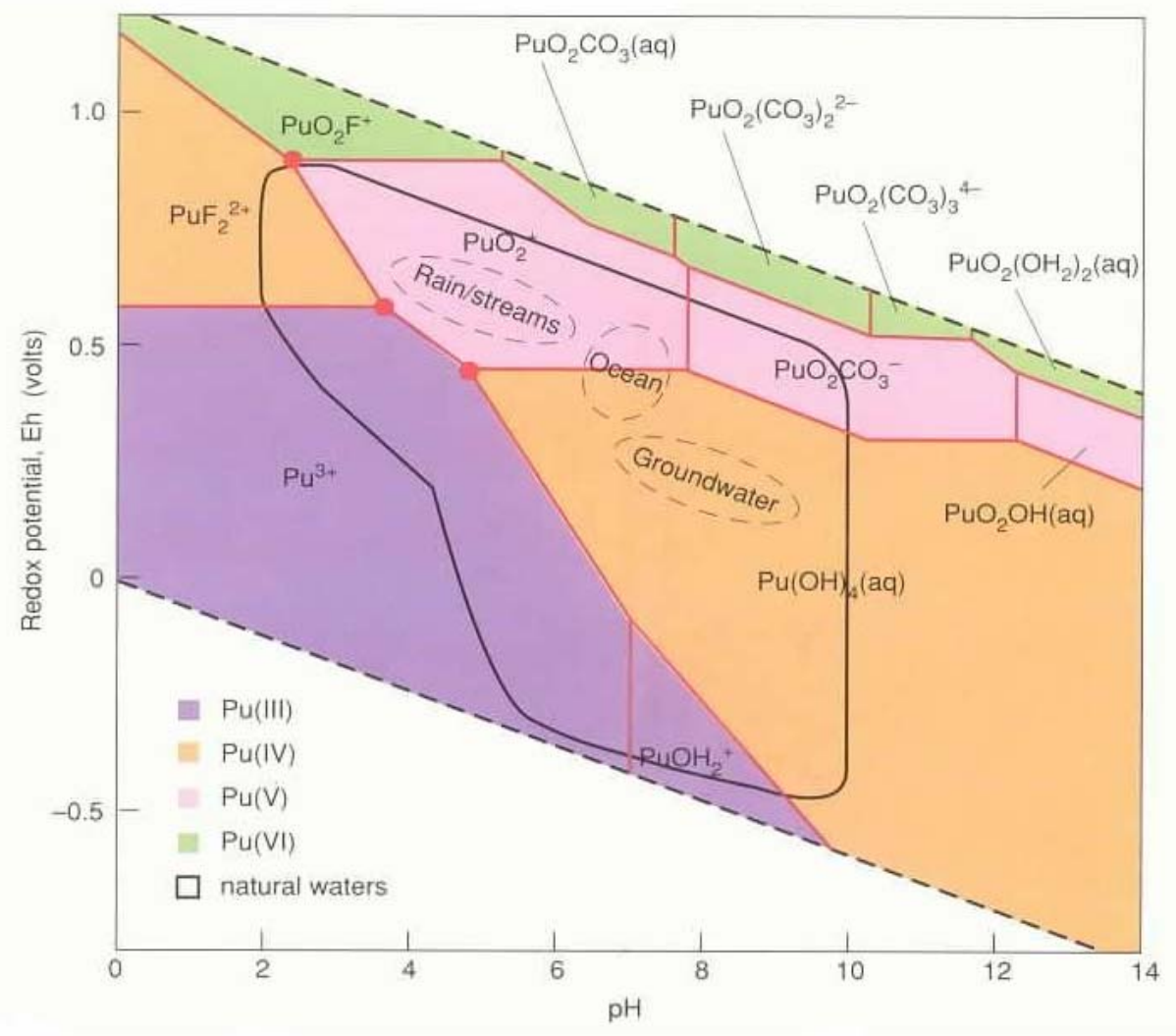

Figure 1.4. Eh-pH Diagram for Plutonium in Groundwater Containing Hydroxide, Carbonate, and Fluoride Ions. The ligand concentrations are comparable to those found in water from well J-13 at Yucca Mountain, Nevada (Runde 2000). The total Pu concentration is fixed at $10 \mu \mathrm{M}$. 


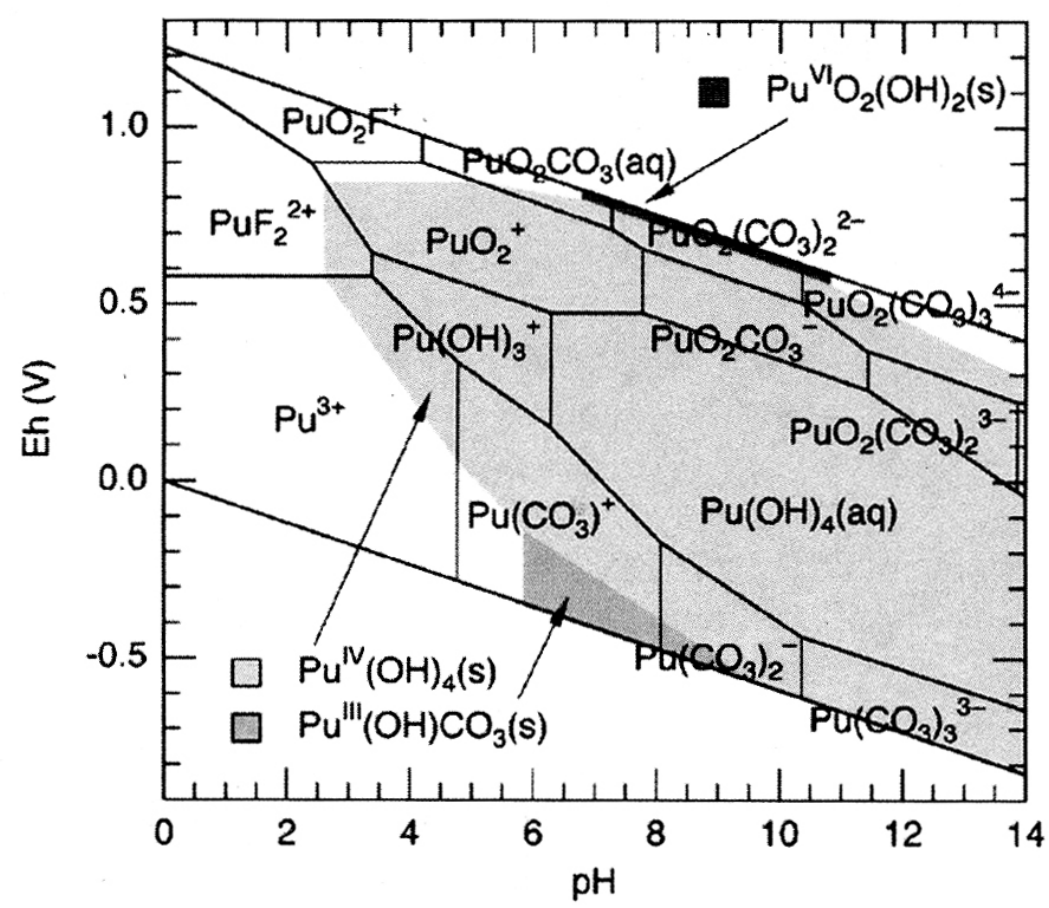

Figure 1.5. Eh-pH Diagram for Plutonium in Groundwater at $25^{\circ} \mathrm{C}$ Under Conditions Representative of J-13 Water Found Near the Proposed Yucca Mountain Nuclear Waste Repository. The total $\mathrm{Pu}$ concentration is $10 \mu \mathrm{M}$, and the total carbonate concentration is $10^{-2.6} \mathrm{M}(2.51 \mathrm{mM})$ (Reilly et al. 2007).

\subsection{Direct Speciation of Pu at Low Micromolar Concentrations by Spectroscopic Techniques}

OAS is recognized as a direct noninvasive technique for studying Redox and complexation reactions of plutonium in solution. The applicability of conventional OAS is typically limited to a $10^{-5}$ to $10^{-3} \mathrm{M}$ concentration range of $\mathrm{Pu}$, depending on the oxidation state and the signal-to-noise ratio of the spectrophotometer (for measurements with 10-mm thick optical cells). The solubility of Pu compounds in neutral to moderately alkaline solutions is typically below $10^{-6} \mathrm{M}$, which precludes the application of conventional OAS for $\mathrm{Pu}$ speciation analysis.

Laser-Induced Photoacoustic Spectroscopy (LIPAS) was proposed several decades ago for 100 to 1000 times more sensitive detection of actinide species compared with OAS, including plutonium ions in solution. This method employs a tunable laser system to scan through the spectral region of interest, which generates an ultrasound signal in solution, detectable by a piezoelectric transducer. The magnitude of this signal is proportional to the extent of light attenuation by absorbing species in solution (Beitz et al. 1990). It has been shown that the photoacoustic technique provides comparable results versus liquidliquid extraction in studies of Pu solution chemistry at low concentrations (Neu et al. 1994). To its disadvantage, applying the LIPAS technique requires the use and maintenance of expensive and complex equipment. 
The development of liquid-core waveguides over the last decade has allowed for the use of extremely long path lengths with small sample volumes and rapid sampling times (Waterbury et al. 1997). This method uses narrow-diameter capillary tubing for light transmission through a thick layer of solution under conditions of total internal reflection of the light from the tubing walls surrounding the solution. Cells of this type showed a good sensitivity in the analysis of trace transition metals, nitrate, and other analytes of interest in aquatic systems (Byrne et al. 2002). The first and so far the only application of a 100-cm long Liquid Waveguide Capillary Cell (hereafter LWCC) for plutonium detection and quantification was reported very recently (Wilson et al. 2005). Detection limits of $0.7 \mu \mathrm{M}$ for $\mathrm{Pu}(\mathrm{VI})$, $16 \mu \mathrm{M}$ for $\mathrm{Pu}(\mathrm{V}), 5 \mu \mathrm{M}$ for $\mathrm{Pu}(\mathrm{IV})$, and $8 \mu \mathrm{M}$ for $\mathrm{Pu}(\mathrm{III})$ in acidic medium were achieved. The limits of detection represented increases of 18 to 33 times with respect to those achievable using a conventional 1-cm pathlength. To the best of our knowledge, no attempts were made to test the LWCC method for detection of lanthanides or actinides in an alkaline medium.

It should be mentioned that both LIPAS detection and LWCC detection achieve significant improvements in sensitivity in a limited spectral range from $\sim 250$ to $\sim 750 \mathrm{~nm}$. According to the LWCC manufacturer's specifications, the operation range of $100-\mathrm{cm} \mathrm{LWCC} \mathrm{is} \mathrm{limited} \mathrm{to} 230$ to $750 \mathrm{~nm}$, and that of $500-\mathrm{cm}$ cell narrows down to the 300- to 700-nm spectral window. This limitation is related to the absorbance spectrum of water $\left(\mathrm{H}_{2} \mathrm{O}\right)$ as a solvent. The absorption coefficient of water is at its minimum of 0.015 to $0.030 \mathrm{~m}^{-1}$ in the 370 - to $510-\mathrm{nm}$ range. Beyond this range of wavelengths, it quickly grows both in ultraviolet (UV) and near infrared (IR) directions, and at 210 and $800 \mathrm{~nm}$, it reaches a $2.0 \mathrm{~m}^{-1}$ value. An increase in water absorbance in the IR direction becomes even more dramatic starting from $\sim 870 \mathrm{~nm}$, which precludes reliable spectrophotometric measurements using LWCC detection in the near-IR range of the spectrum where a number of analytically important absorbance bands of $\mathrm{Pu}$ are possibly located in alkaline solution.

On the other hand, it is known that deuterated or heavy water $\left(\mathrm{D}_{2} \mathrm{O}\right)$ has a very low and flat optical absorbance coefficient in the wide near-IR range of the spectrum. This difference in the optical properties of $\mathrm{H}_{2} \mathrm{O}$ and $\mathrm{D}_{2} \mathrm{O}$ could be exploited to perform $\mathrm{Pu}$ speciation analysis over a much wider optical window of several hundred nanometers (from $\sim 300$ to $1200 \mathrm{~nm}$ ), provided that heavy water can be used as a solvent to prepare all the solutions for spectrophotometric analysis of $\mathrm{Pu}$. No adverse effect by the use of $\mathrm{D}_{2} \mathrm{O}$ instead of $\mathrm{H}_{2} \mathrm{O}$ is expected in terms of measurable changes in the absorption peaks' positions and intensities of $\mathrm{Pu}(\mathrm{IV}, \mathrm{V}, \& \mathrm{VI})$. This expectation is based on the very close similarity of absorption spectra of rare-earth ions in $\mathrm{H}_{2} \mathrm{O}$ and $\mathrm{D}_{2} \mathrm{O}$ solutions (Carnall 1979). Only one reference is found for actinide elements (Neck et al. 2001), which demonstrates that the peak position of tetravalent neptunium [Np(IV)] at $723 \mathrm{~nm}$ remains the same both in $\mathrm{HClO}_{4} / \mathrm{H}_{2} \mathrm{O}$ and $\mathrm{DClO}_{4} / \mathrm{D}_{2} \mathrm{O}$ solutions over $\mathrm{pH}(\mathrm{pD})$ range of 0 to 3.3 .

The expected presence of chromate in alkaline solutions relevant to leachates originating from oxidative alkaline treatment of Hanford tank sludges (see next section for more details) might produce serious limitations to the window of optical transparency of water from near-UV to the visible range of the optical spectrum. This fact makes the application of $\mathrm{D}_{2} \mathrm{O}$ as a solvent in studies of $\mathrm{Pu}$ speciation in chromate-containing solutions even more important to extend the operation range of LWCC toward the previously inaccessible near-IR region of the spectrum.

The main focus of this project is to determine the spectral features of $\mathrm{Pu}(\mathrm{IV}), \mathrm{Pu}(\mathrm{V})$, and $\mathrm{Pu}(\mathrm{VI})$ in a moderately alkaline medium $\left(\mathrm{D}_{2} \mathrm{O}+\mathrm{NaOD}\right)$ at low micromolar concentrations of $\mathrm{Pu}$. These spectral features were compared whenever possible with the respective spectral signatures of $\mathrm{Pu}$ in a conventional 
solvent both from the acidic side $\left(\mathrm{H}_{2} \mathrm{O}+\mathrm{HNO}_{3}\right)$ and the alkaline side $\left(\mathrm{H}_{2} \mathrm{O}+\mathrm{NaOH}\right)$ reported in the literature. In all cases when such comparison was possible, no differences were found in the positions or molar intensities of the respective absorbance bands. This proves that the presence of $\mathrm{D}_{2} \mathrm{O}$ and $\mathrm{OD}^{-}$in the primary coordination sphere of hydrolyzed $\mathrm{Pu}$ ions does not change their optical properties or the extent of their interaction with other complex forming agents, such as carbonate.

In regard to the isotopic effect on kinetics and thermodynamics of $\mathrm{Cr}(\mathrm{III}), \mathrm{Pu}(\mathrm{IV})$, and $\mathrm{Pu}(\mathrm{V})$ oxidation to their higher oxidation states by permanganate, it should be noted that the oxidation potentials of $\mathrm{Mn}(\mathrm{VII}) / \mathrm{Mn}(\mathrm{VI})$ and $\mathrm{Pu}(\mathrm{VI}) / \mathrm{Pu}(\mathrm{V})$ couples in deuterated alkaline media determined in the course of this project are in close agreement with the respective values reported for these couples in an ordinary solvent $\left(\mathrm{H}_{2} \mathrm{O}+\mathrm{NaOH}\right)$. This similarity suggests that the thermodynamics of the oxidative action of permanganate does not change when regular water is used instead of $\mathrm{D}_{2} \mathrm{O}$. The differences in the reaction rates of permanganate with $\mathrm{Cr}(\mathrm{III})$ and the lower oxidation states of $\mathrm{Pu}$ in $\mathrm{D}_{2} \mathrm{O}$ vs. $\mathrm{H}_{2} \mathrm{O}$ are likely to be more pronounced than the possible subtle differences in the magnitudes of oxidation potentials. However, all reactions studied in this project were found to reach equilibrium in less than 2 to $3 \mathrm{hrs}$. The rate constants of reactions of oxidizable compounds with permanganate in "protium" medium are typically higher than in deuterated medium. Consequently, it is believed that the oxidation processes in regular water should be less kinetically hindered and should approach a state of equilibrium even more rapidly.

\subsection{Pu Solubilization and Speciation in the Process of Oxidative Alkaline Leaching of Hanford Tank Sludges}

Chromium(III), one of the major components in Hanford tank sludge, originated mostly from the REDOX process. Chromium can interfere with high-level waste vitrification. Alkaline oxidative treatment of Hanford Site tank-waste sludges is currently under development to remove insoluble $\mathrm{Cr}$ (III) phases from the sludge by converting it into soluble $\mathrm{Cr}(\mathrm{VI})$ species.

Permanganate proved to be the best oxidizing agent among six candidates tested (hydrogen peroxide, ozone, persulfate, ferrate, peroxynitrite, oxygen, and permanganate, Rapko et al. 2004). One of its advantages compared with persulfate is moderate extent of TRU solubilization. It is expected that oxidizing conditions would partially dissolve co-precipitated $\mathrm{Pu}(\mathrm{IV})$ hydrous oxide present in the sludge by formation of anionic $\mathrm{Pu}(\mathrm{V})$ and/or $\mathrm{Pu}(\mathrm{VI})$ species.

Identification of $\mathrm{Pu}$ oxidation states in the sludge leachates is critical for understanding and predicting $\mathrm{Pu}$ behavior at the later stages of treatment of the leachate solutions including ${ }^{137} \mathrm{Cs}$ removal by ion exchange and regeneration of the resin.

\subsection{The Project Goals}

The following goals have been identified to achieve the project objectives as summarized in Table S.1. These goals are based on the description of the tests (Tasks 1 to 5) provided in the Test Plan TP-RPPWTP-445.

- Determine the usable spectral range of 5-meter-long LWCC in alkaline $\mathrm{H}_{2} \mathrm{O}$ and $\mathrm{D}_{2} \mathrm{O}$ media in the presence of chromate. 
- Demonstrate the applicability of LWCC-based optical absorbance spectroscopy for enhanced detection of various oxidation states of plutonium in alkaline media in the visible and near-IR range of the spectrum.

- Establish spectral signatures of $\mathrm{Pu}(\mathrm{IV}, \mathrm{V}$, and VI) in weakly to moderately caustic solutions ( $0.1 \mathrm{M}$ to $1 \mathrm{M}$ hydroxide) at low micromolar concentrations of $\mathrm{Pu}$. Determine detection limits of $\mathrm{Pu}$ for the respective oxidation states under these conditions.

- Evaluate the effect of carbonate on the spectral characteristics of $\mathrm{Pu}(\mathrm{IV}, \mathrm{V}$, and VI) in alkaline media and estimate the extent of solubility enhancement of $\mathrm{Pu}(\mathrm{IV})$ in the presence of carbonate at $0.25 \mathrm{M}$ of $\mathrm{NaOD}$.

- Study redox stability of $\mathrm{Pu}(\mathrm{IV})$ and $\mathrm{Pu}(\mathrm{V})$ in the presence of chromate and permanganate in alkaline medium and examine redox-state perturbation upon acidification of initially alkaline solutions.

- Study Pu leaching from the $\mathrm{Fe}(\mathrm{OH})_{3} / \mathrm{Cr}(\mathrm{OH})_{3} / \mathrm{Pu}(\mathrm{OH})_{4}$ sludge simulant with homogeneously co-precipitated $\mathrm{Pu}$ as a function of time, $\mathrm{Mn}(\mathrm{VII})$-to- $\mathrm{Cr}$ (III) ratio, and hydroxide concentration.

\subsection{Quality Assurance and Quality Control}

The following sections describe the quality assurance (QA) program and quality control (QC) measures applied to the conduct of work. The data represented in this report will refer to PNWD (in support of Bechtel National, Inc. Support Project [BNI-SP] before February 12, 2007) or PNNL (in support of Waste Treatment Plant Support Program [RPP-WTP] following February 12, 2007). Both of these projects performed work to the same QA program.

\subsubsection{Application of RPP-WTP Quality Assurance Requirements}

As of February 2007, the QA program is described as follows:

PNNL's QA program is based on requirements defined in DOE Order 414.1C, Quality Assurance and 10 CFR 830, Energy/Nuclear Safety Management, Subpart A-Quality Assurance Requirements (a.k.a., the Quality Rule). PNNL has chosen to implement the requirements of DOE Order 414.1C and 10 CFR 830, Subpart A by integrating them into the laboratory's management systems and daily operating processes. The procedures necessary to implement the requirements are documented through PNNL's Standards-Based Management System.

PNNL implemented the RPP-WTP quality requirements by performing work in accordance with the River Protection Project - Waste Treatment Plant Support Program (RPP-WTP) Quality Assurance Plan (RPP-WTP-QA-001, QAP). Work was performed to the quality requirements of NQA-1-1989 Part I, Basic and Supplementary Requirements, NQA-2a-1990, Part 2.7 and DOE/RW-0333P, Rev 13, Quality Assurance Requirements and Descriptions (QARD). These quality requirements are implemented through the River Protection Project - Waste Treatment Plant Support Program (RPP-WTP) Quality Assurance Manual (RPP-WTP-QA-003, QAM). 
A matrix that cross-references the NQA-1, NQA-2a, and QARD requirements with PNNL's procedures for this work is given in Table A1. It includes justification for those requirements not implemented.

\subsubsection{Conduct of Experimental and Analytical Work}

Experiments that were not method-specific were performed in accordance with PNNL's procedures QA-RPP-WTP-1101 “Scientific Investigations" and QA-RPP-WTP-1201 "Calibration Control System," verifying that sufficient data were taken with properly calibrated measuring and test equipment (M\&TE) to obtain quality results.

Spectrophotometric equipment was calibrated as described in Section 2.3. The oxidation-reductionpotential electrode and the $\mathrm{pH}$ electrode were calibrated with standard solutions as described in Section 2.7. The plutonium concentrations in simulants were measured according to the ASO procedure RPG-CMC-474, "Liquid Scintillation Counting," using a Perkin Elmer Tricarb model 3100 counter.

\subsubsection{Internal Data Verification and Validation}

PNNL addressed internal verification and validation activities by conducting an independent technical review of the final data report in accordance with PNNL's procedure QA-RPP-WTP-604. This review verified that the reported results were traceable, that inferences and conclusions were soundly based, and the reported work satisfied the Test Plan objectives. This review procedure is part of PNNL's RPP-WTP Quality Assurance Manual. 


\subsection{Experimental and Data Processing}

This section discusses the experimental details of the experiments, including the reagents and solvents used; the preparation of Pu stock solutions; spectrophotometric equipment; calibration and speciation experiments with LWCC; the determination of Pu concentration in calibration solutions and leachates; the preparation of the sludge simulant and oxidative-leaching procedure; measurements of Eh and $\mathrm{pH}$; the determination of $\mathrm{Cr}(\mathrm{VI}), \mathrm{Mn}(\mathrm{VII})$, and $\mathrm{Mn}(\mathrm{VI})$ concentrations in the oxidative-leaching experiments; the determination of baseline subtraction and net-peak intensity in calibration experiments; and the simulation and elimination of spectral interference in LWCC spectra.

\subsection{Reagents and Solvents Used in Calibration, Sludge Preparation, and Oxidative-Leaching Experiments}

The following solvents and chemicals were used in the course of this project:

- $\mathrm{D}_{2} \mathrm{O}$ (99.8 atom \% purity available from Aldrich) was stored in sealed vials inside of a dessicator and used directly before experiments.

- $\mathrm{DNO}_{3} 65 \mathrm{wt} \%$ with an estimated molar concentration of $14.7 \mathrm{M}$.

- $\mathrm{NaOD} 40$ wt\% (99.5 atom\% of $\left.\mathrm{D}_{2} \mathrm{O}\right)$; measured density of $1.527 \mathrm{~g} / \mathrm{mL}$; calculated molar concentration $14.9 \mathrm{M}$.

- $\mathrm{Nd}\left(\mathrm{NO}_{3}\right)_{3}$ 10,000 ppm (0.0693 M) stock solution in $5 \% \mathrm{HNO}_{3}$; (Ricca Chemical Company). $\mathrm{Nd}$ stock was converted from $\mathrm{H}_{2} \mathrm{O} / \mathrm{HNO}_{3}$ medium to $\mathrm{D}_{2} \mathrm{O} / \mathrm{DNO}_{3}$ medium by several cycles of evaporation-redissolution in $0.05 \mathrm{M}$ of $\mathrm{DNO}_{3}$.

- $\mathrm{Na}_{4}$ EDTA.

- $\mathrm{Na}_{2} \mathrm{CO}_{3}$.

- $\mathrm{Na}_{2} \mathrm{CrO}_{4} \cdot 4 \mathrm{H}_{2} \mathrm{O}$.

- $\mathrm{NaMnO}_{4} \cdot \mathrm{H}_{2} \mathrm{O}$.

- $\mathrm{Fe}\left(\mathrm{NO}_{3}\right)_{3} \cdot 9 \mathrm{H}_{2} \mathrm{O}$. Used for preparation of $1.33 \mathrm{M} \mathrm{Fe}\left(\mathrm{NO}_{3}\right)_{3}$ stock solution in $0.3 \mathrm{M} \mathrm{HNO}_{3}$.

- $\mathrm{Cr}\left(\mathrm{NO}_{3}\right)_{3} \cdot 9 \mathrm{H}_{2} \mathrm{O}$. Used for preparation of $1.0 \mathrm{M}$ stock solution of $\mathrm{Cr}(\mathrm{III})$ nitrate in $0.3 \mathrm{M} \mathrm{HNO}_{3}$.

All reagents used in calibration experiments in $\mathrm{D}_{2} \mathrm{O}$ media were dried overnight at $140^{\circ} \mathrm{C}$ in a ventilated oven to remove moisture or hydration water before preparing their solutions in $\mathrm{D}_{2} \mathrm{O}$. In the case of $\mathrm{Na}_{2} \mathrm{CrO}_{4} \cdot 4 \mathrm{H}_{2} \mathrm{O}$, complete dehydration of this substance was confirmed by excellent correspondence between calculated and observed weight loss.

\subsection{The Preparation, Purification, and Valence-State Adjustment of Pu Stock Solutions}

$\mathrm{Pu}$ Isotopic Composition and Admixtures of Other TRU. The plutonium stock material used in the course of this project had the following isotopic composition: ${ }^{238} \mathrm{Pu} 0.014$ atom $\%,{ }^{239} \mathrm{Pu} 93.48 \%,{ }^{240} \mathrm{Pu} 6.51 \%$, ${ }^{241} \mathrm{Pu} 0.011 \%$, and ${ }^{242} \mathrm{Pu} 0.018 \%$. These numbers correspond to the following alpha-activity fractions in 
the total alpha-activity balance of this Pu sample: ${ }^{238} \mathrm{Pu} 3.04 \%,{ }^{239} \mathrm{Pu} 75.6 \%,{ }^{240} \mathrm{Pu} 19.2 \%,{ }^{241} \mathrm{Pu}$-none (beta emitter), and ${ }^{242} \mathrm{Pu}<0.001 \%$. The specific alpha activity of this ${ }^{238,239,240} \mathrm{Pu}$ stock sample was calculated to be $2.79 \mathrm{MBq} / \mathrm{mg}$. The main stock solution of ${ }^{238,239,240} \mathrm{Pu}$ was available as a $0.9 \mathrm{M}$ solution of more than $99.5 \%$ pure $\mathrm{Pu}(\mathrm{IV})$ in $\sim 4 \mathrm{M}$ of $\mathrm{HNO}_{3}$. It was purified by ion-exchange from ${ }^{241} \mathrm{Am}$ (daughter product of beta-emitting ${ }^{241} \mathrm{Pu}$ ) early in 2002. The estimated contribution of newly formed ${ }^{241} \mathrm{Am}$ to the total alpha activity of this Pu sample (over 5 years of storage since the last purification) is less than $0.13 \%$. Admixtures of other oxidation states of $\mathrm{Pu}[\mathrm{Pu}(\mathrm{III})$ and $\mathrm{Pu}(\mathrm{VI})]$ in the stock solution were not spectrophotometrically detectable.

Conversion of $\mathrm{Pu}(\mathrm{IV})$ Stock to Deuterated Acidic Medium. $\mathrm{Pu}(\mathrm{IV})$ in $\mathrm{DNO}_{3} / \mathrm{D}_{2} \mathrm{O}$ was prepared by careful drying of an aliquot of an original $\mathrm{Pu}(\mathrm{IV})$ stock under vacuum at $\sim 30^{\circ} \mathrm{C}$ for several weeks and redissolution of $\mathrm{Pu}\left(\mathrm{NO}_{3}\right)_{4} \cdot \mathrm{xH}_{2} \mathrm{O}$ crystals in $4 \mathrm{M} \mathrm{DNO}_{3}$ to make an $18 \mathrm{mM}$ solution of $\mathrm{Pu}(\mathrm{IV})$. The cycle of vacuum drying and redissolution of dry residue in $\mathrm{DNO}_{3}$ was repeated two times to minimize the admixture of $\mathrm{H}_{2} \mathrm{O}$ of hydration in the final solution.

No attempt to prepare $\mathrm{Pu}(\mathrm{IV})$ alkaline stock solution in concentrated $\mathrm{NaOD}$ using an excess of holding reductant was made in this project because of problems with spectrophotometric characterization of this stock using LWCC.

Preparation of $\mathrm{Pu}(\mathrm{V})$ Stock in $\mathrm{D}_{2} \mathrm{O} / \mathrm{NaOD}$. A solution of pentavalent $\mathrm{Pu}$ in concentrated $\mathrm{NaOD}$ was prepared by adding a small amount of $\mathrm{Pu}(\mathrm{IV})$ acidic stock solution to an excess of $14.9 \mathrm{M}$ of $\mathrm{NaOD}$. This was followed by continuous agitation of this mixture via magnetic stirring over 20 days with periodical spectrophotometric control of the oxidation state of soluble plutonium after centrifugation of insoluble $\mathrm{Pu}$ (IV) hydroxide. Finally, the $\mathrm{Pu}(\mathrm{V})$ solution was filtered through a $0.45-\mu \mathrm{m}$ polysulfone syringe filter and stored in a sealed container to prevent its contamination with carbonate.

Preparation of $\mathrm{Pu}(\mathrm{VI})$ in $\mathrm{D}_{2} \mathrm{O} / \mathrm{DNO}_{3}$. Hexavalent $\mathrm{Pu}$ was prepared by oxidation of $\mathrm{Pu}(\mathrm{IV})$ in near boiling $1 \mathrm{M} \mathrm{DNO}_{3}$ with reflux during $4 \mathrm{hr}$ followed by complete evaporation of all liquids and redissolution of the residue in $0.5 \mathrm{M}_{\text {of }} \mathrm{DNO}_{3}$. The admixture of $\mathrm{Pu}(\mathrm{IV})$ in $\mathrm{Pu}(\mathrm{VI})$ was controlled spectrophotometrically [absence of major $\mathrm{Pu}(\mathrm{IV})$ peak at $476 \mathrm{~nm}$ ] and was found not to exceed $1 \%$. The $\mathrm{Pu}(\mathrm{VI})$ stock solution was regenerated periodically and used within 10 days since its oxidation to minimize the spontaneous reduction of $\mathrm{Pu}(\mathrm{VI})$ to $\mathrm{Pu}(\mathrm{IV})$ with time via the radiolytic decomposition of water.

\subsection{Spectrophotometric Equipment}

Two spectrophotometers were used to collect spectral data:

- SI Photonics 400 with scanning range from 200 to $950 \mathrm{~nm}$ and 1.19-nm spectral resolution

- Ocean Optics USB 2000 with scanning range from 550 to $1100 \mathrm{~nm}$ and $0.34-\mathrm{nm}$ spectral resolution.

Optical fibers (400- $\mu \mathrm{m}$ core diameter ultraviolet-visible [UV-Vis] fibers from Ocean Optics) were used to conduct light to the LWCC and to collect the transmitted light and direct it to the spectrophotometer.

A 500-cm pathlength LWCC (World Precision Instruments) was used for enhanced Pu detection in deuterated solutions. 
Plastibrand cells with a 1-cm pathlength (220- to 950-nm transparency range) were used to collect spectral data for calculating $\mathrm{Mn}(\mathrm{VI}), \mathrm{Mn}(\mathrm{VII})$, and $\mathrm{Cr}(\mathrm{VI})$ concentrations in oxidative leaching and homogeneous oxidation experiments.

The spectrophometric equipment was calibrated daily using a NIST-traceable neutral density filter set RM-1N2N3N available from Starna.

\subsection{Calibration and Speciation Experiments with LWCC (cold testing and Pu calibrations)}

\section{Constant Alkalinity (acidity) Single Macrocomponent Series with Growing Pu Concentration.}

In a typical calibration experiment, a relatively large portion of a desired background solution was prepared, and six 2-mL portions of this solution were placed into 2-mL-capacity Nalgene plastic tubes. Targeted amounts of $\mathrm{Nd}$ or $\mathrm{Pu}$ stock solutions were added to each tube to create a desired range of $\mathrm{Pu}$ concentrations [e.g., 0.5 to $20 \mu \mathrm{M}$ in $\mathrm{Pu}(\mathrm{VI})$ alkaline calibration experiments or 2 to $200 \mu \mathrm{M}$ of $\mathrm{Nd}$ (III) in $\mathrm{Nd}$ (III)-EDTA calibration experiments]. Special care was taken to minimize matrix dilution by using smaller volumes of more concentrated $\mathrm{Pu}$ stock solutions. In the case of $\mathrm{Pu}(\mathrm{V})$ calibration experiments with relatively dilute $\mathrm{Pu}(\mathrm{V})$ stock solution available at high alkalinity (14 $\mathrm{M}$ of $\mathrm{NaOD})$, the problem of maintaining constant alkalinity across the calibration series was solved by lowering the initial concentration of $\mathrm{NaOD}$ in background solutions when going from smaller to higher spike volumes of $\mathrm{Pu}(\mathrm{V})$ stock.

Speciation Series with Two Macrocomponents (mixed carbonate hydroxide systems) at Constant Hydroxide and $\mathrm{Pu}$ Concentration

In these series of experiments, one stock solution of pure $\mathrm{NaOD}$ was prepared first using volumetric dilution of $14.9 \mathrm{M}$ of $\mathrm{NaOD}$ in $\mathrm{D}_{2} \mathrm{O}$. One half of this solution was then used to prepare an equimolar solution of $\mathrm{Na}_{2} \mathrm{CO}_{3}$ in $\mathrm{NaOD}$ (e.g., $1 \mathrm{M}$ of $\mathrm{Na}_{2} \mathrm{CO}_{3}$ in $1 \mathrm{M}$ of $\mathrm{NaOD}$ or $0.25 \mathrm{M}$ of $\mathrm{Na}_{2} \mathrm{CO}_{3}$ in $0.25 \mathrm{M}$ of $\mathrm{NaOD})$. To create a variation of carbonate concentration at constant level of hydroxide, these two stock solutions were mixed in 100:0, 80:20, 60:40, 40:60, 20:80, and 0:100 volume ratios. These six mixtures were prepared in $8-\mathrm{mL}$ amounts and later split onto four equal portions of $2 \mathrm{~mL}$ each. The first three portions were used as cold background solutions, and the last portion with the same $\mathrm{CO}_{3}{ }^{2-} / \mathrm{OD}^{-}$ratio was used to add stock solution of $\mathrm{Pu}(\mathrm{IV}, \mathrm{V}$, or VI). It was necessary to inject three successive portions of the cold background solution of the same composition before injecting the $\mathrm{Pu}$-containing sample to completely eliminate the LWCC memory effect of the previous sample with a different $\mathrm{CO}_{3}{ }^{2-} / \mathrm{OD}^{-}$ratio.

\subsection{Determination of Pu Concentration in Calibration Solutions and Leachates}

In $\mathrm{Pu}(\mathrm{VI})$ calibration experiments in an alkaline medium [0.5- to $20-\mu \mathrm{M}$ concentration range of $\mathrm{Pu}(\mathrm{VI})]$, all $\mathrm{Pu}$ was assumed to be soluble, and the final $\mathrm{Pu}$ concentration was assumed to be equal to an initially added concentration. No subsamples were withdrawn for Pu concentration analysis by LSC.

In selected oxidative-leaching experiments with $\mathrm{Pu}(\mathrm{OH})_{4}$ and permanganate in acidic medium (Section 3.8), the concentration of total dissolved $\mathrm{Pu}$ was determined via the optical absorbance peak intensity of $\mathrm{PuO}_{2}{ }^{2+}$ at $831 \mathrm{~nm}$. The same procedure was used to estimate the extent of $\mathrm{Pu}(\mathrm{IV})$ to $\mathrm{Pu}(\mathrm{VI})$ 
conversion in monomeric $\mathrm{Pu}(\mathrm{IV})$ oxidation experiments with $\mathrm{Cr}(\mathrm{VI})$ and/or $\mathrm{Mn}(\mathrm{VII})$ in nitric acid (Section 3.8).

In all other calibrations, speciation and oxidative-leaching experiments with $\mathrm{Pu}(\mathrm{IV})$ and $\mathrm{Pu}(\mathrm{V})$ in alkaline media with a dissolved $\mathrm{Pu}$ concentration were determined by LSC. All alkaline Pu-containing samples were acidified with $\mathrm{HNO}_{3}$ or $\mathrm{HCl}$ within the first few hours after completing the experiment. $\mathrm{HCl}$ was used to acidify $\mathrm{Mn}(\mathrm{VII})$ and $\mathrm{Mn}(\mathrm{VI})$-containing samples to destroy these highly colored species by their reduction with $\mathrm{Cl}^{-}$to produce colorless $\mathrm{Mn}^{2+}$.

\subsection{Preparation of the $\mathrm{Fe}(\mathrm{OH})_{3} / \mathrm{Cr}(\mathrm{OH})_{3} / \mathrm{Pu}(\mathrm{OH})_{4}$ Sludge Simulant and Oxidative-Leaching Procedure}

The $\mathrm{Fe}(\mathrm{III})$ to $\mathrm{Cr}$ (III) molar ratio in the sludge simulant was set at 1.0 to 0.7 . The targeted amount of sludge was $5 \mathrm{~g}$. The sludge amount was planned assuming six hydration waters, both for $\mathrm{Fe}(\mathrm{OH})_{3}$ and $\mathrm{Cr}(\mathrm{OH})_{3}$. To prepare $5 \mathrm{~g}$ of $\mathrm{Fe}(\mathrm{OH})_{3} 6 \mathrm{H}_{2} \mathrm{O}(\mathrm{F} . \mathrm{W} .=215)$ and $\mathrm{Cr}(\mathrm{OH})_{3} 6 \mathrm{H}_{2} \mathrm{O}(\mathrm{F} . \mathrm{W} .=211)$, a mixture of $3 \mathrm{~g}$ of $\mathrm{Fe}(\mathrm{III})$ hydroxide and $2 \mathrm{~g}$ of $\mathrm{Cr}$ (III) hydroxide should be mixed to achieve roughly the 1.0 to 0.7 molar ratio. This corresponds to $3 \times 56 / 215=0.78 \mathrm{~g}$ of $\mathrm{Fe}$ (as element) and $\sim 0.78 \times 0.7=0.545 \mathrm{~g}$ of $\mathrm{Cr}$ (as element).

The solution of $10.6 \mathrm{~mL}$ of $1.33 \mathrm{M} \mathrm{Fe}(\mathrm{III})$ stock mixed with $10.6 \mathrm{~mL}$ of $1.0 \mathrm{M} \mathrm{Cr}$ (III) stock (60-mL bottle) was transferred into a radiological fume hood. A stock solution of $28 \mu \mathrm{L}$ of $18 \mathrm{mM}$ of $\mathrm{Pu}(\mathrm{IV})$ in $2 \mathrm{M} \mathrm{DNO}_{3}$ was added to the $\mathrm{Fe}(\mathrm{III})+\mathrm{Cr}$ (III) mixture under stirring (targeted Pu concentration is $1 \times 10^{-4}$ moles per kg of sludge). This mixture was neutralized under stirring with $\sim 8.5 \mathrm{~mL}$ of $25 \% \mathrm{NaOH}$ and aged for 3 days under continuous slow stirring. The precipitate color was dark brown. Three days after preparation, the sludge sample was centrifuged and supernatant $\left(\mathrm{NaNO}_{3}\right.$ solution) was discarded. The visually estimated volume of compacted sludge was 22 to $23 \mathrm{~mL}$. The sludge was washed with water in three steps to remove most of the $\mathrm{NaNO}_{3}$. Finally, $\sim 37 \mathrm{~mL}$ of $\mathrm{H}_{2} \mathrm{O}$ was added to the centrifuged sludge, and the sludge slurry was homogenized by shaking and then by stirring for $4 \mathrm{hr}$. The total visible volume of the agitated sludge slurry was about $60 \pm 3 \mathrm{~mL}$. Twelve equal portions of this slurry $(3.0 \mathrm{~mL}$ each) were subsampled from the bottle into separate 2-dram-capacity vials with a 9.5-mm-diameter Spin-Plus stir bar placed inside. Sampling was performed within 6 to 8 seconds after terminating the intense stirring using a $5-\mathrm{mL}$ pipette tip with $\sim 50 \%$ of full depth immersion into the bottle. For each subsequent sampling, the stirring was resumed for another 2 to 3 minutes to make sure that the remaining bulk sample of the sludge got freshly mixed, and no fractionation of liquid and solid phases occurred due to sedimentation. All sludge-containing vials were centrifuged for 8 to 10 minutes. The visual volume of the compacted sludge was $1.1 \pm 0.1 \mathrm{~mL}$ per vial, and it contained $40 \mathrm{mg}$ Fe (as elemental Fe), $28 \mathrm{mg}$ of $\mathrm{Cr}$ (as elemental $\mathrm{Cr}$ ), and $6 \mu \mathrm{g}$ of $\mathrm{Pu}$ (as elemental $\mathrm{Pu}$ ). The mass ratio of $\mathrm{Pu}$ to the sum of $\mathrm{Fe}$ and $\mathrm{Cr}$ in the sludge simulant was $8.8 \times 10^{-5} \mathrm{~g} / \mathrm{g}$. The estimated interstitial liquid volume in this sludge sample was $0.8 \mathrm{~mL}$ ( $\sim 75 \%$ of the total visible volume). No attempts were made to remove interstitial water from the sludge by evaporation or vacuum drying to determine the fraction of free water in the wet sludge sample.

In a typical sludge leaching experiment, $3 \mathrm{~mL}$ of alkaline permanganate solution at a calculated concentration to achieve the desired $\mathrm{Mn}(\mathrm{VII}) / \mathrm{Cr}$ (III) ratio (from $0.66: 1$ to $1.45: 1$ ) was added to the sludge-containing vial. An approximate volume ratio of the leaching solution-to-sludge volume was 3:1. The estimated $\mathrm{Cr}(\mathrm{VI})$ concentration in the leachate in the case of complete oxidation of $\mathrm{Cr}(\mathrm{OH})_{3}$ to chromate was $0.13 \mathrm{M}$. The estimated concentration of soluble $\mathrm{Pu}$ in the same leachate was $6 \mu \mathrm{M}$, 
assuming the hypothetical case of complete conversion of insoluble $\mathrm{Pu}(\mathrm{OH})_{4}$ to fully soluble $\mathrm{Pu}(\mathrm{VI})$ and neglecting the possible co-precipitation of $\mathrm{Pu}(\mathrm{VI})$ with the newly formed solid phase of $\mathrm{MnO}_{2}$. The mixture was put onto a stirrer, and full-speed stirring started $\sim 20$ to $30 \mathrm{sec}$ after applying the stirrer motor. The 30-sec delay time was associated with difficulty in breaking the stir bar loose from the compacted sludge volume. The vial content was too dark to verify that the entire sludge volume was completely dispersed within the filled portion of the vial, but a deep and stable vortex pattern within the suspension volume indicated a very efficient mixing process in this heterogeneous mixture. In most cases, the first kinetic point was obtained by sampling 3 minutes after starting the full-speed stirring process. Typically, $60 \mu \mathrm{L}$ of the sludge suspension were filtered through a $0.45-\mu \mathrm{m}$ syringe filter, and 6 to $8 \mu \mathrm{L}$ of the filtrate was diluted into $2000 \mu \mathrm{L}$ of $0.24 \mathrm{M} \mathrm{NaOH}$ for determination of $\mathrm{Cr}(\mathrm{VI})$ and the remaining $\mathrm{Mn}$ (VII) or $\mathrm{Mn}(\mathrm{VI})$ concentration by UV-vis spectroscopy. Immediately after spectral measurement, $100 \mu \mathrm{L}$ of $37 \%$ $\mathrm{HCl}$ were added to the diluted solution to acidify it and perform the same-day determination of soluble $\mathrm{Pu}$ concentration by LSC. For LSC measurements, $200 \mu \mathrm{L}$ of the acidified solution were mixed with $5 \mathrm{~mL}$ of Ultima Gold liquid scintillation cocktail. All acidified samples were later submitted to ASO for $\mathrm{Pu}$ concentration determination via total alpha activity measurement by LSC.

\subsection{Measurements of Eh and pH}

Oxidation-reduction potentials in alkaline solutions from selected calibration and leaching experiments were measured with a combination oxidation-reduction potential (ORP) electrode (Orion) coupled with a Thermo Corporation ORION 5 star multimeter. A commercially available ORP standard solution (ORION 967961) was used for the electrode calibration. In most of our samples containing strong oxidizers (permanganate and/or manganate) and solid phases $\left[\mathrm{MnO}_{2}, \mathrm{Fe}(\mathrm{OH})_{3}\right]$, the measured ORPs showed a slow drift with time. In diluted homogeneous permanganate-manganate mixtures, the ORP drift was invariably negative with time, which correlated with a progressive decrease of permanganate concentration due to its oxidative interaction with plastic surfaces of a stir bar and a polyethylene vial used for ORP measurements (Section 3.9.1). In these cases, the potential observed within the first 3 to 4 minutes from the moment of the electrode immersion into solution was accepted. In all other cases, when the stable ORP reading could not be achieved, the potential observed after 10 to 15 minutes was accepted. The uncertainty of ORP measurements performed in this project is typically $\pm 10 \mathrm{mV}$.

For $\mathrm{pH}$ measurements of selected alkaline solutions, an ORION 8103 combination electrode was used. The electrode was calibrated using standard $\mathrm{pH}=4.00$ and $\mathrm{pH}=10.01$ buffer solutions. The electrode performance after calibration was checked using a series of $\mathrm{NaOH}$ and $\mathrm{NaOD}$ solutions in the hydroxide (deuteroxide) concentration range from $0.001 \mathrm{M}$ to $1.0 \mathrm{M}$. It was observed that starting from $0.1 \mathrm{M}$ of hydroxide concentration, the electrode response showed prolonged drifts in $\mathrm{pH}$ and little difference in $\mathrm{pH}$ (pD) readings between $0.1 \mathrm{M}, 0.25 \mathrm{M}$, and $1.0 \mathrm{M}$ of $\mathrm{NaOH}(\mathrm{NaOD})$ concentrations. Re-checking the electrode response with the standard $\mathrm{pH}$ buffers after its exposure to the $\mathrm{NaOH}(\mathrm{NaOD})$ solutions showed significant positive deviations from the expected $\mathrm{pH}$ values with an extended negative drift (often exceeding one $\mathrm{pH}$ unit) to lower $\mathrm{pH}$ values. For these reasons, $\mathrm{pH}(\mathrm{pD})$ measurements were not applied systematically to measure the alkalinity of Pu-containing solutions in calibration and leaching experiments at $0.25 \mathrm{M}$ to $1 \mathrm{M} \mathrm{NaOD}$ concentrations. 


\subsection{Determination of $\mathrm{Cr}(\mathrm{VI}), \mathrm{Mn}(\mathrm{VII})$, and $\mathrm{Mn}(\mathrm{VI})$ Concentrations in the Course of Oxidative-Leaching Experiments}

An $\mathrm{Mn}$ (VII) stock solution in $\mathrm{D}_{2} \mathrm{O}$ was prepared by dissolving a known amount of $\mathrm{NaMnO}_{4} \cdot \mathrm{H}_{2} \mathrm{O}_{\text {in }} \mathrm{D}_{2} \mathrm{O}$, and the concentration of $\mathrm{Mn}$ (VII) was determined by spectrophotometric analysis by comparing the $528 \mathrm{~nm}$ peak intensity with the respective value of a standard permanganate solution with an Mn(VII) concentration known from titration with oxalate.

The $\mathrm{Mn}(\mathrm{VI})$ concentration in leaching experiments with $\mathrm{Pu}(\mathrm{OH})_{4}$ and $\mathrm{Fe}(\mathrm{OH})_{3} / \mathrm{Cr}(\mathrm{OH})_{3} / \mathrm{Pu}(\mathrm{OH})_{4}$ sludge simulant was determined spectrophotometrically using a major absorbance band of manganate at $603 \mathrm{~nm}$ with $\varepsilon=1598 \mathrm{M}^{-1} \mathrm{~cm}^{-1}$ (Gmelin 1975, pp. 17-42).

In the case of mutual presence of manganate and permanganate, the extent of $\mathrm{Mn}(\mathrm{VII})$ conversion to $\mathrm{Mn}(\mathrm{VI})$ in the course of reduction by $\mathrm{Pu}(\mathrm{IV}), \mathrm{Pu}(\mathrm{V})$, and $\mathrm{Cr}(\mathrm{III})$ was calculated by normalizing the net gain in optical absorbance at $603 \mathrm{~nm}$ onto the difference between the molar absorptivities of $\mathrm{Mn}(\mathrm{VI})$ and $\mathrm{Mn}(\mathrm{VII})$ at this wavelength position

$\Delta \varepsilon_{603}=\varepsilon_{603 \mathrm{Mn}(\mathrm{VI})}-\varepsilon_{603 \mathrm{Mn}(\mathrm{VII})}=1598 \mathrm{M}^{-1} \mathrm{~cm}^{-1}-216 \mathrm{M}^{-1} \mathrm{~cm}^{-1 .}=1382 \mathrm{M}^{-1} \mathrm{~cm}^{-1}$.

\subsection{Baseline Subtraction and Net Peak Intensity Determination in Nd and Pu Calibration Experiments}

To minimize the effects of baseline irreproducibility in LWCC measurements on peak-intensity calculations in the spectra of $\mathrm{Nd}(\mathrm{III})$ and $\mathrm{Pu}(\mathrm{V}, \mathrm{VI})$, baseline corrections were made as follows:

$\mathrm{Nd}(\mathrm{III})$ : The baselines in $\mathrm{Nd}$ spectra were approximated with a parabolic function using five to six groups of anchor points in the spectral regions with no absorbance from $\mathrm{f}-\mathrm{f}$ transitions of $\mathrm{Nd}$, and this was subtracted from the raw spectrum.

$\mathrm{Pu}(\mathrm{V})$ : The net intensities of $653-\mathrm{nm}$ and $809-\mathrm{nm}$ peaks of pentavalent $\mathrm{Pu}$ were determined by subtracting calculated baseline positions at the peaks' maxima from the raw spectrum of $\mathrm{Pu}(\mathrm{V})$. Baselines in the regions of interest were approximated by linear functions with anchor points at 646 and $660 \mathrm{~nm}$ for the $653-\mathrm{nm}$ peak and at 776 and $835 \mathrm{~nm}$ for the $809-\mathrm{nm}$ peak as illustrated in Figure 2.1.

$\mathrm{Pu}(\mathrm{VI})$ : The major peak of $\mathrm{Pu}(\mathrm{VI})$ at $625 \mathrm{~nm}$ was treated in the same manner as peaks of $\mathrm{Pu}(\mathrm{V})$ by using linear baseline calculation with anchor points at 563 and $710 \mathrm{~nm}$.

\subsection{Simulation and Elimination of Waveform-Shaped Spectral Interference in LWCC Spectra Burdened with Low-Frequency Noise}

In spectral measurements with LWCC, special care was taken to match chemical composition and concentrations of major components in blank and sample solutions to suppress baseline distortions associated with chemical-composition differences. In most cases, this procedure resulted in good-quality spectral measurements with minimal baseline perturbations. However, in some measurements, the spectral signal was burdened by oscillating waveform-shaped distortions with a wavelength-dependent periodicity (fewer oscillations at higher wavelength values). This pattern is frequently observed in thinfilm spectroscopy when the wavelength interval between two adjacent minima or maxima can be used to 
calculate the film thickness of the tested material. In this project, no films were intentionally introduced or created along the light-propagation pathway in the process of solution injection, but they could be inadvertently formed within the liquid-core waveguide in the process of not completing the displacement of previously injected solution with a new one with a slightly different refractive index or chemical composition. The exact nature of this spectral distortion remains unclear, but an attempt was made to simulate this interference so it can be subtracted from the distorted spectrum to improve its quality.

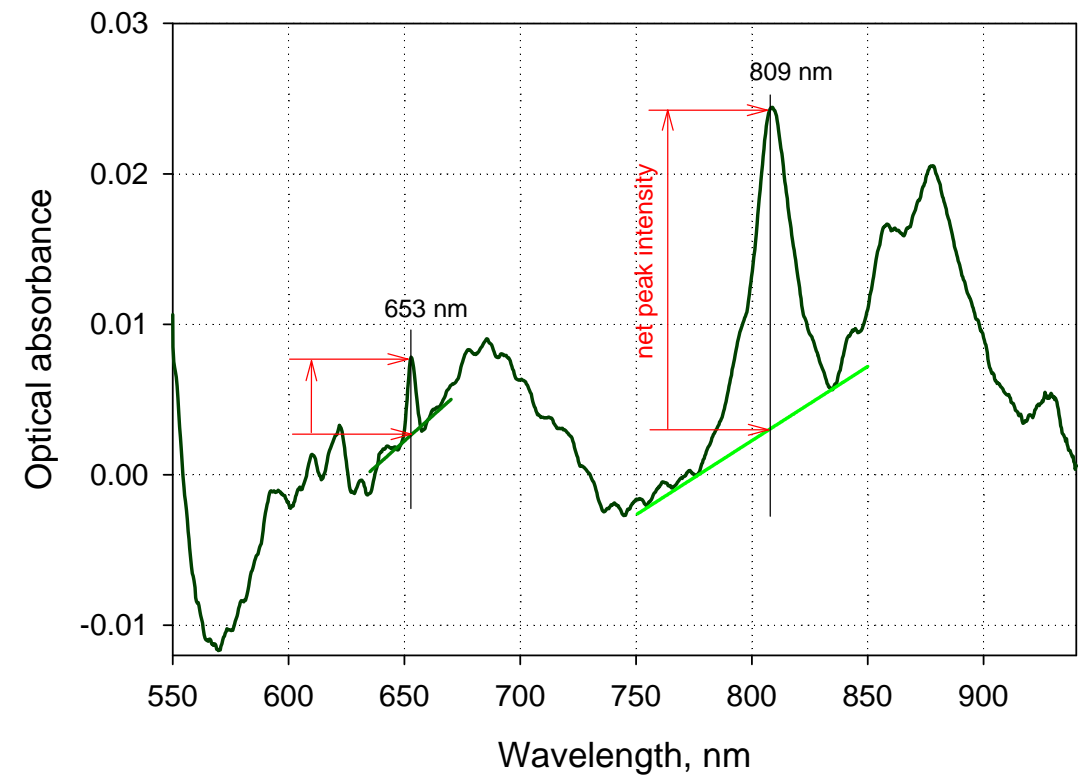

Figure 2.1. Net Peaks' Intensity Determination in $\mathrm{Pu}(\mathrm{V})$ Spectra

The following functional expression was used to simulate the waveform interference:

$$
\mathrm{A}(\lambda)=\mathrm{a}+\mathrm{b} \cdot \sin (\mathrm{c} / \lambda+\mathrm{d})+\mathrm{e} \cdot \sin (\mathrm{c} / 2 \lambda+\mathrm{f})
$$

where $\lambda$ is the wavelength, and $\mathrm{a}, \mathrm{b}, \mathrm{c}, \mathrm{d}$, e, and $\mathrm{f}$ are variable parameters that allow the waveform bias (a), the amplitude (b and e), the frequency (c), the phase shift ( $\mathrm{d}$ and f), and skewedness (b/e) of the background oscillations to be adjusted. This approach was used to suppress waveform distortions in the spectral analysis of $\mathrm{Pu}(\mathrm{V})$ interaction with $\mathrm{Mn}(\mathrm{VI})$ (Figure 2.2). 


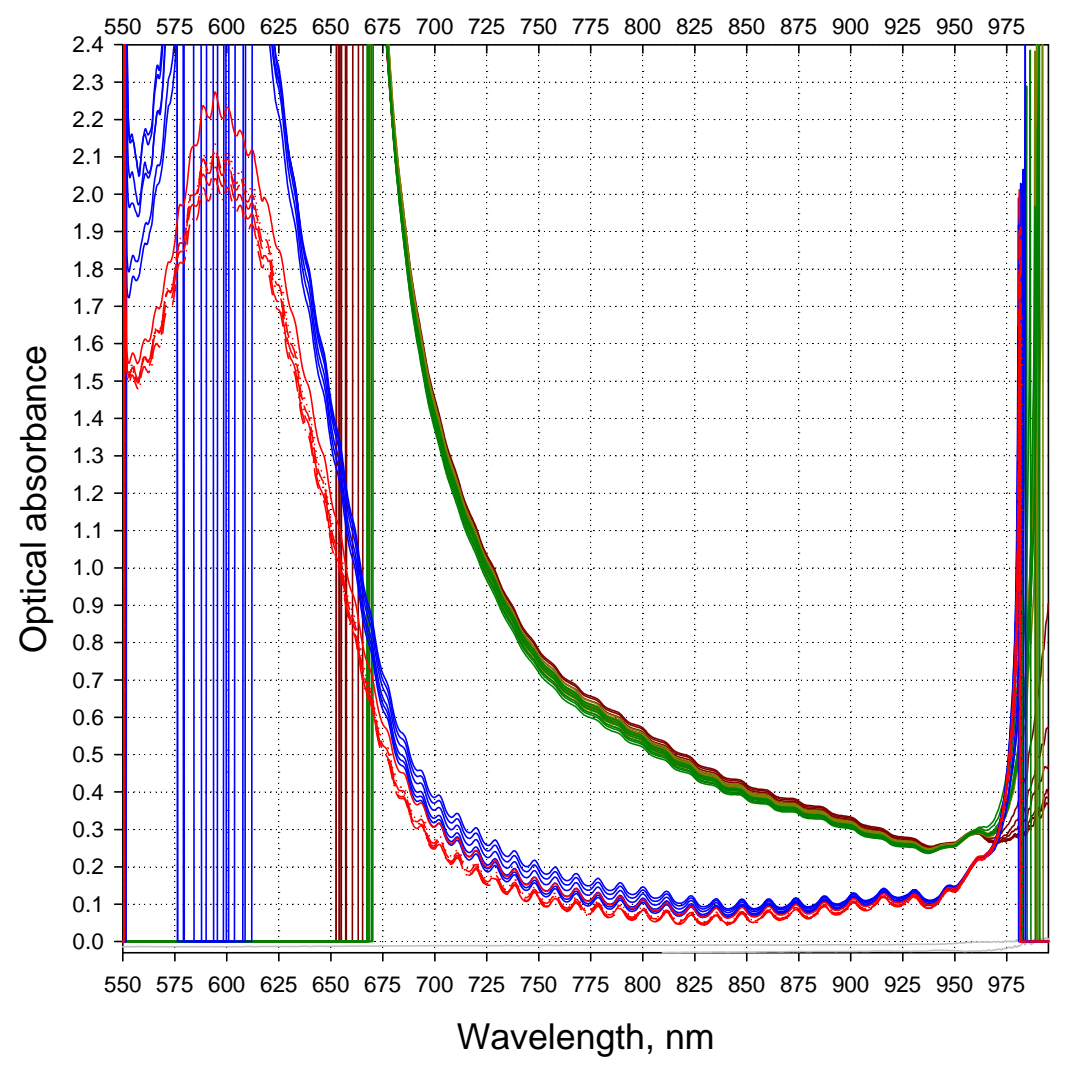

Figure 2.2. Manganate Reduction After Adding $\mathrm{Pu}(\mathrm{V})$. Initial $\mathrm{Mn}(\mathrm{VI})$ and $\mathrm{Pu}(\mathrm{V})$ concentrations are $15 \mu \mathrm{M}$ and $12.5 \mu \mathrm{M}$, respectively. Green series: a number of repeated injections of $15 \mu \mathrm{M}$ cold solution of $\mathrm{Mn}(\mathrm{VI})$ aimed at saturation of $\mathrm{Mn}(\mathrm{VI})$ reducing sites within the capillary cell and $\mathrm{Mn}(\mathrm{VI})$ signal stabilization. Blue and red series: first and second injection of the same $\mathrm{Pu}$-containing solution 5 and 10 minutes after mixing $\mathrm{Pu}(\mathrm{V})$ and $\mathrm{Mn}(\mathrm{VI})$. 


\subsection{Results and Discussion}

This section discusses the light-transmission efficiency of LWCC; the demonstration of the identity of spectral features of $\mathrm{Nd}(\mathrm{III})$ in $\mathrm{H}_{2} \mathrm{O}$ and $\mathrm{D}_{2} \mathrm{O}$; the cold testing of LWCC; $\mathrm{Pu}(\mathrm{VI})$ and $\mathrm{Pu}(\mathrm{V})$ calibration and speciation experiments; spectral measurements, oxidative dissolution, and oxidation of $\mathrm{Pu}(\mathrm{IV})$; interaction of $\mathrm{Pu}(\mathrm{V})$ with low levels of manganate; and the oxidative leaching of sludge simulant with permanganate.

\subsection{Light-Transmission Efficiency of LWCC}

According to the manufacturer's specifications, the 5-m-long LWCC employed for this project had the usable spectral range from 350 to $700 \mathrm{~nm}$ due to the limited optical transparency range of $\mathrm{H}_{2} \mathrm{O}$. The main idea of this project was to use deuterated water instead $\mathrm{H}_{2} \mathrm{O}$ to extend the operation range of LWCC all the way to $1100 \mathrm{~nm}$. Therefore, the first testing of the LWCC was performed with $\mathrm{D}_{2} \mathrm{O}$ without any other solutes present to make sure that the assumption about the possibility of the scanning range extension could be realized in practice. For this testing, a near-IR optimized spectrophotometer from Ocean Optics with a scanning range capability from 550 to $1200 \mathrm{~nm}$ (as claimed by the manufacturer) was used, which was coupled with LWCC and a light source using two optical fibers. The first experiment performed with 99.8\% pure $\mathrm{D}_{2} \mathrm{O}$ injected into the LWCC showed that the amount of light reaching the spectrophotometer after passing through a 500-cm layer of $\mathrm{D}_{2} \mathrm{O}$ dropped down very sharply, starting from $\sim 930 \mathrm{~nm}$ to practically immeasurable levels in the 975- to 1060-nm window (Figure 3.1). This "black window" effect cannot be attributed to optical absorbance of the solvent known to be highly transparent all the way to $1200 \mathrm{~nm}$. A small admixture of $\mathrm{H}_{2} \mathrm{O}$ in $\mathrm{D}_{2} \mathrm{O}(0.2 \%)$ should have some minor attenuation effect in the 950- to 1070-nm spectral range, but its calculated magnitude can account only for $\left[1-1 /\left(10^{0.2 \times 0.002 \times 500}\right)\right] \times 100=37 \%$ of light intensity loss at the major absorbance peak maximum of $\mathrm{H}_{2} \mathrm{O}$ at $975 \mathrm{~nm}$. Clearly, this minor attenuation due to the presence of $\mathrm{H}_{2} \mathrm{O}$ cannot explain the drastic blackeningout effect in the 975- to 1060-nm window shown in Figure 3.1. Possibility of light attenuation by $-\mathrm{OH}$ moieties on the interior of the quartz fiber was also considered but this effect should be significant only in a relatively narrow spectral range from 925 to $975 \mathrm{~nm}$ (based on a high $\mathrm{OH}$ fiber attenuation curve presented in the Ocean Optics catalog).

In the second experiment, the spectrophotometer was coupled with a standard 1-cm plastic cell filled with the same solvent to see whether the observed effect originates from the spectral characteristics of the LWCC itself or is associated predominantly with the limited spectral range of the spectrophotometer. According to Figure 3.2, switching to the standard pathlength-measurement mode results in a significant extension of the usable spectral range to $\sim 1100 \mathrm{~nm}$, which demonstrates that the black-window effect cannot be explained by limitations in the scanning range of the Ocean Optics Instrument.

Finally, the spectrophotometer was tested in a direct coupling mode with a light source without using any optical fibers to exclude the possible effect of optical fiber material on the light-transmission efficiency. Results of this test shown in Figure 3.3 confirm that there are no limitations in the spectral characteristics of both the light source and the spectrophotometer, which might be responsible for the appearance of the light cut-off effect starting from $970 \mathrm{~nm}$. 


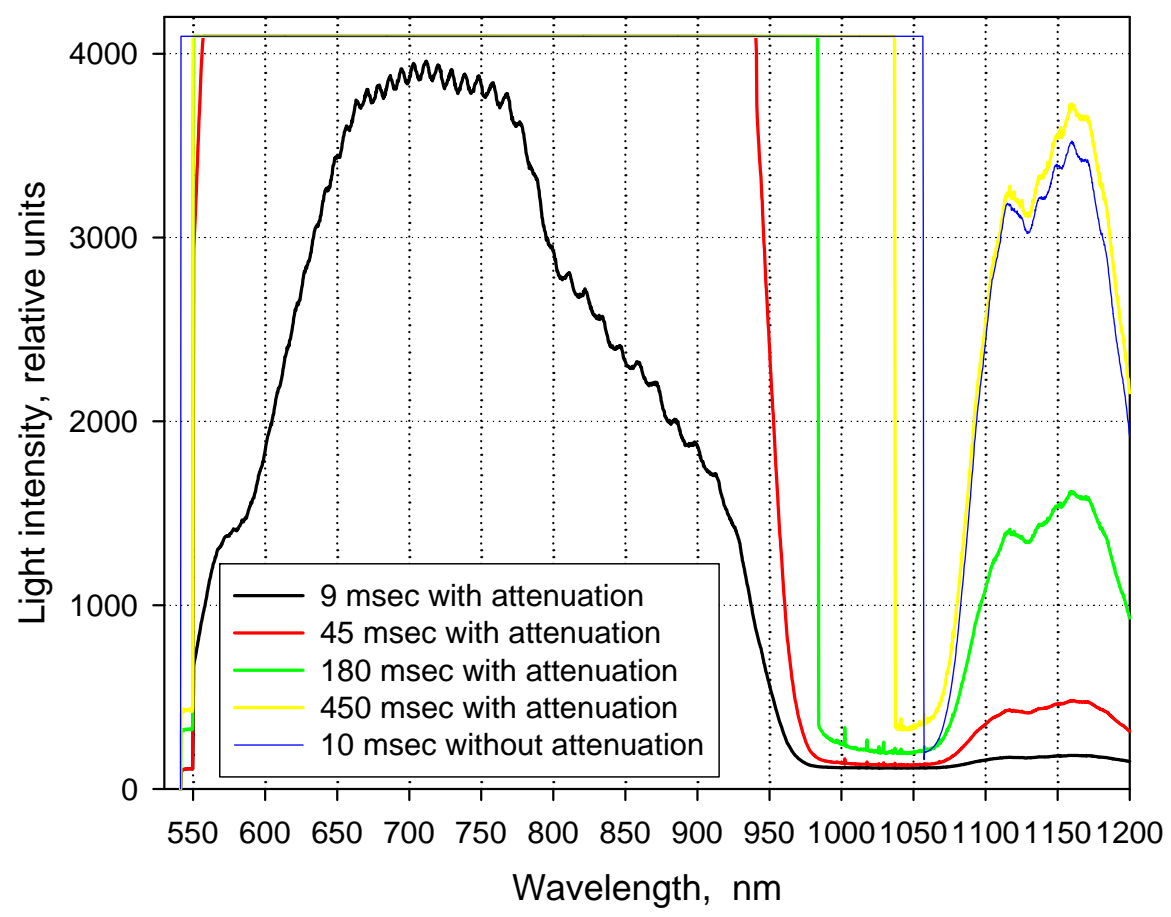

Figure 3.1. Light Intensity Spectra After Exiting a 5-m LWCC Filled with $99.8 \% \mathrm{D}_{2} \mathrm{O}$. The legend shows different integration times used to acquire light-intensity spectra.

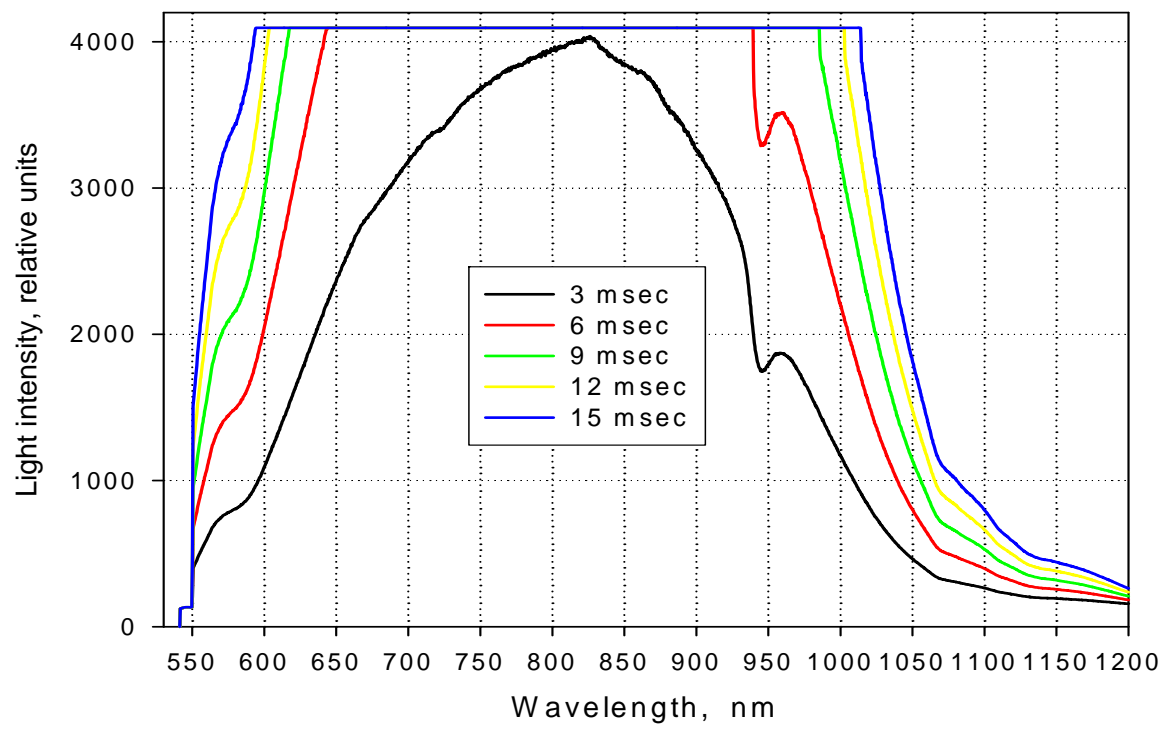

Figure 3.2. Light-Intensity Spectra After Passing Through a 1-cm Quartz Cell Filled with $99.8 \% \mathrm{D}_{2} \mathrm{O}$. The legend shows different integration times used to acquire light-intensity spectra. 


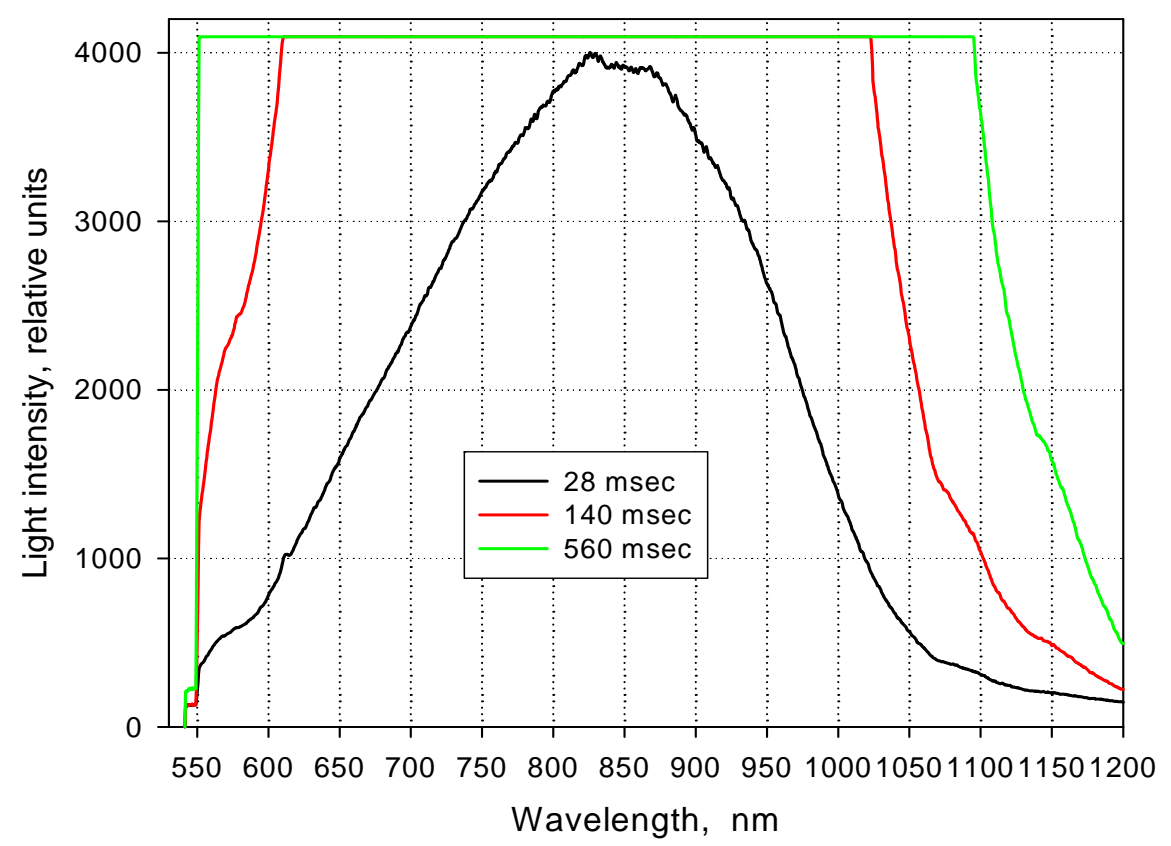

Figure 3.3. Light-Intensity Spectra with Direct Light Coupling to the Spectrophotometer (without any spectrophotometric cells or optical fibers). The legend shows different integration times used to acquire light-intensity spectra.

All the data shown in this section were sent to technical experts at World Precision Instruments (WPI) where the LWCC was manufactured with a request to express their opinion on what might be the reason of the blackening-out effect in the 970- to 1070-nm region of the spectrum when using LWCC measurements in the $\mathrm{D}_{2} \mathrm{O}$ medium. Some comments from their representative are reproduced below as they were received in the summer of 2006:

This black-window effect you are speaking of is most likely the intrinsic water absorption. What light source are you using? The silica tubing glass is clear, and light percent throughput is $95 \%$, so $5 \%$ is lost via the glass.

Note: Type 1 material is no longer available. However, this will not make a difference theoretically as intrinsic absorbance of the water effect is the same no matter what the material of the waveguide is.

We do not have any experience with using LWCC in the range, so a modification will more than likely be out of the question in this case.

In conclusion, if the WPI comments on the attribution of this effect to the intrinsic absorption of water are correct, then the application of higher-purity $\mathrm{D}_{2} \mathrm{O}$ should extend the usable range of LWCC deeper into the IR region of the spectrum, but this possibility was not explored in the course of this project. 


\subsection{Demonstration of Identity of Spectral Features of $\mathrm{Nd}(\mathrm{III})$ in $\mathrm{H}_{2} \mathrm{O}$ and $\mathbf{D}_{2} \mathbf{O}$}

A number of questions were raised by the test-plan reviewers at the project planning stage as to what extent the spectral features of plutonium measured in $\mathrm{D}_{2} \mathrm{O}$ solvent could be applicable to Pu solutions in $\mathrm{H}_{2} \mathrm{O}$ in terms of the equivalency of the absorbance peaks' positions and the molar absorptivities in the both solvents. The first attempt to answer this question was a cold experiment based on comparing the spectral features of $\mathrm{Nd}(\mathrm{III})$ in $\mathrm{D}_{2} \mathrm{O}$ and $\mathrm{H}_{2} \mathrm{O}$. A trivalent neodymium cation with three electrons on the $4 \mathrm{f}$ electronic energy level (i.e., $4 \mathrm{f}^{3}$ valence electronic configuration) can be considered as an iso-electronic analog of $\mathrm{Pu}(\mathrm{V})$, which possesses a $5 \mathrm{f}^{3}$ electronic configuration. This experiment was performed with $\sim 350$-fold diluted $\mathrm{Nd}$ (III) stock solution both in $\mathrm{D}_{2} \mathrm{O}$ and $\mathrm{H}_{2} \mathrm{O}$ solvents at a low concentration of nitric acid using LWCC detection. The results are presented in Figure 3.4. One can see that while the deuterated medium allows all five absorbance bands of $\mathrm{Nd}$ (III) in the 550- to $900-\mathrm{nm}$ range to be detected, spectral measurement in the $\mathrm{H}_{2} \mathrm{O}$ solvent results in the disappearance of the last three bands at 740,794 , and $865 \mathrm{~nm}$ from the spectrum due to an insufficient amount of light reaching the detector starting from $700 \mathrm{~nm}$. Therefore, only two bands of $\mathrm{Nd}(\mathrm{III})$ are available to evaluate the solvent effect. As Figure 3.4 shows, the spectral shapes and intensities of both $575 \mathrm{~nm}$ and $683 \mathrm{~nm}$ are practically undistinguishable from each other, regardless of the solvent's nature. Hot experiments conducted with $\mathrm{Pu}(\mathrm{IV}, \mathrm{V}$, and VI) solutions (see subsequent sections) further served as an additional proof of this spectral equivalence.

The molar absorptivity of the $\mathrm{Nd}(\mathrm{III})$ peak at $576 \mathrm{~nm}$, which was estimated from the peak intensity, indicated that the $\mathrm{Nd}$ concentration and the optical pathlength of $500 \mathrm{~cm}$ was $6.1 \mathrm{M}^{-1} \mathrm{~cm}^{-1}$, which corresponds to $85 \%$ of the $7.2-\mathrm{M}^{-1} \mathrm{~cm}^{-1}$ value reported in the literature (Carnall 1979). Two possible reasons for this discrepancy should be mentioned: 1) insufficient spectral resolution of the spectrophotometer due to an entrance aperture that was too wide ( $50-\mu \mathrm{m}$ slit); 2) collection of a small portion of light that did not travel through the liquid medium, but through the quartz walls of the capillary cell, which could result in lowering effective optical absorbances measured by the spectrophotometric detector.

It should be mentioned here that the absorbance peak at $\sim 1152 \mathrm{~nm}$ observed in the both spectra was initially believed to represent a real absorbance band of $\mathrm{Nd}(\mathrm{III})$. However, it turned out that it is not listed among other peaks of $\mathrm{Nd}$ in the band register for lanthanide (aquo) ions in $\mathrm{H}_{2} \mathrm{O}-\mathrm{D}_{2} \mathrm{O}$ (Carnall 1979), or in other words, $\mathrm{Nd}(\mathrm{III})$ does not have any absorbance bands centered at this wavelength. After discussing this finding with technical experts from Ocean Optics, the following comments were received:

One of the problems with the USB2000 spectrometer detectors is that they are not very efficient in the range that you are looking at. What this means is that you would need a very good signal to be able to see anything there and it seems that you have a very weak one. Another thing that looks strange is that you are able to detect a signal after $1100 \mathrm{~nm}$, those peaks look like secondary peaks or harmonics which could mean that we made a mistake and did not install the OFL-OF550. It would be good if you can send us the spectrometer so we can verify that the filter is there or if it got loose for some reason.

Based on the above comment and taking into account that the 1152-nm peak position corresponds to a double value (harmonic) of the 576-nm peak position of $\mathrm{Nd}(\mathrm{III})$, and their intensities match, it has to be 
concluded that the 1152 peak is just an overtone of the 576-nm peak. Any spectral features detected beyond $1100 \mathrm{~nm}$ with this instrument represent artifacts.

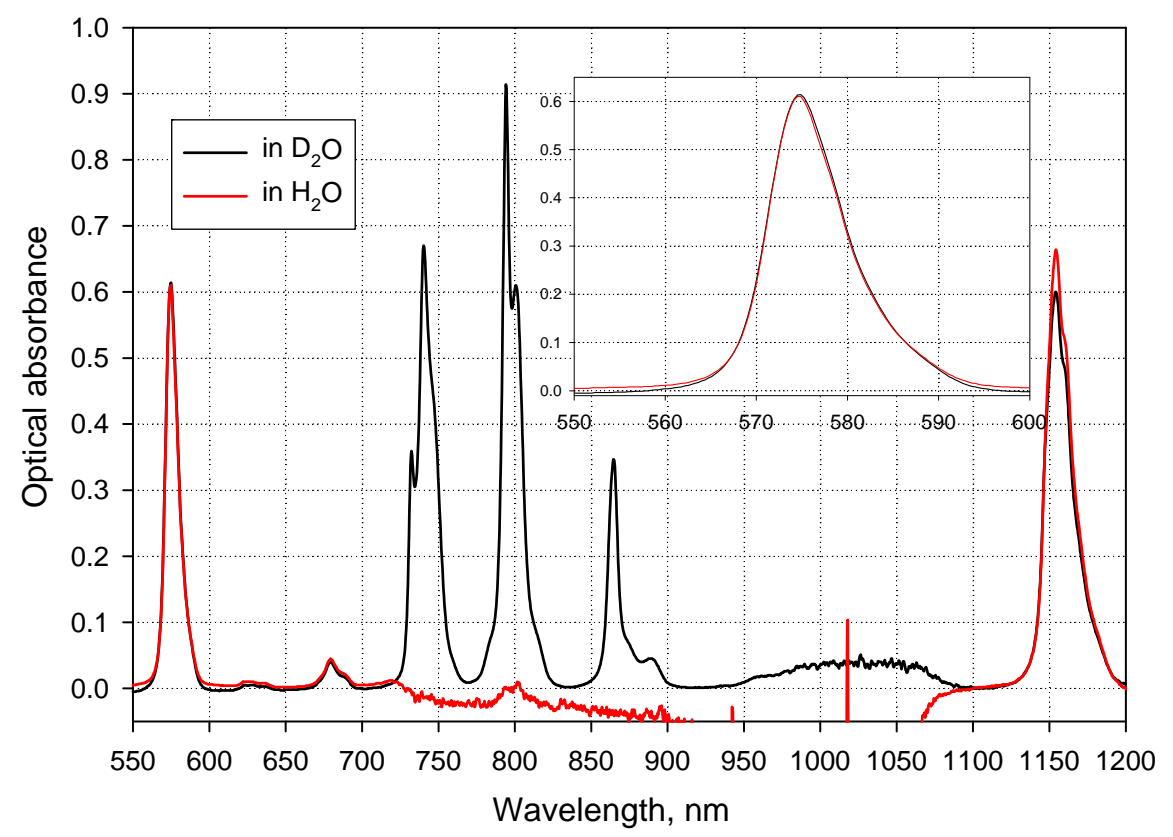

Figure 3.4. Spectra of $0.2 \mathrm{mM} \mathrm{Nd}\left(\mathrm{NO}_{3}\right)_{3}$ Solution in $\mathrm{D}_{2} \mathrm{O}$ and $\mathrm{H}_{2} \mathrm{O}$ in $0.015 \% \mathrm{HNO}_{3}$ and $\mathrm{DNO}_{3}$, Respectively, Using LWCC Detection

\subsection{Cold Testing of LWCC Using Nd(III) Complex with EDTA in $0.1 \mathrm{M}$ $\mathrm{NaOH}$ and $0.1 \mathrm{M}$ NaOD}

For a more systematic evaluation of the capabilities of enhanced detection of weak absorbance bands of $f$ elements in alkaline aqueous solution, several series of calibration experiments were performed using an alkaline solution of $\mathrm{Nd}$ in the presence of EDTA. EDTA was used as a holding complexing agent to prevent $\mathrm{Nd}(\mathrm{III})$ precipitation as $\mathrm{Nd}(\mathrm{OH})_{3}$ from solution in the presence of hydroxide. These experiments were performed both in chromate-free solutions and in the presence of $50 \mathrm{mM}$ of chromate. As a preliminary experiment, absorbance spectra of chromate in $\mathrm{D}_{2} \mathrm{O}$ (with no $\mathrm{Nd}$ and EDTA present) were taken to see to what extent the tailing effect of the major absorbance band of chromate (with a peak maximum at $372 \mathrm{~nm}$ ) propagates into the visible range of the spectrum, starting from $550 \mathrm{~nm}$, and possibly interferes with absorbance bands of interest. The results of this measurement are shown in Figure 3.5. As follows from these data, the presence of chromate up to $40 \mathrm{mM}$ in concentration exhibits only a minor effect of optical absorbance in the 550- to 570-nm range of the spectrum. This leaves practically the entire range of the optical transparency of $\mathrm{D}_{2} \mathrm{O}$ (up to $960 \mathrm{~nm}$ with present instrumentation) suitable for enhanced detection of characteristic absorbance bands of $\mathrm{Nd}$ and $\mathrm{Pu}$. 


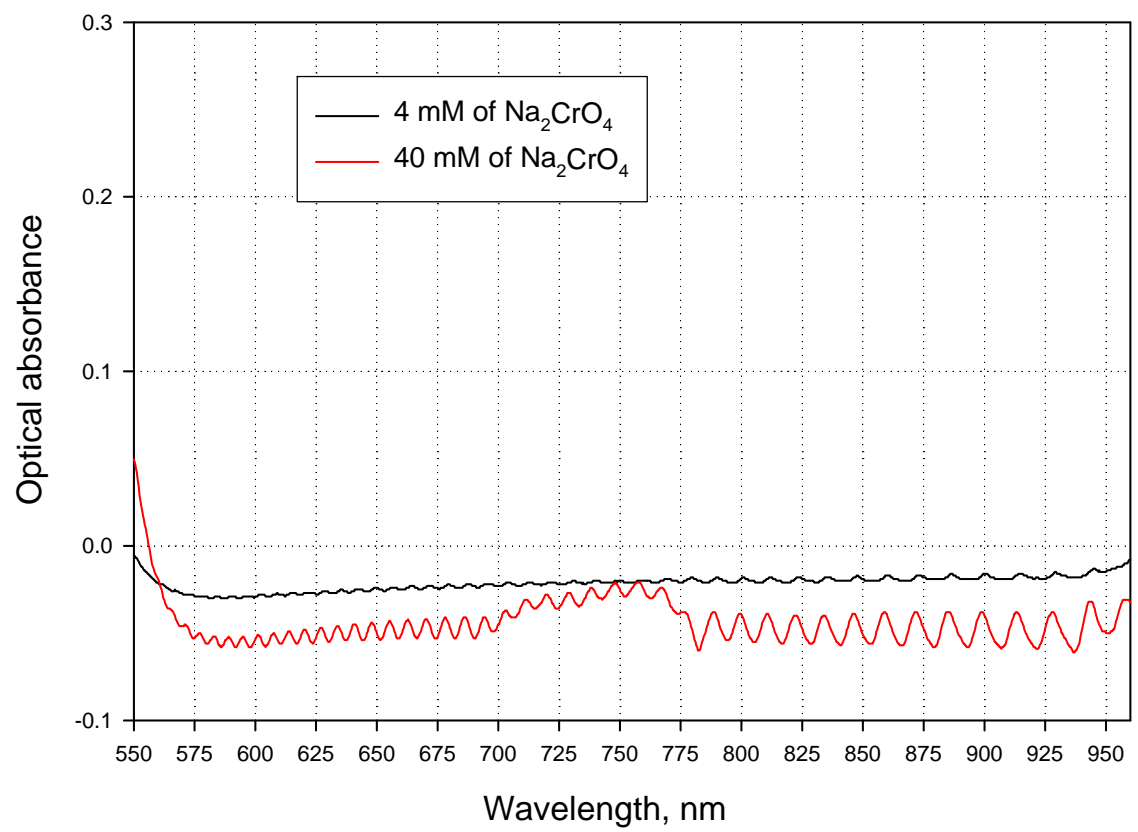

Figure 3.5. Spectra of $\mathrm{Na}_{2} \mathrm{CrO}_{4}$ Solution in $\mathrm{D}_{2} \mathrm{O}$ at $4 \mathrm{mM}$ and $40 \mathrm{mM}$ of $\mathrm{Cr}(\mathrm{VI})$. Pure solvent was used for baseline acquisition.

Nd-EDTA calibration experiments were conducted both in $\mathrm{H}_{2} \mathrm{O}$ and $\mathrm{D}_{2} \mathrm{O}$ medium in the presence of $0.1 \mathrm{M}$ of $\mathrm{NaOH}$ and $0.1 \mathrm{M}$ of $\mathrm{NaOD}$, respectively. The spectral data from these experiments are shown in Figure 3.6. Similar to the Nd spectral detection in a weakly acidic medium, the usable window of optical transparency in $\mathrm{H}_{2} \mathrm{O} / \mathrm{NaOD}$ solvent was found to be limited to 550 to $700 \mathrm{~nm}$, whereas spectral measurements in $\mathrm{D}_{2} \mathrm{O} / \mathrm{NaOD}$ allow spectral information to be collected in a much broader range up to $960 \mathrm{~nm}$. Calibration curves show good linearity both in $\mathrm{H}_{2} \mathrm{O}$ and $\mathrm{D}_{2} \mathrm{O}$ solvents, and their slopes show little or no difference within each series with or without chromate present in solution for the first three peaks of $\mathrm{Nd}$ at 581, 628, and $683 \mathrm{~nm}$. Detection limits for Nd-EDTA peaks with molar absorptivities of 6 $\mathrm{M}^{-1} \mathrm{~cm}^{-1}$ and higher (including three additional major bands of $\mathrm{Nd}$ in the 720 - to $880-\mathrm{nm}$ range in $\mathrm{D}_{2} \mathrm{O}$ medium) were found to be in the submicromolar range of $\mathrm{Nd}$ concentrations. Two peaks of $\mathrm{Nd}$ at $576 \mathrm{~nm}$ $\left(\varepsilon=9.1 \mathrm{M}^{-1} \mathrm{~cm}^{-1}\right)$ and $801 \mathrm{~nm}\left(\varepsilon=10.2 \mathrm{M}^{-1} \mathrm{~cm}^{-1}\right)$ showed exceptionally low detection limits, in the 0.04 to $0.08-\mu \mathrm{M}$ range, mostly due to very low background signal fluctuations in the blank spectra in these spectral regions. Table 3.1 summarizes results of all four calibration series shown in Figure 3.6.

Overall, cold testing of LWCC using Nd-EDTA complexes in an alkaline media showed promising results and demonstrated the possibility of much more sensitive detection of relatively weak but well defined absorbance bands of f-elements in the visible and near-IR range of the spectrum. Most importantly, the presence of up to $50 \mathrm{mM}$ chromate in these solutions (if properly compensated via blank signal acquisition) did not produce any adverse effects on the sensitivity of LWCC detection or spectral signal perturbations in a wide range of the spectrum starting from $\sim 560 \mathrm{~nm}$. 

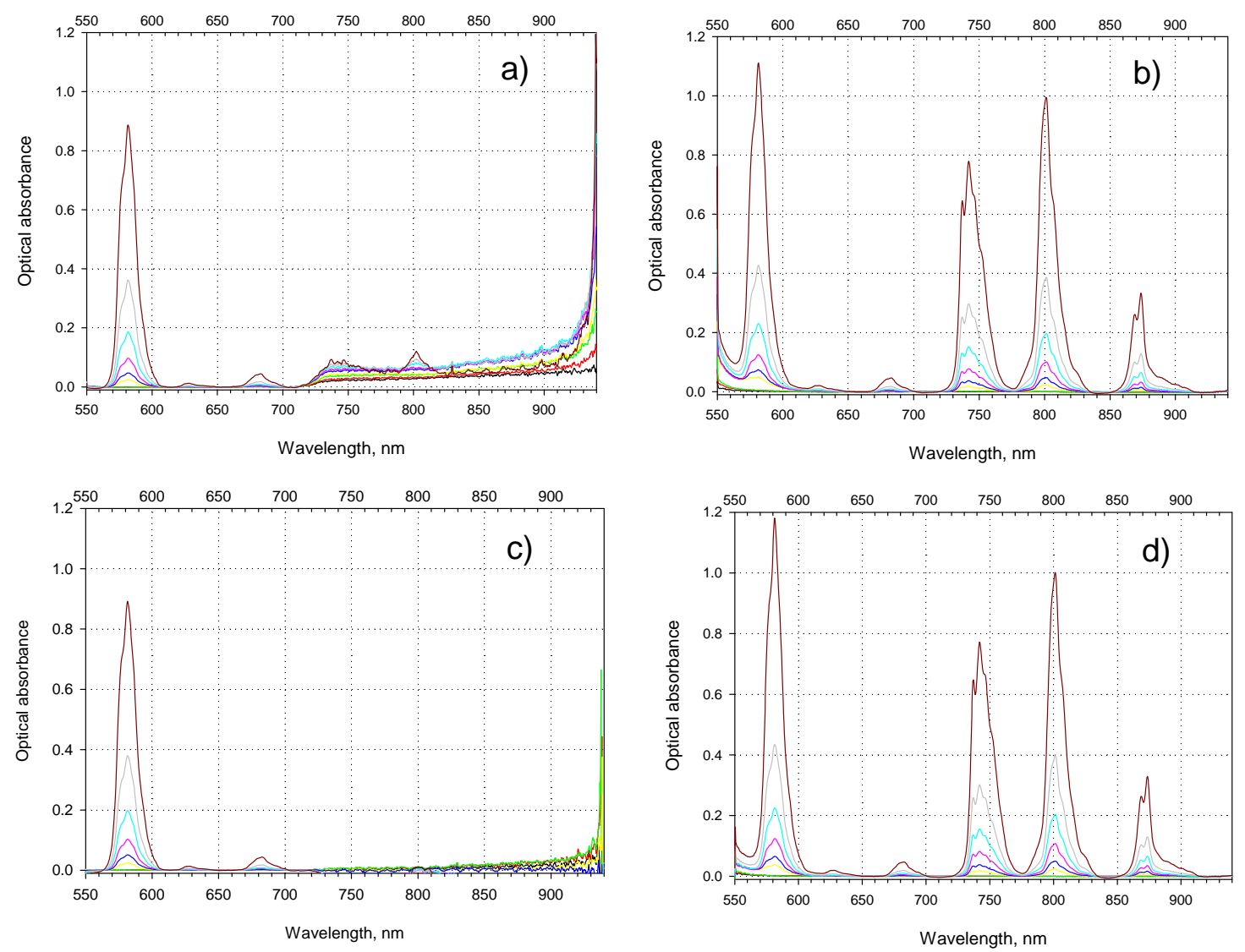

Figure 3.6. Calibration of LWCC Using Nd(III) Solution in the Presence of $0.25 \mathrm{M}$ of $\mathrm{Na}_{4} \mathrm{EDTA}$ in $0.1 \mathrm{M}$ of Sodium Hydroxide:
a) $\mathrm{NaOH} / \mathrm{H}_{2} \mathrm{O}$ no chromate
b) $\mathrm{NaOD} / \mathrm{D}_{2} \mathrm{O}$ no chromate
c) $\mathrm{NaOH} / \mathrm{H}_{2} \mathrm{O}+50 \mathrm{mM}$ of $\mathrm{Na}_{2} \mathrm{CrO}_{4}$
d) $\mathrm{NaOD} / \mathrm{D}_{2} \mathrm{O}+50 \mathrm{mM}$ of $\mathrm{Na}_{2} \mathrm{CrO}_{4}$ 
Table 3.1. Summary of Calibration Experiments with 5-m LWCC Using Nd-EDTA Complex in $\mathrm{NaOH}$ and $\mathrm{NaOD}$

\begin{tabular}{|c|c|c|c|c|c|c|c|c|}
\hline \multirow[b]{2}{*}{ Solvent } & \multirow[b]{2}{*}{$\begin{array}{c}\text { Peak } \\
\text { Position, } \\
\text { nm }\end{array}$} & \multirow[b]{2}{*}{$\begin{array}{c}\text { Peak } \\
\text { Detecta } \\
\text {-bility }\end{array}$} & \multicolumn{2}{|c|}{$\begin{array}{c}\text { Calibration } \\
\text { Curve Slope, } \mathbf{M}^{-1}\end{array}$} & \multicolumn{2}{|c|}{$\begin{array}{c}\text { Molar Absorptivity, } \\
\mathbf{M}^{-1} \mathbf{c m}^{-1}\end{array}$} & \multicolumn{2}{|c|}{$\begin{array}{c}\text { Detection Limit, } \\
\mu \mathrm{M}\end{array}$} \\
\hline & & & $\begin{array}{l}\text { No } \\
\text { Cr(VI) }\end{array}$ & $\begin{array}{c}50 \mathrm{mM} \\
\text { of } \\
\operatorname{Cr}(\mathrm{VI})\end{array}$ & $\begin{array}{l}\text { No } \\
\text { Cr(VI) }\end{array}$ & $\begin{array}{c}50 \mathrm{mM} \\
\text { of } \\
\mathrm{Cr}(\mathrm{VI})\end{array}$ & $\begin{array}{c}\text { No } \\
\text { Cr(VI) }\end{array}$ & $\begin{array}{c}50 \mathrm{mM} \text { of } \\
\mathrm{Cr}(\mathrm{VI})\end{array}$ \\
\hline \multirow{8}{*}{$\begin{array}{l}\mathrm{H}_{2} \mathrm{O}+ \\
0.1 \mathrm{M} \\
\mathrm{NaOH}\end{array}$} & 581.4 & Yes & 4512 & 4543 & 9.02 & 9.09 & 0.078 & 0.038 \\
\hline & 627.75 & Yes & 64 & 66 & 0.13 & 0.13 & 2.11 & 4.61 \\
\hline & 682.83 & Yes & 222 & 222 & 0.44 & 0.44 & 2.39 & 1.77 \\
\hline & 737.21 & No & - & - & - & - & - & - \\
\hline & 742.01 & No & - & - & - & - & - & - \\
\hline & 801.25 & No & - & - & - & - & - & - \\
\hline & 868.98 & No & - & - & - & - & - & - \\
\hline & 873.53 & No & - & - & - & - & - & - \\
\hline \multirow{8}{*}{$\begin{array}{l}\mathrm{D}_{2} \mathrm{O}+ \\
0.1 \mathrm{M} \\
\mathrm{NaOD}\end{array}$} & 581.4 & Yes & 5583 & 5950 & 11.2 & 11.9 & 0.94 & 0.29 \\
\hline & 627.75 & Yes & 104 & 96 & 0.21 & 0.20 & 7.3 & 8.2 \\
\hline & 682.83 & Yes & 237 & 239 & 0.47 & 0.48 & 5.4 & 4.2 \\
\hline & 737.21 & Yes & 3272 & 3290 & 6.5 & 6.6 & 0.8 & 0.8 \\
\hline & 742.01 & Yes & 3949 & 3920 & 7.9 & 7.8 & 0.64 & 0.57 \\
\hline & 801.25 & Yes & 5056 & 5095 & 10.1 & 10.2 & 0.08 & 0.05 \\
\hline & 868.98 & Yes & 1331 & 1340 & 2.7 & 2.7 & 1.1 & 1.1 \\
\hline & 873.53 & Yes & 1700 & 1670 & 3.4 & 3.3 & 1.7 & 1.1 \\
\hline
\end{tabular}

\subsection{Pu(VI) Calibration and Speciation Experiments in $\mathrm{DNO}_{3}$ and $\mathrm{NaOD}$}

\subsection{1 $\mathrm{Pu}(\mathrm{VI})$ Calibration Experiment in $\mathrm{DNO}_{3}$}

$\mathrm{Pu}(\mathrm{VI})$ in an acidic medium is known to have the most intense and sharp absorbance band of any of the other actinide metal cations. The peak maximum is at $830.5 \mathrm{~nm}$ in acidic aqueous solutions and (as shown in this work with stock solution of $\mathrm{Pu}(\mathrm{VI})$, Figure 3.7) has the same $\lambda_{\max }$ in $\mathrm{D}_{2} \mathrm{O} / \mathrm{DNO}_{3}$. The peak position beyond the 700-nm border of the transparency of $\mathrm{H}_{2} \mathrm{O}$ makes it undetectable in the $500-\mathrm{cm}$ LWCC in $\mathrm{H}_{2} \mathrm{O}$. Therefore, it was of interest to demonstrate the detectability of this peak in deuterated aqueous solvent and to determine its molar absorptivity, linearity of the calibration curve, and detection limit. 

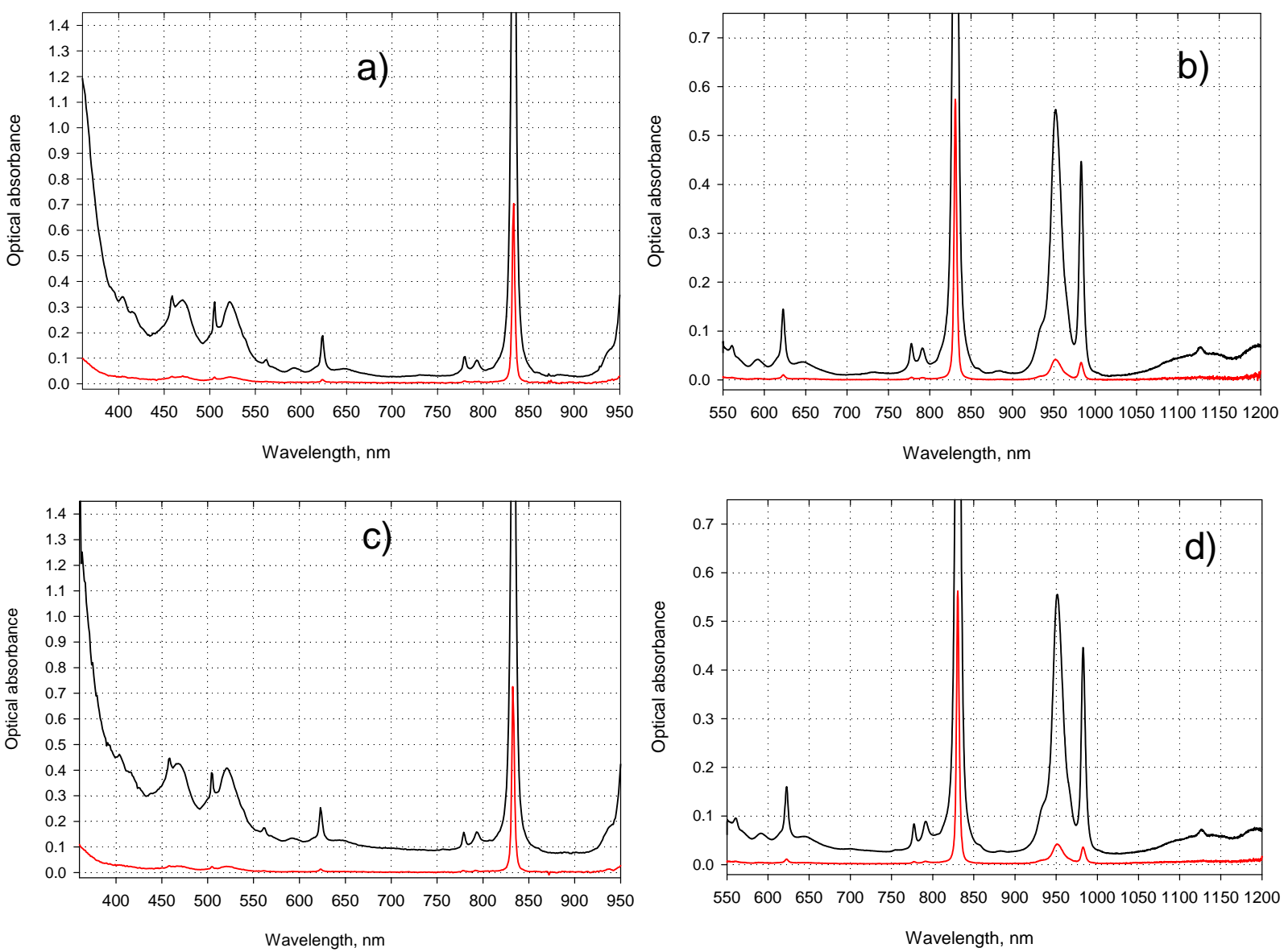

Figure 3.7. $\mathrm{Pu}(\mathrm{VI})$ Acidic Stock Solution Spectra in $0.5 \mathrm{M}$ of $\mathrm{HNO}_{3}$ [a) and b)] and $0.5 \mathrm{M}$ of $\mathrm{DNO}_{3}[\mathrm{c}$ ) and d)]. Black trace: $26.4 \mathrm{mM}$ of $\mathrm{Pu}(\mathrm{VI})$; red trace:0.306 $\mathrm{mM}$ of $\mathrm{Pu}(\mathrm{VI})$. Spectral sets a) and c) are recorded with SI-400 spectrophotometer (360- to 950-nm scanning range); spectral sets b) and d) are recorded with an Ocean Optics spectrophotometer (550- to 1100nm scanning range). A 1-cm plastic cell was used in all spectral measurements.

Figure 3.8 shows results of this calibration experiment performed in $\mathrm{D}_{2} \mathrm{O} / \mathrm{DNO}_{3}$ solution. The linear regression data are summarized in the upper section of Table 3.2. The detection limit achieved in this experiment is $5.6 \mathrm{nM}$ of $\mathrm{Pu}(\mathrm{VI})$. The peak position of $\mathrm{Pu}(\mathrm{VI})$ and its molar absorptivity are in excellent correspondence with previously published data on $\mathrm{Pu}(\mathrm{VI})$ detection by visible spectroscopy using $100-\mathrm{cm}$ LWCC in $\mathrm{H}_{2} \mathrm{O}$ medium (Wilson et al. 2005). It is noteworthy that, because of selecting a $\mathrm{D}_{2} \mathrm{O}$ medium for spectroscopic measurements, a 125-fold improvement in the detection limit of $\mathrm{Pu}(\mathrm{VI})$ was achieved by increasing the optical pathlength by just five times. The invariability of the $\mathrm{Pu}(\mathrm{VI})$ peak position and its intensity by the nature of the aqueous solvent serves as another proof that $\mathrm{D}_{2} \mathrm{O}$ does not perturb spectral features of $5 \mathrm{f}$ metal cations in solution compared with conventional $\mathrm{H}_{2} \mathrm{O}$ solvent. 


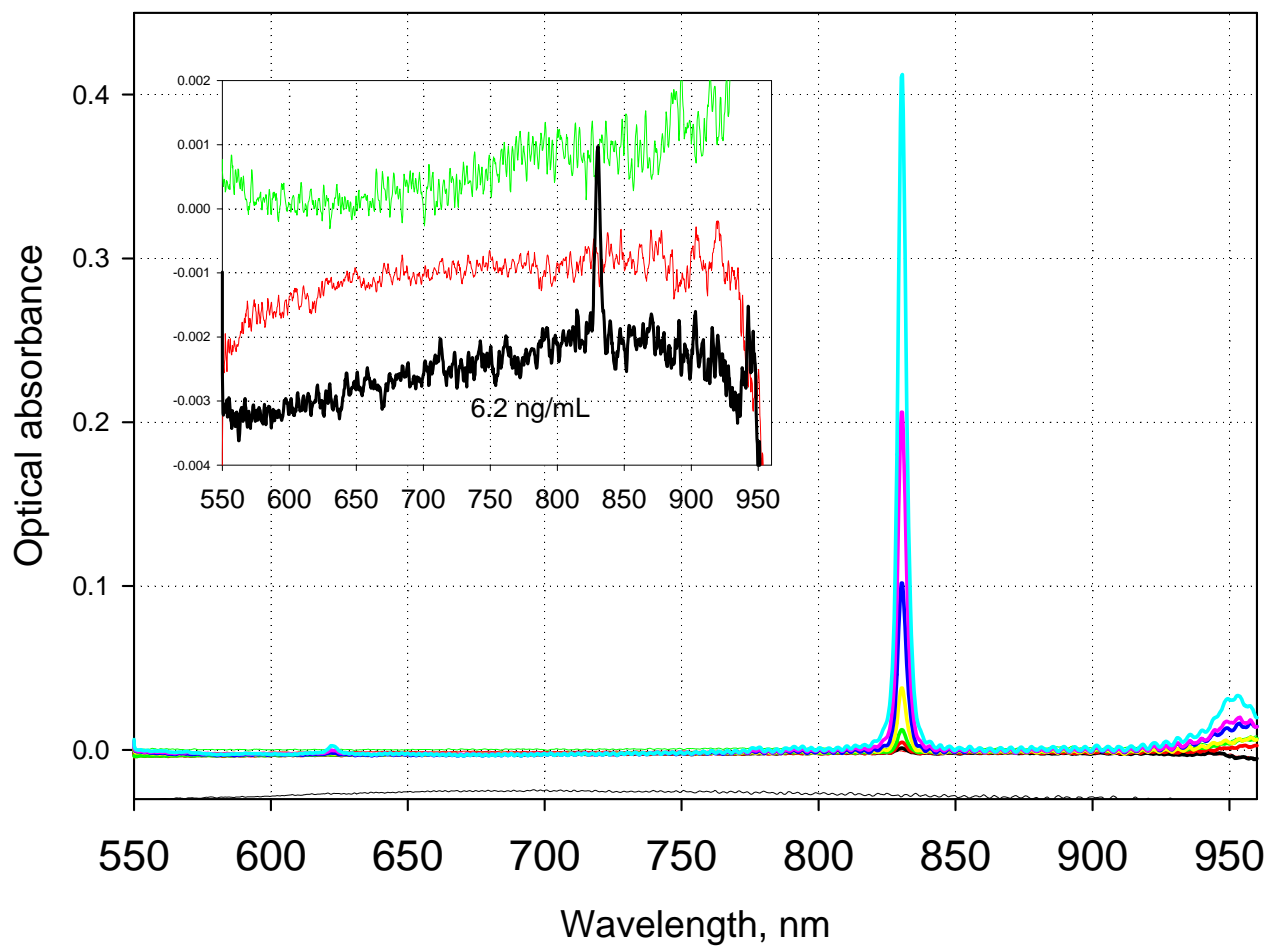

Figure 3.8. Calibration Experiment with $\mathrm{Pu}(\mathrm{VI})$ in $0.1 \mathrm{M}$ of $\mathrm{DNO}_{3}$ Using $500 \mathrm{~cm} \mathrm{LWCC}$. The $\mathrm{Pu}(\mathrm{VI})$ Concentration Range Is from $0.021 \mu \mathrm{M}(6.2 \mathrm{ng} / \mathrm{L}$, black trace) to $2.12 \mu \mathrm{M}$ (pale blue trace). Red and green traces in the inset show typical baseline spectra obtained with a blank solution of $0.1 \mathrm{M}$ of $\mathrm{DNO}_{3}$.

Table 3.2. Summary of Calibration Experiments with $\mathrm{Pu}(\mathrm{VI})$ in $0.1 \mathrm{M}$ of $\mathrm{DNO}_{3}, 0.1 \mathrm{M}$ and $1 \mathrm{M}$ of $\mathrm{NaOD}$

\begin{tabular}{||l|c|c|c|c|c|c||}
\hline \hline Medium & $\begin{array}{c}\text { Solution } \\
\text { Age, } \mathbf{h r}\end{array}$ & $\begin{array}{c}\text { Concentration } \\
\text { Range, } \boldsymbol{\mu M}\end{array}$ & $\begin{array}{c}\text { Calibration } \\
\text { Curve } \\
\text { Linearity, } \\
\mathbf{R}^{\mathbf{2}}\end{array}$ & Slope, $\mathbf{M}^{-\mathbf{1}}$ & $\begin{array}{c}\text { Extent of } \\
\text { Reduction } \\
\text { to Pu(V) }\end{array}$ & $\begin{array}{c}\text { Detection } \\
\text { Limit, } \boldsymbol{\mu M}\end{array}$ \\
\hline $\begin{array}{l}0.1 \mathrm{M} \text { of } \\
\mathrm{DNO}_{3}\end{array}$ & $1.5 \pm 0.5$ & $0.021-2.12$ & 0.9999 & $190060 \pm 660$ & $\begin{array}{l}\mathrm{Pu}(\mathrm{V}) \text { is not } \\
\text { detected }\end{array}$ & 0.0056 \\
\hline $\begin{array}{l}0.1 \mathrm{M} \text { of } \\
\mathrm{NaOD}\end{array}$ & $1.5 \pm 0.5$ & $0.53-15.6$ & 0.995 & $5530 \pm 130$ & $<2 \%$ & 0.47 \\
\cline { 2 - 7 } $\begin{array}{l}1.0 \mathrm{M} \text { of } \\
\mathrm{NaOD}\end{array}$ & $72 \pm 3$ & $0.53-15.6$ & 0.980 & $4670 \pm 270$ & $<2 \%$ & 0.71 \\
\cline { 2 - 7 } & $72 \pm 0.5$ & $0.53-15.6$ & 0.995 & $5740 \pm 170$ & $8 \%$ & 0.55 \\
\hline
\end{tabular}

\subsubsection{Pu(VI) Calibration Experiments in NaOD}

Literature data on the spectral features of $\mathrm{Pu}(\mathrm{VI})$ in alkaline medium are contradictory. One of the first spectral measurements of $\mathrm{Pu}(\mathrm{VI})$ in alkaline medium was performed and published by Spitsyn and coauthors (Spitsyn et al. 1969). Their spectrum of $\mathrm{Pu}(\mathrm{VI})$ in $1 \mathrm{M} \mathrm{KOH}$ shows a very prominent band at 
$870 \mathrm{~nm}\left(\varepsilon=300 \mathrm{M}^{-1} \mathrm{~cm}^{-1}\right)$ and a broader and much less intense peak at $\sim 640 \mathrm{~nm}\left(\varepsilon=70 \mathrm{M}^{-1} \mathrm{~cm}^{-1}\right)$. Both peaks can be considered as red-shifted transforms of the peaks of cationic $\mathrm{PuO}_{2}{ }^{2+}$ at $830 \mathrm{~nm}$ and $616 \mathrm{~nm}$, respectively, as result of $\mathrm{Pu}(\mathrm{VI})$ hydrolysis and the formation of anionic hydroxocomplexes. The similar but less symmetrical and $\sim 40 \%$ less intense peak of $\mathrm{Pu}(\mathrm{IV})$ was reported by Ray and colleagues in $0.05 \mathrm{M} \mathrm{NaOH}$ (Ray et al. 1988). On the other hand, a much more recent publication from the former Spitsyn's institution (Budantseva et al. 1997) indicated that in $2 \mathrm{M} \mathrm{NaOH}$ and higher, the 870-nm band of $\mathrm{Pu}(\mathrm{VI})$ is barely detectable and has a molar absorptivity of $\sim 10 \mathrm{M}^{-1} \mathrm{~cm}^{-1}$ while the $630-\mathrm{nm}$ band is about $60 \%$ more intense, but still a factor of 4.2 lower than Spitsyn's value for the same peak. In a study by Bourges (1972), electrochemically generated $\mathrm{Pu}(\mathrm{VI})$ in $1 \mathrm{M} \mathrm{NaOH}$ did not exhibit the 870-nm spectral feature at all. Therefore, it was of interest to take advantage of the higher sensitivity offered by LWCC detection and the wide spectral window in $\mathrm{D}_{2} \mathrm{O}$ solvent for re-examination of the spectral characteristics of $\mathrm{Pu}(\mathrm{VI})$ in $\mathrm{NaOD}$. If the very intense and clearly defined $870-\mathrm{nm}$ absorbance band of $\mathrm{Pu}(\mathrm{VI})$ reported by Spitsyn could be confirmed in this study, that feature would be very beneficial for a much more sensitive detection of alkaline $\mathrm{Pu}(\mathrm{VI})$ in the low-nanomolar concentration range.

A series of $\mathrm{Pu}(\mathrm{VI})$ solutions in $0.1 \mathrm{M}$ of $\mathrm{NaOD}$ was prepared in duplicate by spiking tiny amounts of acidic $\mathrm{Pu}(\mathrm{VI})$ solution in $0.025 \mathrm{M}$ of $\mathrm{HNO}_{3}$ into an excess of $0.1 \mathrm{M}$ of $\mathrm{NaOD}$. The perturbation of the initial $\mathrm{NaOD}$ concentration with this preparation was less than $0.75 \%$ for the highest amount of acidic stock of $\mathrm{Pu}(\mathrm{VI})$ added. The solutions were quickly homogenized by shaking, and the first series was spectrally measured 1 to $1.5 \mathrm{hr}$ after preparation. The results of this experiment are shown in Figure 3.9 (plot a). The net intensity of the major peak of $\mathrm{Pu}(\mathrm{VI})$ at $625 \mathrm{~nm}$ was calculated using the spectral treatment described in Section 2.9, and the respective calibration plot is shown as plot b) in the same Figure. A good proportionality between $\mathrm{Pu}(\mathrm{VI})$ concentration and the peak intensity is observed for all concentration points with a slightly lower slope of the calibration curve for the first three points $(0.65$ to $3.25 \mu \mathrm{M})$. The same tendency of the calibration slope decrease at a lower metal concentration was observed previously with acidic $\mathrm{Pu}(\mathrm{VI})$, and in both cases this effect may be attributed to the presence of low concentrations of unidentified reductant in the prepared solutions. This reductant might be introduced with solvent $\left(\mathrm{D}_{2} \mathrm{O}\right), \mathrm{NaOD}$, or $\mathrm{DNO}_{3}$, or it may come into solution from plastic containers used to store the samples.

Duplicate portions of the same solutions were stored without additional agitation over 3 days before spectral measurement. The results are shown in Figure 3.9 (c and d). Comparing spectral sets a) and c) shows that $\mathrm{Pu}(\mathrm{VI})$ is stable in a $0.1 \mathrm{M} \mathrm{NaOD}$ medium for at least 3 days with spectral features observed in the freshly prepared series clearly identifiable in the aged series at higher Pu concentrations. However, in the lower range of $\mathrm{Pu}(\mathrm{VI})$ concentrations, no positive signal of $\mathrm{Pu}(\mathrm{VI})$ could be discriminated against the 570- to $660-\mathrm{nm}$ baseline. This observation may indicate that a slight deficiency in the $\mathrm{Pu}(\mathrm{VI})$ signal in the low concentration region of the freshly prepared series becomes more pronounced with time because of the partial reduction of $\mathrm{Pu}(\mathrm{VI})$ to one of the lower oxidation states. As regards the 870 -nm peak reported as the major spectral feature in $1 \mathrm{M}$ of KOH (Spitsyn et al. 1969) and in $0.05 \mathrm{M}$ of $\mathrm{NaOH}$ (Ray et al. 1988), our data do not confirm those findings (see Section 3.4.3 for correct attribution of the $870 \mathrm{~nm}$ peak of $\mathrm{Pu}(\mathrm{VI})$. 

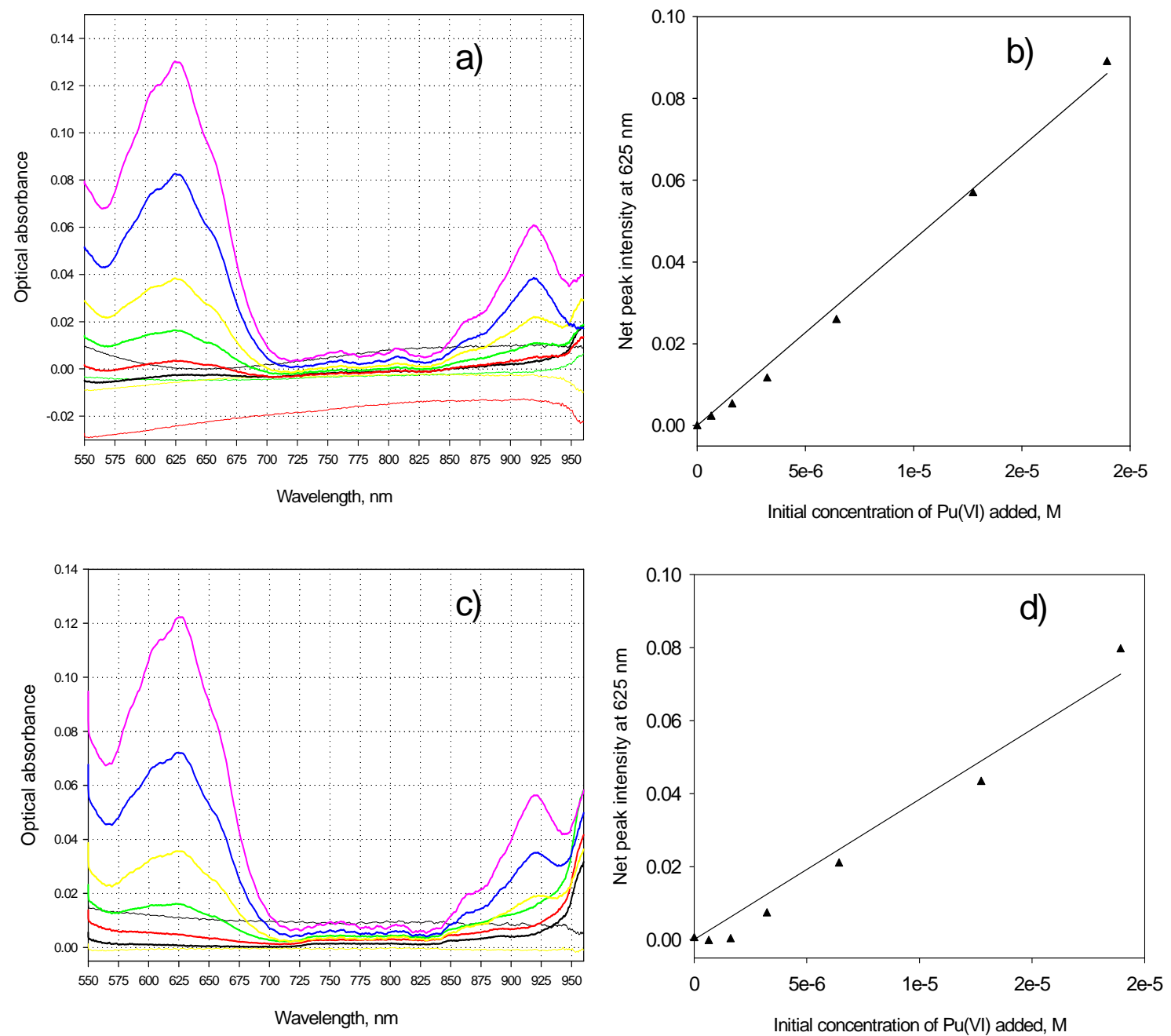

Figure 3.9. Calibration Experiments with $\mathrm{Pu}(\mathrm{VI})$ in $0.1 \mathrm{M}$ of $\mathrm{NaOD}$. Freshly prepared series a) and b), and 3 days between solution preparation and measurement $\mathrm{c}$ ) and d). Initial concentrations of $\mathrm{Pu}(\mathrm{VI})$ are $0.53,1.33,2.66,5.30,10.5$, and $15.6 \mu \mathrm{M}$ for black, red, green yellow, blue, and pink spectral traces, respectively.

The same experimental approach was used to prepare and study $\mathrm{Pu}(\mathrm{VI})$ speciation in $1 \mathrm{M} \mathrm{NaOD}$. The results obtained with freshly prepared series are shown in Figure 3.10 [plots a) and b)]. There are very minor (if any) changes in the major absorbance peak shape and intensity compared with the $0.1 \mathrm{M} \mathrm{NaOD}$ data. More noticeable changes were observed in the 800- to 950-nm spectral range. First, a very weak spectral feature initially observed at 808 to $812 \mathrm{~nm}$ is now more pronounced and manifests itself as a narrow and nearly symmetrical peak centered at $809 \mathrm{~nm}$. What is more interesting, kinetic monitoring of the intensity of this band at $15.6 \mu \mathrm{M}$ of initially added $\mathrm{Pu}(\mathrm{VI})$ indicates that the 809 -nm peak intensity slowly increases with time, while the 625-nm peak of $\mathrm{Pu}(\mathrm{VI})$ simultaneously decreases (black, red, green, yellow, and blue traces in Figure 3.11). The 809-nm peak position and spectral shape are in excellent correspondence with the $\mathrm{Pu}(\mathrm{V})$ spectrum reported previously in the literature for higher hydroxide concentrations (Delegard 1987). Therefore, the observed spectral changes are consistent with the partial conversion of $\mathrm{Pu}(\mathrm{VI})$ to $\mathrm{Pu}(\mathrm{V})$ by an unidentified reductant. Overall, the extent of $\mathrm{Pu}(\mathrm{VI})$ conversion to 
$\mathrm{Pu}(\mathrm{V})$ is approximately 6 to $8 \%$ over the first 60 minutes of the kinetic sequence. It was not possible to continue kinetic measurements with this solution over a longer period of time because of the aggressive nature of the $1 \mathrm{M} \mathrm{NaOD}$ medium on contact with the inner wall of the liquid waveguide capillary made from quartz. Measuring the same concentration point in a 3-day-old series in $1 \mathrm{M}$ of $\mathrm{NaOD}$ (bold dark yellow trace in the same Figure) indicates that the $\mathrm{Pu}(\mathrm{V})$ signal grew $\sim 1.5$ times with the decrease in intensity of the $\mathrm{Pu}(\mathrm{VI})$ peak to approximately same extent. No new spectral features appeared in the aged sample. These data indicate that most likely, it is the stock solution of $\mathrm{NaOD}$ that supplies reductant to reduce $\mathrm{Pu}(\mathrm{VI})$ to $\mathrm{Pu}(\mathrm{V})$.
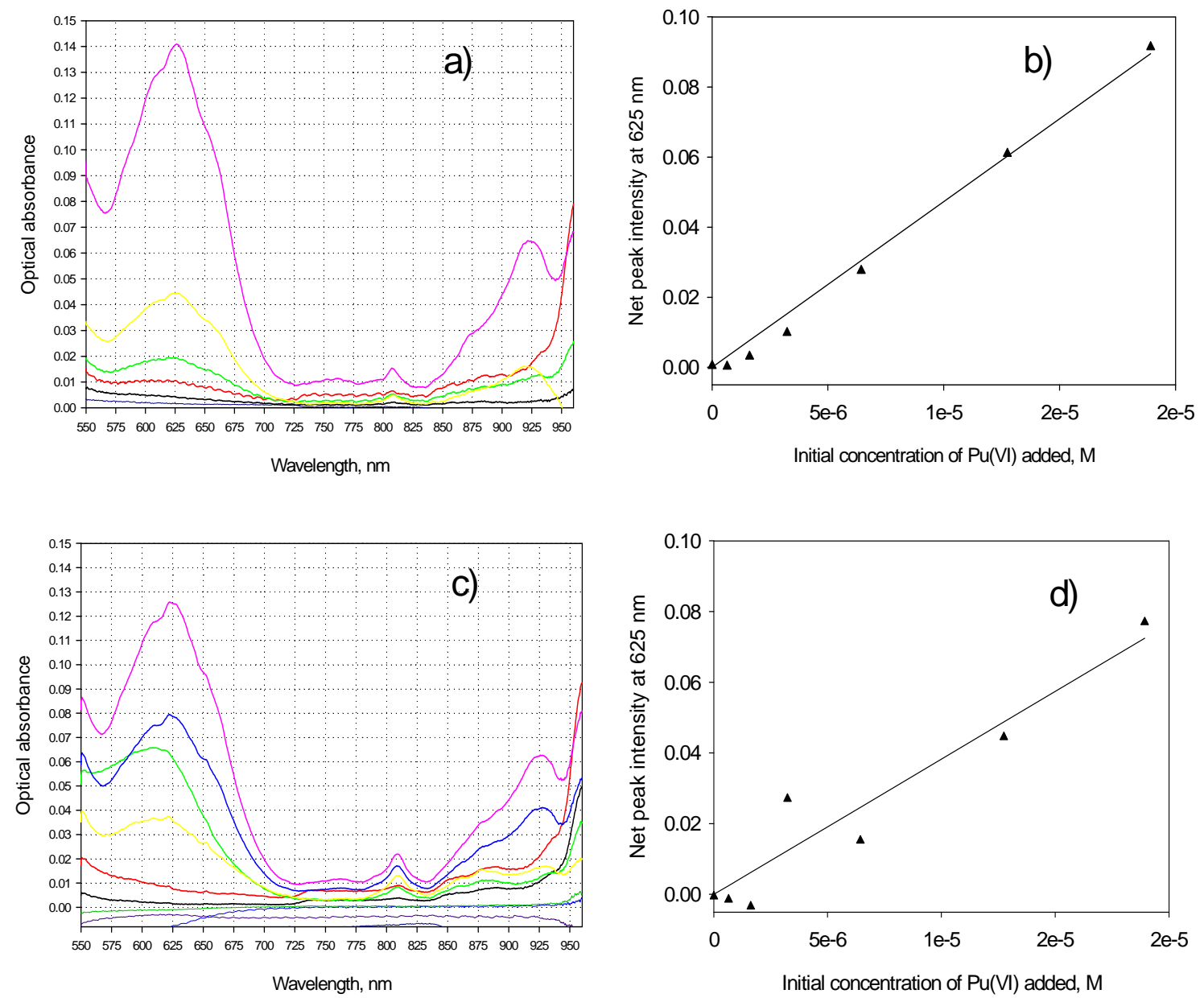

Figure 3.10. Calibration Experiments with $\mathrm{Pu}(\mathrm{VI})$ in $1 \mathrm{M} \mathrm{NaOD}$. Freshly prepared series a) and b), and 3 days between solution preparation and measurement c) and d). Initial concentrations of $\mathrm{Pu}(\mathrm{VI})$ are $0.53,1.33,2.66,5.30,10.5$, and $15.6 \mu \mathrm{M}$ for black, red, green yellow, blue, and pink spectral traces, respectively. 


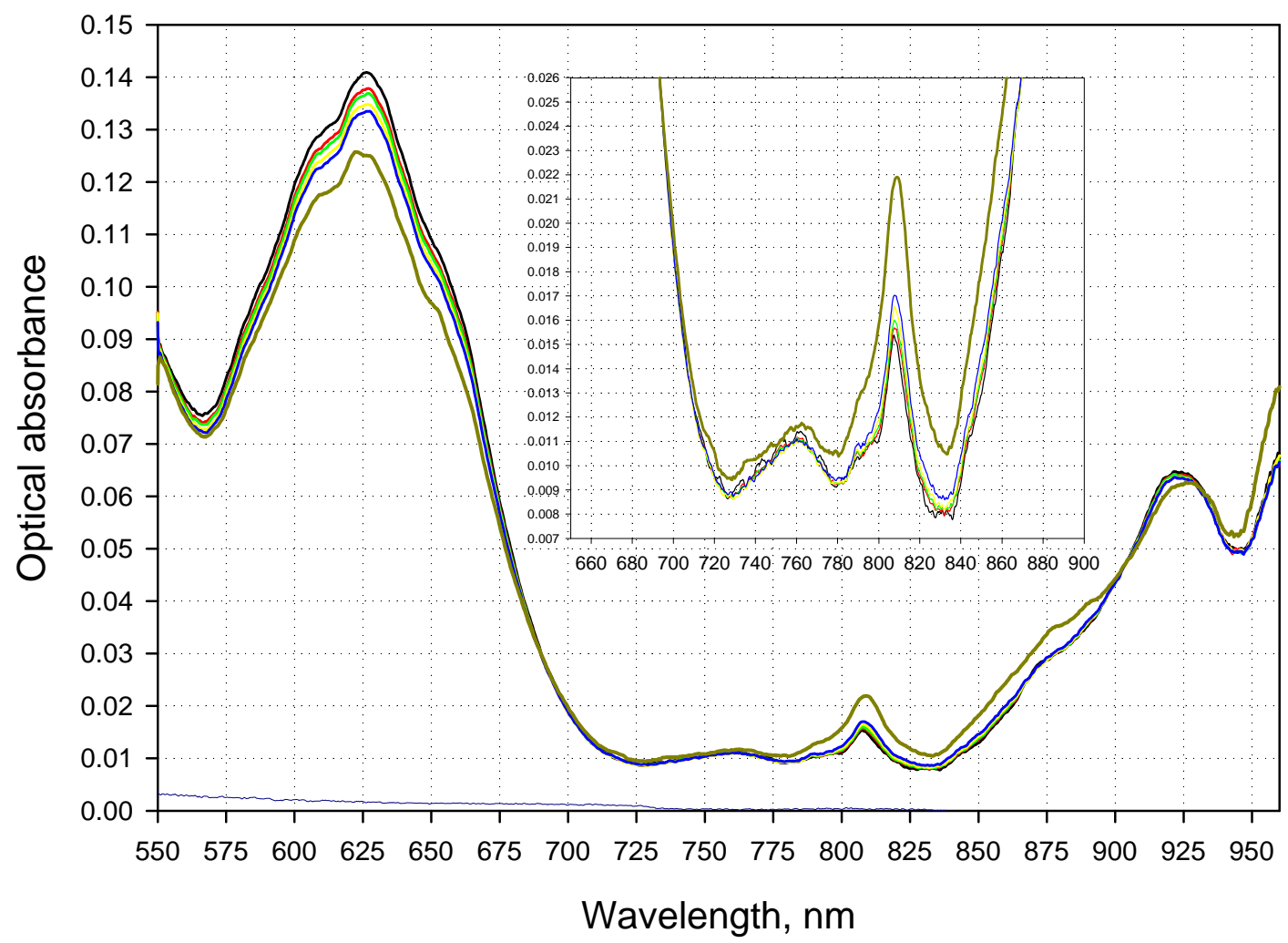

Figure 3.11. Spectral Evidence of Partial Reduction of $\mathrm{Pu}(\mathrm{VI})$ to $\mathrm{Pu}(\mathrm{V})$ in $1 \mathrm{M}$ NaOD with Time. $\mathrm{C}_{\mathrm{Pu}(\mathrm{VI})}^{0}=15.6 \mu \mathrm{M}$. Black trace: 2 minutes after injection. Red, green, yellow, and blue traces: 10, 20, 30, and 50 minutes after the first scan. Dark yellow bold trace: duplicate solution of identical composition measured 3 days after preparation.

As regards the linearity and slopes of the calibration curves, the freshly prepared $1 \mathrm{M} \mathrm{NaOD}$ series shows more pronounced negative deviations for the 625-peak intensity at lower Pu concentrations compared with the $0.1 \mathrm{M} \mathrm{NaOD}$ data. This effect is most noticeable for the first three concentration points. Aging $1 \mathrm{M} \mathrm{NaOD}$ solutions for 3 days [Figure 3.10, plots c) and d)] makes this deviation even more pronounced with all six points going down in intensity and with the first two concentration points showing no positive signal of $\mathrm{Pu}(\mathrm{VI})$ at all.

The second largest peak of $\mathrm{Pu}(\mathrm{VI})$ centered at $920 \mathrm{~nm}$ in $0.1 \mathrm{M} \mathrm{NaOD}$ undergoes a 4- to 5-nm red shift in its position and broadens in $1 \mathrm{M} \mathrm{NaOD}$ solution.

Overall, the data scattering and additional partial reduction of $\mathrm{Pu}(\mathrm{VI})$ to $\mathrm{Pu}(\mathrm{V})$ in $1 \mathrm{M} \mathrm{NaOD}$ aged series results in elevated fluctuations in the spectra of blank solutions and a reduced slope of the calibration curve, which leads to a 1.5 times higher detection limit of $\mathrm{Pu}(\mathrm{VI})$ under these conditions.

No attempts were made to repeat these four series of calibration experiments with $\mathrm{Pu}(\mathrm{VI})$ in the presence of $\mathrm{Cr}(\mathrm{VI})$. It is expected that $\mathrm{Cr}(\mathrm{VI})$ cannot perturb the oxidation state of $\mathrm{Pu}(\mathrm{VI})$ by oxidizing it to $\mathrm{Pu}(\mathrm{VII})$, nor can it compete with hydroxide for the $\mathrm{Pu}(\mathrm{VI})$ metal center to form mixed hydroxy-chromate complexes of $\mathrm{Pu}(\mathrm{VI})$. By analogy with a lack of chromate interference in detecting $\mathrm{Nd}(\mathrm{III})$-EDTA 
species in the 570 - to 685 -nm spectral range, it can be predicted that $\mathrm{Cr}(\mathrm{VI})$ should not have any adverse effect on the quality of spectral detection in the $625-\mathrm{nm}$ peak of $\mathrm{Pu}(\mathrm{VI})$.

$\mathrm{A} \mathrm{Pu}(\mathrm{VI})$ calibration experiment in the $0.25 \mathrm{M} \mathrm{NaOD}$ medium was not performed, but one spectrum was taken at $13 \mu \mathrm{M}$ of $\mathrm{Pu}(\mathrm{VI})$. The spectrum served as a starting point in studying $\mathrm{Pu}(\mathrm{VI})$ speciation in mixed $0.25 \mathrm{M} \mathrm{NaOD}-\mathrm{Na}_{2} \mathrm{CO}_{3}$ media (Section 3.4.3, Figure 3.12, plot b), and it does not show any unusual spectral features compared to those already observed and discussed in this section for $1 \mathrm{M} \mathrm{NaOD}$.

Again, no evidence of the intense spectral feature of $\mathrm{Pu}(\mathrm{VI})$ at $870 \mathrm{~nm}$ was observed in $1 \mathrm{M} \mathrm{NaOD}$. Therefore, the prior published $\mathrm{Pu}(\mathrm{VI})$ spectrum (Spitsyn et al. 1969) was not confirmed in this study. The 625-nm peak appears to be the major spectral feature of $\mathrm{Pu}(\mathrm{VI})$ in a purely hydroxide medium in the concentration range from $0.1 \mathrm{M}$ to $1 \mathrm{M} \mathrm{NaOD}$. Unfortunately, the peak is too broad to be discriminated reliably from other light absorbing species with absorbance maxima in this region of the spectrum. On the positive side, the peak location below $700 \mathrm{~nm}$ should make it detectable in a $\mathrm{H}_{2} \mathrm{O} / \mathrm{NaOH}$ medium, provided no other spectral interferences are present in the same solution.

\subsubsection{Pu(VI) Spectra in the Presence of Carbonate at Constant Concentration of Hydroxide}

The formation of mixed hydroxy-carbonate complexes of $\mathrm{Np}(\mathrm{VI})$ and $\mathrm{Pu}(\mathrm{VI})$ of unidentified composition was reported by Varlashkin and co-workers (Varlashkin et al. 1984a; Varlashkin et al. 1984b) who used optical absorbance spectroscopy to observe significant spectral changes in the spectrum of a triscarbonate complex of $\mathrm{Pu}(\mathrm{VI})$ in $2 \mathrm{M}$ of $\mathrm{Na}_{2} \mathrm{CO}_{3}$ after adding $\mathrm{NaOH}$ up to 1.44 to $2.0 \mathrm{OH}^{-} / \mathrm{CO}_{3}{ }^{2-}$ molar ratio. The spectra were measured at a high concentration of $\mathrm{Pu}(\mathrm{VI})(16 \mathrm{mM})$. A relatively low solubility of $\mathrm{PuO}_{2}(\mathrm{OH})_{2}$ in moderately alkaline solutions $(\leq 1 \mathrm{M} \mathrm{NaOH})$ did not allow the authors to study this process from a purely alkaline (carbonate-free) side. The most pronounced spectral changes were found in the 850- to 890-nm range of the spectrum where a sharp and intense absorbance band developed and reached its maximum intensity at $0.6: 2$ molar ratio of $\mathrm{OH}^{-}$to $\mathrm{CO}_{3}{ }^{2-}$. The exact peak position and molar intensity was not reported explicitly in the paper, and it is difficult to deduce these parameters from the published spectra with an arbitrarily drawn vertical scale and a very compressed horizontal scale. Qualitatively, the mixed ligand spectrum resembles the $870-\mathrm{nm}$ peak of $\mathrm{Pu}(\mathrm{VI})$ in $1 \mathrm{M} \mathrm{KOH}$ reported by Spitsyn and colleagues (1969).

The study of fundamental complexation chemistry of mixed hydroxy-carbonate complexes of $\mathrm{Pu}(\mathrm{VI})$ was beyond the scope of this project, but it was of practical interest to find conditions in an $\mathrm{NaOH}-\mathrm{Na}_{2} \mathrm{CO}_{3}$ solution under which the spectral signature of $\mathrm{Pu}(\mathrm{VI})$ could be maximized to allow more sensitive and selective detection of $\mathrm{Pu}(\mathrm{VI})$ in alkaline solutions relevant to the oxidative-leaching process. Moreover, even if carbonate is not to be added for leaching of alkaline solutions, it is always present as a minor contaminant in stock solutions of $\mathrm{NaOH}$. More carbonate enters the leaching solutions and leachates with time as a result of their exposure to air. 


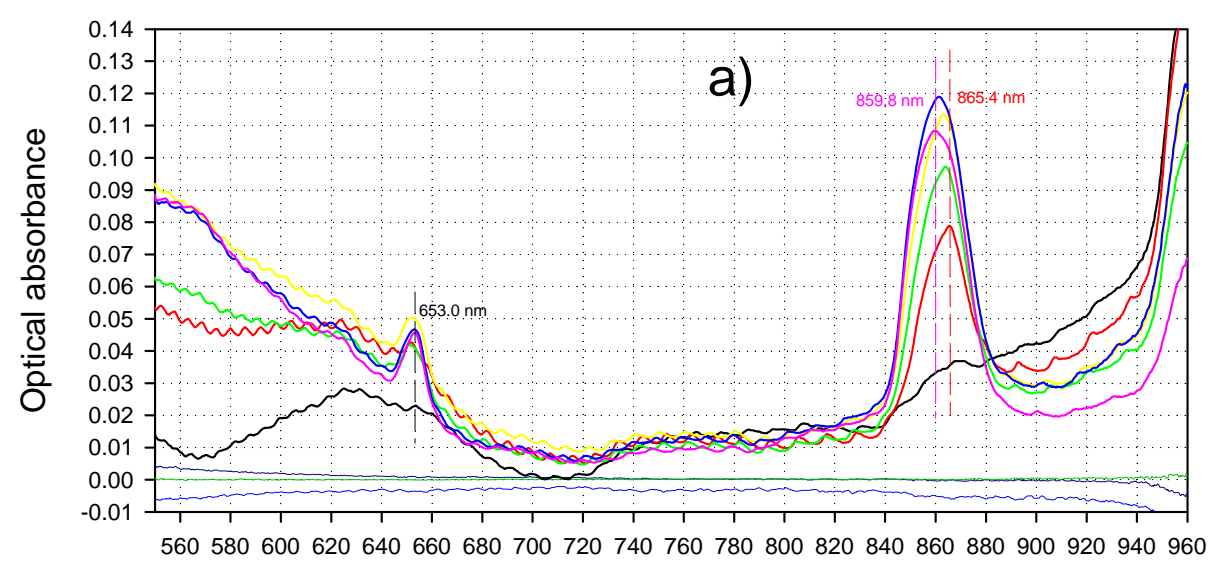

Wavelength, $\mathrm{nm}$
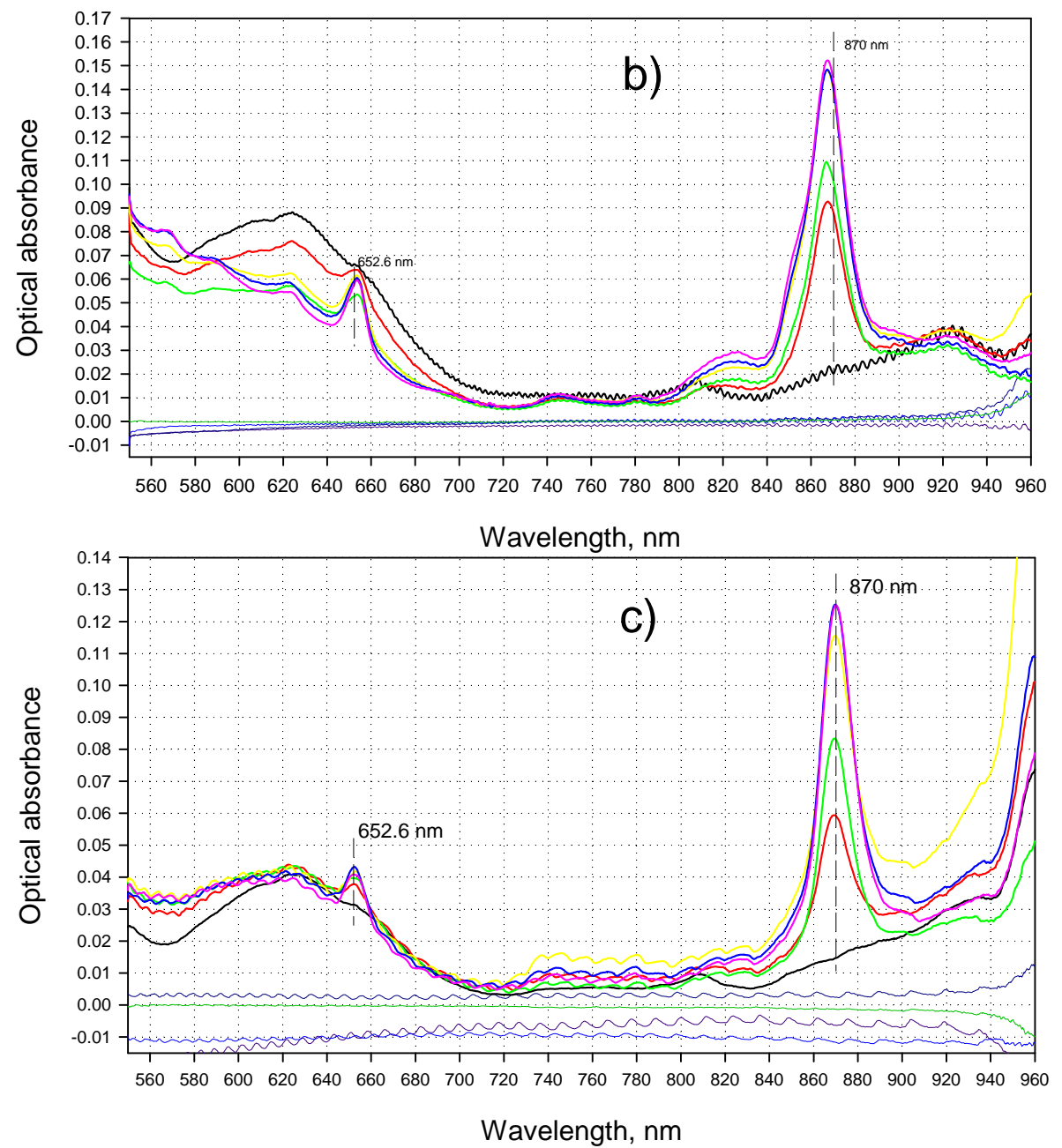

Figure 3.12. $\mathrm{Pu}(\mathrm{VI})$ Spectra in $0.1 \mathrm{M} \mathrm{NaOD}$ a), $0.25 \mathrm{M} \mathrm{NaOD} b)$, and $1 \mathrm{M} \mathrm{NaOD} \mathrm{c}$ ) in the Presence of Carbonate. In all cases, the carbonate concentration varies from $0 \%$ to $100 \%$ with $20 \%$ increments relative to the respective molar concentration of hydroxide for black, red, yellow, green, blue, and pink spectral traces, respectively. The $\mathrm{Pu}(\mathrm{VI})$ concentration is fixed at $8 \mu \mathrm{M}$ for sets a) and c) and at $13 \mu \mathrm{M}$ for set $\mathrm{b}$ ). 
In this study, the effect of carbonate on the spectral features of alkaline Pu(VI) was studied at three constant levels of $\mathrm{NaOD}$. The carbonate concentration was varied in five increments up to the equimolar ratio for the given hydroxide level. The results are presented in Figure 3.12.

The $0.1 \mathrm{M} \mathrm{NaOD}$ data [plot a)] show significant spectral changes after adding the first portion of carbonate up to $0.02 \mathrm{M}$. The most prominent new spectral feature emerges at $865 \mathrm{~nm}$, and at a higher concentration of carbonate, its intensity grows. The peak position gradually shifts to higher energy, and at $0.08 \mathrm{M}$ of carbonate, the peak maximum is at $860 \mathrm{~nm}$. Its molar absorptivity is approximately $30 \mathrm{M}^{-1} \mathrm{~cm}^{-}$. There is a slight decrease in the peak intensity with a further $20 \%$ increase in carbonate concentration. Another evidence of the formation of mixed complexes in this system is a weaker but sharper absorbance band at $653 \mathrm{~nm}$. Its position remains the same regardless of the $\mathrm{CO}_{3}{ }^{2-}$ to $\mathrm{OD}^{-}$ratio.

The $0.25 \mathrm{M} \mathrm{NaOD}$ spectral data [plot b)] show less complex behavior of the major peak in the region of 840 to $890 \mathrm{~nm}$. This peak position is more red shifted $(868 \mathrm{~nm})$ compared with the $0.1 \mathrm{M} \mathrm{NaOD}$ data set, and the peak maximum value does not change as a function of carbonate concentration. It appears that the peak intensity reaches a maximum at $0.20 \mathrm{M}$ of carbonate and does not change further with an additional increase in carbonate concentration to $0.25 \mathrm{M}$. The molar absorptivity of this peak is $23.5 \mathrm{M}^{-1} \mathrm{~cm}^{-1}$. The peak is not quite symmetrical as it contains a weak shoulder at $\sim 855 \mathrm{~nm}$. The secondary peak maximum remains at $653 \mathrm{~nm}$ (no change vs. a $0.1 \mathrm{M} \mathrm{NaOD}$ spectral set).

The 1.0 M NaOD spectral set [plot c)] shows an additional red shift in the major absorbance band of the mixed complex by $2 \mathrm{~nm}$ compared with the $0.25 \mathrm{M} \mathrm{NaOD}$ data. The peak intensity grows more slowly for the same $\mathrm{CO}_{3}{ }^{2-} / \mathrm{OD}$ ratio as it was observed at 4 times lower alkalinity and reaches a maximum value in the 0.8 - to $1.0-\mathrm{M}$ concentration range of carbonate. Its molar absorptivity is $31.3 \mathrm{M}^{-1} \mathrm{~cm}^{-1}$. The secondary peak position remains unchanged at $653 \mathrm{~nm}$, although its intensity is two times less compared with the lower alkalinity experiments.

In summary, all newly observed spectral features indicate that the formation of mixed hydroxyl-carbonate complexes is a complicated process that depends not only on the carbonate to hydroxide ratio but is governed by absolute levels of their concentrations. Evidence of at least three complex species is obtained from spectral data.

For practical applications, the major peak intensity of the mixed complex with a molar absorptivity of $\sim 30$ $\mathrm{M}^{-1} \mathrm{~cm}^{-1}$ may offer a 2.5 times better sensitivity for $\mathrm{Pu}(\mathrm{VI})$ detection in mixed hydroxy-carbonate media. Unfortunately, the peak position in the 860 - to 870 -nm range would require conversion of the analyzed solution to a deuterated medium to allow its detection by LWCC.

\subsection{Pu(V) Calibration and Speciation Experiments in NaOD}

\subsubsection{Preparation and Characterization of $\mathrm{Pu}(\mathrm{V})$ Solution in $14 \mathrm{M}$ of $\mathrm{NaOD}$}

Alkaline solutions of $\mathrm{Pu}(\mathrm{V})$ were first produced via electrochemical reduction of $\mathrm{Pu}(\mathrm{VI})$ in $4 \mathrm{M}$ of $\mathrm{NaOH}$ and spectrally characterized by Bourges (1972). Later, it was shown by Delegard (1987) that the same oxidation state of $\mathrm{Pu}$ in solution can be prepared by a prolonged exposure of the suspension of freshly formed $\mathrm{Pu}(\mathrm{OH})_{4}$ to an aerated solution of $15 \mathrm{M}$ of $\mathrm{NaOH}$. The highest concentration of $\mathrm{Pu}(\mathrm{V})$ that can be 
prepared in this way was found to be $0.884 \mathrm{mM}$. The spectrum of this solution (Figure 3.13 bottom) matched closely the spectrum of $\mathrm{Pu}(\mathrm{V})$ observed by Bourges (1972; shown in the same Figure as the top spectrum). The relative easiness of preparing a $\mathrm{Pu}(\mathrm{V})$ stock solution from $\mathrm{Pu}(\mathrm{IV})$ without using any redox reagents prompted us to study a possibility of $\mathrm{Pu}(\mathrm{V})$ generation in concentrated NaOD. Delegard (1987) also observed that initially homogeneous solutions of $4 \mathrm{mM}$ of $\mathrm{Pu}(\mathrm{VI})$ in $15 \mathrm{M}$ of $\mathrm{NaOH}$ after a few weeks produced a solid phase of $\mathrm{Pu}(\mathrm{IV})$ hydrated oxide, and the concentration of soluble $\mathrm{Pu}$ dropped down to the concentration levels of $\mathrm{Pu}(\mathrm{V})$ found in tests begun by $\mathrm{Pu}(\mathrm{IV})$ nitrate added to $\mathrm{NaOH}$.

However, the solutions with $\mathrm{Pu}(\mathrm{VI})$ addition were not characterized spectrally to identify the oxidation state of $\mathrm{Pu}$ in them. Therefore, a parallel experiment based on $\mathrm{Pu}(\mathrm{VI})$ addition to 14.9 $\mathrm{M}$ of $\mathrm{NaOD}$ was conducted in search of an alternative and possibly quicker way to produce $\mathrm{Pu}(\mathrm{V})$ stock solution for subsequent experiments.
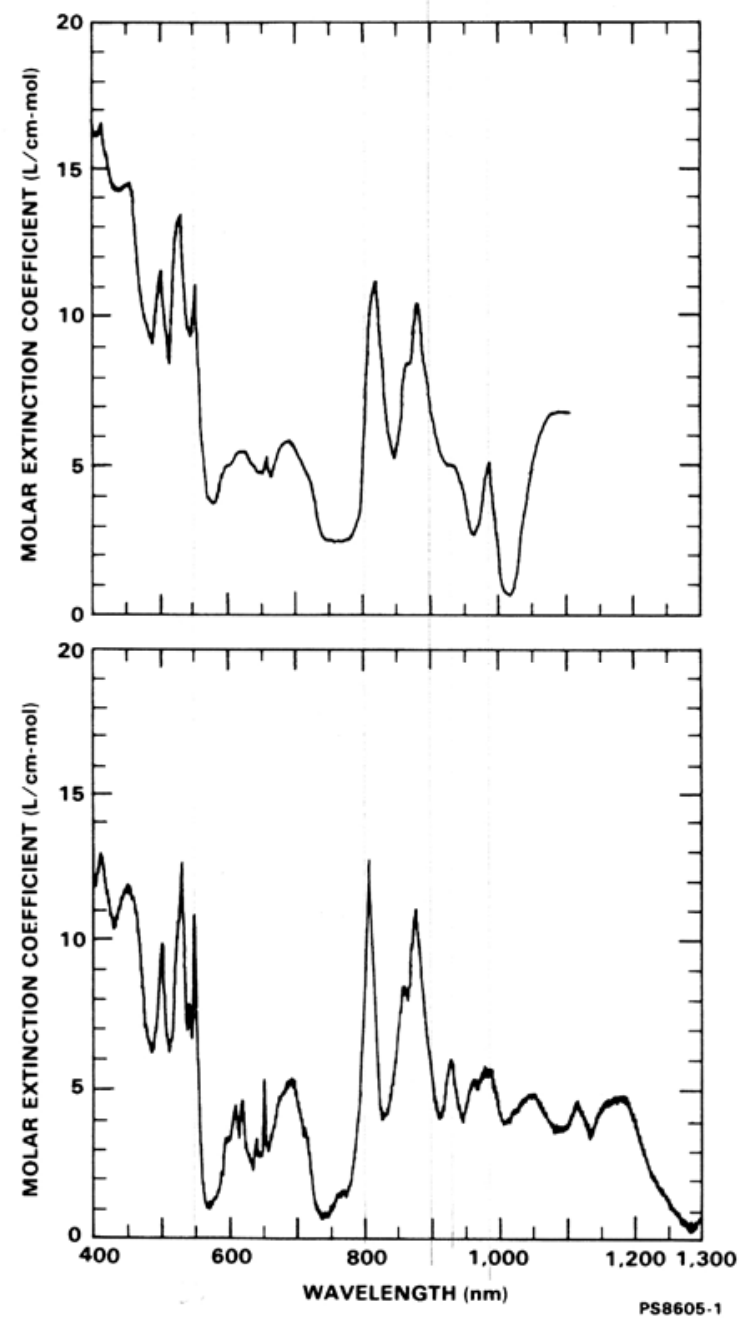

Figure 3.13. Literature Data on $\mathrm{Pu}(\mathrm{V})$ Spectra in Concentrated Sodium Hydroxide. $\mathrm{Pu}(\mathrm{V})$ spectrum in $4 \mathrm{M} \mathrm{NaOH}$ (top) (Bourges 1972) and $15 \mathrm{M} \mathrm{NaOH}$ (bottom) (Delegard 1987).

In the first experiment, $65 \mu \mathrm{L}$ of $18-\mathrm{mM}$ acidic stock solution of $\mathrm{Pu}(\mathrm{IV})$ in $2 \mathrm{M} \mathrm{DNO}_{3}$ was added to $1.1 \mathrm{~mL}$ of $14.9 \mathrm{M} \mathrm{NaOD}$. Simultaneously, $92 \mu \mathrm{L}$ of $10.7 \mathrm{mM} \mathrm{Pu}(\mathrm{VI})$ solution in $0.5 \mathrm{M} \mathrm{DNO}_{3}$ was spiked into the same volume of concentrated NaOD. Both preparations were made directly in 1-cm plastic 
spectrophotometric cells equipped with stir bars, and in both cases, the targeted concentrations of Pu were selected to be close to $1 \mathrm{mM}$ if no precipitation occurs. The cells were sealed to minimize the penetration of $\mathrm{CO}_{2}$ from the atmosphere and its reaction with excess $\mathrm{NaOD}$ to form carbonate. Stirring started just before $\mathrm{Pu}$ solutions were added and continued for 3 days before the first spectral measurement. Both solutions appeared to contain small amounts of colloidal matter of unidentifiable color; therefore, centrifugation was applied to obtain better quality spectra (data not shown). Stirring continued for several weeks with periodical interruption for centrifugation and spectral measurement. The first signs of characteristic peaks of $\mathrm{Pu}(\mathrm{V})$ at 620, 653, 809, 877, and $930 \mathrm{~nm}$ were detected after 1 week of stirring. The stirring-centrifugation-spectral measurement-reagitation-stirring cycle was repeated several more times until no statistically significant difference between peak intensities of $\mathrm{Pu}(\mathrm{V})$ in both solutions were found after 15 and 20 days of observation. After that, the solutions were filtered through a $0.45-\mu \mathrm{m}$ Supor (polyethersulfone; Pall Corporation) membrane, and their spectra were measured multiple times to improve the signal-to-noise ratio. The results of these measurements are shown in Figure 3.14. One can see that both spectra look very similar to each other, and their peaks' positions, shapes, and relative intensities are in good correspondence with the spectrum of $\mathrm{Pu}(\mathrm{V})$ in $15 \mathrm{M} \mathrm{NaOD}$ reported by Delegard (1987; Figure 3.13).

Assuming that the molar absorptivities found in $15 \mathrm{M} \mathrm{NaOH}$ can be applied to $14 \mathrm{M} \mathrm{NaOD}$ solutions in this study, the calculated concentrations of $\mathrm{Pu}(\mathrm{V})$ were estimated as $0.53 \mathrm{mM}$ and $0.49 \mathrm{mM}$ for the $\mathrm{Pu}(\mathrm{IV})$ and $\mathrm{Pu}(\mathrm{VI})$ samples, respectively, based on the $809-\mathrm{nm}$ peak. LSC analysis, however, returned somewhat higher values $[0.81 \mathrm{mM}$ and $0.88 \mathrm{mM}$ for the $\mathrm{Pu}(\mathrm{IV})$ and $\mathrm{Pu}(\mathrm{VI})$ solutions respectively]. This discrepancy can be explained by incomplete spectral resolution of sharp $\mathrm{Pu}(\mathrm{V})$ peaks in spectral measurements using the Ocean Optics spectrophotometer. The fact that $\mathrm{Pu}(\mathrm{V})$ produced using $\mathrm{Pu}(\mathrm{VI})$ as the starting material, has an $\sim 5 \%$ less-intense peak at $809 \mathrm{~nm}$ but $8 \%$ more plutonium concentration compared with $\mathrm{Pu}(\mathrm{IV}) \rightarrow \mathrm{Pu}(\mathrm{V})$ conversion might also indicate that not all $\mathrm{Pu}(\mathrm{VI})$ was converted to $\mathrm{Pu}(\mathrm{V})$ in this sample.

In all subsequent calibration and speciation experiments, $\mathrm{Pu}(\mathrm{V})$ stock prepared by spontaneous oxidation of $\mathrm{Pu}(\mathrm{IV})$ was used to prepare diluted solutions of $\mathrm{Pu}(\mathrm{V})$.

It was of interest to compare the original spectrum of undiluted $\mathrm{Pu}(\mathrm{V})$ stock in $14 \mathrm{M} \mathrm{NaOD}$ measured with a 1-cm cell (Figure 3.14 a) with the spectrum of a 34-fold diluted sample of the same solution at a $1 \mathrm{M} \mathrm{NaOD}$ concentration measured by LWCC. Figure 3.15 shows results of this comparison. It can be seen that many spectral features observed at higher alkalinity remain mostly unchanged in $1 \mathrm{M} \mathrm{NaOD}$. There are two spectral regions where the changes are more noticeable: a) 670- to 740-nm region where an $\sim 12-\mathrm{nm}$ red shift of the broad absorbance band of $\mathrm{Pu}(\mathrm{V})$ initially at $682 \mathrm{~nm}$ is observed with an increasing concentration of hydroxide; b) 910- to 940-nm region where the 930-nm peak of $\mathrm{Pu}(\mathrm{V})$ undergoes an $\sim 6-$ to 7-nm blue shift as the NaOD concentration grows. These minor changes indicate that the coordination sphere of the $\mathrm{Pu}^{\mathrm{V}} \mathrm{O}_{2}{ }^{+}$cation is practically saturated with hydroxide ligands already in $1 \mathrm{M}$ NaOD solution and further 14-fold increase in deuteroxide concentration causes only a minor equilibrium shift from $\mathrm{PuO}_{2}(\mathrm{OD})_{\mathrm{n}-1}{ }^{\mathrm{n}-2}$ to $\mathrm{PuO}_{2}(\mathrm{OD})_{\mathrm{n}}{ }^{\mathrm{n}-1}$ species, where $\mathrm{n}$ is the number of deuteroxide ligands around the metal center at the higher $\mathrm{OD}^{-}$concentration. The spectrum of $\mathrm{Pu}(\mathrm{V})$ measured with LWCC detection represents the first spectrum of this oxidation state of $\mathrm{Pu}$ measured at such a low $\mathrm{Pu}(\mathrm{V})$ concentration in 1 $\mathrm{M} \mathrm{NaOD}$. 


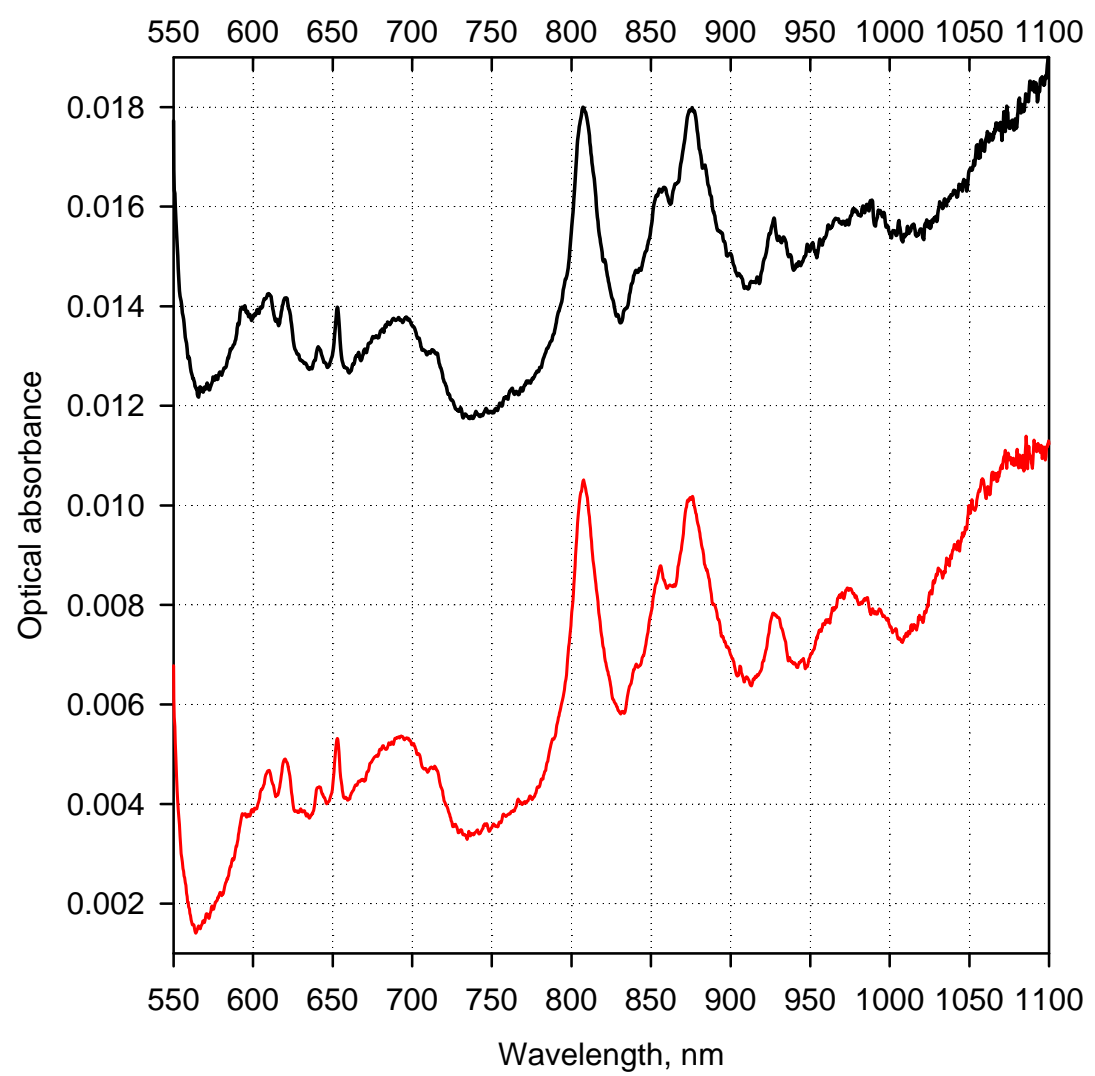

Figure 3.14. $\mathrm{Pu}$ Spectra in $14 \mathrm{M}$ NaOD 20 Days After Adding Acidic Pu(IV) (red trace) and $\mathrm{Pu}(\mathrm{VI})$ (black trace) to an Excess of 14.9 M NaOD. Both solutions were filtered through a $0.45-\mu \mathrm{m}$ Supor membrane filter to remove insoluble $\mathrm{Pu}$ phases. The spectra represent the averages of 10 individual scans. A 1-cm plastic cell was used for measurements, and $14 \mathrm{M}$ of $\mathrm{NaOD}$ was used as a blank solution. Pu concentrations in solutions that started from $\mathrm{Pu}(\mathrm{IV})$ and $\mathrm{Pu}(\mathrm{VI})$, which were determined by LSC counting, are $0.81 \mathrm{mM}$ and $0.88 \mathrm{mM}$, respectively.

\subsection{2 $\mathrm{Pu}(\mathrm{V})$ Calibration and Speciation Experiments in NaOD}

\section{Chromate-Free Medium.}

Preparing diluted series of $\mathrm{Pu}(\mathrm{V})$ solutions in $0.25 \mathrm{M}$ and $1 \mathrm{M} \mathrm{NaOD}$ required more careful planning compared with $\mathrm{Pu}(\mathrm{VI})$ calibration experiments due to a much lower concentration of $\mathrm{Pu}(\mathrm{V})$ stock available and the very high alkalinity of this stock. To maintain constant alkalinity through the calibration series, the concentration of $\mathrm{NaOD}$ in cold solutions before spiking them with $\mathrm{Pu}(\mathrm{V})$ was individually adjusted for each concentration point of $\mathrm{Pu}(\mathrm{V})$. The $1 \mathrm{M} \mathrm{NaOD}$ series was studied first to take advantage of a better stability of $\mathrm{Pu}(\mathrm{V})$ solutions, which are prone to disproportionation at a sodium hydroxide concentration lower than $8 \mathrm{M}$. Similar to the $\mathrm{Pu}(\mathrm{VI})$ calibration experiments, two series of solutions were prepared the same day with the first series spectrally measured within the first 60 to 90 minutes after adding $\mathrm{Pu}(\mathrm{V})$, and the second series was stored for 3 to 4 days and measured after that. Figure 3.16 shows spectral data from this testing along with respective calibration plots based on the net signal intensity of the two most characteristic peaks of $\mathrm{Pu}(\mathrm{V})$ at 653 and $809 \mathrm{~nm}$ as a function of the 
initially added $\mathrm{Pu}(\mathrm{V})$ concentration. The freshly prepared series [plots a) and b)] exhibit all characteristic spectral features of $\mathrm{Pu}(\mathrm{V})$ up to the highest concentration of $\mathrm{Pu}(\mathrm{V})$ of $23.6 \mu \mathrm{M}$ and excellent linearity of the calibration plots for both peaks of $\mathrm{Pu}(\mathrm{V})$. This proves that all $\mathrm{Pu}$ is present in solution as $\mathrm{Pu}(\mathrm{V})$, and no disproportionation or other redox processes accompanied by precipitation of lower oxidation states of $\mathrm{Pu}$ occurs under these conditions. The 4-day-old series, however, shows a very interesting redox behavior of $\mathrm{Pu}$ at the highest concentration of initially added $\mathrm{Pu}(\mathrm{V})$. As can be seen by comparing the blue and pink spectral traces in plot c), there is a sudden drop in the intensities of $\mathrm{Pu}(\mathrm{V})$ peaks while the newly emerged broad absorbance band at $625 \mathrm{~nm}$ is clearly attributable to $\mathrm{Pu}(\mathrm{VI})$ (compare this spectrum with spectral sets of $\mathrm{Pu}(\mathrm{VI})$ shown in Figure 3.16). The LSC analysis of total $\mathrm{Pu}$ concentration indicates that only $11 \mu \mathrm{M}(46 \%$ of initially added $\mathrm{Pu})$ remains in solution. This observation is consistent with the disproportionation of $\mathrm{Pu}(\mathrm{V})$ at a higher concentration. It is not clear, though, why this process is so concentration sensitive because going down in $\mathrm{Pu}(\mathrm{V})$ concentration just two times (blue trace) preserves most $\mathrm{Pu}$ as $\mathrm{Pu}(\mathrm{V})$. One possible explanation of this effect may involve the precipitation of $\mathrm{Pu}(\mathrm{OH})_{4}$ as one of the disproportionation products that forms in solution initially as a soluble anionic complex of $\mathrm{Pu}(\mathrm{IV})$ and precipitates out with time as its concentration reaches some critical value. More research is needed to explore the kinetics and thermodynamics of this process.

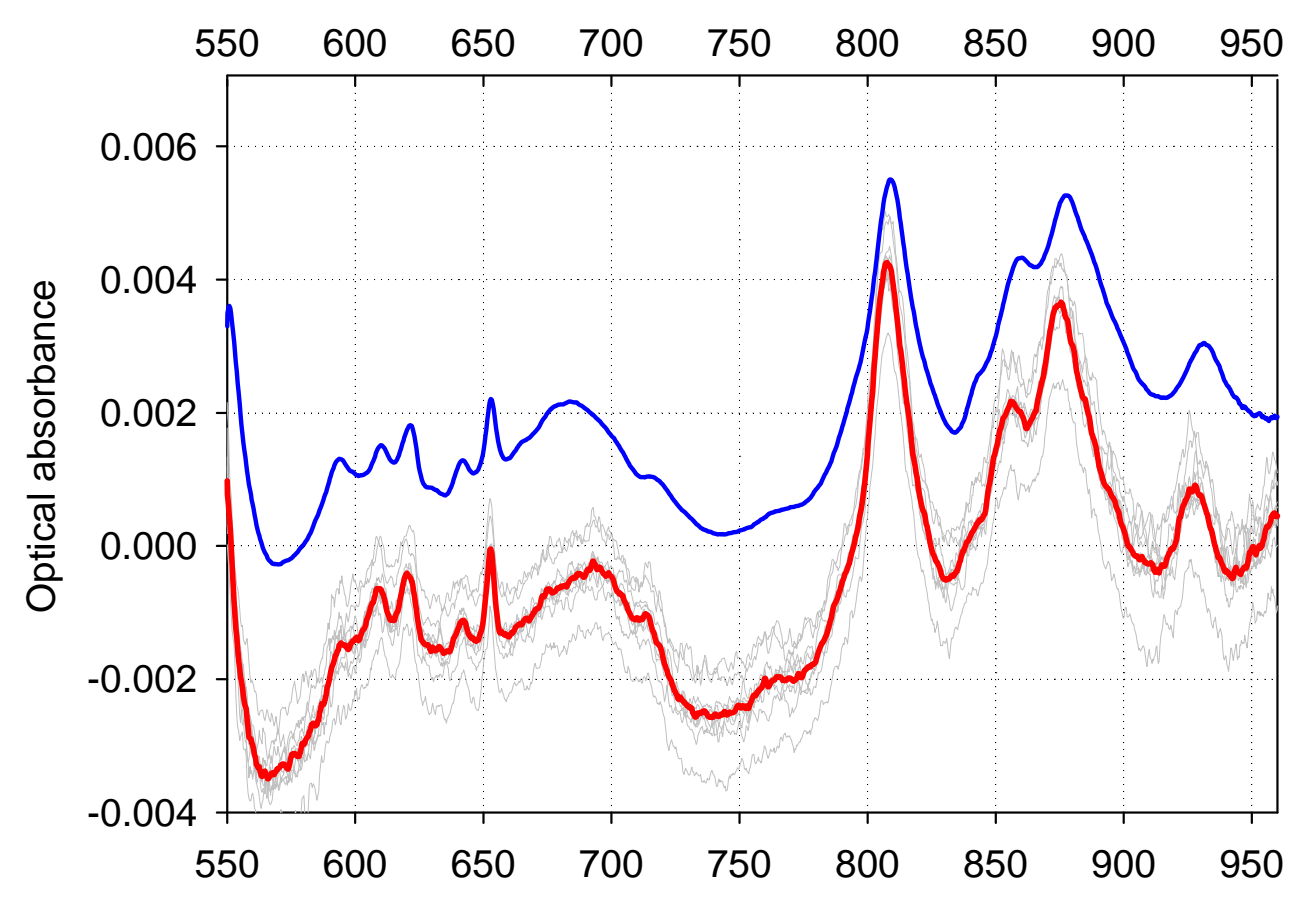

Figure 3.15. Comparison of the Stock Solution of $0.811 \mathrm{mM} \mathrm{Pu}(\mathrm{V})$ in $14 \mathrm{M} \mathrm{NaOD}$ Measured with 1-cm cell (red trace) with 23.6- $\mu \mathrm{M} \mathrm{Pu}(\mathrm{V})$ Solution Spectrum in $1 \mathrm{M}$ NaOD Measured by LWCC (blue trace). The latter spectrum was scaled down 35 times to fit the vertical scale. Gray traces around red spectrum are single scans used for averaging to improve the signal-tonoise ratio in the $\mathrm{Pu}(\mathrm{V})$ stock solution spectrum. 

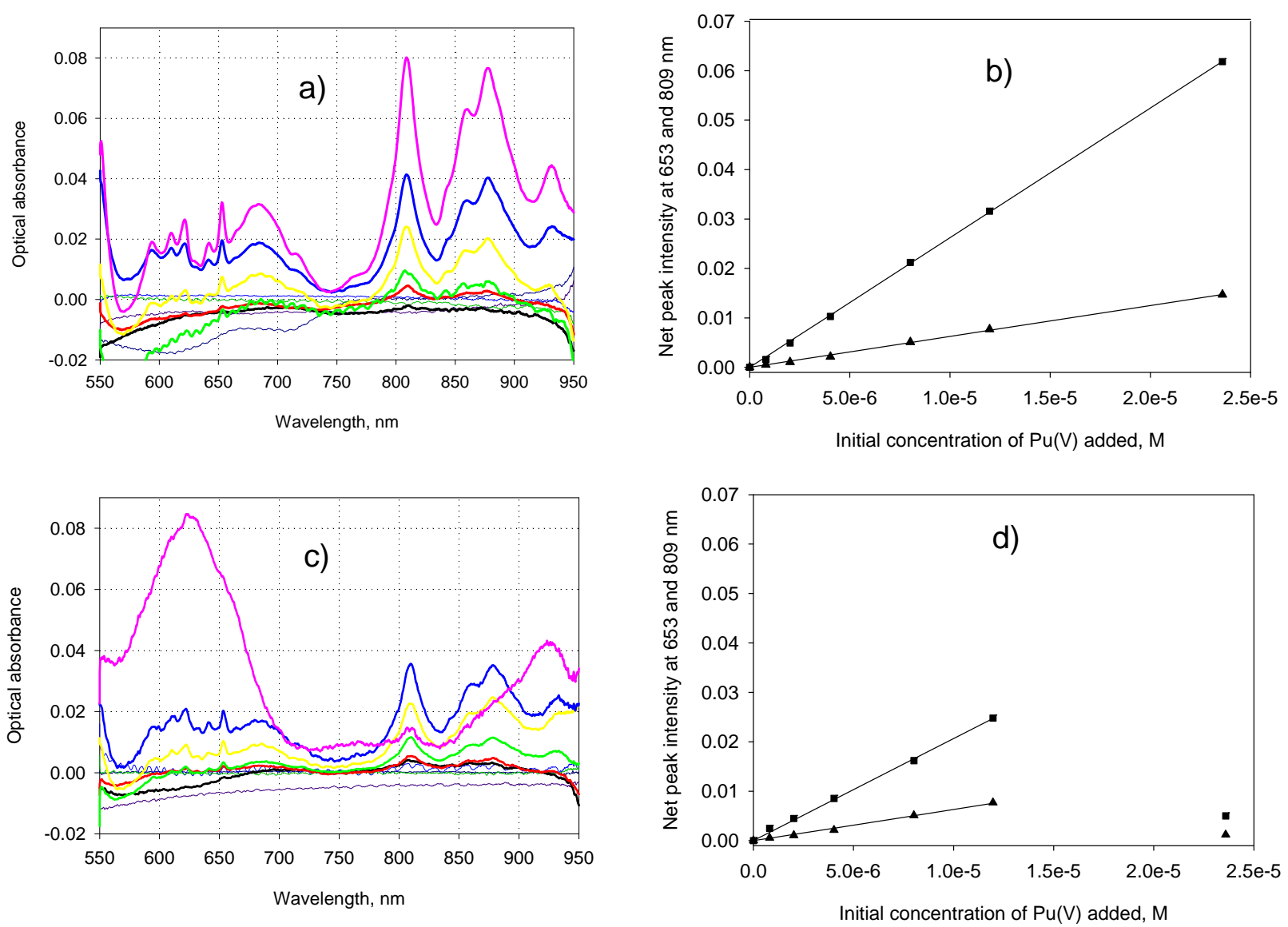

Figure 3.16. Calibration Experiments with $\mathrm{Pu}(\mathrm{V})$ in $1 \mathrm{M} \mathrm{NaOD}$. Initial concentrations of $\mathrm{Pu}(\mathrm{V})$ are $0.81,2,4,8,12$, and $24 \mu \mathrm{M}$ for the black, red, green, yellow, blue, and pink spectral traces, respectively. Freshly prepared series a) and b); 4 days between solution preparation and measurement c) and d). In plots b) and d), triangles denote the net peak intensity at $653 \mathrm{~nm}$ while squares refer to the peak at $809 \mathrm{~nm}$.

Similar experiments were performed at a $0.25 \mathrm{M}$ concentration of $\mathrm{NaOD}$. In this system, even for freshly prepared and measured series of samples, significant negative deviations between the total initial concentration of $\mathrm{Pu}(\mathrm{V})$ added and observable peak intensities of $\mathrm{Pu}(\mathrm{V})$ were found [Figure 3.17 a) and b)]. The magnitude of this effect becomes more pronounced at higher total $\mathrm{Pu}$ concentration. A limited linearity of the calibration curve is observed for the first two additions of $\mathrm{Pu}(\mathrm{V})$ stock. Spectral features of the last three additions of $\mathrm{Pu}(\mathrm{V})$ clearly indicate the presence of $\mathrm{Pu}(\mathrm{VI})$ in the solutions. Total concentrations of soluble $\mathrm{Pu}$ (by LSC analysis) in this series indicate that the percentage of remaining soluble $\mathrm{Pu}$ decreases as the initially created concentration of Pu increases. These results are consistent with the redox transformation of $\mathrm{Pu}(\mathrm{V})$ into higher $[\mathrm{Pu}(\mathrm{VI})]$ and lower $[\mathrm{Pu}(\mathrm{IV})]$ oxidation states at this alkalinity. The aging of $\mathrm{Pu}(\mathrm{V})$ solutions in $0.25 \mathrm{M} \mathrm{NaOD}$ for 3 days [Figure $3.17 \mathrm{c}$ ) and d)] shows significant additional decreases of the $\mathrm{Pu}(\mathrm{V})$ spectral intensities to very low levels, regardless of the initial level of $\mathrm{Pu}(\mathrm{V})$ concentration. The spectral intensities of $\mathrm{Pu}(\mathrm{VI})$ peaks remain approximately at the same level as found in the freshly spiked and measured series. Soluble Pu levels were found to go further down by $-25 \%, 51 \%, 16 \%, 10 \%, 9 \%$, and $1 \%$ compared with the freshly added $\mathrm{Pu}(\mathrm{V})$ series (the negative value 
of $-25 \%$ is most likely associated with pipetting irreproducibility for the $1^{\text {st }}$ concentration point). This drop is consistent with a decrease in solubility of $\mathrm{Pu}(\mathrm{IV})$ with time.
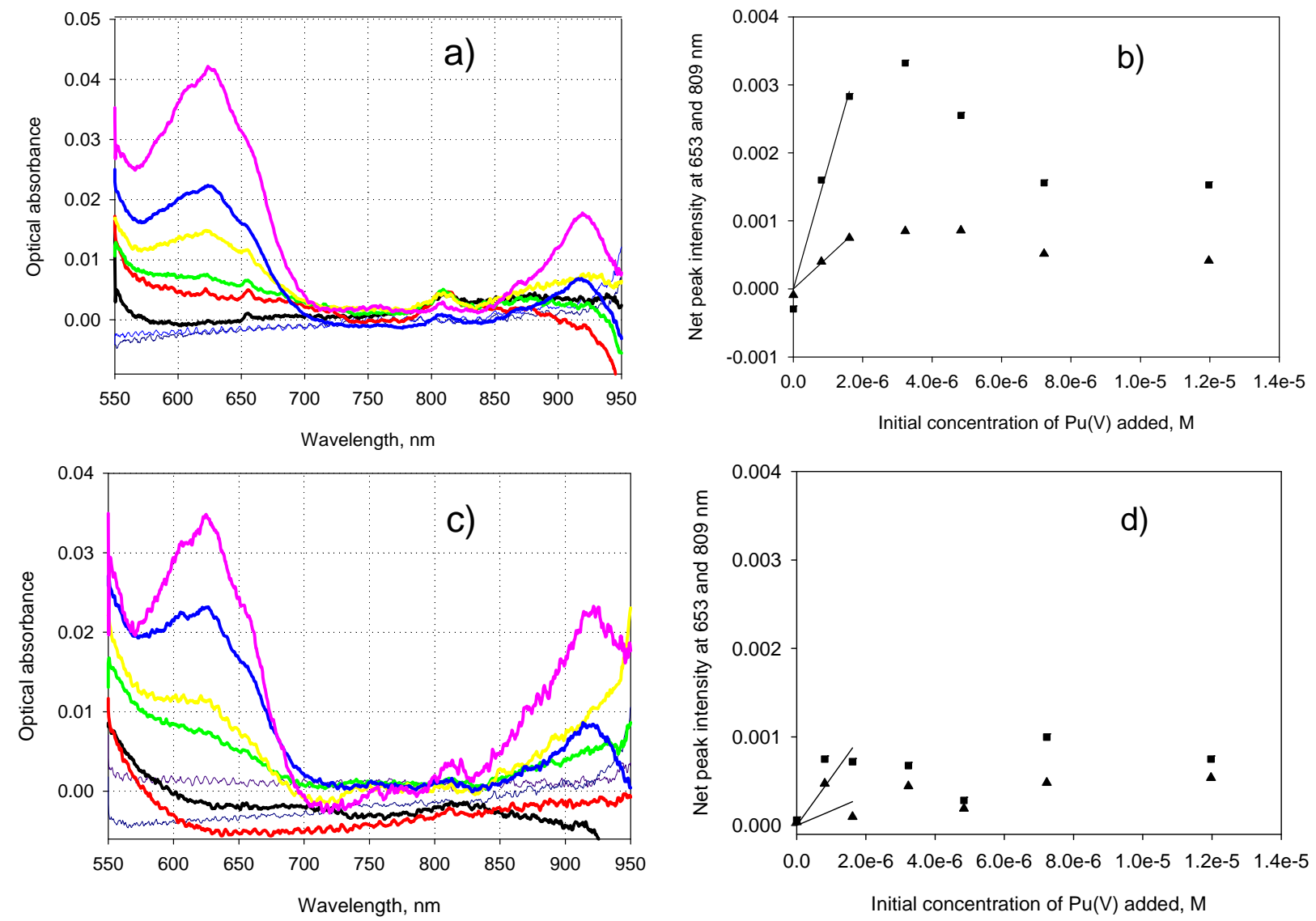

Figure 3.17. Calibration Experiment with $\mathrm{Pu}(\mathrm{V})$ in $0.25 \mathrm{M} \mathrm{NaOD}$. Initial concentrations of $\mathrm{Pu}(\mathrm{V})$ are $0.81,1.6,3.2,4.8,7.2$, and $12 \mu \mathrm{M}$ for the black, red, green, yellow, blue, and pink spectral traces, respectively. Freshly prepared series a); 3 days between solution preparation and measurement $b$ ). In plots $b$ ) and d), triangles denote the net peak intensity at $653 \mathrm{~nm}$ while squares refer to peak at $809 \mathrm{~nm}$.

\section{Effect of Chromate on $\mathrm{Pu}(\mathrm{V})$ Redox Speciation}

As pentavalent $\mathrm{Pu}$ represents an intermediate oxidation state between $\mathrm{Pu}(\mathrm{IV})$ and $\mathrm{Pu}(\mathrm{VI})$, its redox speciation in alkaline solution may be affected not only by levels of $\mathrm{NaOD}$, but also by the presence of other redox reagents. Chromate is expected to be present in alkaline solutions as a soluble product of the oxidation of $\mathrm{Cr}$ (III) phases present in Hanford tank sludge after their oxidative leaching with permanganate. $\mathrm{Cr}(\mathrm{VI})$ is known to be a moderately strong oxidizer in an acidic medium where it is present as dichromate, but its oxidation ability in alkaline solutions is not well explored. Therefore, it was of interest to investigate $\mathrm{Pu}(\mathrm{V})$ redox behavior in $0.25 \mathrm{M}$ and $1 \mathrm{M} \mathrm{NaOD}$ media in the presence of $\mathrm{Cr}(\mathrm{VI})$. The experiments were executed in the same manner as those conducted in the Cr(VI) freealkaline medium. $\mathrm{Cr}(\mathrm{VI})$ in all four experiments described in this section was fixed at $50 \mathrm{mM}$. 
The $1 \mathrm{M} \mathrm{NaOD}$ spectral and calibration series with freshly measured samples (Figure $3.18 \mathrm{a}$ ) and b) below) show practically no difference compared with the $\mathrm{Cr}(\mathrm{VI})$-free experiment described above. All $\mathrm{Pu}$ added as $\mathrm{Pu}(\mathrm{V})$ remains as $\mathrm{Pu}(\mathrm{V})$ under these conditions. A slight deviation of the $\mathrm{Pu}(\mathrm{V})$ signal intensity for the $809 \mathrm{~nm}$ peak is probably related to increased waveform noise level in the pink spectrum (plot a), which distorted the peak shape and intensity. Allowing more time for the $\mathrm{Cr}(\mathrm{VI})$ and $\mathrm{Pu}(\mathrm{V})$ to interact with each other in the same solution [Figure $3.18 \mathrm{c}$ ) and d)] does not lead to any additional conversion of $\mathrm{Pu}(\mathrm{V})$ to $\mathrm{Pu}(\mathrm{VI})$ by the action of $\mathrm{Cr}(\mathrm{VI})$. The level of the $\mathrm{Pu}(\mathrm{VI})$ signal observed in the most concentrated solution corresponds to the one observed in the chromate-free experiment and can be explained solely by partial disproportionation of $\mathrm{Pu}(\mathrm{V})$. Therefore, it can be concluded that $\mathrm{Cr}(\mathrm{VI})$ does not show any oxidizing effect with respect to $\mathrm{Pu}(\mathrm{V})$ in $1 \mathrm{M} \mathrm{NaOD}$.

Experiments in $0.25 \mathrm{M} \mathrm{NaOD}$ in the presence of $50 \mathrm{mM} \mathrm{Cr}(\mathrm{VI})$ with freshly spiked $\mathrm{Pu}(\mathrm{V})$ [Figure 3.19 a) and b)] show very similar behavior of $\mathrm{Pu}(\mathrm{V})$ to the respective $\mathrm{Cr}(\mathrm{VI})$-free series.

The 3-day-old series at the same alkalinity [Figure $3.19 \mathrm{c}$ ) and d)] shows approximately the same levels of residual $\mathrm{Pu}(\mathrm{V})$ as in the $\mathrm{Cr}(\mathrm{VI})$-free series, but practically no $\mathrm{Pu}(\mathrm{VI})$, which was spectrally observed before as a broad spectral feature with a maximum at $625 \mathrm{~nm}$ [compare Figure $3.17 \mathrm{c}$ and Figure $3.19 \mathrm{c}$ )]. For technical reasons (an emergency response to fire alarm), the solution with the highest concentration of added $\mathrm{Pu}(\mathrm{V})$ was not spectrally measured. No explanation of the absence of a $\mathrm{Pu}(\mathrm{VI})$ signal in the $\mathrm{Cr}(\mathrm{VI})$ tests can be offered at this time. It is possible that the $\mathrm{Cr}(\mathrm{VI})$ used in this work contained a trace amount of $\mathrm{Cr}(\mathrm{III})$, which acted slowly as a three-electron reductant to convert the $\mathrm{Pu}(\mathrm{VI})$ that was initially formed via the disproportionation of $\mathrm{Pu}(\mathrm{V})$ to practically insoluble $\mathrm{Pu}(\mathrm{IV})$. Even a $0.01 \%$ admixture of $\mathrm{Cr}(\mathrm{III})$ in a $50 \mathrm{mM} \mathrm{Cr}(\mathrm{VI})$ solution [which would correspond to $5 \mu \mathrm{M}$ of $\mathrm{Cr}$ (III) in the solution] would be sufficient to seriously perturb the yield of $\mathrm{Pu}(\mathrm{VI})$ in this system with a total initial $\mathrm{Pu}$ concentration below $20 \mu \mathrm{M}$. The results of determining the total soluble $\mathrm{Pu}$ concentration in this series confirm a significant drop in $\mathrm{Pu}$ concentration for all samples compared with the chromate-free series.

All results obtained in the course of the eight calibration experiments described above are summarized in Table 3.3 with an emphasis on the linearity ranges, slopes, and detection limits.

\subsection{3 $\mathrm{Pu}(\mathrm{V})$ Spectra in the Presence of Carbonate at Constant Concentration of Hydroxide}

A significant effect of the presence of hydroxide on the optical absorbance spectrum of the triscarbonate complex of $\mathrm{Pu}(\mathrm{V})$ in concentrated $\mathrm{Na}_{2} \mathrm{CO}_{3}$ solution was noted by Varlashkin and co-workers (1984b). This effect can be explained by the formation of mixed hydroxy-carbonate complexes of $\mathrm{Pu}(\mathrm{V})$. The most pronounced spectral changes were found in the 640- to 1000-nm range of the spectrum where a number of absorbance peaks of $\mathrm{Pu}^{\mathrm{V}} \mathrm{O}_{2}\left(\mathrm{CO}_{3}\right)_{3}{ }^{5-}$ changed their peak positions and intensities as one or more carbonates were displaced by a growing hydroxide concentration. Unfortunately, the authors did not try (or were limited by solubility problems) to study $\mathrm{Pu}(\mathrm{V})$ speciation in the presence of carbonate, starting from a purely hydroxide medium, and in their experiments, the $\mathrm{OH}^{-} / \mathrm{CO}_{3}{ }^{2-}$ ratio was at or below 2.29:2. In this project, it was considered important to study redox and complexation speciation of $\mathrm{Pu}(\mathrm{V})$ in an alkaline media in the presence of carbonate for two reasons. First, the presence of carbonate may affect the redox speciation of $\mathrm{Pu}(\mathrm{V})$ with its partial conversion to other oxidation states, which in turn may impact the solubility of Pu. Second, in searching for more intense and clearly defined spectral features of 
$\mathrm{Pu}(\mathrm{V})$ in an alkaline medium, the presence or artificial addition of carbonate could be beneficial to improve the sensitivity of its detection by optical absorbance spectroscopy.

In this study [similar to $\mathrm{Pu}(\mathrm{VI})$ speciation in a mixed hydroxy-carbonate medium, Section 3.4.3], the effect of carbonate on the spectral features of alkaline $\mathrm{Pu}(\mathrm{V})$ was studied at two constant levels of NaOD. The carbonate concentration was varied in 5 increments up to the equimolar ratio for the given hydroxide level. The results are presented in Figure 3.20.
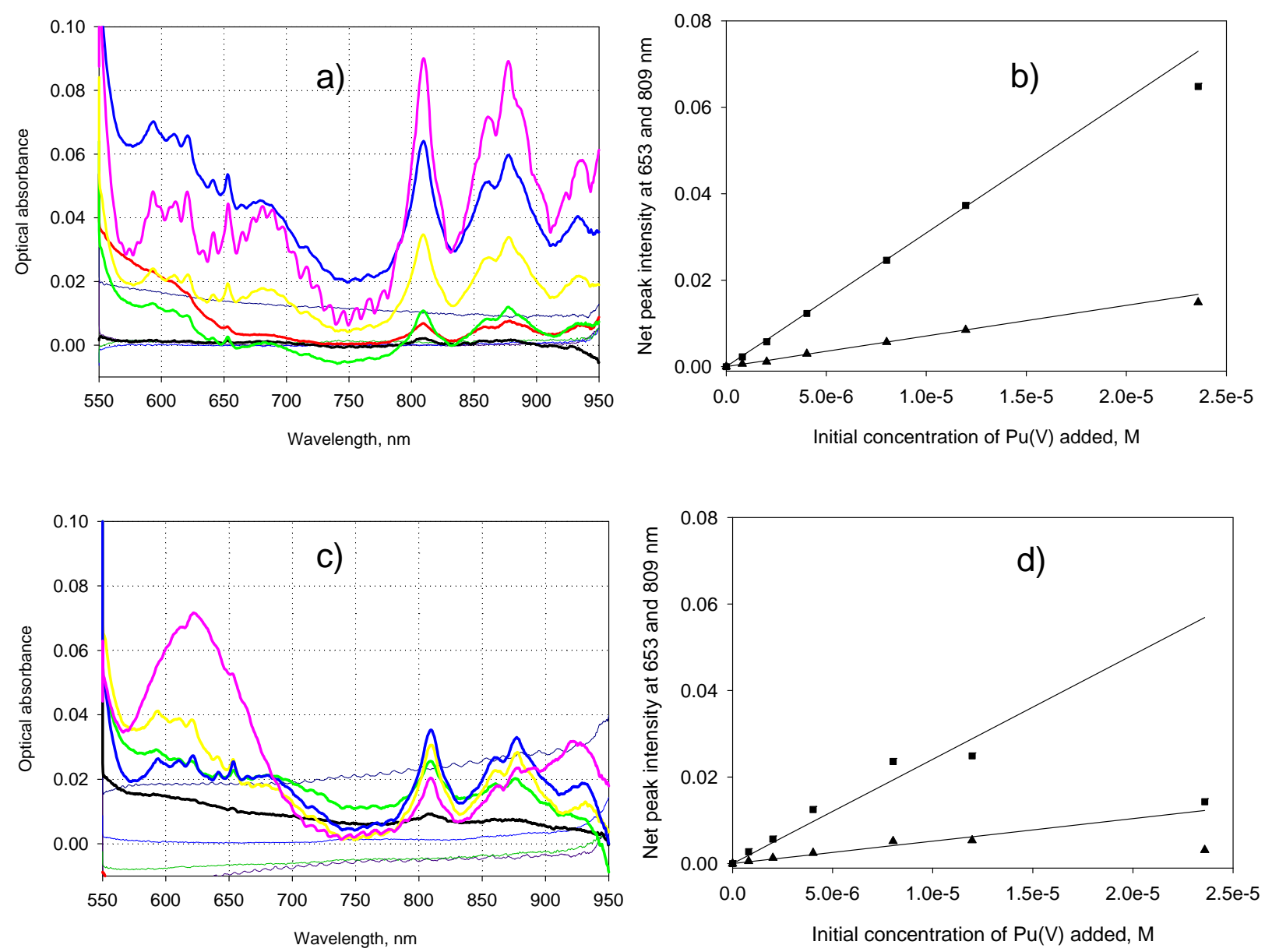

Figure 3.18. Calibration Experiments with $\mathrm{Pu}(\mathrm{V})$ in $1 \mathrm{M} \mathrm{NaOD}$ in the Presence of $50 \mathrm{mM}$ Chromate. Freshly prepared series a); 3 days between solution preparation and measurement $b$ ). Initial concentrations of $\mathrm{Pu}(\mathrm{V})(0.81,2,4,8,12$, and $24 \mu \mathrm{M})$ are the same as those indicated in caption to Figure 3.16. 

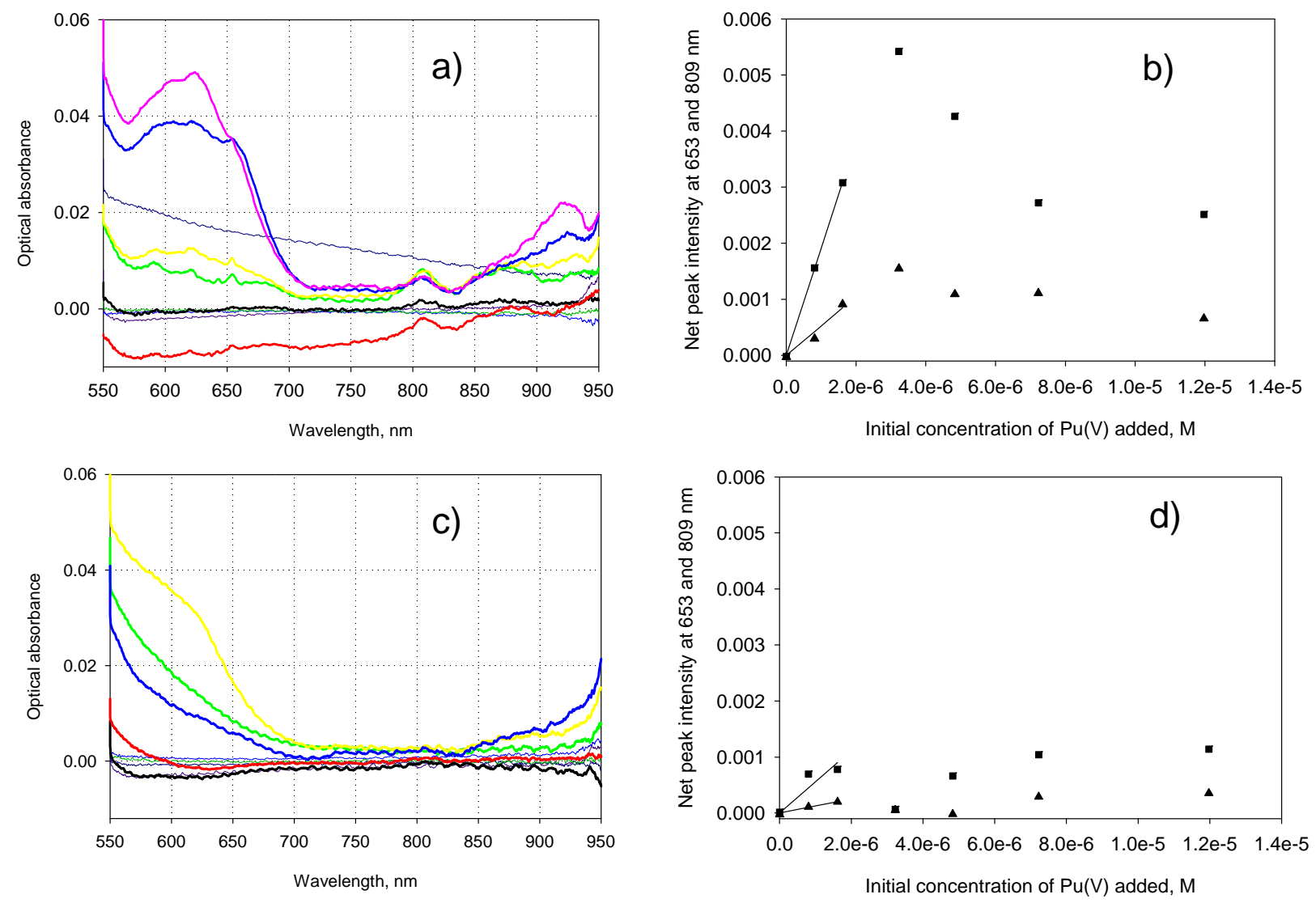

Figure 3.19. Calibration Experiments with $\mathrm{Pu}(\mathrm{V})$ in $0.25 \mathrm{M} \mathrm{NaOD}$ in the Presence of $50 \mathrm{mM}$ Chromate. Freshly prepared series a); 3 days between solution preparation and measurement $b$ ).

At the $1 \mathrm{M} \mathrm{NaOD}$ concentration [plot b)], the carbonate-free spectrum (black trace) shows that $\mathrm{Pu}(\mathrm{V})$ is the only oxidation state in solution that is consistent with previously discussed results on $\mathrm{Pu}(\mathrm{V})$ stability up to 3 days at this concentration of $\mathrm{Pu}(\mathrm{V})$. The very first addition of carbonate induces significant spectral changes, which progress further as the carbonate concentration grows. The most sensitive range of the spectrum of $\mathrm{Pu}(\mathrm{V})$ to the presence of carbonate is the 720- to 770-nm where a new peak at $\sim 735$ $\mathrm{nm}$ becomes clearly visible, even at the very first addition of carbonate. The major peak of $\mathrm{Pu}(\mathrm{V})$ at $809 \mathrm{~nm}$ also shows significant changes as it red shifts to $822 \mathrm{~nm}$ as result of complexation with carbonate, but no intensification of the new absorbance band occurs in this case. Another very characteristic band of $\mathrm{Pu}(\mathrm{V})$ at $653 \mathrm{~nm}$ gets $\sim 2.5$ times more intense at the one-to-one $\mathrm{OD}^{-}: \mathrm{CO}_{3}{ }^{2-}$ molar ratio. Spectral analysis does not give any indication of the conversion of $\mathrm{Pu}(\mathrm{V})$ species to the $\mathrm{Pu}(\mathrm{VI})$ complex, which should be clearly visible as a separate peak at $870 \mathrm{~nm}$ even in case of the partial conversion of $\mathrm{Pu}(\mathrm{V})$ to $\mathrm{Pu}(\mathrm{VI})$. 
Table 3.3. Summary of Calibration Experiments with $\mathrm{Pu}(\mathrm{V})$ in $0.25 \mathrm{M}$ and $1 \mathrm{M} \mathrm{NaOD}$

\begin{tabular}{|c|c|c|c|c|c|c|c|}
\hline \multicolumn{2}{|c|}{ Medium } & $\begin{array}{c}\text { Concentration } \\
\text { Range, } \mu \mathrm{M}\end{array}$ & $\begin{array}{l}\text { Solutions } \\
\text { Age, hr }\end{array}$ & $\begin{array}{l}\text { Pu(V) Peak } \\
\text { Used for } \\
\text { Calibration, } \\
\text { nm }\end{array}$ & $\begin{array}{c}\text { Calibration } \\
\text { Curve } \\
\text { Linearity }^{(a)} \\
\mathbf{R}^{2}\end{array}$ & Slope, $\mathbf{M}^{-1}$ & $\begin{array}{c}\text { Detection } \\
\text { Limit, } \mu \mathrm{M}\end{array}$ \\
\hline \multirow{8}{*}{$\begin{array}{l}1 \mathrm{M} \\
\mathrm{NaOD}\end{array}$} & \multirow{4}{*}{ No $\mathrm{Cr}(\mathrm{VI})$} & \multirow{4}{*}{$0.81-23.6$} & \multirow{2}{*}{$1.5 \pm 0.5$} & 653 & $0.999_{2}(6)$ & $624 \pm 7$ & 0.24 \\
\hline & & & & 809 & $0.999_{9}(6)$ & $2620 \pm 14$ & 0.38 \\
\hline & & & \multirow{2}{*}{$96 \pm 3$} & 653 & $0.999_{5}(5)$ & $480 \pm 12$ & 0.054 \\
\hline & & & & 809 & $0.998_{8}(5)$ & $2020 \pm 34$ & 0.36 \\
\hline & \multirow{4}{*}{$\begin{array}{l}50 \mathrm{mM} \\
\mathrm{Cr}(\mathrm{VI})\end{array}$} & \multirow{4}{*}{$0.81-23.6$} & \multirow{2}{*}{$1.5 \pm 0.5$} & 653 & $0.999_{1}(5)$ & $709 \pm 10$ & 0.19 \\
\hline & & & & 809 & $0.999_{7}(5)$ & $3090 \pm 20$ & 0.33 \\
\hline & & & \multirow{2}{*}{$72 \pm 3$} & 653 & $0.967(5)$ & $521 \pm 43$ & 0.59 \\
\hline & & & & 809 & $0.969(5)$ & $2410 \pm 190$ & 0.13 \\
\hline \multirow{8}{*}{$\begin{array}{l}0.25 \mathrm{M} \\
\mathrm{NaOD}\end{array}$} & \multirow{4}{*}{ No Cr(VI) } & \multirow{4}{*}{$0.81-11.9$} & \multirow{2}{*}{$1.5 \pm 0.5$} & 653 & $0.988(2)$ & $470 \pm 37$ & 0.71 \\
\hline & & & & 809 & $0.989(2)$ & $1800 \pm 130$ & 0.40 \\
\hline & & & \multirow{2}{*}{$72 \pm 3$} & 653 & $0.379(2)$ & $170 \pm 150$ & 1.7 \\
\hline & & & & 809 & $0.884(2)$ & $540 \pm 140$ & 1.3 \\
\hline & \multirow{4}{*}{$\begin{array}{l}50 \mathrm{mM} \\
\mathrm{Cr}(\mathrm{VI})\end{array}$} & \multirow{4}{*}{$0.81-11.9$} & \multirow{2}{*}{$1.5 \pm 0.5$} & 653 & $0.976(2)$ & $520 \pm 60$ & 0.50 \\
\hline & & & & 809 & $0.999(2)$ & $1910 \pm 11$ & 0.31 \\
\hline & & & \multirow{2}{*}{$72 \pm 3$} & 653 & $0.985(2)$ & $126 \pm 11$ & 2.4 \\
\hline & & & & 809 & $0.931(2)$ & $560 \pm 110$ & 1.5 \\
\hline \multicolumn{8}{|c|}{$\begin{array}{l}\text { (a) Number in brackets corresponds to numbers of concentration points of } \mathrm{Pu} \text { used for linear regression: } 6 \text { points } \\
\text { correspond to full range of } \mathrm{Pu}(\mathrm{V}) \text { additions; } 5 \text { points correspond to first } 5 \text { additions of } \mathrm{Pu}(0.810 \text { - to } 11.9 \mu \mathrm{M} \\
\text { range); } 2 \text { points correspond to first two additions }(0.81 \text { - to } 1.62 \mu \mathrm{M} \text { range). }\end{array}$} \\
\hline
\end{tabular}

The 0.25 M NaOD spectral series [plot a)] represents a more complicated case because of the partial conversion of $\mathrm{Pu}(\mathrm{V})$ to $\mathrm{Pu}(\mathrm{VI})$ at this reduced level of hydroxide observed in a carbonate-free medium. It should be noted that in all $\mathrm{OD}^{-}-\mathrm{CO}_{3}{ }^{2-}$ experiments, including this one, a series of six solutions with a varying carbonate-to-hydroxide ratio was prepared first, and then equal amounts of $\mathrm{Pu}(\mathrm{V})$ stock solution in $14 \mathrm{M}$ of $\mathrm{NaOD}$ were spiked into each solution, followed by mixing and equilibration for 1 to $1.5 \mathrm{hr}$ before spectral measurement. In other words, it was not a titration experiment with an increasing amount of carbonate added to the same solution, but a series of separately prepared solutions used to collect spectral information after all samples were allowed sufficient and approximately equal time for equilibration.

In the very first spectrum [black trace in plot a)], $\mathrm{Pu}$ is present as a mixture of $57 \%$ of $\mathrm{Pu}(\mathrm{VI})$ and $43 \%$ of $\mathrm{Pu}(\mathrm{V})$ (this estimate is approximate as it based on the assumption that the molar absorptivity of the $\mathrm{Pu}(\mathrm{V})$ peak at $809 \mathrm{~nm}$ remains the same in the $0.25 \mathrm{M} \mathrm{NaOD}$ medium as was found to in $1 \mathrm{M} \mathrm{NaOD}$ ). However, in the presence of $0.05 \mathrm{M}$ of carbonate (red trace), very drastic spectral changes were noted:

- Very prominent spectral features of the mixed $\mathrm{Pu}(\mathrm{V})$ hydroxy-carbonate complex at 735 and $820 \mathrm{~nm}$ were observed.

- Their spectral intensities were comparable with those observed in the $1 \mathrm{M} \mathrm{NaOD}+$ carbonate experiment at the highest concentration of $\mathrm{Na}_{2} \mathrm{CO}_{3}(1 \mathrm{M})$.

- No characteristic absorbance band of mixed hydroxy-carbonate complex of $\mathrm{Pu}(\mathrm{VI})$ at $868 \mathrm{~nm}$ was present, which should be clearly visible at an $\sim 8-\mu \mathrm{M}$ concentration of $\mathrm{Pu}(\mathrm{VI})$. 

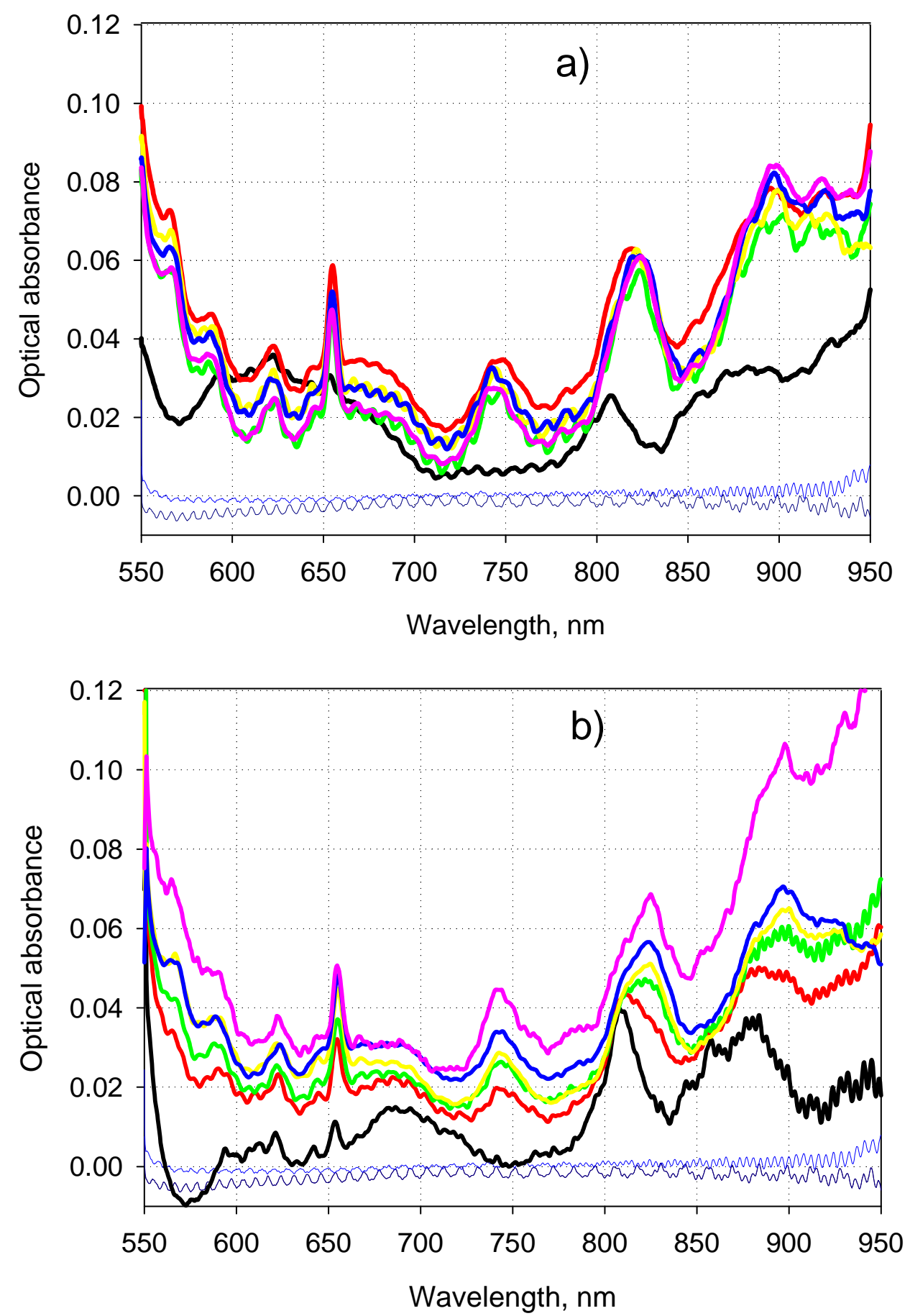

Figure 3.20. $\mathrm{Pu}(\mathrm{V})$ Spectra in $0.25 \mathrm{M} \mathrm{NaOD}$ a), and $1 \mathrm{M} \mathrm{NaOD}$ b) in the Presence of Carbonate. In all cases, the carbonate concentration grows from $0 \%$ to $100 \%$ with $20 \%$ increments relative to the respective molar concentration of hydroxide for black, red, yellow, green, blue, and pink spectral traces, respectively. The $\mathrm{Pu}(\mathrm{V})$ concentration is fixed at $14.3 \mu \mathrm{M}$ and at 12 $\mu \mathrm{M}$ for the $0.25 \mathrm{M}$ and $1.0 \mathrm{M} \mathrm{NaOD}$ series, respectively. 
A further increase in carbonate concentration $(0.1,0.15,0.20$, and $0.25 \mathrm{M})$ produced only minor changes in absorbance spectra compared with the very first addition of this ligand.

All of these observations indicate that carbonate plays an important role in stabilizing $\mathrm{Pu}(\mathrm{V})$ in its initial oxidation state at $0.25 \mathrm{M}$ hydroxide concentration, most likely via suppression of the disproportionation reaction of $\mathrm{Pu}(\mathrm{V})$ to $\mathrm{Pu}(\mathrm{IV})$ and $\mathrm{Pu}(\mathrm{VI})$, which would be followed by the precipitation of $\mathrm{Pu}(\mathrm{IV})$ as poorly soluble $\mathrm{Pu}(\mathrm{IV})$ hydroxide.

\subsubsection{Pu(V) Redox Speciation After Acidification of Initially Alkaline Pu(V) Solution by $\mathrm{DNO}_{3}$ at a Low Micromolar Concentration of $\mathrm{Pu}(\mathrm{V})$}

As has been shown in Section 3.4, Pu(VI) detection in an acidic medium by optical absorbance spectroscopy is $\sim 100$ times more sensitive than in an alkaline medium. The spectrum of $\mathrm{Pu}(\mathrm{V})$ in acid is reported to have two relatively sharp and intense absorbance bands centered at $569 \mathrm{~nm}$ and at $775 \mathrm{~nm}$ (Cohen 1961). At a millimolar concentration range of $\mathrm{Pu}(\mathrm{V})$, this oxidation state has a limited lifetime due to the disproportionation at $\mathrm{pH}$ below 2. On the other hand, it is known that the rate of the disproportionation reaction of $\mathrm{Pu}(\mathrm{V})$ is a sensitive function of the initial concentration of $\mathrm{Pu}(\mathrm{V})$.

Therefore, the disproportionation of $\mathrm{Pu}(\mathrm{V})$ is slowed considerably at a low micromolar concentration. In this project, it was of interest to determine under what conditions the acidification of an initially alkaline $\mathrm{Pu}(\mathrm{V})$ solution may produce a stable spectrum of $\mathrm{Pu}(\mathrm{V})$ without significant perturbation of its redox equilibrium with other oxidation states possibly present in the same alkaline solution. Two simple tests were performed: 1) acidification of $\mathrm{Pu}(\mathrm{V})$ alkaline stock by slight excess of $\mathrm{DNO}_{3}$ to achieve $\sim 0.05 \mathrm{M}$ acidity level; 2) repetition of the same experiment in the presence of $5 \mathrm{mM}$ chromate.

\section{Chromate Free Medium}

Fifty $\mu \mathrm{L}$ of $0.81 \mathrm{mM}$ alkaline $\mathrm{Pu}(\mathrm{V})$ stock solution in $14 \mathrm{M}$ NaOD were spiked into $2 \mathrm{~mL}$ of $0.4 \mathrm{M} \mathrm{DNO}_{3}$ solution in $\mathrm{D}_{2} \mathrm{O}$. The estimated acidity of the resulting mixture is $0.06 \mathrm{M}$ of $\mathrm{DNO}_{3}$. The acidified $\mathrm{Pu}(\mathrm{V})$ solution was injected into LWCC 3 to 4 minutes after the solution was homogenized, and a kinetic series of 22 spectra was taken. The solution was left inside the cell overnight, and one more spectrum was taken the next morning. Figure 3.21 shows the results of this experiment. Only four spectral scans are shown for simplicity ( 6 minutes, 28 minutes, 60 minutes, and 17 hours after acidification). The very first spectral scan (black trace), taken $\sim 6$ minutes after acidification, shows four absorbance bands of $\mathrm{Pu}(\mathrm{V})$ at $569,775,848$, and $895 \mathrm{~nm}$ as well as a prominent peak of $\mathrm{Pu}(\mathrm{VI})$ at $831 \mathrm{~nm}$. The estimated fraction of $\mathrm{Pu}(\mathrm{VI})$ for this spectrum is $8 \%$ of the total $\mathrm{Pu}$ present in solution. This percentage slowly increases with time $[17 \%$ and $33 \%$ of $\mathrm{Pu}(\mathrm{VI})$ were found in solution after 60 minutes and 17 hours of exposure to acidic conditions, respectively]. The remaining fraction of $\mathrm{Pu}$ is present as $\mathrm{Pu}(\mathrm{V})$. No absorbance bands of $\mathrm{Pu}(\mathrm{IV})$ and $\mathrm{Pu}(\mathrm{III})$ could be distinguished in the overnight spectrum. For this reason, we believe that the observed process of a slow build-up of $\mathrm{Pu}(\mathrm{VI})$ from $\mathrm{Pu}(\mathrm{V})$ is purely oxidation rather than disproportionation. Both nitric and nitrous acids (the latter is always present as a trace admixture in untreated nitric acid solutions) might be acting as mild oxidizing agents. It would be desirable to repeat this experiment using $\mathrm{DCl}$ as a non-oxidizing acidifying agent to understand the role of nitrous and/or nitric acid in this process.

The $8 \%$ admixture of $\mathrm{Pu}(\mathrm{VI})$ in $\mathrm{Pu}(\mathrm{V})$ solution 6 minutes after acidification most likely is result of a relatively quick oxidation of $\mathrm{Pu}(\mathrm{V})$ by the oxidizing components of the acidic mixture. More careful 
analysis of kinetic data is needed to extrapolate the 6-min data back to zero time to determine the actual level of $\mathrm{Pu}(\mathrm{VI})$ (if any) in the $\mathrm{Pu}(\mathrm{V})$ stock solution.

\section{In the Presence of $5 \mathrm{mM}$ Chromate}

A similar experiment was conducted but in the presence of $5 \mathrm{mM}$ chromate. The chromate solution converts to $2.5 \mathrm{mM}$ dichromate in acid. In this case, a $100 \%$ conversion of $\mathrm{Pu}(\mathrm{V})$ to $\mathrm{Pu}(\mathrm{VI})$ was observed already at the moment of the very first spectral scan (black trace in Figure 3.22). Five more spectral scans with 2-min time intervals (only the second scan is shown in the figure for simplicity) showed no further spectral changes. This experiment proves that the technique of acid strike can not be used to determine the ratio between $\mathrm{Pu}(\mathrm{V})$ and $\mathrm{Pu}(\mathrm{VI})$ by acidification of an initially alkaline solution if the solution contains chromate. Dichromate appears to be too strong an oxidizer in an acidic medium for $\mathrm{Pu}(\mathrm{V})$ to survive in its presence. Another problem with dichromate in terms of the LWCC detection range is its much stronger optical absorbance in the 550 - to $600-\mathrm{nm}$ spectral range compared to chromate. This is noticeable even at a relatively low $2.5 \mathrm{mM}$ concentration of this species. The detection range of LWCC is expected to be narrowed even further with 10 - to 20 -fold higher concentrations of dichromate.

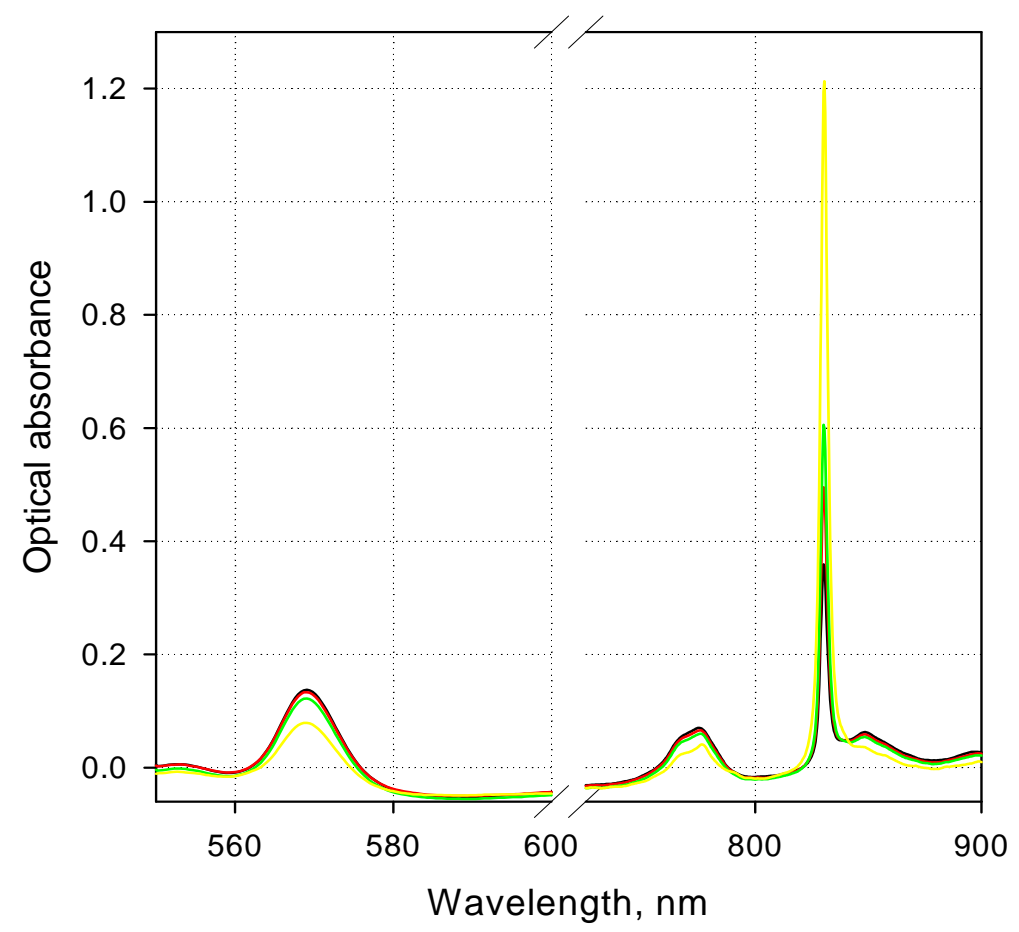

Figure 3.21. Spectra of $\mathrm{Pu}(\mathrm{V})$ After Acidic Strike of Small Amount of Pu(V) Stock in $14 \mathrm{M} \mathrm{NaOD}$ with a Slight Molar Excess of $0.4 \mathrm{M} \mathrm{DNO}_{3}$ Solution. The total concentration of $\mathrm{Pu}$ is $19.7 \mu \mathrm{M}$. Black, red, green, and yellow spectral traces correspond to 6-minute, 28-minute, 60-minute, and 17-hour exposures of alkaline $\mathrm{Pu}(\mathrm{V})$ to an acidic medium. 


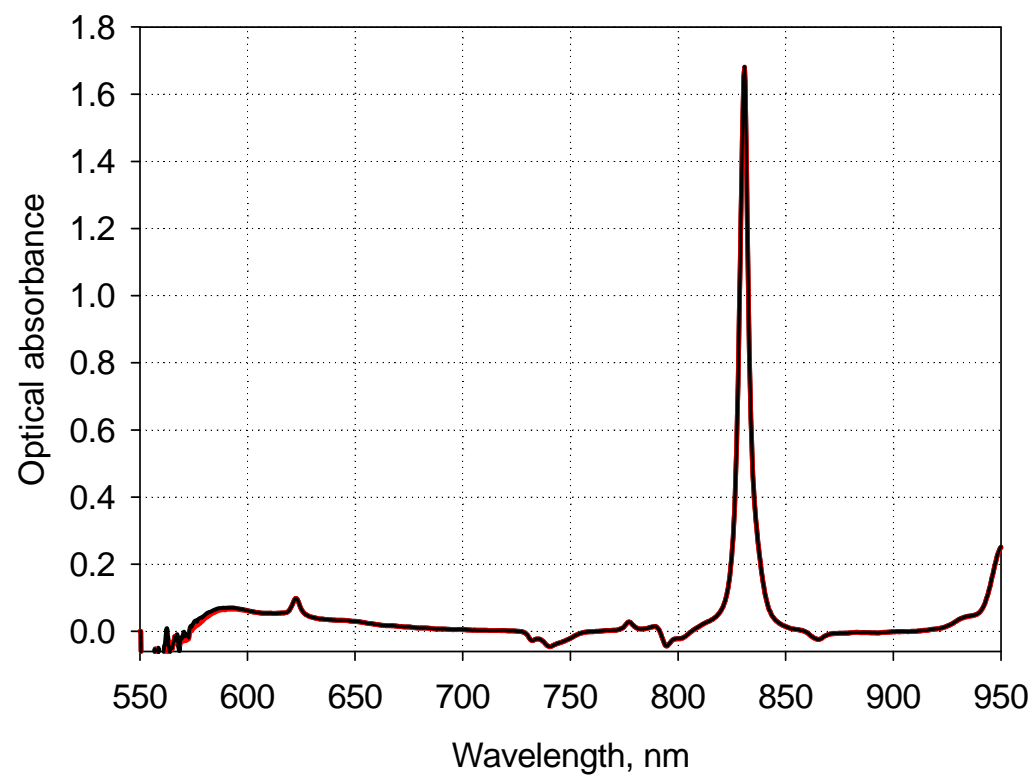

Figure 3.22. Spectra of $\mathrm{Pu}(\mathrm{V})$ After Acidic Strike of Tiny Amount of $\mathrm{Pu}(\mathrm{V})$ Stock in $14 \mathrm{M} \mathrm{NaOD}$ into a Slight Molar Excess of $0.4 \mathrm{M} \mathrm{DNO}_{3}$ Containing $5 \mathrm{mM}$ of Chromate (physically present as $2.5 \mathrm{mM}$ dichromate). Black trace: $\sim 10$ minutes after acidification. Red trace: 30 minutes later.

\subsubsection{Determination of Formal Electrochemical Potential of $\mathrm{Pu}(\mathrm{VI}) / \mathrm{Pu}(\mathrm{V})$ Couple in 0.25 M to 1.0 M NaOD Using Direct Potentiometric Measurement with an ORP Electrode}

Experiments on $\mathrm{Pu}(\mathrm{VI})$ speciation in $\mathrm{NaOD}$ described in Section 3.4.2 showed that a $1 \mathrm{M} \mathrm{NaOD} \mathrm{Pu(VI)}$ solution contained a spectrophotometrically detectable concentration of $\mathrm{Pu}(\mathrm{V})$ (see $\mathrm{Pu}(\mathrm{V})$ peak at $809 \mathrm{~nm}$ in Figure 3.11). Knowing the initial concentration of $\mathrm{Pu}(\mathrm{VI})$ that was added to the alkaline solution and calculating the $\mathrm{Pu}(\mathrm{V})$ concentration from the 809 -nm peak intensity should make it possible to calculate the remaining concentration of $\mathrm{Pu}(\mathrm{VI})$ in equilibrium with $\mathrm{Pu}(\mathrm{V})$. The ratio of $[\mathrm{Pu}(\mathrm{VI})] /[\mathrm{Pu}(\mathrm{V})]$ can be incorporated then into the Nernst equation, which describes the relationship between the measured potential in the $\mathrm{Pu}(\mathrm{VI})+\mathrm{Pu}(\mathrm{V})$-containing solution and the formal potential of the $\mathrm{Pu}(\mathrm{VI}) / \mathrm{Pu}(\mathrm{V})$ couple as shown below:

$$
\mathrm{E}_{\text {measured }}=\mathrm{E}_{\text {formal }}^{\mathrm{o}}+\mathrm{RT} / \mathrm{nF} \cdot \log \{[\mathrm{Pu}(\mathrm{VI})] /[\mathrm{Pu}(\mathrm{V})]\}
$$

where the $\mathrm{RT} / \mathrm{nF}$ term is equal to $0.0592 \mathrm{~V}$ at $25^{\circ} \mathrm{C}$ (for $\mathrm{n}=1$ ) after conversion of the natural logarithm scale $(\ln )$ to the base-10 logarithm scale $(\log )$.

There are a limited number of studies of the determination of the electrochemical potential of the $\mathrm{Pu}(\mathrm{VI}) / \mathrm{Pu}(\mathrm{V})$ redox couple as summarized by Barney and Delegard (1999) with no data available in the low alkalinity range $(<1 \mathrm{M} \mathrm{NaOH})$. According to a recent paper on Np electrochemistry (Gelis et al. 2001), the corresponding $\mathrm{Np}(\mathrm{VI}) / \mathrm{Np}(\mathrm{V})$ couple becomes irreversible at $\mathrm{NaOH}$ below $1.3 \mathrm{M}$, presumably due to the formation of solid $\mathrm{Np}(\mathrm{V})$ hydroxide in an initially homogeneous solution from the process of cyclic voltametry measurements under these conditions. Therefore, it was of interest to perform one more 
set of spectral experiments with a $\mathrm{Pu}(\mathrm{VI})$ solution in a lower alkalinity range of $\mathrm{NaOD}$ concentrations with simultaneous measurement of the oxidation-reduction potential in a portion of the same solution. Six solutions of $\mathrm{NaOD}$ were prepared in the deuteroxide concentration range from $0.25 \mathrm{M}$ to $1.0 \mathrm{M}$, followed by adding a small volume of weakly acidic $\mathrm{Pu}(\mathrm{VI})$ solution to make a $20-\mu \mathrm{M}$ Pu concentration. Solutions were homogenized and stored for 1 to $2 \mathrm{hr}$ before spectral measurements. ORP measurements were performed simultaneously with spectral measurements of the same Pu-containing solution split into two equal 2-mL portions. The ORP readings were taken within the first 7 to 10 minutes after the solution made contact with the electrode to minimize a positive temperature drift due to a prolonged intense stirring during ORP measurements.

The spectral data that were used to determine the extent of $\mathrm{Pu}(\mathrm{VI})$ spontaneous conversion to $\mathrm{Pu}(\mathrm{V})$ are shown in Figure 3.23, and the ORP measurements are presented in Table 3.4. As follows from these data, a higher alkalinity favors a higher percentage of $\mathrm{Pu}(\mathrm{V})$ in equilibrium with $\mathrm{Pu}(\mathrm{VI})$, but the measured ORP potential is not a simple monotoneous function of the $\mathrm{Pu}(\mathrm{V})$ fraction in total $\mathrm{Pu}$ balance as it goes through a minimum at $0.55 \mathrm{M}$ of NaOD. Accordingly, the formal potential calculated from these data also shows a minimum at this alkalinity. This complex behavior of the magnitude of a formal potential might be associated with the effect of non-constant ionic strength, but it might also indicate a lack of structural "identity" between $\mathrm{Pu}(\mathrm{VI})$ and $\mathrm{Pu}(\mathrm{V})$ species in this range of hydroxide concentrations [see Gelis et al. 2001 for more details about this effect for the $\mathrm{Np}(\mathrm{VI}) / \mathrm{Np}(\mathrm{V})$ couple]. The formal potential determined in $1.0 \mathrm{M} \mathrm{NaOD}(+0.145 \mathrm{~V})$ is in satisfactory agreement with the value of $+0.233 \mathrm{~V}$ reported for $\mathrm{Pu}(\mathrm{VI}) / \mathrm{Pu}(\mathrm{V})$ at $0.9 \mathrm{M} \mathrm{NaOH}$ for much higher Pu concentration (Peretrukhin et al. 1982). The difference between these two values can be partially explained by the liquid-junction potential between the working electrode (filled with saturated $\mathrm{KCl}$ ) and the electrolyte solution $(1 \mathrm{M} \mathrm{NaOH})$.

From a practical point of view, the most important result of this study is the finding that the formal potential of the $\mathrm{Pu}(\mathrm{VI}) / \mathrm{Pu}(\mathrm{V})$ couple is about $400 \mathrm{mV}$ lower than potentials of $\mathrm{Mn}(\mathrm{VII}) / \mathrm{Mn}(\mathrm{VI})$ and $\mathrm{Mn}(\mathrm{VI}) / \mathrm{Mn}(\mathrm{IV})$ couples in an alkaline medium. This indicates that any $\mathrm{Pu}(\mathrm{V})$ possibly present in solution before oxidative alkaline treatment is expected to be quantitatively oxidized by an excess of permanganate and/or manganate to $\mathrm{Pu}(\mathrm{VI})$.

\subsection{Pu(IV) Spectral Measurements in $\mathrm{DNO}_{3}$ and NaOD}

\subsubsection{Verification of Identity of Spectral Features of $\mathrm{Pu}(\mathrm{IV})$ in $4 \mathrm{M}$ of $\mathrm{HNO}_{3}$ and $4 \mathrm{M}$ of $\mathrm{DNO}_{3}$}

A stock solution of $\mathrm{Pu}(\mathrm{IV})$ in $4 \mathrm{M} \mathrm{DNO}_{3}$ was prepared by careful evaporation of $\mathrm{Pu}(\mathrm{IV})$ solution in $4 \mathrm{M}$ $\mathrm{HNO}_{3}$ under vacuum at room temperature and redissolution of $\mathrm{Pu}\left(\mathrm{NO}_{3}\right)_{4}$ in $\mathrm{DNO}_{3}$. The cycle of evaporation-redissolution was repeated two times to minimize the admixture of $\mathrm{H}_{2} \mathrm{O}$ in $\mathrm{D}_{2} \mathrm{O}$. The spectrum of $18 \mathrm{mM}$ of $\mathrm{Pu}(\mathrm{IV})$ is shown in Figure 3.24. All peak positions and their relative intensities are in excellent correspondence with the spectrum of $\mathrm{Pu}(\mathrm{IV})$ at the same $\mathrm{Pu}$ concentration in $4 \mathrm{M}$ of $\mathrm{HNO}_{3}$ (black spectral trace in the same Figure). Therefore, the entire body of spectral data [Nd(III), $\mathrm{Nd}(\mathrm{EDTA})$, $\mathrm{Pu}(\mathrm{VI}), \mathrm{Pu}(\mathrm{V})$, and $\mathrm{Pu}(\mathrm{IV})]$ accumulated so far proves that there is no effect of $\mathrm{H}_{2} \mathrm{O}, \mathrm{HNO}_{3}$ substitution by $\mathrm{D}_{2} \mathrm{O}$, and $\mathrm{DNO}_{3}$ on the spectral features of light-absorbing species of lanthanide and actinide metal cations and their complexes. 


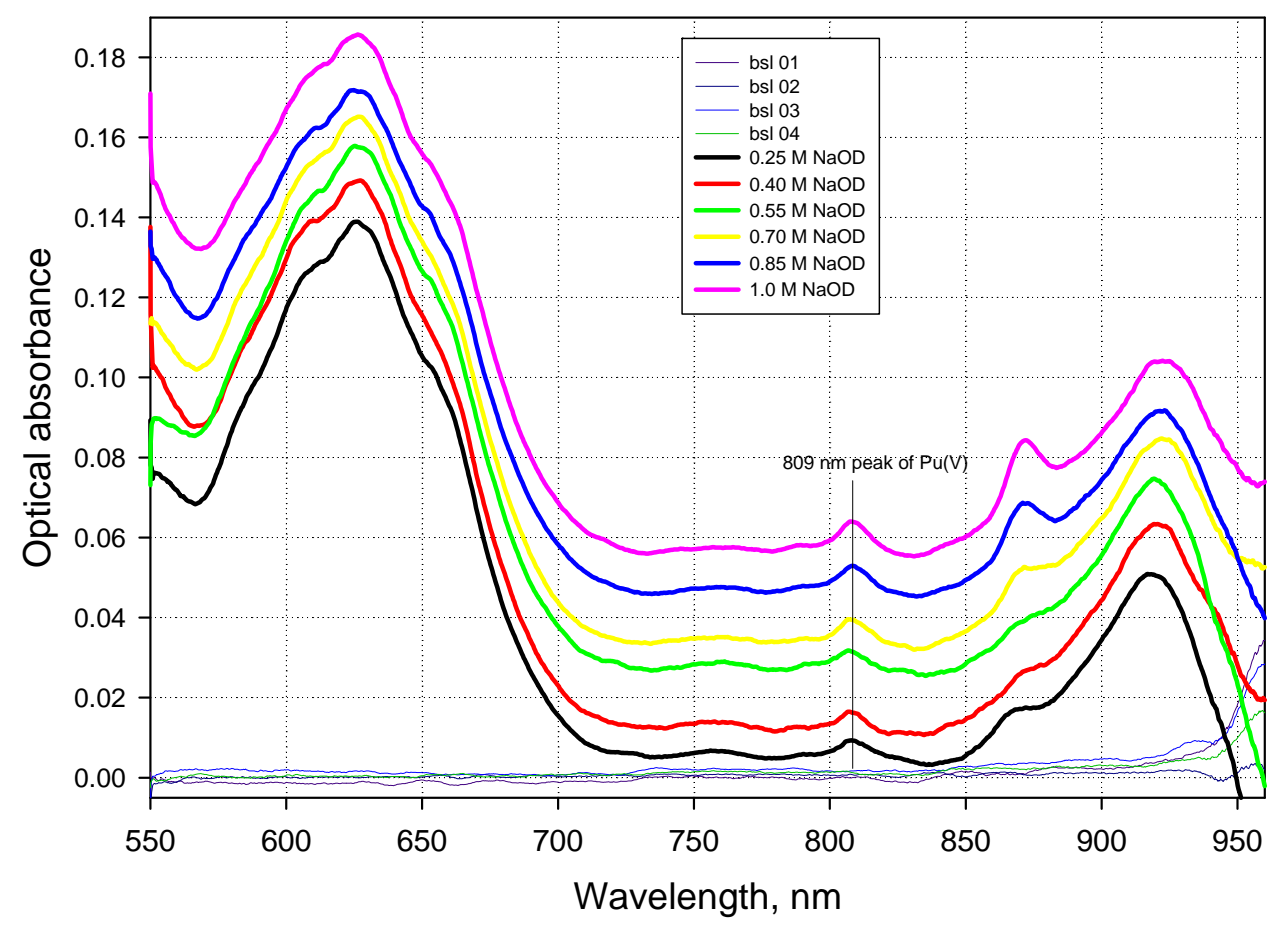

Figure 3.23. Spectra of $\mathrm{Pu}(\mathrm{VI})+\mathrm{Pu}(\mathrm{V})$ Solutions in $\mathrm{NaOD}$ Solutions at Total Concentration of $\mathrm{Pu}$ at $20 \mu \mathrm{M}$. Admixture of $\mathrm{Pu}(\mathrm{V})$ is seen as a minor peak at $809 \mathrm{~nm}$. Spectra are vertically offset by $0.00,+0.007,+0.023,+0.026,+0.04$, and +0.05 absorbance units for $0.25-, 0.40-$, $0.55-, 0.70-, 0.85-$, and 1.0-M NaOD concentrations, respectively.

Table 3.4. Calculation of Formal Potentials of the $\mathrm{Pu}(\mathrm{VI}) / \mathrm{Pu}(\mathrm{V})$ Couple in NaOD Solution

\begin{tabular}{|c|c|c|c|c|c|c|c|c|c|}
\hline $\begin{array}{l}\mathrm{C}_{\mathrm{NaOD}}, \\
\mathbf{M}\end{array}$ & $\begin{array}{l}\text { A }_{809} \\
\text { a.u. }\end{array}$ & $\begin{array}{l}\mathrm{C}_{\mathbf{P u}(\mathrm{V})}, \\
\boldsymbol{\mu M}\end{array}$ & $\begin{array}{l}\mathrm{C}_{\mathrm{Pu}} \\
\text { total } \\
\boldsymbol{\mu M}\end{array}$ & $\begin{array}{r}\mathrm{C}_{\mathrm{Pu}(\mathrm{VI}),} \\
\boldsymbol{\mu M}\end{array}$ & $\mathrm{C}_{\mathrm{Pu}(\mathrm{VI})} / \mathrm{C}_{\mathrm{Pu}(\mathrm{V})}$ & $\begin{array}{l}\text { Fraction } \\
\text { of } \\
\mathrm{Pu}(\mathrm{V}) \\
\%\end{array}$ & $\begin{array}{l}\text { Log term } \\
\{59.2 \times \\
\left.\log \left[C_{\mathrm{Pu}(\mathrm{VI})} / \mathrm{C}_{\mathrm{Pu}(\mathrm{V})}\right]\right\} \\
\mathrm{mV}\end{array}$ & $\begin{array}{l}\mathbf{E}_{\text {measured }} \\
\mathrm{mV}\end{array}$ & $\begin{array}{l}E_{\text {formal }} \\
\mathrm{mV}\end{array}$ \\
\hline 0.25 & 0.0051 & 1.92 & 20 & 18.1 & 9.4 & 9.6 & 57.4 & 182 & 125 \\
\hline 0.40 & 0.00477 & 1.80 & 20 & 18.2 & 10.1 & 9.0 & 59.3 & 173 & 114 \\
\hline 0.55 & 0.00505 & 1.90 & 20 & 18.1 & 9.5 & 9.5 & 57.7 & 165 & 108 \\
\hline 0.70 & 0.00627 & 2.36 & 20 & 17.6 & 7.5 & 11.8 & 51.5 & 169 & 117 \\
\hline 0.85 & 0.00679 & 2.56 & 20 & 17.4 & 6.8 & 12.8 & 49.2 & 193 & 143 \\
\hline 1.00 & 0.00759 & 2.86 & 20 & 17.1 & 6.0 & 14.3 & 45.9 & 191 & 145 \\
\hline
\end{tabular}




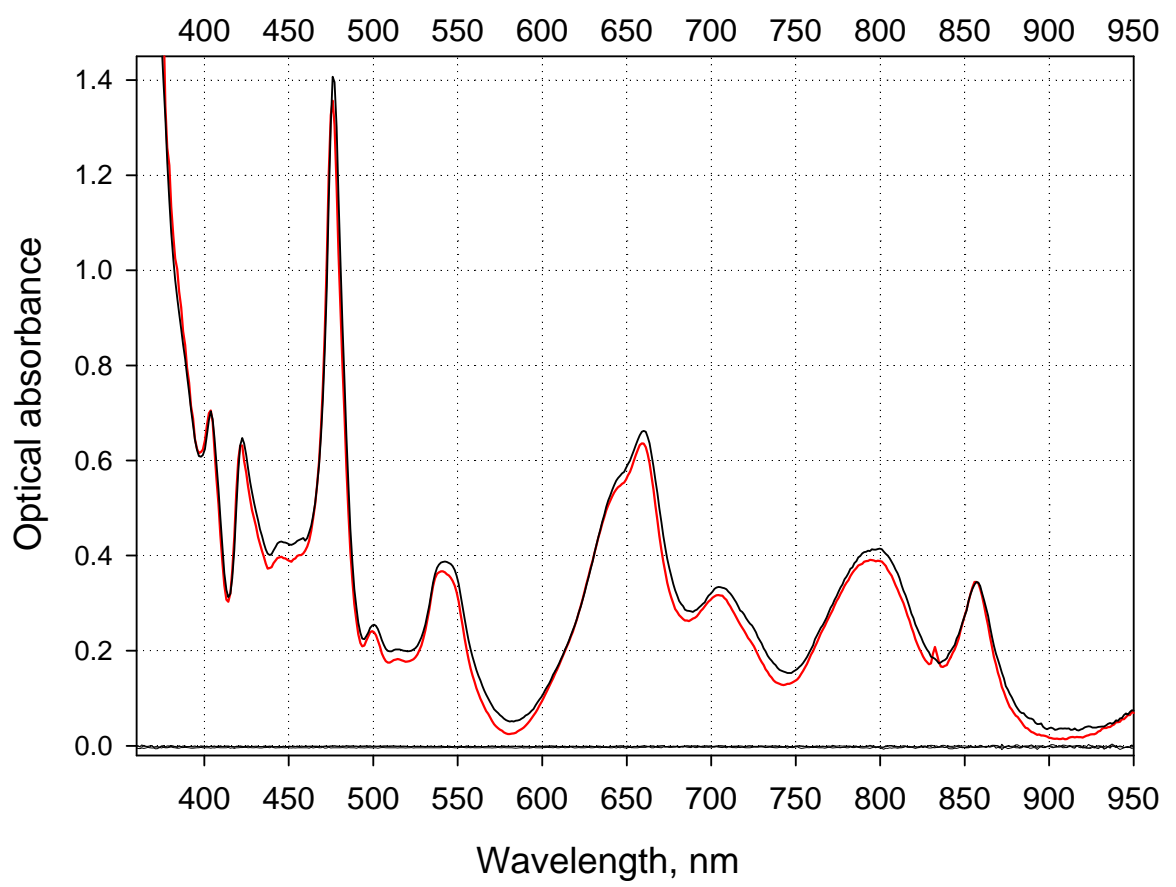

Figure 3.24. Optical Absorbance Spectra of $18 \mathrm{mM} \mathrm{Pu(IV)} \mathrm{in} 4.0 \mathrm{M} \mathrm{HNO}_{3}$ (black trace) and $4.0 \mathrm{M}$ $\mathrm{DNO}_{3}$ (red trace). The black spectrum is upshifted by 0.025 absorbance units for clarity.

\subsection{2 $\mathrm{Pu}(\mathrm{IV})$ Calibration Experiment in $0.75 \mathrm{M}$ of $\mathrm{DNO}_{3}$}

It was of interest to determine the detection limit of $\mathrm{Pu}(\mathrm{IV})$ in an acidic medium using LWCC detection before performing experiments with $\mathrm{Pu}(\mathrm{IV})$ from the alkaline side. The acidification of an initially alkaline solution possibly containing multiple oxidation state species of this metal was expected to provide better detection limits [as has been already demonstrated with $\mathrm{Pu}(\mathrm{VI})$ ]. Conventional optical absorbance spectroscopy (with 1-cm optical pathlength) offers a limited sensitivity for $\mathrm{Pu}(\mathrm{IV})$ detection in an acidic medium with a detection limit on the order of $160 \mu \mathrm{M}$ using a major peak of $\mathrm{Pu}(\mathrm{IV})$ at $476 \mathrm{~nm}$ (Wilson et al. 2005). In this project, the 476-nm peak was inaccessible with the near-IR optimized Ocean Optics instrument coupled with LWCC. For this reason, the second major peak of $\mathrm{Pu}(\mathrm{IV})$ at $660 \mathrm{~nm}$ was selected for calibration experiment in $0.75 \mathrm{M} \mathrm{DNO}_{3}$. The reduced level of acidity was considered to be still sufficient for suppressing the hydrolysis of $\mathrm{Pu}(\mathrm{IV})$ and preventing its disproportionation to $\mathrm{Pu}(\mathrm{III})$ and $\mathrm{Pu}(\mathrm{VI})$. A series of diluted $\mathrm{Pu}(\mathrm{IV})$ solutions in $0.75 \mathrm{M}$ of $\mathrm{DNO}_{3}$ was prepared and spectrally measured to cover the concentration range of $\mathrm{Pu}$ from $0.18 \mu \mathrm{M}$ to $8.8 \mu \mathrm{M}$. The results of this measurement are shown in Figure 3.25. The net signal intensity of the 660-nm peak measured against its valleys at $585 \mathrm{~nm}$ and $692 \mathrm{~nm}$ was used to establish a correlation between its magnitude and the $\mathrm{Pu}$ concentration in solution (data not shown). The calibration plot showed good linearity $\left(\mathrm{R}^{2}=0.9971\right)$ and high sensitivity ( worse than the $5.6 \mathrm{nM}$ value found earlier for $\mathrm{Pu}(\mathrm{VI})$ in acidic solution. Therefore, the technique of acid strike (using deuterated acid and solvent) might be useful to establish the presence of $\mathrm{Pu}(\mathrm{IV})$ and $\mathrm{Pu}(\mathrm{VI})$ in an initially alkaline solution if both oxidation states are present at low submicromolar concentration levels. However, the conversion of soluble hydrolyzed forms of $\mathrm{Pu}(\mathrm{IV})$ into its monomeric cationic form of $\mathrm{Pu}^{\mathrm{IV}}\left(\mathrm{NO}_{3}\right)_{2}{ }^{2+}$ is expected to be quick and quantitative only if the hydrolyzed form is monomeric itself. If alkaline $\mathrm{Pu}(\mathrm{IV})$ is present as low-nanometer-sized colloidal particles (which can easily penetrate 
through 200- or 450-nm pore-size membrane filters and thus qualify as a soluble fraction), then depolymerization of this material may take a much longer times and would require much higher acid concentrations for completion.

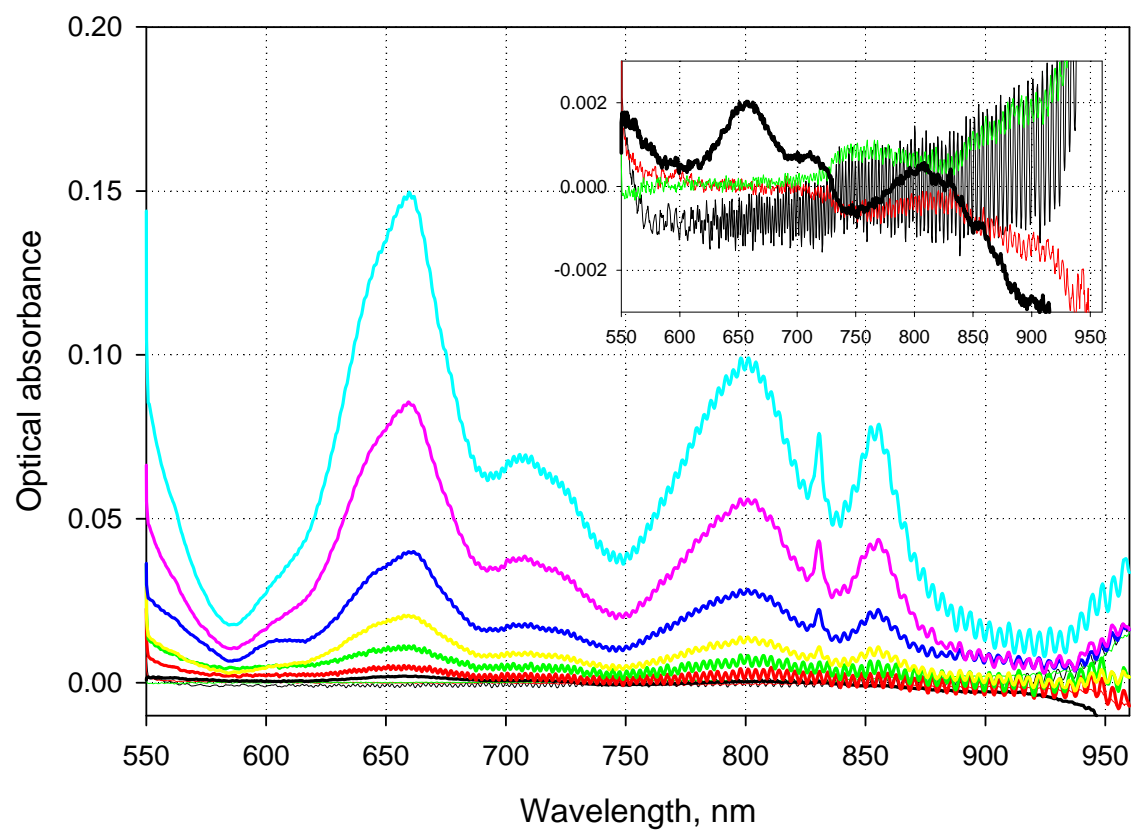

Figure 3.25. Calibration Experiment with $\mathrm{Pu}(\mathrm{IV})$ in $0.75 \mathrm{M}$ of $\mathrm{DNO}_{3}$ Using a $500-\mathrm{cm} \mathrm{LWCC}$. $\mathrm{Pu}(\mathrm{IV})$ concentrations are as follows: black $-0.18 \mu \mathrm{M}$; red $-0.36 \mu \mathrm{M}$; green $-0.72 \mu \mathrm{M}$; yellow$1.43 \mu \mathrm{M}$; blue $-2.86 \mu \mathrm{M}$; pink-5.32 $\mu \mathrm{M}$; pale blue $-8.8 \mu \mathrm{M}$. The inset shows the lowest concentration of the $\mathrm{Pu}(\mathrm{IV})$ spectrum vertically magnified along with typical blank spectra (thin black, red, and green traces).

\subsubsection{Pu(IV) Speciation and Solubility in 0.25 M NaOD}

The alkaline chemistry of $\mathrm{Pu}(\mathrm{IV})$ remains poorly explored, mainly because of the very low solubility of this oxidation state of $\mathrm{Pu}$ in $\mathrm{NaOH}$ solution. The total $\mathrm{Pu}$ concentration in equilibrium with $\mathrm{Pu}(\mathrm{OH})_{4}$ in deaerated and carbonate-free weakly alkaline solutions is reported not to exceed $10 \mathrm{nM}$. (Rai et al. 1999; Neck et al. 2007). Indirect redox speciation analysis by solvent extraction indicates that the fraction of $\mathrm{Pu}(\mathrm{IV})$ in the total balance of soluble Pu does not exceed a few percent, which corresponds to subnanomolar levels of tetravalent $\mathrm{Pu}$. Even under these well-controlled conditions of solubility studies performed in inert atmosphere gloveboxes, it was noted that partial conversion of $\mathrm{Pu}(\mathrm{IV})$ species to other oxidation states occurred over long equilibration times (more than one week).

In this project, no technical capability existed to protect alkaline solutions of $\mathrm{NaOD}$ from dissolved oxygen and atmospheric $\mathrm{CO}_{2}$. For this reason, we chose to minimize the time between the preparation of the alkaline solution of $\mathrm{Pu}(\mathrm{IV})$ and the spectral measurement to 10 minutes for the freshly prepared sample and 3 days for "aged" sample. The alkaline solution of $\mathrm{Pu}(\mathrm{IV})$ in $0.25 \mathrm{M} \mathrm{NaOD}$ was prepared by spiking $5 \mu \mathrm{L}$ of $0.36 \mathrm{mM} \mathrm{Pu}(\mathrm{IV})$ acidic stock in $2 \mathrm{M} \mathrm{DNO}_{3}$ into $2 \mathrm{~mL}$ of $0.25 \mathrm{M} \mathrm{NaOD}$. The estimated perturbation of the initial alkalinity via $\mathrm{Pu}(\mathrm{IV})$ introduction did not exceed $2 \%$. The total amount of added $\mathrm{Pu}(\mathrm{IV})$ corresponded to $9 \mu \mathrm{M}$ of total $\mathrm{Pu}$ concentration under the assumption that all added $\mathrm{Pu}$ 
remains in solution. The results of spectral measurements of the "fresh" and "aged" sample are shown in Figure 3.26. One can see that the spectrum of the fresh sample (bold black trace) does not exhibit any peak-like spectral features in all the spectral ranges available for scanning. A monotonous elevation of optical absorbance toward shorter wavelengths starting from $\sim 740 \mathrm{~nm}$ was not observed before with $\mathrm{Pu}(\mathrm{VI})$ and freshly prepared $\mathrm{Pu}(\mathrm{V})$ solutions at the same alkalinity, but the similar spectral trend was noted for aged $\mathrm{Pu}(\mathrm{V})$ samples [see Figure 3.19 plot c)]. For the aged sample (bold red trace), two weak and broad peaks at $700 \mathrm{~nm}$ and $\sim 820 \mathrm{~nm}$ were detected, but this spectral measurement is heavily distorted by negative fluctuations of baseline from the both ends of the spectrum. The monotonous elevation of the background signal is more pronounced for the aged sample than for the freshly spiked specimen, which would be consistent with a higher presence of the same unidentified form of soluble $\mathrm{Pu}$ in the aged sample. However, according to LSC analysis, concentrations of total soluble Pu in these samples amounted to $0.027 \mu \mathrm{M}$ and $0.016 \mu \mathrm{M}$ for fresh and aged samples, respectively. These levels of concentrations are well below detection limits for $\mathrm{Pu}(\mathrm{VI})$ and $\mathrm{Pu}(\mathrm{V})$. Therefore, the presence of neither $\mathrm{Pu}(\mathrm{VI})$ nor $\mathrm{Pu}(\mathrm{V})$ could be established by these spectra even in a hypothetical case of $100 \%$ conversion of $\mathrm{Pu}(\mathrm{IV})$ to any of these oxidation states. In addition, no reliable spectrum of a $\mathrm{Pu}(\mathrm{IV})$ dissolved species was observed.

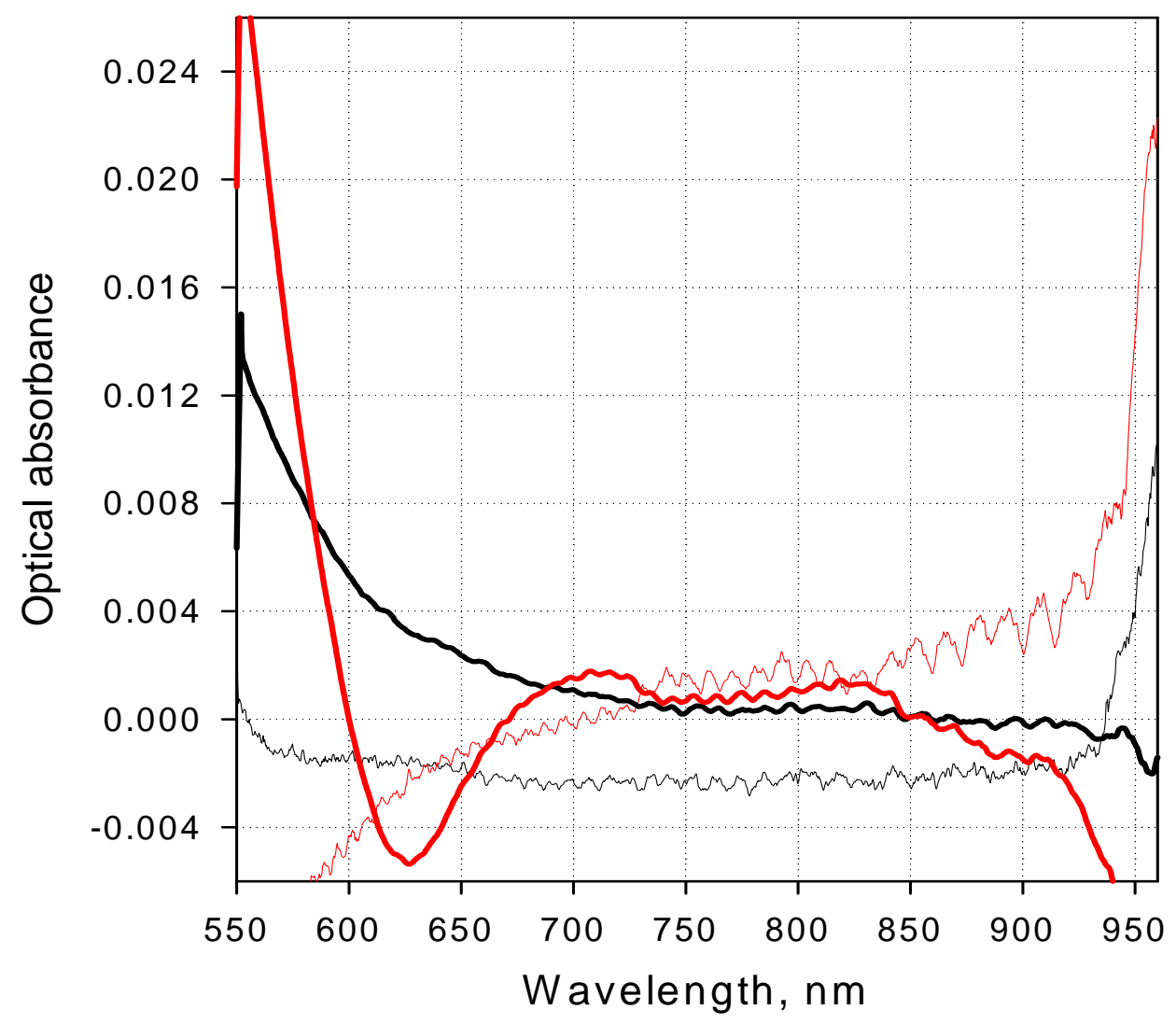

Figure 3.26. $\mathrm{Pu}(\mathrm{IV})$ Spectra in $0.25 \mathrm{M} \mathrm{NaOD}$ for Freshly Spiked (bold black trace, $0.027 \mu \mathrm{M}$ of total $\mathrm{Pu}$ ) and 3-Day-Old Solution (bold red trace; $0.016 \mu \mathrm{M}$ of total $\mathrm{Pu}$ ). Thin black and red traces represent the spectra of blank solutions $(0.25 \mathrm{M}$ of $\mathrm{NaOD}$ before injection of $\mathrm{Pu}$ containing samples). 


\subsection{4 $\mathrm{Pu}(\mathrm{IV})$ Speciation and Solubility in 0.25 $\mathrm{M}$ NaOD in the Presence of Carbonate}

Carbonate is known as a strong complexing agent for tetravalent plutonium (Lierse and Kim 1986; Clark et al. 1995; Yamaguchi et al. 1994; Rai et al. 1999; Neck et al. 2007). Its presence in a weakly alkaline medium $(0.01 \mathrm{M} \mathrm{KOH})$ starting from $0.1 \mathrm{M}$ of carbonate was reported to enhance the solubility of $\mathrm{Pu}(\mathrm{IV})$ many orders of magnitude up to $0.003 \mathrm{~m}$ in a $6.2 \mathrm{~m} \mathrm{~K}_{2} \mathrm{CO}_{3}$ solution. At this high concentration, the carbonate complex of $\mathrm{Pu}(\mathrm{IV})$ was characterized by a number of techniques (including optical absorbance spectroscopy) and proved to have five carbonate ions coordinated around a metal center: $\mathrm{Pu}^{\mathrm{IV}}\left(\mathrm{CO}_{3}\right)_{5}{ }^{6-}$ (Clark et al. 1995). The same species predominates in a concentrated solution of bicarbonate (1.04 $\mathrm{m}$ of $\mathrm{KHCO}_{3}$ ). At a lower carbonate concentration, the stoichiometry and the spectral features of mixed hydroxy-carbonate complexes of $\mathrm{Pu}(\mathrm{IV})$ could not be established because of an insufficient concentration of these species. Solubility curve analysis using a thermodynamic model developed by Rai and coworkers indicated that just one hydroxyl-carbonate species of $\mathrm{Pu}(\mathrm{IV})$ of the 2:2 stoichiometry $\left[\mathrm{Pu}(\mathrm{OH})_{2}\left(\mathrm{CO}_{3}\right)_{2}{ }^{2-}\right]$ needs to be included in the model in addition to the limiting pentacarbonate complex to explain the observed solubility behavior of $\mathrm{PuO}_{2}(\mathrm{am})$ in bicarbonate systems. However, the same twospecies model did not describe adequately the solubility curve of $\mathrm{Pu}(\mathrm{IV})$ in a carbonate solution at a carbonate concentration less than $1 \mathrm{~m}$. This discrepancy indicated that additional species are needed to better fit the carbonate data. Yamaguchi et al. determined the solubility of $\mathrm{PuO}_{2}(\mathrm{am})$ in relatively low ionic strength solutions $(0.1 \mathrm{M})$ at total carbonate concentrations of $<0.1 \mathrm{M}$ and at $\mathrm{pH}$ values ranging from 9.4 to 13.0. The authors interpreted their data assuming the formation of $\mathrm{Pu}(\mathrm{OH})_{2}\left(\mathrm{CO}_{3}\right)_{2}{ }^{2-}$ in the bicarbonate region and the formation of $\mathrm{Pu}(\mathrm{OH})_{4}\left(\mathrm{CO}_{3}\right)_{2}{ }^{4-}$ in the carbonate region. However, these species were found to exist at concentrations too low to be verified by spectroscopic techniques.

For oxidative alkaline leaching that was proposed for chromium dissolution from Hanford tank sludges, carbonate is not considered as one of the intentionally added chemicals to the leaching solution, but it can be present in solution as an impurity or contributing component in sodium hydroxide, or it can accumulate in leaching solutions and leachates upon their exposure to an ambient air atmosphere with $\sim 300 \mathrm{ppm}$ of $\mathrm{CO}_{2}$. Therefore, in this project, the effect of carbonate on the solubility and speciation of $\mathrm{Pu}(\mathrm{IV})$ was studied at a constant concentration of $\mathrm{NaOD}$ at $0.25 \mathrm{M}$ and a variation of carbonate concentration from 0 to $0.25 \mathrm{M}$. Solutions were prepared in duplicate with the first series spectrally measured 10 minutes after adding $\mathrm{Pu}(\mathrm{IV})$ acidic stock to the excess of $\mathrm{NaOD}+\mathrm{Na}_{2} \mathrm{CO}_{3}$. The second series was measured 3 days after $\mathrm{Pu}$ introduction to the solutions. Acidic $\mathrm{Pu}(\mathrm{IV})$ was added to achieve a $\mathrm{Pu}$ concentration at the $9 \mu \mathrm{M}$ in case all added Pu should remain in alkaline solution. Both experiments were conducted under aerobic conditions. Concentrations of soluble $\mathrm{Pu}$ in these solutions were determined by LSC analysis after acidification of the filtered samples with an $\mathrm{HCl}$ excess immediately after the spectral measurement. The spectral data are shown in Figure 3.27, and the solubility data are plotted in Figure 3.28. The freshly prepared and measured series [plot a)] does not show any peak-like spectral features regardless of the carbonate concentration except the previously observed monotonous increase of optical absorbance in the short-wavelength range of the spectrum. The solubility of Pu shows a modest enhancement at increasing carbonate levels (from $0.027 \mu \mathrm{M}$ in carbonate-free solution to $0.14 \mu \mathrm{M}$ in 0.25 $\mathrm{M} \mathrm{Na}_{2} \mathrm{CO}_{3}$ ). The magnitude of the spectral elevation at $560 \mathrm{~nm}$ does not correlate with total soluble $\mathrm{Pu}$ levels in these series. No spectral features of $\mathrm{Pu}(\mathrm{V})$ and $\mathrm{Pu}(\mathrm{VI})$ previously established in mixed hydroxycarbonate media can be distinguished in this spectral set regardless of carbonate level. 

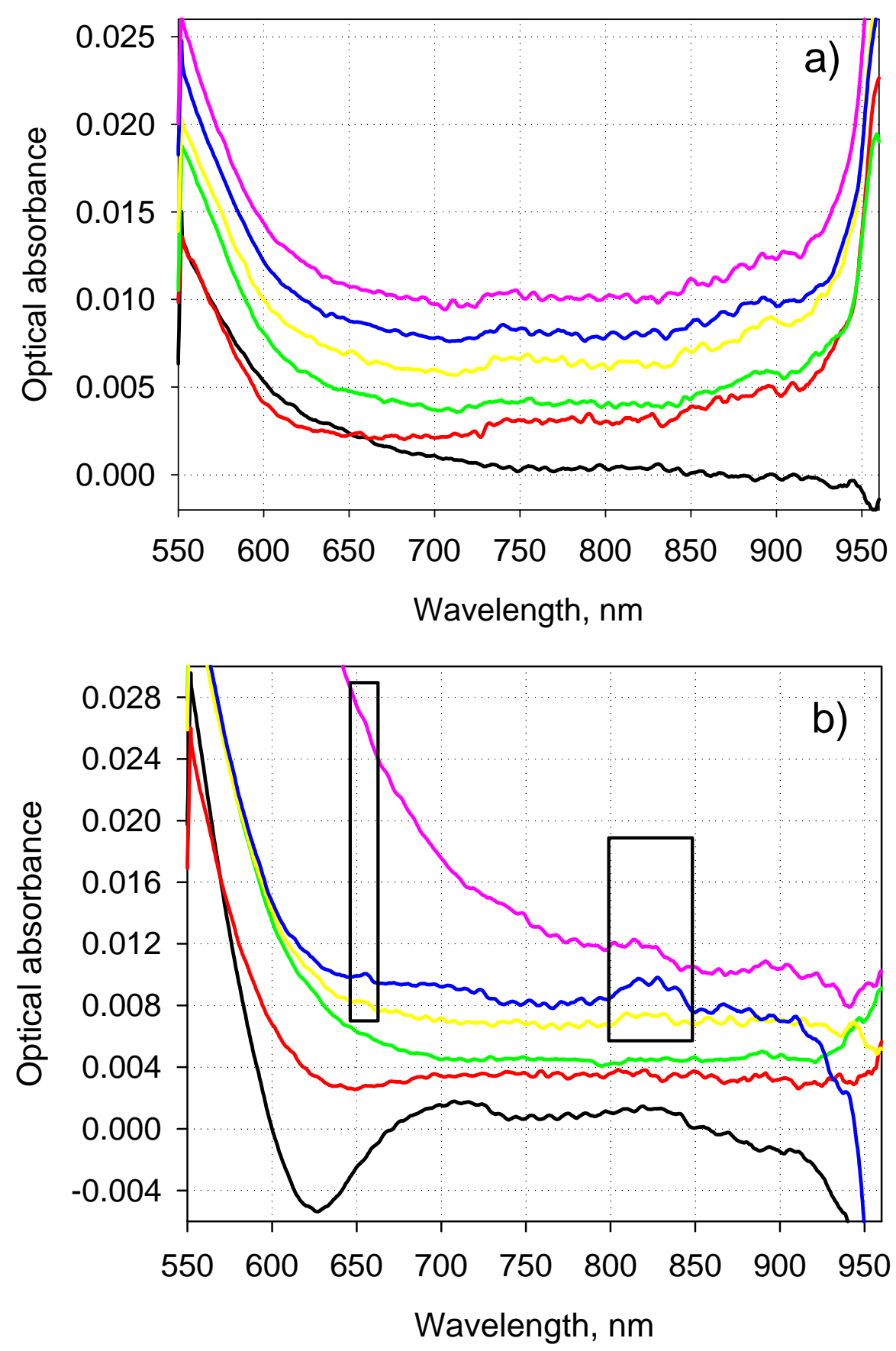

Figure 3.27. $\mathrm{Pu}(\mathrm{IV})$ Spectra in $0.25 \mathrm{M} \mathrm{NaOD}$ in the Presence of Carbonate. Freshly prepared series a); 3 -day-old series b). Carbonate concentration is 0-, 0.05-, 0.10-, 0.15-, 0.20-, and 0.25-M black, red, yellow, green, blue, and pink spectral traces, respectively. The expected initial concentration of $\mathrm{Pu}(\mathrm{IV})$ is $9 \mu \mathrm{M}$ assuming all added $\mathrm{Pu}$ remains in solution. Black rectangular frames in plot b) show regions of weak spectral features at $653 \mathrm{~nm}$ and $825 \mathrm{~nm}$. 


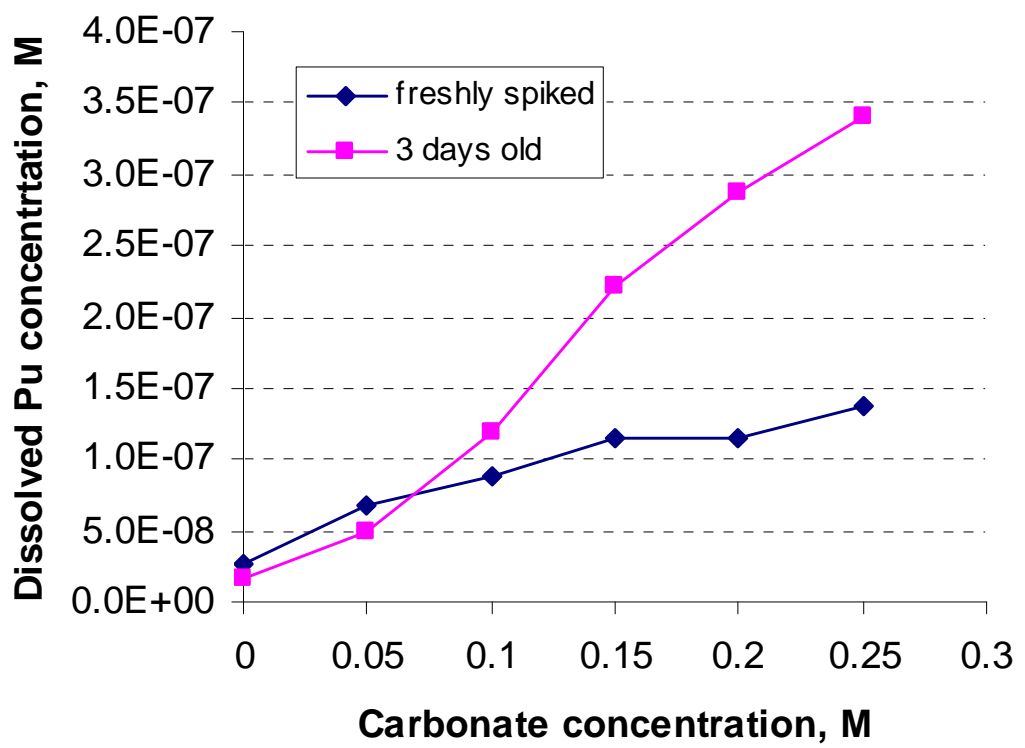

Figure 3.28. Effect of Carbonate on the Solubility of $\mathrm{Pu}(\mathrm{IV})$ in $0.25 \mathrm{M} \mathrm{NaOD}$

The 3-day-old series of $\mathrm{Pu}(\mathrm{IV})$ solutions showed somewhat different data, both spectrally and in terms of the concentration of soluble $\mathrm{Pu}$. The first three levels of carbonate concentration $[0,0.05$, and $0.10 \mathrm{M}$ with black, red and green spectral traces, respectively, in plot b)] did not produce any new spectral features compared with featureless spectra of these solutions observed in the freshly spiked series. The only spectral difference between freshly spiked and 3-day-old spectra for these carbonate concentrations is a more pronounced monotonous increase of optical absorbance in the short wavelength range of the spectrum. Solubility data (Figure 3.28, first three points in the pink curve) indicate that only at $0.10 \mathrm{M}$ of carbonate, the total concentration of soluble Pu increased about 35\% compared with a freshly prepared sample of the same composition. At lower carbonate concentrations, an opposite effect was observed, which can be explained by aging of initially fresh $\mathrm{Pu}(\mathrm{OH})_{4}$ solid.

At higher carbonate concentrations [0.15, 0.20, and $0.25 \mathrm{M}$ with yellow, blue, and pink spectral traces, respectively, in plot b)], weak but sufficiently distinct peaks at $653 \pm 1 \mathrm{~nm}$ and $823 \pm 3 \mathrm{~nm}$ can be identified on the spectra. These peaks' positions are in good correspondence with the spectra of $\mathrm{Pu}(\mathrm{V})$ in $0.25 \mathrm{M}$ of $\mathrm{NaOD}$ with an increasing concentration of carbonate [Figure 3.20, plot a)]. The 823-nm peak

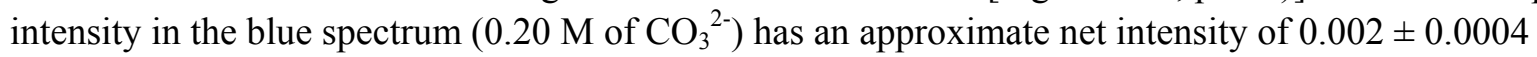
absorbance units. If it is assumed that the mixed hydroxy-carbonate complex of $\mathrm{Pu}(\mathrm{V})$ is the only species that accounts for the total dissolved Pu concentration in this solution $(0.29 \mu \mathrm{M})$, then the expected peak intensity should amount to $0.04 \times 0.29 / 14.3=0.0008$ absorbance units [0.04 is net peak intensity of $\mathrm{Pu}(\mathrm{V})$ complex shown in Figure 3.20 a) at a $14.3 \mu \mathrm{M}$ concentration of $\mathrm{Pu}(\mathrm{V})]$. Therefore, the observed magnitude of the $\mathrm{Pu}^{\mathrm{V}}(\mathrm{OD})_{\mathrm{x}}\left(\mathrm{CO}_{3}\right)_{\mathrm{y}}$ complex absorbance is $\sim 2.5$ times higher than can be predicted from the molar absorptivity observed in the mixed complex study (Section 3.5.3). The reason for this discrepancy is difficult to understand unless the tenuous assumption is made that the molar absorptivity of the mixed hydroxyl-carbonate complex of $\mathrm{Pu}(\mathrm{V})$ increases at lower concentrations of $\mathrm{Pu}(\mathrm{V})$.

The data on $\mathrm{Pu}(\mathrm{IV})$ solubility in a mixed $\mathrm{NaOD}-\mathrm{Na}_{2} \mathrm{CO}_{3}$ medium were plotted in a log-log scale and analyzed in terms of the slope of this dependence (the plot is not shown). Originally, this treatment was applied by Yamaguchi and co-workers who studied the solubility of $\mathrm{Pu}(\mathrm{IV})$ in aqueous carbonate solution 
at $\mathrm{pH} 9$ to 10 (bicarbonate region) and at pH 12 and 13 (carbonate region). Their measured solubility of $\mathrm{Pu}(\mathrm{IV})$ for the higher $\mathrm{pH}$ region was found to be proportional to the square of the carbonate concentration (slope $=2$ in the log-log plot), which was sufficient in their opinion to conclude that the predominant soluble species of $\mathrm{Pu}(\mathrm{IV})$ had the following composition: $\mathrm{Pu}(\mathrm{OH})_{4}\left(\mathrm{CO}_{3}\right)_{2}{ }^{4-}$. The similar treatment applied to the present work data returned the following values of the slope: $0.45 \pm 0.03\left(R^{2}=0.983\right)$ for the freshly spiked series and $1.24 \pm 0.07\left(\mathrm{R}^{2}=0.989\right)$ for the 3 -day-old series. Caution should be exercised in the attempt to derive the mixed complex stoichiometry from these slopes. The 3-day-old series cannot be analyzed this way because of the significant presence of $\mathrm{Pu}(\mathrm{V})$ in solution. The fresh series was measured quickly enough to minimize $\mathrm{Pu}(\mathrm{IV})$ to $\mathrm{Pu}(\mathrm{V})$ oxidation, but a significant variation of the ionic strength as a function of the sodium-carbonate concentration at a constant level of $0.25 \mathrm{M}$ of $\mathrm{NaOD}$ (from $0.25 \mathrm{M}$ to $1 \mathrm{M}$ ) may distort the real stoichiometry because the assumption of the steady value of the equilibrium constant for the mixed complex formation under these conditions was not valid.

Nevertheless, the similar value of the fractional slope was derived by the author of this study from the recently published report on the solubility of $\mathrm{ThO}_{2} \cdot \mathrm{xH}_{2} \mathrm{O}(\mathrm{am})$ in a carbonate solution at $[\mathrm{OH}]=0.1 \mathrm{M}$ (Altmaier et al. 2005). The solubility of Th derived from one of the plots in that publication was estimated to be $10^{-8 \pm 0.5} \mathrm{M}, 10^{-8.2 \pm 0.3} \mathrm{M}$, and $10^{-8.4 \pm 0.3} \mathrm{M}$ at carbonate concentrations of $0.1 \mathrm{M}, 0.04 \mathrm{M}$, and $0.015 \mathrm{M}$, respectively (closed-system experiment). These data allow the slope value of 0.47 to be derived, formally corresponding to less than one carbonate ion per Th ion in the mixed complex formula, but in terms of the speciation diagram, this represents an equilibrium between $\mathrm{Th}(\mathrm{OH})_{4}{ }^{0}$ and $\mathrm{Th}(\mathrm{OH})_{4} \mathrm{CO}_{3}{ }^{2-}$. Excellent correspondence between the slope value obtained by Altmaier and colleagues (2005) for the redox stable Th(IV) and the respective parameter found in this study for the freshly prepared $\mathrm{Pu}(\mathrm{IV})$ solubility series in $0.25 \mathrm{M} \mathrm{NaOD}+\mathrm{Na}_{2} \mathrm{CO}_{3}$ indicates that soluble $\mathrm{Pu}(\mathrm{IV})$ in our experiments did not get oxidized to any significant extent to more soluble $\mathrm{Pu}(\mathrm{V})$.

A recent solubility study of $\mathrm{Pu}$ and Am in alkaline salt solutions representative of SRNL tank waste (Rudisill et al. 2004) identified hydroxide and carbonate as the two most significant factors determining the $\mathrm{Pu}$ solubility in these six-component media containing also aluminate, sulfate, nitrate, and nitrite as their sodium salts. The functional dependence established in that study can be expressed as follows:

$$
[\mathrm{Pu}]=-7.48 \times 10^{-8}+1.2 \times 10^{-6}\left[\mathrm{OH}^{-}\right]+4.9 \times 10^{-6}\left[\mathrm{CO}_{3}^{2-}\right]
$$

The derived coefficients are valid for $\mathrm{OH}^{-}$and $\mathrm{CO}_{3}{ }^{2-}$ concentrations expressed in molar scale. This relationship was established using experimental points in the range of 0.45 to $15 \mathrm{M}$ of $\mathrm{NaOH}$ and of 0.001 - to $0.95 \mathrm{M} \mathrm{CO}_{3}{ }^{2-}$ concentrations, and it is based on solubility data obtained from 40 to 90 days of equilibration. It is of interest to test the predictive power of this equation for conditions used to determine the solubility of $\mathrm{Pu}$ in the test described in this section (i.e., a constant level of $0.25 \mathrm{M} \mathrm{NaOD}$ and variable carbonate). Table 3.5 compares predicted values with experimentally-determined solubilities.

Comparing predicted and actually observed solubilities shows that the SRNL model overestimates Pu solubilities observed in this work for freshly spiked series by a factor of $8.8 \pm 1.4$ (the average number and standard deviation for all six points). It should be mentioned again here that the SRNL equilibration times (40 to 90 days) were much longer than those used in this work, which, on the one hand, should produce $\mathrm{Pu}(\mathrm{IV})$ hydrous oxide with a higher degree of microcrystallinity and, hence, a lower concentration of soluble $\mathrm{Pu}(\mathrm{IV})$ in equilibrium with $\mathrm{PuO}_{2} \mathrm{xH}_{2} \mathrm{O}$. On the other hand, longer equilibration times should allow a slow $\mathrm{Pu}(\mathrm{IV})$ oxidation by dissolved oxygen to proceed to a much higher extent, resulting in significant conversion of poorly soluble $\mathrm{Pu}(\mathrm{IV})$ to more soluble $\mathrm{Pu}(\mathrm{V})$. Comparing the 
freshly spiked series with the 3-day-old series indicates that the rate of this reaction increases in the presence of higher levels of carbonate. This conclusion is based on comparing the model overestimation factors for the first three levels of carbonate $(9.8 \pm 3.9)$ with the last three experimental points $(4.3 \pm 0.1)$. More experiments in more detail are needed to examine the kinetics of $\mathrm{Pu}(\mathrm{IV})$ to $\mathrm{Pu}(\mathrm{V})$ conversion at various levels of hydroxide and carbonate.

Table 3.5. Comparison of Experimentally Determined Solubilities of Pu in Mixed Hydroxy-Carbonate Medium at Constant Level of $0.25 \mathrm{M} \mathrm{NaOD} / \mathrm{D}_{2} \mathrm{O}$ with Predictions of the SRNL Pu Solubility Model (Rudisill et al. 2004)

\begin{tabular}{|c|c|c|c|c|c||}
\hline $\begin{array}{c}\text { Carbonate, } \\
\mathbf{M}\end{array}$ & $\begin{array}{c}\mathbf{P} \mathbf{u}_{\text {predicted, }}, \\
\boldsymbol{\mu M}\end{array}$ & $\begin{array}{c}\mathbf{P} \mathbf{u}_{\text {fresh }} \mathbf{o b s e r v e d ,} \\
\mathbf{\mu M}\end{array}$ & $\mathbf{P u}_{\text {fresh }} / \mathbf{P u}_{\text {predicted }}$ & $\begin{array}{c}\mathbf{P} \mathbf{u}_{\text {3 days old }} \\
\mathbf{o b s e r v e d , ~} \boldsymbol{\mu M}\end{array}$ & $\begin{array}{c}\mathbf{P} \mathbf{u}_{\mathbf{3} \text { days old }} / \\
\mathbf{P} \mathbf{u}_{\text {predicted }}\end{array}$ \\
\hline 0 & 0.225 & 0.0268 & 0.119 & 0.0163 & 0.072 \\
\hline 0.05 & 0.470 & 0.0669 & 0.142 & 0.0491 & 0.104 \\
\hline 0.10 & 0.715 & 0.0886 & 0.124 & 0.119 & 0.166 \\
\hline 0.15 & 0.960 & 0.0115 & 0.120 & 0.221 & 0.230 \\
\hline 0.20 & 1.21 & 0.115 & 0.095 & 0.288 & 0.239 \\
\hline 0.25 & 1.45 & 0.138 & 0.095 & 0.340 & 0.235 \\
\hline
\end{tabular}

In summary, we believe that our experimental data represent the solubility of $\mathrm{Pu}(\mathrm{IV})$ in equilibrium with freshly precipitated $\mathrm{PuO}_{2} \mathrm{xH}_{2} \mathrm{O}$ more correctly than can be assessed through the SRNL model prediction, which produces highly overestimated values presumably because of the significant conversion of $\mathrm{Pu}(\mathrm{IV})$ to $\mathrm{Pu}(\mathrm{V})$.

\subsection{Oxidative Dissolution of Pu(IV) Hydroxide Suspension by Permanganate and Manganate in 0.25 $\mathrm{M}$ NaOD}

\subsubsection{Oxidative Dissolution of $\mathrm{Pu}^{\mathrm{IV}}(\mathrm{OH})_{4}$ Suspension by $\mathrm{NaMnO}_{4}$ in $0.25 \mathrm{M} \mathrm{NaOD}$}

The $\mathrm{Pu}(\mathrm{OH})_{4}$ solid was prepared by neutralizing the $\mathrm{Pu}(\mathrm{IV})$ solution in nitric acid with a slight excess of the $0.25 \mathrm{M}$ NaOD solution. The brown-greenish precipitate was formed immediately after neutralization and aged under the mother liquid for 3 days. The amount of $\mathrm{Pu}(\mathrm{OH})_{4}$ used in the oxidative leaching experiments was controlled volumetrically by sampling out a known volume of continuously stirred suspension [with a formal $\mathrm{Pu}(\mathrm{IV})$ concentration of $4.5 \mathrm{mM}$ ] and delivering it to a reaction vessel containing oxidizer.

The first experiment was performed in a $0.25 \mathrm{M} \mathrm{NaOD}$ medium at 3.38-fold molar excess of permanganate with respect to $\mathrm{Pu}$. In earlier experiments on permanganate stability in alkaline solutions, it was observed that permanganate undergoes a slow reduction to manganate in the process of spectrophotometric monitoring when the solution is in contact with a plastic wall of a $1-\mathrm{cm}$ spectrophotometric cell. Therefore, to make a distinction between permanganate consumption in the process of $\mathrm{Pu}(\mathrm{IV})$ oxidation to $\mathrm{Pu}(\mathrm{V})$ or $\mathrm{Pu}(\mathrm{VI})$ and permanganate decomposition by water and/or plastic material of the cell, a control experiment was run in parallel with the Pu-dissolution experiment. Both experiments were started at the same time by placing equal portions of $0.2 \mathrm{mM} \mathrm{NaMnO}_{4}$ solution in 0.25 $\mathrm{M} \mathrm{NaOD}$ into two identical spectrophotometric cells equipped with Teflon stir bars and taking the spectra 
of these identical solutions (spectral traces 00 in the Figure 3.29). At time zero, an aliquot of $\mathrm{Pu}(\mathrm{OH})_{4}$ suspension was added to one of the cells, and stirring was continued for 5 minutes before the first spectral measurement with $\mathrm{Pu}$ present. Both cells were returned to the stirrer, and stirring continued for another 5 minutes before the next spectral scan. No centrifugation or filtration was applied to separate unreacted $\mathrm{Pu}(\mathrm{OH})_{4}$ before spectrophotometric measurements. In total, 12 spectral scans were taken with hot and cold samples before taking an aliquot of hot solution for filtration and LSC analysis to determine the concentration of dissolved Pu. The spectral data are shown in Figure 3.29. The cold series (shown in green color) is plotted as is, while the hot series (red color) is upshifted by 0.175 absorbance units for clarity.

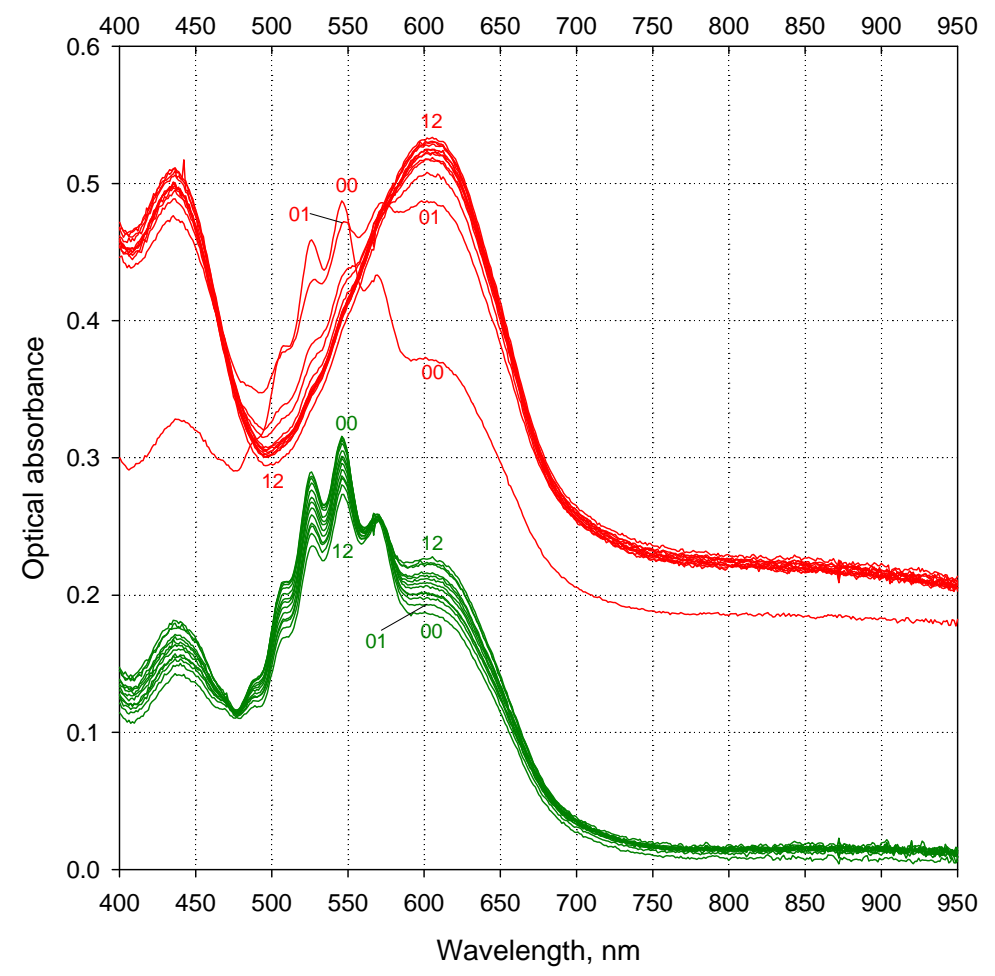

Figure 3.29. Spectral Monitoring over Mn(VII) Conversion to $\mathrm{Mn}(\mathrm{VI})$ in the Presence of Added $\mathrm{Pu}(\mathrm{OH})_{4}$. Green series: control experiment without $\mathrm{Pu}(\mathrm{OH})_{4}$; red series: identical solution and volume of $0.2 \mathrm{mM} \mathrm{Mn}(\mathrm{VII})$ after addition of $30.1 \mu \mathrm{g}$ of $\mathrm{Pu}$ (as metal) in a form of $\mathrm{Pu}(\mathrm{OH})_{4}$ (solid). The red series is upshifted by 0.175 absorbance units for clarity. The molar ratio of permanganate to plutonium is set to 3.38:1. Time intervals between consecutive spectral scans within each series are $7.5 \pm 0.5$ minutes.

Qualitatively, the hot sample changed its color from purple-gray to green-gray very quickly in the first 5 to 6 minutes after Pu addition, whereas no appreciable color changes were noticed for the cold sample. Spectrally, this difference can be illustrated by comparing 00 and 01 spectra in both series. It can be seen that significant conversion of $\mathrm{Mn}(\mathrm{VII})$ to $\mathrm{Mn}(\mathrm{VI})$ occurred within the first few minutes after introducing a suspension of $\mathrm{Pu}(\mathrm{IV})$ hydroxide. Subsequent measurements showed a relatively quick additional conversion of the remaining $\mathrm{Mn}(\mathrm{VII})$ to $\mathrm{Mn}(\mathrm{VI})$ in the hot sample with a solution color change to purely green in the first 60 to 70 minutes. In the case of a hypothetical conversion of $\mathrm{Pu}(\mathrm{IV})$ to $\mathrm{Pu}(\mathrm{VI})$, one equivalent of $\mathrm{Pu}$ should reduce 2 equivalents of $\mathrm{Mn}(\mathrm{VII})$ or, in other words, the consumption of $\mathrm{Mn}(\mathrm{VII})$ 
should stop when all $\mathrm{Pu}(\mathrm{IV})$ gets dissolved. On the other hand, if the final oxidation state of $\mathrm{Pu}$ in solution is $\mathrm{Pu}(\mathrm{V})$, then 1:1 reaction stoichiometry is expected. In reality, however, more than 2 equivalents of $\mathrm{Mn}(\mathrm{VII})$ were consumed at the moment of the last spectral scan [red trace \#12 shows not less than $95 \%$ of $\mathrm{Mn}(\mathrm{VII})$ converted to $\mathrm{Mn}(\mathrm{VI})$, which is the equivalent of $0.95 \times 3.38=3.2$ molar equivalents of $\mathrm{Mn}$ (VII) spent per one equivalent of $\mathrm{Pu}(\mathrm{IV})$ added]. The possibility of $\mathrm{Pu}(\mathrm{IV})$ oxidation to $\mathrm{Pu}(\mathrm{VII})$ can be excluded at such low alkalinity. Therefore, the experimentally observed superstoichiometric consumption of permanganate indicated another possible pathway of its decomposition via catalytic reduction by water in the presence of unreacted $\mathrm{Pu}(\mathrm{OH})_{4}$ solid. This possibility was confirmed by LSC analysis, which showed only $53 \%$ of total $\mathrm{Pu}$ dissolved in $2.3 \mathrm{hr}$ since $\mathrm{Pu}$ introduction.

Both samples were stirred for several more days with only occasional spectrophotometic monitoring. Two more samples were taken for determination of dissolved $\mathrm{Pu}$ in solution 1 day and 4 days after the beginning of this experiment. According to LSC data, the fraction of the dissolved Pu dropped down from $53 \%$ to $49 \%$ for the "1-day-after" sample and further to $38 \%$ for the "4-day-after" sample. This decreasing trend in concentration of leachable Pu qualitatively correlated with a progressive accumulation of dark brown precipitate of $\mathrm{MnO}_{2}$ in the hot sample, which likely acted as a precipitating agent for initially soluble $\mathrm{Pu}(\mathrm{V})$ or $\mathrm{Pu}(\mathrm{VI})$ under these conditions.

In summary, this experiment did not provide sufficient data to establish the stoichiometry of permanganate consumption to distinguish between $\mathrm{Pu}(\mathrm{V})$ (expected 1:1 $\mathrm{Pu}: \mathrm{Mn}(\mathrm{VII})$ molar ratio) and $\mathrm{Pu}(\mathrm{VI})$ (expected 1:2 $\mathrm{Pu}: \mathrm{Mn}(\mathrm{VII})$ ratio) as the final oxidation state of $\mathrm{Pu}$ in the leachate.

For the second experiment, it was decided to generate $\mathrm{Pu}(\mathrm{OH})_{4}$ directly in the oxidizer-containing solution by adding a small amount of acidic $\mathrm{Pu}(\mathrm{IV})$ solution to an excess of the alkaline solution of $\mathrm{NaMnO}_{4}$. The idea of this experiment was to minimize catalytic decomposition effects of permanganate by solid $\mathrm{Pu}^{\mathrm{IV}}(\mathrm{OH})_{4}$ particles to calculate the stoichiometry of permanganate consumption in the process of $\mathrm{Pu}(\mathrm{IV})$ oxidation. The approach was to prepare freshly hydrolyzed $\mathrm{Pu}(\mathrm{IV})$ hydroxide in the same solution where permanganate was already present. This was achieved by spiking a tiny volume of relatively concentrated acidic $\mathrm{Pu}(\mathrm{IV})$ solution in $1 \mathrm{M} \mathrm{DNO}_{3}$ into a much larger volume of $0.2 \mathrm{mM}$ of $\mathrm{NaMnO}_{4}$ in $0.25 \mathrm{M}$ of $\mathrm{NaOD} / \mathrm{D}_{2} \mathrm{O}$. The estimated perturbation of the alkalinity level of the initial $0.25 \mathrm{M} \mathrm{NaOD}$ solution was less than $4 \%$. The calculated concentration of $\mathrm{Pu}$ in solution in the case of $100 \%$ solubilization was $18.9 \mu \mathrm{M}$ (three times less than in the previous experiment). In terms of other experimental details (application of cold solution as control, solution stirring mode, frequency of spectral data acquisition), this experiment was identical to the first one described above. The spectral data from this run are shown in Figure 3.30. Again, as in the previously observed case, adding Pu results in a much more noticeable in-growth of $\mathrm{Mn}(\mathrm{VI})$ compared with the control (see spectral traces 00 and 01 in both series). Further spectral changes in the hot sample indicate a practically complete conversion of Mn(VII) to $\mathrm{Mn}(\mathrm{VI})$ in the time frame of spectral monitoring $(2.3 \mathrm{hr})$. This fact indicates that the effect of catalytic decomposition of $\mathrm{Mn}(\mathrm{VII})$ by $\mathrm{Pu}(\mathrm{IV})$ or its oxidation products could not be completely eliminated even with freshly formed $\mathrm{Pu}(\mathrm{IV})$ hydroxide.

LSC analysis indicated that $81 \%(15.3 \mu \mathrm{M})$ of total Pu spiked into solution was found in dissolved form after spectral scan \#6 ( 1 hour of contact time), and 76\% was found after spectral scan \#12 ( $2 \mathrm{hr}$ of agitation). By comparing the peak intensities of manganate at $603 \mathrm{~nm}$ for spectral scans $\# 00$ and $\# 06$, the concentration of permanganate consumed in contact with $\mathrm{Pu}(\mathrm{VI})$ can be estimated as $45 \mu \mathrm{M}$. 


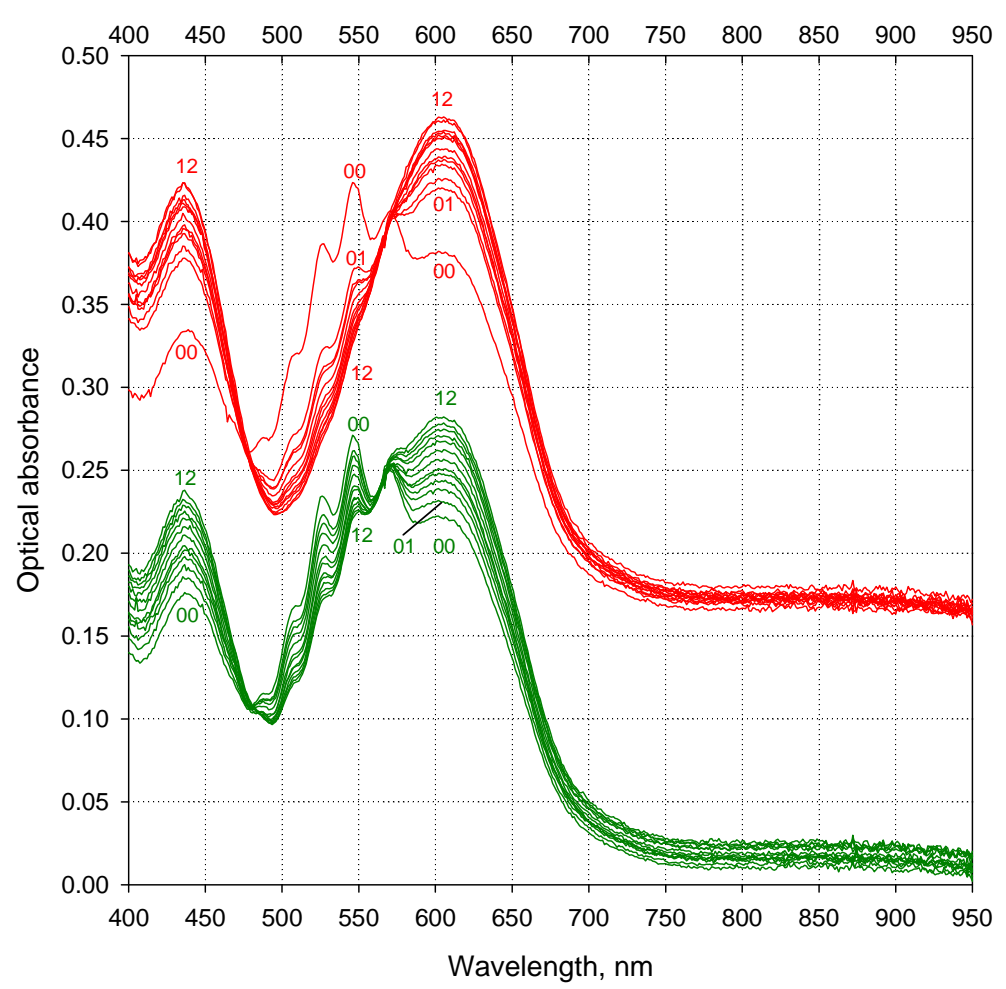

Figure 3.30. Spectral Monitoring over Mn(VII) Conversion to Mn(VI) in the Presence of in situ Generated $\mathrm{Pu}(\mathrm{OH})_{4}$ in Alkaline Solution of $\mathrm{Mn}(\mathrm{VII})$. Green series: control experiment without $\mathrm{Pu}(\mathrm{OH})_{4}$; red series: identical solution and volume of $0.2 \mathrm{mM}$ of $\mathrm{Mn}(\mathrm{VII})$ after adding $12.6 \mu \mathrm{g}$ of $\mathrm{Pu}$ in the form of $\mathrm{Pu}(\mathrm{IV})$ nitrate in $4 \mathrm{M}$ of $\mathrm{DNO}_{3}$. The red series is upshifted by 0.15 absorbance units for clarity. The molar ratio of permanganate to the total plutonium added is set to 10.5:1. Time intervals between consecutive spectral scans within each series are $7.5 \pm 0.5$ minutes.

Thus, the calculated molar ratio of Mn(VII) consumption to soluble Pu generation is found to be $45: 15.3=3: 1$. This ratio is $50 \%$ higher than the expected $2: 1$ ratio in the case of $\mathrm{Pu}(\mathrm{IV})$ oxidation to $\mathrm{Pu}(\mathrm{VI})$ and 3 times higher than the anticipated 1:1 ratio for the hypothetical case of $\mathrm{Pu}(\mathrm{IV})$ oxidation to $\mathrm{Pu}(\mathrm{V})$. Excessive consumption of permanganate might be related to its catalytical decomposition by the remaining $19 \%$ of undissolved $\mathrm{Pu}$ present in solution (most likely in the form of $\mathrm{Pu}(\mathrm{OH})_{4}$ ).

At this stage, it can be concluded that the data obtained provide more support for $\mathrm{Pu}(\mathrm{VI})$ as the final oxidation state of leachable $\mathrm{Pu}$ in the presence of excess manganate and residual permanganate in solution. A detailed discussion of the possibility of $\mathrm{Pu}(\mathrm{V})$ coexistence with manganate in the same solution will be given later in Section 3.9.

After the stoichiometry of the $\mathrm{Pu}(\mathrm{IV})$ reaction with $\mathrm{Mn}(\mathrm{VII})$ was established, one more experiment with $\mathrm{Pu}(\mathrm{OH})_{4}$ solid was performed. In this experiment, oxidative leaching of $\mathrm{Pu}(\mathrm{OH})_{4}$ was studied as a function of the oxidizer concentration at three different levels of permanganate. For each level of $\mathrm{Mn}(\mathrm{VII})$, the kinetics of Pu solubilization was measured in a more systematic way with a sampling 
frequency of 15 minutes. The amount of $\mathrm{Pu}(\mathrm{OH})_{4}$ taken for dissolution was sufficient to create $\mathrm{Pu}$ concentration in solution at $31 \mu \mathrm{M}$ in the case of complete dissolution of the starting compound. No spectral measurements were conducted in this series. The results are shown in Figure 3.31.

The data presented show that a) the kinetics of this process is relatively fast with no statistically significant changes in the concentration of leached Pu observed after the fourth kinetic point (60 minutes after $\mathrm{Pu}(\mathrm{IV})$ addition; $\mathbf{b})$ the extent of $\mathrm{Pu}$ solubilization is a sensitive and non-linear function of the initial concentration of permanganate in solution.

The lowest level of $\mathrm{Mn}(\mathrm{VII})$ used in this experiment $(0.19 \mathrm{mM})$ was tested earlier for leaching $\mathrm{Pu}(\mathrm{OH})_{4}$ at the same alkalinity. Earlier data revealed a progressively higher leaching efficiency of $\mathrm{Pu}$ from its hydroxide (53\% in the very first experiment, and then $39 \%$ in the next experiment 8 days after). This data scattering for the same initial concentration of the oxidant becomes more understandable after taking into account the age of the $\mathrm{Pu}(\mathrm{OH})_{4}$ at the day of run of each experiment. In the very first test with 53\% dissolution, the extent of $\mathrm{Pu}(\mathrm{OH})_{4}$ suspension was 3 days old; in the second test, it was 11 days old, and in the last test with $16 \%$ of Pu leached, the age of the suspension increased to 17 days. Apparently, the $\mathrm{Pu}(\mathrm{OH})_{4}$, which was stored under mother liquid, underwent slow transformation from a completely amorphous material to a substance with a higher degree of microcrystallinity, and this process determined the progressively increased resistance of the $\mathrm{Pu}(\mathrm{IV})$ phase in each subsequent oxidative-leaching experiment. For future studies, it would be desirable to prepare $\mathrm{Pu}(\mathrm{OH})_{4}$ well in advance of oxidativeleaching testing and accelerate its aging process by digesting the precipitate at a elevated temperature for several weeks. This treatment should minimize time drift in its degree of aggregation and microcrystallinity for different experiments.

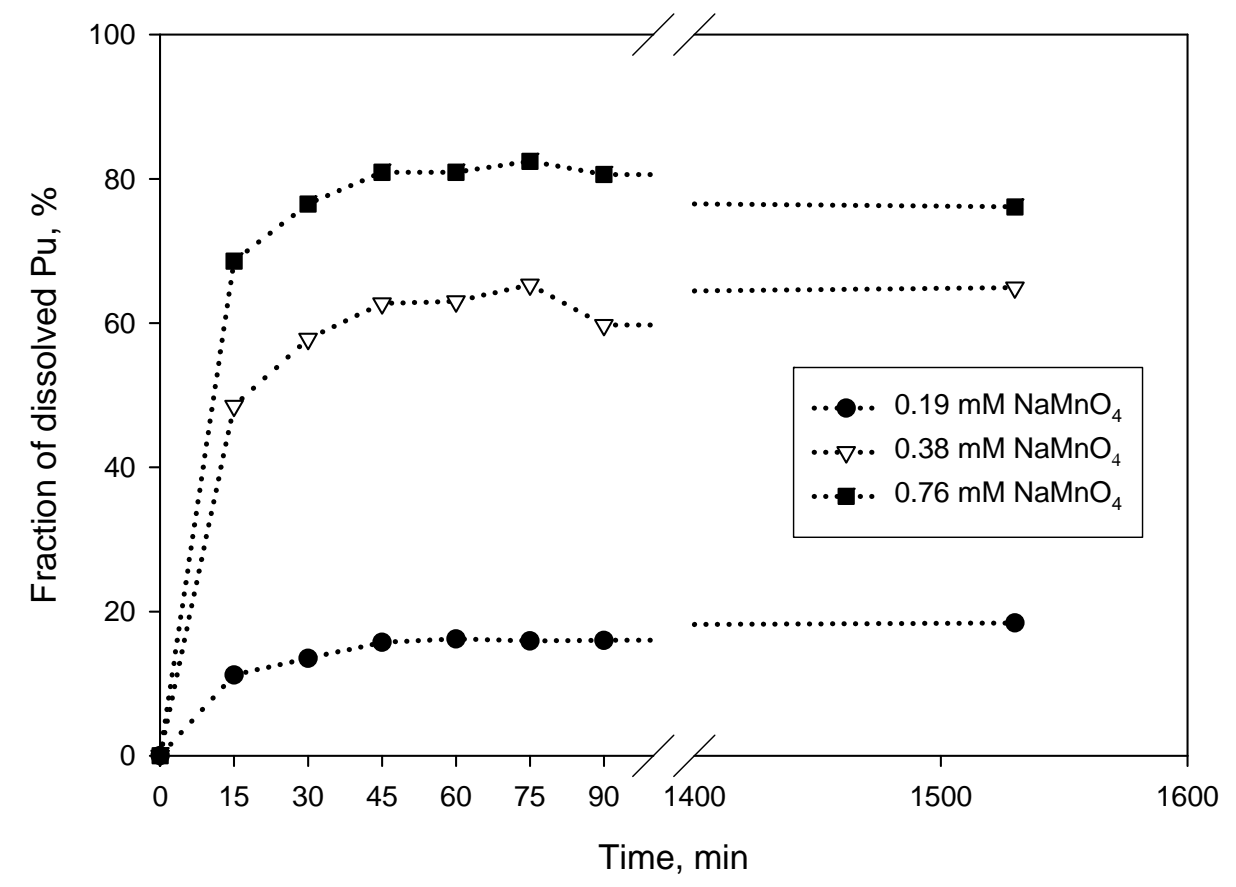

Figure 3.31. The Kinetics of Oxidative Dissolution of $\mathrm{Pu}^{\mathrm{IV}}(\mathrm{OH})_{4}$ Suspension in a Series of $\mathrm{NaMnO}_{4}$ Solutions in $0.25 \mathrm{M}$ of $\mathrm{NaOD} / \mathrm{D}_{2} \mathrm{O}$ at Three Levels of Permanganate. The $\mathrm{Mn}$ (VII) to 
$\mathrm{Pu}(\mathrm{IV})$ molar ratio is $6: 1,12: 1$, and $24: 1$ for $0.19-\mathrm{mM}, 0.38-\mathrm{mM}$, and $0.76-\mathrm{mM}$ concentrations of $\mathrm{Mn}(\mathrm{VII})$, respectively.

In the very first leaching experiment (with 53\% dissolution efficiency of $\mathrm{Pu}(\mathrm{OH})_{4}$ achieved in $2 \mathrm{hr}$ ), it was found that the level of soluble Pu decreased with time from $32 \mu \mathrm{M}$ to $29 \mu \mathrm{M}$ and further to $23 \mu \mathrm{M}$ in 1 day and 4 days, respectively. Two alternative possibilities were considered to explain this negative drift. First, the $32 \mu \mathrm{M}$ concentration of leached Pu might be close enough to the solubility of $\mathrm{Pu}^{\mathrm{VI}} \mathrm{O}_{2}(\mathrm{OH})_{2}$ under these conditions of moderate alkalinity and with time that the level of $\mathrm{Pu}(\mathrm{VI})$ concentration decreased because of a decrease in the solubility product of $\mathrm{Pu}(\mathrm{VI})$ hydroxide. Second, the increasing amount of $\mathrm{MnO}_{2}$ might be slowly formed in the $\mathrm{Pu}(\mathrm{VI})$-containing leachate with time as a result of manganate decomposition at this alkalinity. The $\mathrm{MnO}_{2}$ is known to be an efficient adsorbent for $\mathrm{Pu}(\mathrm{VI})$ in a weakly alkaline medium at $\mathrm{pH}<10$ (Reilly et al. 2003). It is possible that this compound can co-precipitate $\mathrm{Pu}(\mathrm{VI})$ in solution at a $0.25 \mathrm{M} \mathrm{NaOD}$ concentration used in this study.

To test the first possibility, an additional experiment was performed in which sodium carbonate was added to the leaching solution of $0.2 \mathrm{mM} \mathrm{NaMnO}_{4}$ in $0.25 \mathrm{M} \mathrm{NaOD}$. Carbonate is known as a strong complexing agent for $\mathrm{Pu}(\mathrm{VI})$ in alkaline medium, which should significantly enhance the solubility of $\mathrm{Pu}(\mathrm{VI})$ hydroxide and eliminate possible oversaturation conditions for this compound. Three different levels of carbonate addition were tested for the same $\mathrm{Mn}(\mathrm{VII})$ concentration: $0 \mathrm{M}, 0.125 \mathrm{M}$, and $0.25 \mathrm{M}$. The $\mathrm{Pu}$ concentration (if fully dissolved) was set at $31 \mu \mathrm{M}$, and the permanganate concentration (initial) at $0.750 \mathrm{mM}$ with a $\mathrm{Mn}$ (VII)-to- $\mathrm{Pu}(\mathrm{IV})$ molar ratio at 25 to 1 . The results of this experiment are shown in Figure 3.32. No effect of the presence of carbonate on kinetics and the extent of dissolution of $\mathrm{Pu}(\mathrm{OH})_{4}$ was observed. In all three cases, 65 to $75 \%$ of the Pu was dissolved after a 1-hr contact time with stirring. Overnight exposure of the remaining $\mathrm{Pu}(\mathrm{OH})_{4}$ under the same solutions (no stirring) resulted in complete conversion of permanganate to manganate (solutions turned green), but the extent of dissolution of plutonium hydroxide did not increase. After 3 days of observation, all three solutions remained equally green and homogeneous with no colloidal $\mathrm{MnO}_{2}$ visibly formed. After approximately 1 week of observation, it was qualitatively noted that the presence of carbonate had no effect on manganate stability (green color of manganate faded away to the same extent in all three samples).

Therefore, this experiment led to the conclusion that the drop in $\mathrm{Pu}(\mathrm{VI})$ concentration with time is not related to the limited solubility of $\mathrm{Pu}(\mathrm{VI})$ hydroxide in the 20 - to $30-\mu \mathrm{M}$ range of $\mathrm{Pu}(\mathrm{VI})$ concentration.

\subsubsection{Oxidative Dissolution of $\mathrm{Pu}^{\mathrm{IV}}(\mathrm{OH})_{4}$ Suspension by Sodium Manganate in $0.25 \mathrm{M}$ NaOD}

It was of interest to examine the dissolution behavior of $\mathrm{Pu}(\mathrm{OH})_{4}$ in an alkaline solution of sodium manganate. The reduction potential for $\mathrm{Mn}(\mathrm{VI}) / \mathrm{Mn}(\mathrm{IV})$ in $1 \mathrm{M} \mathrm{NaOH}$ is $+0.62 \mathrm{~V}$ (Nash et al. 2005); hence, thermodynamically, it is as powerful an oxidizer as permanganate.

A sodium manganate solution was produced by the spontaneous conversion of Mn(VII) to Mn(VI) while storing permanganate solution in a plastic cell overnight. Approximately $10 \%$ of the manganate anion was found reduced to colloidal $\mathrm{MnO}_{2}$. Therefore, the solution was not perfectly homogeneous at the moment of $\mathrm{Pu}(\mathrm{OH})_{4}$ addition to it. The amount of $\mathrm{Pu}(\mathrm{OH})_{4}$ added $(30.1 \mu \mathrm{g}$ as elemental $\mathrm{Pu})$ was sufficient to achieve a concentration of dissolved $\mathrm{Pu}$ in solution at $59 \mu \mathrm{M}$ in the case of complete dissolution. The manganate to $\mathrm{Pu}$ molar ratio was set at 3:1 for this experiment. Spectral data are presented in Figure 3.33. 


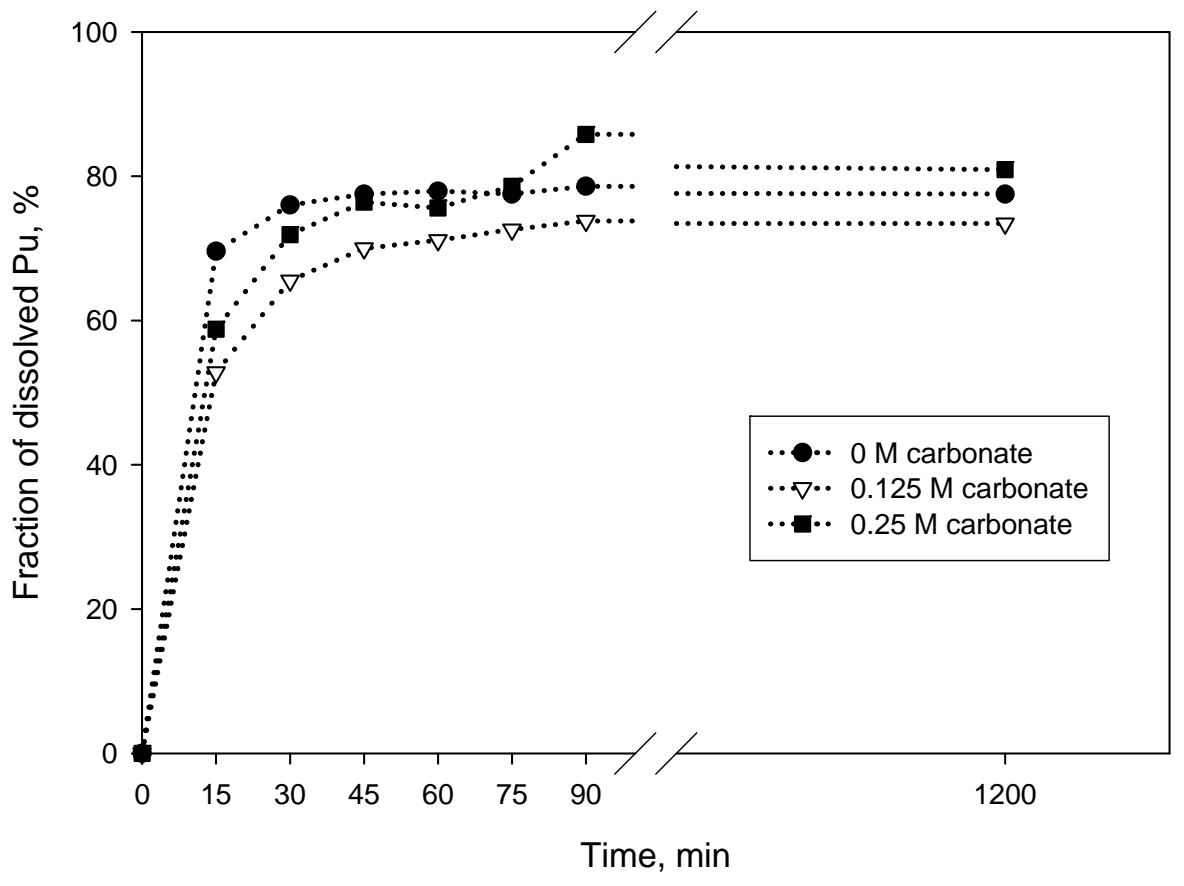

Figure 3.32. The Effect of Carbonate Concentration on the Kinetics of Oxidative Dissolution of $\mathrm{Pu}^{\mathrm{IV}}(\mathrm{OH})_{4}$ Suspension in a Series of $\mathrm{NaMnO}_{4}$ Solutions in $0.25 \mathrm{M} \mathrm{NaOD} / \mathrm{D}_{2} \mathrm{O}$ at $0.75 \mathrm{mM}$ of Permanganate. The $\mathrm{Mn}(\mathrm{VII})$ to $\mathrm{Pu}(\mathrm{IV})$ molar ratio is 25:1.

A significant baseline shift of the $\mathrm{Mn}(\mathrm{VI})$ spectrum after adding $\mathrm{Pu}(\mathrm{OH})_{4}$ (spectral traces 00 and 01 in the red series) is an indication of increased turbidity as a result of the light-scattering from fine solid plutonium hydroxide particles. Both series showed a gradual decomposition of manganate, but in the presence of $\mathrm{Pu}(\mathrm{OH})_{4}$, this process occurred with a significantly faster rate (compare residual magnitude of manganate peak for spectral traces \#12 in both series). Assuming that the oxidation of $\mathrm{Pu}(\mathrm{IV})$ proceeds to $\mathrm{Pu}(\mathrm{VI})$ and the $\mathrm{Mn}(\mathrm{VI})$ reduction proceeds to $\mathrm{Mn}(\mathrm{IV})$, the 1:1 stoichiometry of the oxidative dissolution reaction is expected, which should leave 2 equivalents of $\mathrm{Mn}(\mathrm{VI})$ in solution in case of complete dissolution of $\mathrm{Pu}(\mathrm{VI})$. A tentative estimate of $\mathrm{Mn}(\mathrm{VI})$ consumption in the presence of $\mathrm{Pu}(\mathrm{OH})_{4}$ based on the $\mathrm{Mn}(\mathrm{VI})$ peak magnitude analysis (red trace \#12) indicates that $\sim 0.85$ equivalents of manganate were consumed $1.75 \mathrm{hr}$ after $\mathrm{Pu}(\mathrm{IV})$ hydroxide introduction. However, LSC analysis of the solution sample taken shortly after spectral scan \#12 showed that only $7 \%$ of the total $\mathrm{Pu}(\mathrm{IV})$ added was found in dissolved form. The dissolved $\mathrm{Pu}$ fraction increased to $11 \%$ and further to $16 \%$ after $2 \mathrm{hr}$ and $22 \mathrm{hr}$ of additional agitation. The next-day observation showed that the green color of $\mathrm{Mn}(\mathrm{VI})$ almost faded away in the hot sample and to a much lesser extent in the cold-reference sample with partial formation of brown precipitate of $\mathrm{MnO}_{2}$ in both samples. A partial decomposition of $\mathrm{Mn}(\mathrm{VI})$ to $\mathrm{Mn}(\mathrm{IV})$, even in the absence of oxidizable components other than water, proves that the $0.25 \mathrm{M}$ hydroxide concentration is too low to maintain long-term stability of $\mathrm{Mn}(\mathrm{VI})$, even at submillimolar concentrations of this oxidant. 


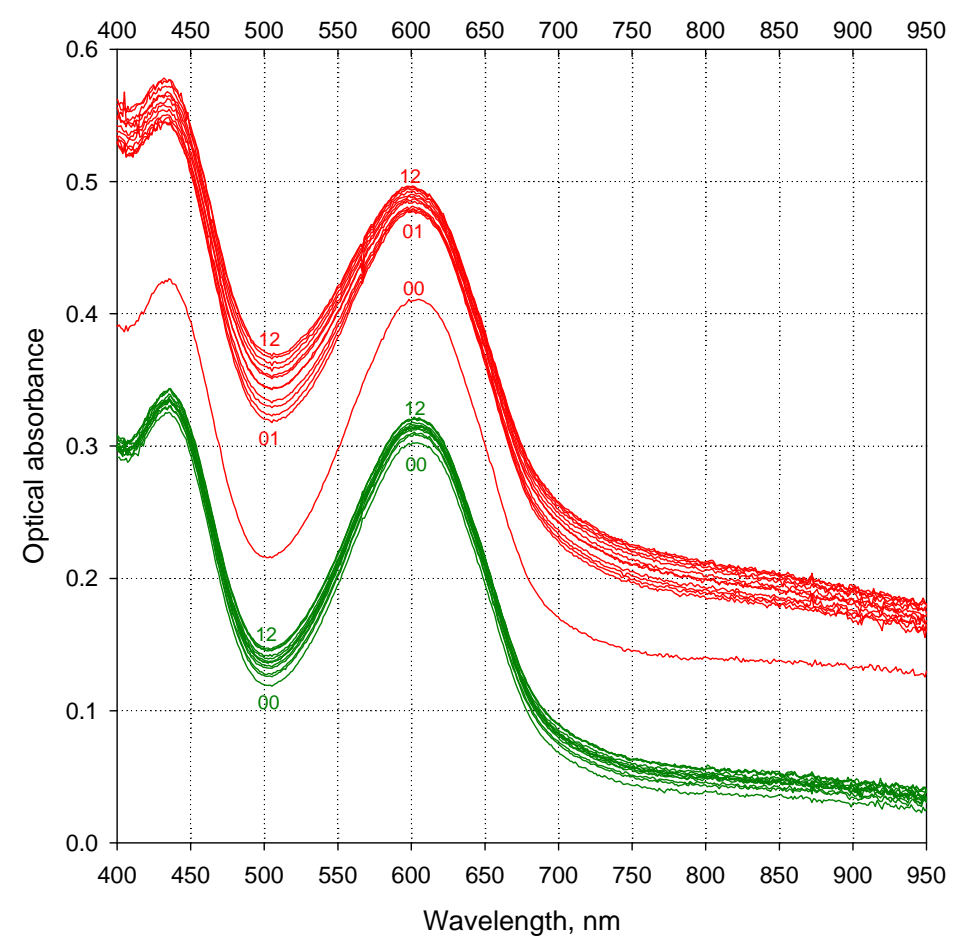

Figure 3.33. Spectral Monitoring over Mn(VI) Consumption in the Presence of Oxidative Alkaline Leaching of $\mathrm{Pu}(\mathrm{OH})_{4}$ in $0.25 \mathrm{M} \mathrm{NaOD}$. Green series: control experiment without $\mathrm{Pu}(\mathrm{OH})_{4}$; red series: identical solution and volume of $0.18 \mathrm{mM} \mathrm{Mn}(\mathrm{VI})$ after adding of $\mathrm{Pu}(\mathrm{OH})_{4}$ (with a Pu metal content of $30.1 \mu \mathrm{g})$. The red series is upshifted by 0.1 absorbance units for clarity. The molar ratio of permanganate to plutonium is set to $3: 1$. Time intervals between consecutive spectral scans are $7.5 \pm 0.5$ minutes.

In summary, the data obtained demonstrate that manganate is a much less efficient Pu solubilizer from $\mathrm{Pu}(\mathrm{OH})_{4}$ compared with permanganate under similar conditions of $0.25 \mathrm{M}$ alkalinity and an $\sim 3$-fold molar excess of $\mathrm{Mn}(\mathrm{VI} / \mathrm{VII})$ to $\mathrm{Pu}(\mathrm{IV})$.

\subsection{Oxidation of Pu(IV) by Permanganate in Acidic Solution}

\subsubsection{Oxidative Dissolution of Pu(IV) Hydroxide Suspension by Permanganate in $1 \mathrm{M}$ $\mathrm{DNO}_{3}$}

After accumulating data on oxidative dissolution of $\mathrm{Pu}(\mathrm{OH})_{4}$ with permanganate in $0.25 \mathrm{M} \mathrm{NaOD}$, it was of interest to compare these findings with the oxidative action of $\mathrm{Mn}(\mathrm{VII})$ on $\mathrm{Pu}(\mathrm{OH})_{4}$ in an acidic medium $\left(\mathrm{DNO}_{3}\right)$. Such a comparison is not only of purely scientific interest, but was potentially practically important in terms of determining the rate of oxidation of poorly soluble $\mathrm{Pu}(\mathrm{OH})_{4}$ present as fine suspensions in an initially alkaline solution after acidic strike. The dissolution behavior of $\mathrm{Pu}(\mathrm{IV})$ hydroxide was studied at three different levels of permanganate in $1 \mathrm{M}$ of $\mathrm{DNO}_{3}$. Spectrophotometric measurement was applied to determine the extent of dissolution of the $\mathrm{Pu}(\mathrm{IV})$ phase by detecting the absorbance band intensity of $\mathrm{Pu}(\mathrm{VI})$ at $831 \mathrm{~nm}$. Data obtained are plotted in Figure 3.34. 
All three kinetic curves show a negative curvature for the first 30 to 45 minutes of reaction time. This kinetic feature was observed earlier (Koltunov 1974, pp. 208-212) in the process of oxidation of monomeric $\mathrm{Pu}(\mathrm{IV})$ by permanganate and was attributed by the author to the autocatalytic action of $\mathrm{Mn}$ (II) as the reduction product of $\mathrm{Mn}(\mathrm{VII})$. The extent of $\mathrm{Pu}(\mathrm{IV})$ conversion to soluble $\mathrm{Pu}(\mathrm{VI})$ is approximately a linear function of the initial permanganate concentration for each given kinetic point during the first 90 minutes of observation.

Comparing the oxidation kinetics of $\mathrm{Pu}(\mathrm{OH})_{4}$ by permanganate in an alkaline and acidic medium shows that, for comparable concentrations of $\mathrm{Mn}(\mathrm{VII})$ and molar ratios of $\mathrm{Mn}(\mathrm{VII}) / \mathrm{Pu}(\mathrm{IV})$, oxidative leaching in an alkaline medium starts more quickly with more than $60 \%$ of the Pu solubilized in the first 15 minutes of contact time as opposed to less than $20 \%$ in nitric acid for the same time interval. On the other hand, while the rate of oxidation of $\mathrm{Pu}(\mathrm{IV})$ in alkali slows down at longer contact times, and the system reaches equilibrium with $\sim 75 \%$ of $\mathrm{Pu}$ dissolved after 90 minutes (and no additional dissolution after an overnight exposure), in an acidic medium, this process first accelerates and then slows down a little bit within the 90-min time interval. After that, it slowly goes to completion with practically all of the Pu oxidized and dissolved after an overnight contact time. One of the factors that might be responsible for reaction-rate retardation in alkaline medium is the relatively fast catalytic conversion of permanganate to manganate in the presence of undissolved $\mathrm{Pu}(\mathrm{OH})_{4}$ (and possibly other particulates, including freshly formed colloidal $\mathrm{MnO}_{2}$ ).

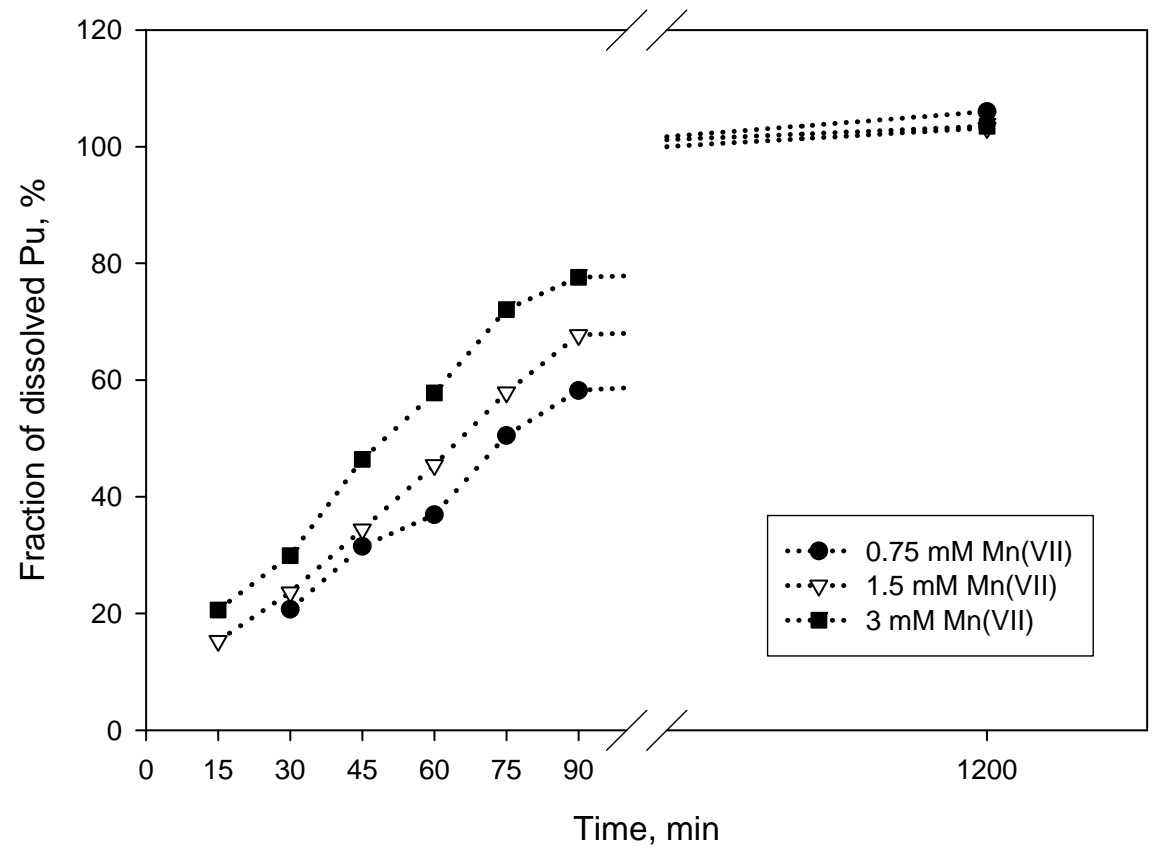

Figure 3.34. The Kinetics of Dissolution of $\mathrm{Pu}(\mathrm{OH})_{4}$ by $\mathrm{Mn}(\mathrm{VII})$ in $1 \mathrm{M} \mathrm{DNO}_{3}$. The starting $\mathrm{Pu}(\mathrm{IV})$ concentration in these tests is $100 \mu \mathrm{M}$ [based on the amount of $\mathrm{Pu}(\mathrm{OH})_{4}$ taken for oxidation]. The $\mathrm{Mn}(\mathrm{VII})$ to $\mathrm{Pu}(\mathrm{IV})$ molar ratio is $7.5: 1,15: 1$, and 30:1 for series 1,2 , and 3 , respectively. 


\subsubsection{Oxidation of Ionic Pu(IV) by Permanganate in $1 \mathrm{M} \mathrm{DNO}_{3}$ and the Effect of Dichromate on the Kinetics of this Process}

As has been previously discussed in Section 3.6, the spectral identification of $\mathrm{Pu}(\mathrm{IV})$ in an alkaline medium is extremely difficult, even with the application of highly sensitive LWCC detection due to the low solubility of tetravalent $\mathrm{Pu}$ and the lack of characteristic absorbance bands suitable for direct speciation of $\mathrm{Pu}(\mathrm{IV})$. In a real oxidative sludge leach process, if any soluble $\mathrm{Pu}(\mathrm{IV})$ survives the oxidative action of permanganate, it would be present in an alkaline solution together with chromate and possibly with unreacted permanganate if the latter were added in excess with respect to $\mathrm{Cr}$ (III) phases in the sludge. The detection of $\mathrm{Pu}(\mathrm{IV})$ is demonstrated to be much more sensitive on the acid side with a detection limit of less than $30 \mathrm{nM}$. Therefore, an attempt was made to examine the stability and redox behavior of $\mathrm{Pu}(\mathrm{IV})$ in the presence of chromate, permanganate, and their mixture after acidification of an initially alkaline solution containing these components. This series of experiments was conducted by spiking an acidic solution of $\mathrm{Pu}(\mathrm{IV})$ into $\mathrm{Cr}(\mathrm{VI})$ and/or a $\mathrm{Mn}$ (VII) solution in $1 \mathrm{M} \mathrm{DNO}_{3}$ and using conventional spectrophotometry to monitor the extent of oxidation of $\mathrm{Pu}(\mathrm{IV})$ to $\mathrm{Pu}(\mathrm{VI})$ by measuring the absorbance band of $\mathrm{Pu}(\mathrm{VI})$ at $831 \mathrm{~nm}$. The starting concentration of $\mathrm{Pu}(\mathrm{IV})$ was set at $200 \mu \mathrm{M}$ and 190 $\mu \mathrm{M}$ for $\mathrm{Mn}(\mathrm{VII})$ and $\mathrm{Mn}(\mathrm{VII})+\mathrm{Cr}(\mathrm{VI})$ tests, respectively. The concentration of $\mathrm{Cr}(\mathrm{VI})$ was set to 7.5 $\mathrm{mM}$ of dichromate (equivalent of $15 \mathrm{mM}$ of chromate from alkaline side), and the concentration of permanganate was fixed at $1.5 \mathrm{mM}$. Two tests were performed with single component oxidizers [Cr(VI) only and $\mathrm{Mn}(\mathrm{VII})$ only], and one test was done with the mixture of $\mathrm{Cr}(\mathrm{VI})$ and $\mathrm{Mn}(\mathrm{VII})$. The results are shown in Figure 3.35. It can be seen that dichromate reacts very slowly with $\mathrm{Pu}(\mathrm{IV})$, resulting in less than $10 \%$ oxidation efficiency in $1.5 \mathrm{hr}$. Permanganate acts more quickly with $50 \%$ of $\mathrm{Pu}(\mathrm{IV})$ oxidized in 30 minutes despite a 5-times-lower concentration compared with dichromate. Again, as was observed in the $\mathrm{Pu}(\mathrm{OH})_{4}+\mathrm{Mn}(\mathrm{VII})$ experiment (Section 3.8.1), the rate of $\mathrm{Pu}(\mathrm{IV})$ oxidation initially is slow with subsequent acceleration of the oxidation process. Most interestingly, the oxidation rate of $\mathrm{Pu}(\mathrm{IV})$ increases drastically when two oxidizers are mixed together with about $50 \%$ of the $\mathrm{Pu}(\mathrm{IV})$ converted to $\mathrm{Pu}(\mathrm{VI})$ within 3 minutes after mixing the reagents and quantitative conversion in less than 10 minutes. This effect was not previously reported in the technical literature to the best of our knowledge, and its nature cannot be fully explained at this time. One possibility is the formation of a complex reaction between $\mathrm{Pu}(\mathrm{IV})$ and dichromate, which makes this new species kinetically less stable toward the oxidative action of permanganate.

In summary, the data obtained indicate that the technique of acidic strike on an initially alkaline $\mathrm{Pu}$ containing solution in the presence of $\mathrm{Cr}(\mathrm{VI})$ and $\mathrm{Mn}(\mathrm{VII})$ causes significant perturbations of lower oxidation states of $\mathrm{Pu}$ with very fast oxidation of $\mathrm{Pu}(\mathrm{V})$ by $\mathrm{Cr}(\mathrm{VI})$ alone (see Section 3.5.4) and rapid oxidation of $\mathrm{Pu}(\mathrm{IV})$ by mixing $\mathrm{Cr}(\mathrm{VI})$ and $\mathrm{Mn}(\mathrm{VII})$. Consequently, the acidification of an initially alkaline $\mathrm{Pu}(\mathrm{IV}+\mathrm{V}+\mathrm{VI})$ solution with chromate can possibly distinguish between soluble $\mathrm{Pu}(\mathrm{IV})$ and $\mathrm{Pu}(\mathrm{V}+\mathrm{VI})$ only in the absence of $\mathrm{Mn}(\mathrm{VII})$. 


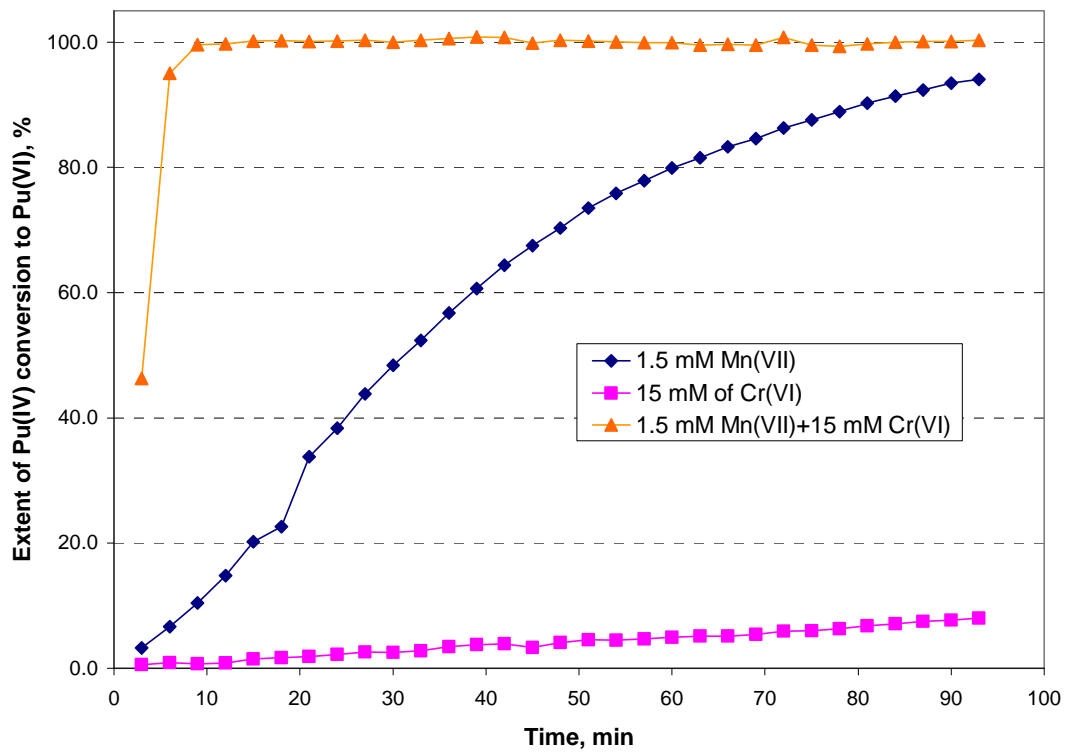

Figure 3.35. The Kinetics of the Oxidation of Monomeric $\mathrm{Pu}(\mathrm{IV})$ by $\mathrm{Mn}(\mathrm{VII}), \mathrm{Cr}(\mathrm{VI})$, and Their Mixture in $1 \mathrm{M} \mathrm{HNO}_{3}$. The initial $\mathrm{Pu}(\mathrm{IV})$ concentration was set at $200 \mu \mathrm{M}$ for $\mathrm{Mn}(\mathrm{VII})$ and $190 \mu \mathrm{M}$ for both $\mathrm{Cr}(\mathrm{VI})$ only and $\mathrm{Cr}(\mathrm{VI})+\mathrm{Mn}(\mathrm{VII})$ tests, respectively.

\subsection{Interaction of $\mathrm{Pu}(\mathrm{V})$ with Low Levels of Manganate in 0.25 M NaOD}

\subsubsection{ORP Measurements in Manganate-Containing Solutions and Manganate- Permanganate Mixtures in NaOD Solutions}

A $2 \mathrm{mM}$ stock solution of manganate was prepared via spontaneous reduction of $2 \mathrm{mM}$ permanganate solution in $2.5 \mathrm{M} \mathrm{NaOD}$. The reaction mixture was stored in a glass container to prevent contact of the solution with any plastic materials. The solution color was observed to change gradually from purple to green. The complete conversion of $\mathrm{Mn}(\mathrm{VII})$ to $\mathrm{Mn}(\mathrm{VI})$ was achieved in 3 months as confirmed by the absence of absorbance bands of $\mathrm{Mn}$ (VII) in the spectrum of the resulting solution. A series of six solutions of $0.2 \mathrm{mM}$ of manganate in $0.25 \mathrm{M}, 0.4 \mathrm{M}, 0.55 \mathrm{M}, 0.70 \mathrm{M}, 0.85 \mathrm{M}$, and $1.0 \mathrm{M}$ of NaOD was prepared by 10 -fold dilution of the $\mathrm{Mn}(\mathrm{VI})$ stock in $\mathrm{NaOD}$ solutions of appropriate concentrations. Oxidation reduction potentials of these solutions were measured according to the procedure described in Section 2.7. After an initial ORP measurement in pure manganate solution was complete, a series of stepwise additions of a $7.5 \mathrm{mM}$ solution of permanganate in $\mathrm{D}_{2} \mathrm{O}$ was made to the starting solution to achieve $0.5,1,2$, and 5 molar ratios of $\mathrm{Mn}(\mathrm{VII})$ to $\mathrm{Mn}(\mathrm{VI})$. Each addition was followed by ORP measurement of the modified solution before adding the next portion of Mn(VII) to the mixture. The results of these measurements are summarized in Table 3.6. 
Table 3.6. Oxidation Reduction Potentials of Manganate Solutions and Permanganate-Manganate Mixtures in $\mathrm{NaOD}$. The $\mathrm{Mn}(\mathrm{VI})$ concentration is fixed at $0.2 \mathrm{mM}$ in all solutions.

\begin{tabular}{|c|c|c|c|c|c|c||}
\hline \multirow{2}{*}{$\begin{array}{c}\text { Mn(VII)/Mn(VI) } \\
\text { Molar Ratio }\end{array}$} & $\begin{array}{c}\mathbf{0 . 2 5} \mathbf{~ M} \\
\text { NaOD }\end{array}$ & $\begin{array}{c}\mathbf{0 . 4} \mathbf{M} \\
\text { NaOD }\end{array}$ & $\begin{array}{c}\mathbf{0 . 5 5} \text { M } \\
\text { NaOD }\end{array}$ & $\begin{array}{c}\mathbf{0 . 7 0 ~ M} \\
\text { NaOD }\end{array}$ & $\begin{array}{c}\mathbf{0 . 8 5} \mathbf{~ M} \\
\text { NaOD }\end{array}$ & $\begin{array}{c}\mathbf{1 . 0} \text { M } \\
\text { NaOD }\end{array}$ \\
\hline 0 (pure manganate) & 0.39 & 0.39 & 0.40 & 0.39 & 0.38 & 0.38 \\
\hline 0.5 & $0.50 \rightarrow 0.46$ & $0.54 \rightarrow 0.51$ & $0.55 \rightarrow 0.53$ & $0.55 \rightarrow 0.52$ & $0.55 \rightarrow 0.53$ & $0.55 \rightarrow 0.52$ \\
\hline 1 & $0.52 \rightarrow 0.50$ & $0.55 \rightarrow 0.54$ & $0.56 \rightarrow 0.55$ & $0.56 \rightarrow 0.54$ & $0.56 \rightarrow 0.55$ & $0.56 \rightarrow 0.54$ \\
\hline 2 & $0.54 \rightarrow 0.52$ & $0.57 \rightarrow 0.56$ & $0.58 \rightarrow 0.56$ & $0.58 \rightarrow 0.56$ & $0.58 \rightarrow 0.56$ & $0.58 \rightarrow 0.56$ \\
\hline 5 & $0.57 \rightarrow 0.56$ & $0.59 \rightarrow 0.58$ & $0.60 \rightarrow 0.59$ & $0.60 \rightarrow 0.59$ & $0.60 \rightarrow 0.59$ & $0.60 \rightarrow 0.59$ \\
\hline
\end{tabular}

Pure manganate solutions showed stable readings of oxidation potential while permanganate-manganate mixtures exhibited a downward drift of the potential with up to 30 to $40 \mathrm{mV}$ of negative difference between the initial reading (within the first 1 to 1.5 minutes after electrode immersion) and final reading ( $\sim 10$ minutes after). This drift correlated with a gradual color change from gray-purple to green, suggesting a relatively fast reduction of permanganate to manganate by water and walls of a plastic vial used for ORP measurements. We believe that the initial readings represent more accurately the oxidation potentials of permanganate-manganate mixtures due to less significant perturbation of the targeted $\mathrm{Mn}(\mathrm{VII}) / \mathrm{Mn}(\mathrm{VI})$ ratio.

Comparing the measured potentials of permanganate-manganate solutions with the formal redox potential of the $\mathrm{Pu}(\mathrm{VI}) / \mathrm{Pu}(\mathrm{V})$ couple (Section 3.5.5) makes it possible to conclude that thermodynamically, $\mathrm{Pu}(\mathrm{V})$ is expected to undergo complete oxidation to $\mathrm{Pu}(\mathrm{VI})$ regardless of the $\mathrm{Mn}(\mathrm{VII}) / \mathrm{Mn}(\mathrm{VI})$ ratio in solution.

\subsubsection{Instability of Permanganate and Manganate in 0.25 M NaOD at Low Micromolar Concentration of Initially Added Mn(VII) by Spectral Measurements with LWCC}

In preliminary experiments on the redox stability of millimolar permanganate solutions in $0.25 \mathrm{M} \mathrm{NaOH}$, it was shown that permanganate is not stable in alkaline solution. It slowly (within hours) gets partially reduced to $\mathrm{Mn}(\mathrm{VI})$ followed by precipitation of $\mathrm{MnO}_{2}$. The nature of the reductant was not identified, but the positive value of the $\mathrm{Mn}$ (VII)/Mn(VI) electrochemical potential is so high that it might be hydroxide itself, which undergoes oxidative decomposition $\left(4 \mathrm{OH}^{-}-4 \mathrm{e}=\mathrm{O}_{2}+2 \mathrm{H}_{2} \mathrm{O}\right)$. Introduction of $\mathrm{K}_{2} \mathrm{~S}_{2} \mathrm{O}_{8}$ as a holding oxidant did not prevent or slow down the unwanted reduction of permanganate in this medium.

At the next stage of studying Mn(VII) behavior, it was of interest to examine permanganate speciation at a low micromolar concentration range of initially added Mn(VII). Using the Ocean Optics instrument with a scanning range from $550 \mathrm{~nm}$, it was not possible to monitor the major peak of $\mathrm{Mn}$ (VII) at $528 \mathrm{~nm}$, but the presence of permanganate could be detected and quantified by its descending slope from 550 to $700 \mathrm{~nm}$ and by its characteristic shoulders at $563 \mathrm{~nm}$ and $\sim 630 \mathrm{~nm}$. A series of four solutions of 
permanganate in $0.25 \mathrm{M}$ of $\mathrm{NaOD}$ was prepared in the concentration range from $1 \mu \mathrm{M}$ to $4 \mu \mathrm{M}$ of initially added Mn(VII). The spectral acquisition started $\sim 1$ minute after solution injection into the LWCC and continued for another 15 to 20 minutes to monitor possible changes in $\mathrm{Mn}$ (VII) redox speciation with time. All solutions were so dilute that it was not possible to distinguish any color after spiking already diluted Mn(VII) stock into $\sim 1000$ excess of the colorless diluent. The results of these experiments are presented in Figure 3.36. Quite surprisingly, all spectra show a complete absence of permanganate in the solution at the moment of the very first spectral scan (absolutely no shoulder at the 563- to 567-nm region, major peak maximum position is at $603 \mathrm{~nm}$, and no decreasing absorbance in the 550- to 603-nm range, which is characteristic for the predominance of $\mathrm{Mn}(\mathrm{VII})$ over $\mathrm{Mn}(\mathrm{VI})$. Even more interesting is the relatively quick disappearance of $\mathrm{Mn}(\mathrm{VI})$ itself from the solutions (see a steady decrease of the 603$\mathrm{nm}$ peak intensity with time within each series). It is not possible to conclude why Mn(VII) reduction under these conditions is so fast compared with a relatively slow kinetics of $\mathrm{Mn}$ (VII) conversion to $\mathrm{Mn}(\mathrm{VI}))$ at 1000 times higher concentrations of $\mathrm{Mn}(\mathrm{VII})$. In addition to a very low level of reductive admixtures already present in $\mathrm{D}_{2} \mathrm{O}$ and $\mathrm{NaOD}$, the membrane filter attached to the inlet fluidic port of LWCC might be a very significant contributor to this process.

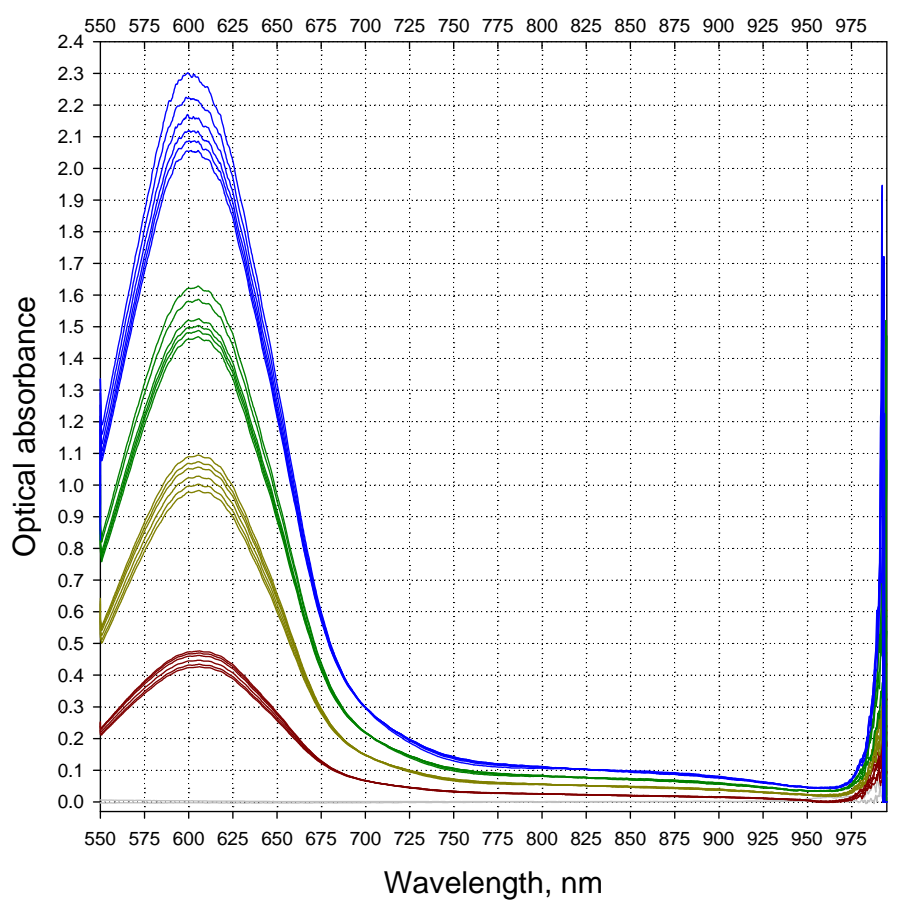

Figure 3.36. Evidence of $\mathrm{Mn}(\mathrm{VII})$ and $\mathrm{Mn}(\mathrm{VI})$ Reduction in $0.25 \mathrm{M} \mathrm{NaOD}$ Using LWCC Detection. Initial concentrations of $\mathrm{Mn}(\mathrm{VII})$ are as follows: $1 \mu \mathrm{M}, 2 \mu \mathrm{M}, 3 \mu \mathrm{M}$, and $4 \mu \mathrm{M}$ for the red, dark yellow, green, and blue series, respectively. Within each series, the intensity of the 603-nm peak of manganate decreases with time. Time intervals between consecutive spectral scans are $2.5 \pm 0.3$ minutes.

Comparing the manganate spectra in a relatively flat range of low absorbances from 750 to $960 \mathrm{~nm}$ shows that the manganate ion still has significant molar absorbitivities there (in the order of 150 to $50 \mathrm{M}^{-1} \mathrm{~cm}^{-1}$ ), which makes it difficult to study $\mathrm{Pu}(\mathrm{V})$ and $\mathrm{Pu}(\mathrm{VI})$ speciation with molar absorptivities in the order of 1 to $15 \mathrm{M}^{-1} \mathrm{~cm}^{-1}$ in the presence of even such low levels of $\mathrm{Mn}(\mathrm{VI})$. 
In a separate series of experiments, more concentrated solutions of permanganate [ 25 to $100 \mu \mathrm{M}$ of initial $\mathrm{Mn}(\mathrm{VII})]$ were used to determine the spectral range still accessible for measurements with a $500-\mathrm{cm}$ LWCC. It was found that the optical range from 550 to $\sim 750 \mathrm{~nm}$ is completely out of scale as no or very little light reaches a spectrophotometric detector. The absorbance measurements would be possible to perform in the $\sim 780$ - to 920 -nm range if a strong positive drift of optical absorbance reading in time [due to conversion of $\mathrm{Mn}(\mathrm{VII})$ to $\mathrm{Mn}(\mathrm{VI})$ ] could be eliminated.

It can also be concluded that plutonium speciation cannot be studied in this region in $\mathrm{H}_{2} \mathrm{O} / \mathrm{NaOH}$ solutions because of the very intense and steeply changing absorbance of $\mathrm{Mn}(\mathrm{VI})$ in the $550-$ to $700-\mathrm{nm}$ spectral range.

\subsubsection{Oxidation of $\mathrm{Pu}(\mathrm{V})$ by Manganate in 0.25 M NaOD Monitored by LWCC Spectroscopy}

Preparation and Characterization of Homogeneous Stock Solution of $\mathrm{Mn}(\mathrm{VI})$ in $0.25 \mathrm{M} \mathrm{NaOD} / \mathrm{D}_{2} \mathrm{O}$

It has been shown that approximately one week is required to obtain a stable homogeneous $\mathrm{Mn}(\mathrm{VI})$ solution in $0.25 \mathrm{M} \mathrm{NaOD} / \mathrm{D}_{2} \mathrm{O}$. The initial preparation is based on spiking permanganate solution into $0.25 \mathrm{M} \mathrm{NaOD}$ to achieve $0.2 \mathrm{mM}$ total Mn concentration. The slow kinetics of Mn(VII) to Mn(VI) conversion (in the absence of any artificially added reductants) gradually ends with a complete disappearance of permanganate from the solution. The solution color becomes purely green with no precipitate or colloidal matter visually present in the sample. The Mn(VI) concentration in the final solution (calculated from a 603 -nm peak intensity of manganate) is $\sim 15 \%$ less than the initial concentration of $\mathrm{Mn}(\mathrm{VII})$. The spectrum of the final solution scanned in a broader range confirms the absence of permanganate and shows some deviations from a classical manganate spectrum in the 300 - to 500-nm range. This difference is most likely associated with the partial conversion of $\mathrm{Mn}(\mathrm{VI})$ to lower oxidation states of Mn, which is consistent with $15 \%$ deficiency in $\mathrm{Mn}(\mathrm{VI})$ concentration with respect to initial $\mathrm{Mn}(\mathrm{VII})$ concentration.

\section{Interaction of $\mathrm{Pu}(\mathrm{V})$ with $\mathrm{Mn}(\mathrm{VI})$}

The above prepared stock solution of $\mathrm{Mn}(\mathrm{VI})$ was diluted down to $15 \mu \mathrm{M}$ in $0.25 \mathrm{M} \mathrm{NaOD}$ and spiked with $\mathrm{Pu}(\mathrm{V})$ stock solution in $14 \mathrm{M} \mathrm{NaOD}$ to achieve an approximately 1.2:1 manganate-to-Pu(V) molar ratio. The spectra measured immediately after mixing the reagents (Figure 2.2, blue and red traces) show a drastic drop in manganate signal intensity, presumably due to its consumption via redox reaction with $\mathrm{Pu}(\mathrm{V})$ :

$$
\mathrm{MnO}_{4}^{2-}+2 \mathrm{Pu}^{\mathrm{V}} \mathrm{O}_{2}(\mathrm{OD})_{\mathrm{n}}^{(\mathrm{n}-1)-}+2 \mathrm{D}_{2} \mathrm{O}=2 \mathrm{Pu}^{\mathrm{VI}} \mathrm{O}_{2}(\mathrm{OD})_{\mathrm{n}}^{(\mathrm{n}-2)-}+\mathrm{MnO}_{2}+4 \mathrm{OD}^{-}
$$

The formation of $\mathrm{MnO}_{2}$ as a possible reduction product is qualitatively confirmed by the appearance of brown coloration on the membrane filter used to protect the liquid waveguide tubing from dust and colloidal matter. No Pu(VI) spectral signature centered at $625 \mathrm{~nm}$ could be identified in the spectrum because of the significant presence of residual manganate in solution, which has a 160-times higher molar absorptivity. The spectral signature of $\mathrm{Pu}(\mathrm{V})$ at $809 \mathrm{~nm}$ is completely absent, which confirms a full conversion of $\mathrm{Pu}(\mathrm{V})$ to a higher oxidation state by manganate. 
As follows from reaction (3.3) above, the oxidation of $\mathrm{Pu}(\mathrm{V})$ by $\mathrm{Mn}(\mathrm{VI})$ should be 2:1 in stoichiometry [one equivalent of $\mathrm{Mn}(\mathrm{VI})$ ], which oxidizes two equivalents of $\mathrm{Pu}(\mathrm{V})$. But in reality, the spectrophotometric analysis of the $\mathrm{Mn}(\mathrm{VI})$ absorbance intensity at $700 \mathrm{~nm}\left(\varepsilon=205 \mathrm{M}^{-1} \mathrm{~cm}^{-1}\right)$ before and after $\mathrm{Pu}(\mathrm{V})$ addition indicates the consumption of $9.64 \mu \mathrm{M}$ of $\mathrm{Mn}(\mathrm{VI})$ in the process of converting $12.5 \mu \mathrm{M}$ of $\mathrm{Pu}(\mathrm{V})$ to a higher oxidation state, or in other words, a 1:1.3 stoichiometry. The possibility of a partial conversion of $\mathrm{Pu}(\mathrm{V})$ oxidation to $\mathrm{Pu}(\mathrm{VII})$ (which should have the 1:1 stoichiometry) can be ruled out based on the inability of $\mathrm{Mn}(\mathrm{VII})$ and $\mathrm{Mn}(\mathrm{VI})$ to produce $\mathrm{Pu}(\mathrm{VII})$ from $\mathrm{Pu}(\mathrm{VI})$, even at much higher alkalinity than the $0.25 \mathrm{M}$ used in this experiment. Another possibility is that the product of Mn(VI) reduction by $\mathrm{Pu}(\mathrm{V})$ is not only $\mathrm{Mn}(\mathrm{IV})$ (as insoluble $\mathrm{MnO}_{2}$ ), but to some extent, $\mathrm{Mn}(\mathrm{V})$ as well. The latter is known to be unstable at a millimolar range of concentrations and higher, but might be more stable for a limited time in the low micromolar range of Mn concentrations used in this study.

Direct proof of the presence of $\mathrm{Pu}(\mathrm{VI})$ in blue and red spectra is difficult to obtain because of the steeply changing optical absorbance of residual $\mathrm{Mn}(\mathrm{VI})$ in the region of the major absorbance band of $\mathrm{Pu}(\mathrm{VI})$ at $625 \mathrm{~nm}$. The second major peak of $\mathrm{Pu}(\mathrm{VI})$ is located in the 890- to 940-nm range with a peak maximum at ca. $920 \mathrm{~nm}$ (see calibration plots in Section 3.4.). However, the spectra in Figure 2.2 are significantly burdened by a waveform-shaped interference of unknown origin. To eliminate this interference, an approach described in Section 2.10 was applied, and the processed spectrum in shown in Figure 3.37. The peak at $920 \mathrm{~nm}$ is seen much more clearly now, and calculating the $\mathrm{Pu}(\mathrm{VI})$ concentration based on its net intensity of 0.012 absorbance units and net molar absorptivity of $1.9 \mathrm{M}^{-1} \mathrm{~cm}^{-1}$ results in a $\mathrm{Pu}(\mathrm{VI})$ concentration in solution of $12.6 \mu \mathrm{M}$. This number is in close correspondence with an initial $\mathrm{Pu}(\mathrm{V})$ concentration of $12.5 \mu \mathrm{M}$. This observation proves that $\mathrm{Pu}(\mathrm{V})$ is not stable in the presence of even very low concentrations of $\mathrm{Mn}(\mathrm{VI})$ and undergoes quantitative oxidation to $\mathrm{Pu}(\mathrm{VI})$ at a $0.25 \mathrm{M}$ concentration of sodium hydroxide.

\subsection{Oxidative Leaching of $\mathrm{Fe}(\mathrm{OH})_{3} / \mathrm{Cr}(\mathrm{OH})_{3} / \mathrm{Pu}(\mathrm{OH})_{4}$ Sludge Simulant with Permanganate}

A relatively large portion of the $\mathrm{Fe}(\mathrm{OH})_{3} / \mathrm{Cr}(\mathrm{OH})_{3} / \mathrm{Pu}(\mathrm{OH})_{4}$ sludge stimulant was prepared as described in detail in Section 2.6 and aged for 2.5 weeks before subsampling small portions ( $5 \%$ of the total amount prepared) for oxidative-leaching experiments described in this section. In all experiments, the ratio of oxidizer-containing solution volume to the compacted sludge volume was approximately $3: 1$. The tests were performed under conditions of very intense magnetic stirring with a highly efficient Spin-Plus stir bar occupying approximately $20 \%$ of the compacted sludge volume. 


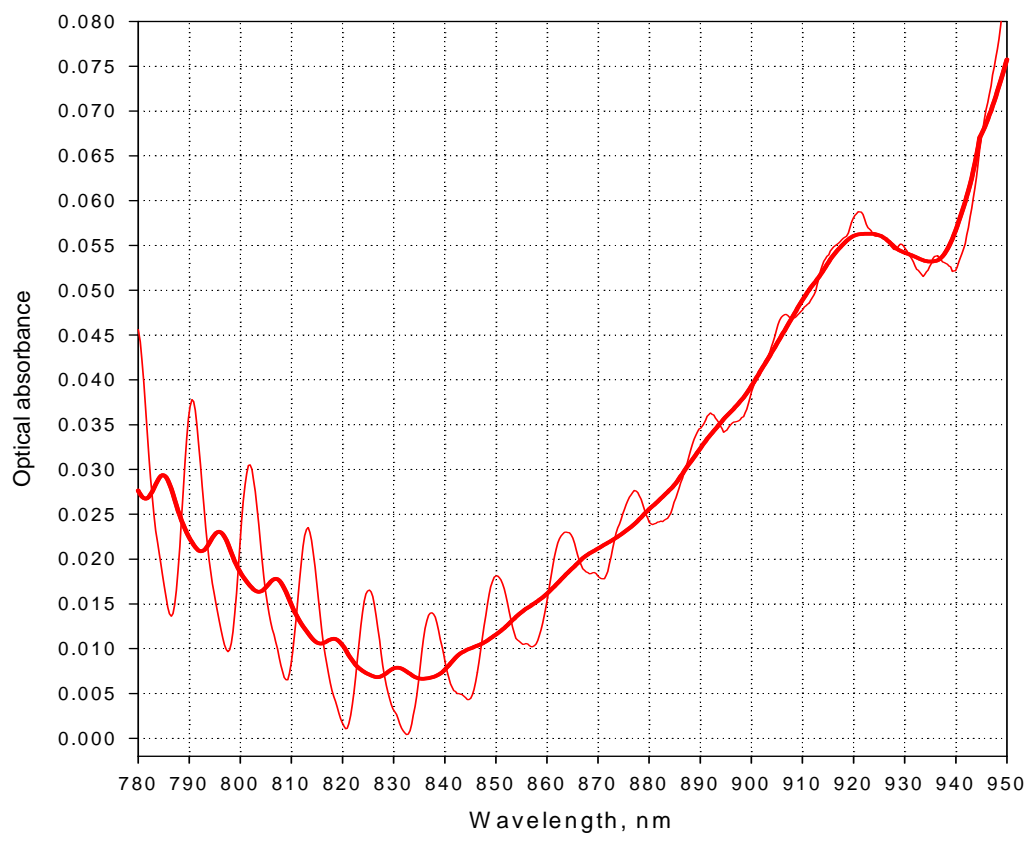

Figure 3.37. Red Trace Spectrum from Figure 2.2 After Application of the Waveform Suppression Treatment and Spectral Smoothing. Thin red line: processed spectrum before smoothing; bold red line: the same spectrum after a 41 points smoothing. The peak at $920 \mathrm{~nm}$ corresponds to $12.6 \mu \mathrm{M}$ of $\mathrm{Pu}(\mathrm{VI})$ in solution.

\subsubsection{Leaching in 0.25 $\mathrm{M}$ NaOD Solution}

\section{Substoichiometric to Stoichiometric Amount of Permanganate}

The initial amount of Mn(VII) added to the sludge sample was calculated so as to achieve a 0.983:1 Mn(VII)/Cr(III) molar ratio. No visual evidence for any unreacted permanganate was observed in the filtered sample withdrawn after 3 to 4 minutes of contact time under stirring as judged by the absence of purplish tint in the lemon yellow color of the filtrate. A 250 -fold dilution of the filtrate in $0.25 \mathrm{M}$ of $\mathrm{NaOH}$ was applied to measure the intensity of the chromate spectrum. The spectrum of this diluted solution along with subsequent spectral analysis data are shown in Figure 3.38. The $\mathrm{Cr}(\mathrm{VI})$ concentration estimated from the spectrum of diluted sample (spectral trace s02) was approximately $85 \%$ of the theoretically expected value. However, the exact expected concentration of $\mathrm{Cr}(\mathrm{VI})$ could not be calculated with high certainty because of the unknown volume of interstitial liquid in the compacted sludge sample. The second sample, withdrawn 30 minutes after additional stirring, did not show any increase in the magnitude of the $\mathrm{Cr}(\mathrm{VI})$ peak at $372 \mathrm{~nm}$ (spectral trace s03). Both spectra indicated the complete absence of any absorbance bands in the 500- to 700-nm range, proving that there was no excessive Mn(VII) and/or Mn(VI) left in the mixture. Complete consumption of permanganate in merely 3 to 4 minutes after its addition to the sludge simulant indicated that the reaction between $\mathrm{Cr}(\mathrm{OH})_{3}$ and the oxidizer was too fast to be studied kinetically, even with a 3-min sampling frequency.

The leaching test was then continued by adding several more portions of permanganate to the reaction mixture to see if any more soluble chromate could be leached out from the sludge and to find conditions for the appearance of excessive $\mathrm{Mn}(\mathrm{VII})$ and/or $\mathrm{Mn}(\mathrm{VI})$ in the spectra. The amount of permanganate in 
the reaction mixture was increased by $17 \%$ in 9 increments (spectral traces s04 to s12) with still no indication of permanganate or manganate in the spectra. The $\mathrm{Cr}(\mathrm{VI})$ signal at the same time increased by approximately $7 \%$. Finally, a further increase of permanganate by $1.7 \%$ indicated a filtrate color change from lemon yellow to reddish-yellow. Diluting this sample resulted in the detection of a weak absorbance band at $\sim 605 \mathrm{~nm}$, which could be attributed to manganate. Two more additions of permanganate were made, and spectral analysis showed progressive intensification of the 605 -nm peak with no additional accumulation of chromate in solution (spectral traces s14 and s15). The spontaneous conversion of excessive permanagante to manganate after dilution was not understandable at first, but later, it was discovered that the $0.24 \mathrm{M}$ of $\mathrm{NaOH}$ used to dilute the filtrates contained some reductive constituents (accumulated as result of its storage in a polycarbonate container), and those admixtures were present at a sufficiently high level to convert excessive $\mathrm{Mn}(\mathrm{VII})$ to $\mathrm{Mn}(\mathrm{VI})$ in the diluted solution.

In total, 15 leachate samples were collected, and samples \#2, 5, 10,12,13, 14, and 15 were acidified and analyzed by liquid scintillation counting. In all samples, no statistically significant difference between the observed counting rate and the background counting rate was found. The estimated percentage of $\mathrm{Pu}$ dissolution in the samples is less than $2.1 \%$, which corresponds to less than $0.021 \times 5.6=0.117 \mu \mathrm{M}$ of soluble $\mathrm{Pu}$ in the leachate $(5.6 \mu \mathrm{M}$ is the estimated level of $\mathrm{Pu}$ concentration in the leachate in a hypothetical case of its complete solubilization).

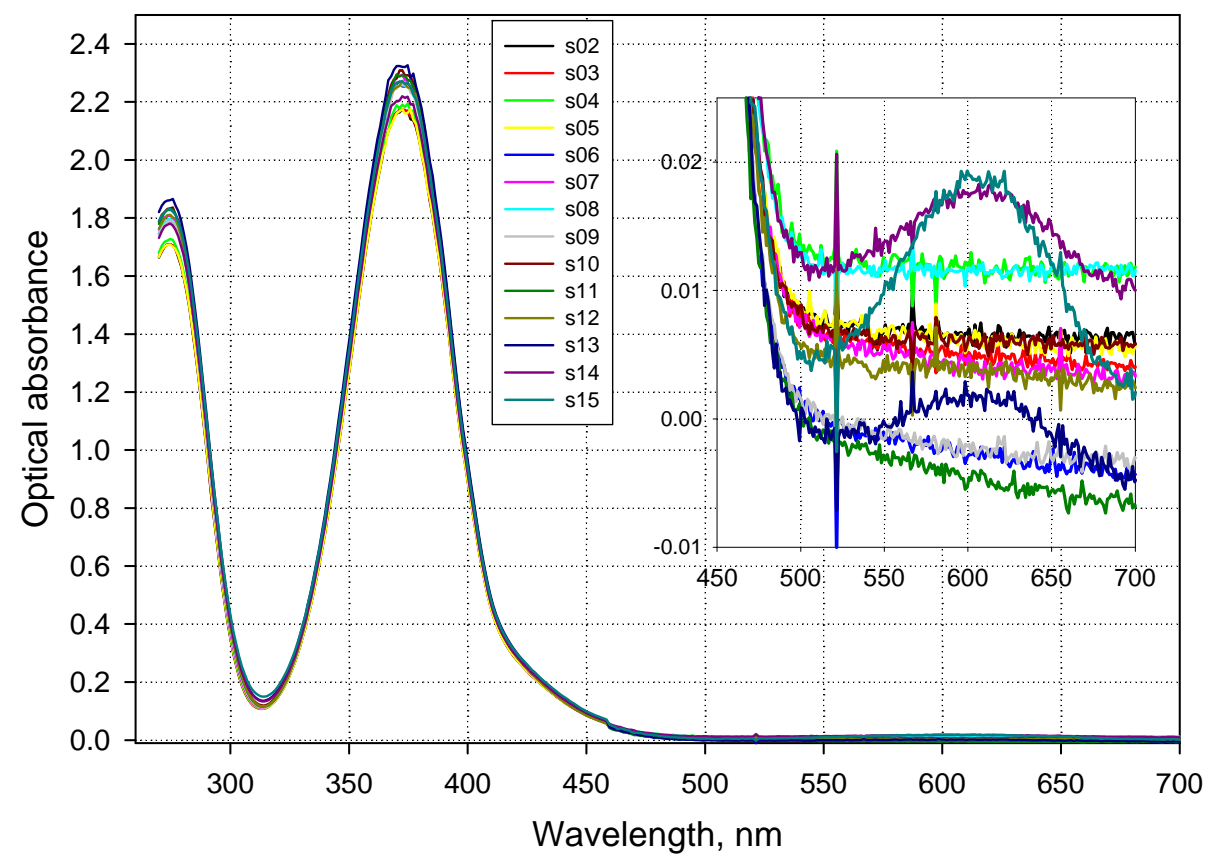

Figure 3.38. Oxidative Leaching of $\mathrm{Fe}(\mathrm{OH})_{3} / \mathrm{Cr}(\mathrm{OH})_{3} / \mathrm{Pu}(\mathrm{OH})_{4}$ Sludge Simulant with a Substoichiometric to Stoichiometric Amount of Permanganate in $0.25 \mathrm{M} \mathrm{NaOH}$. The major peak at $372 \mathrm{~nm}$ belongs to chromate. The inset shows a 500- to 700-nm region in more detail where $\mathrm{Mn}(\mathrm{VII})$ and $\mathrm{Mn}(\mathrm{VI})$ peaks resulting from an excessive amount of added permanganate become visible for the last three additions of permanganate. 


\section{$12 \%$ Molar Excess of Mn(VII)}

In the second experiment, the initial portion of Mn(VII) solution added at the very beginning was equivalent to the condition represented by spectral trace $\mathrm{s} 12$ in the previous experiment when the theoretically calculated amount of $\mathrm{Mn}$ (VII) had to be increased by $17 \%$ in 10 small increments to achieve the real 1:1 Mn(VII)-to-Cr(III) ratio. The spectral analysis data are shown in Figure 3.39. In agreement with the previous experiment, spectral analysis of the diluted sample (s01) did not show any excessive $\mathrm{Mn}(\mathrm{VII})$ or $\mathrm{Mn}(\mathrm{VI})$ (spectral trace s01). After that, the amount of permanganate in the reaction mixture was increased in five increments (spectral traces s02 to s06) to achieve the 1.12:1 $\mathrm{Mn}$ (VII) to $\mathrm{Cr}$ (III) molar ratio. Time intervals between adding $\mathrm{Mn}(\mathrm{VII})$ and withdrawing the respective sample were 30 minutes. After adding the last portion of permanganate, the reaction mixture was stirred for another 120 minutes with four more samples taken out with 30-min intervals (s07 to s10). The spectral data that show that no statistically significant increase in the level of $\mathrm{Cr}(\mathrm{VI})$ concentration in leachate can be found with time compared with the very first sample taken 3 minutes after $\mathrm{Mn}(\mathrm{VII})$ addition to the sludge and the s07 to 10 samples. A small increase in the chromate peak intensity for the s02 to s06 group of samples is related to the contribution of manganate absorbance in this region of the spectrum. This observation confirms that all $\mathrm{Cr}(\mathrm{III})$ present in the sludge stimulant was converted to $\mathrm{Cr}(\mathrm{VI})$ by reaction with one molar equivalent of $\mathrm{Mn}(\mathrm{VII})$. Also, there is no variation on manganate peak intensity in the s06- to s10-group of samples, which indicates that there is no detectable consumption of the excess oxidizer via its potential catalytic decomposition by water in the presence of $\mathrm{Fe}(\mathrm{OH})_{3}$ and newly formed $\mathrm{MnO}_{2}$.

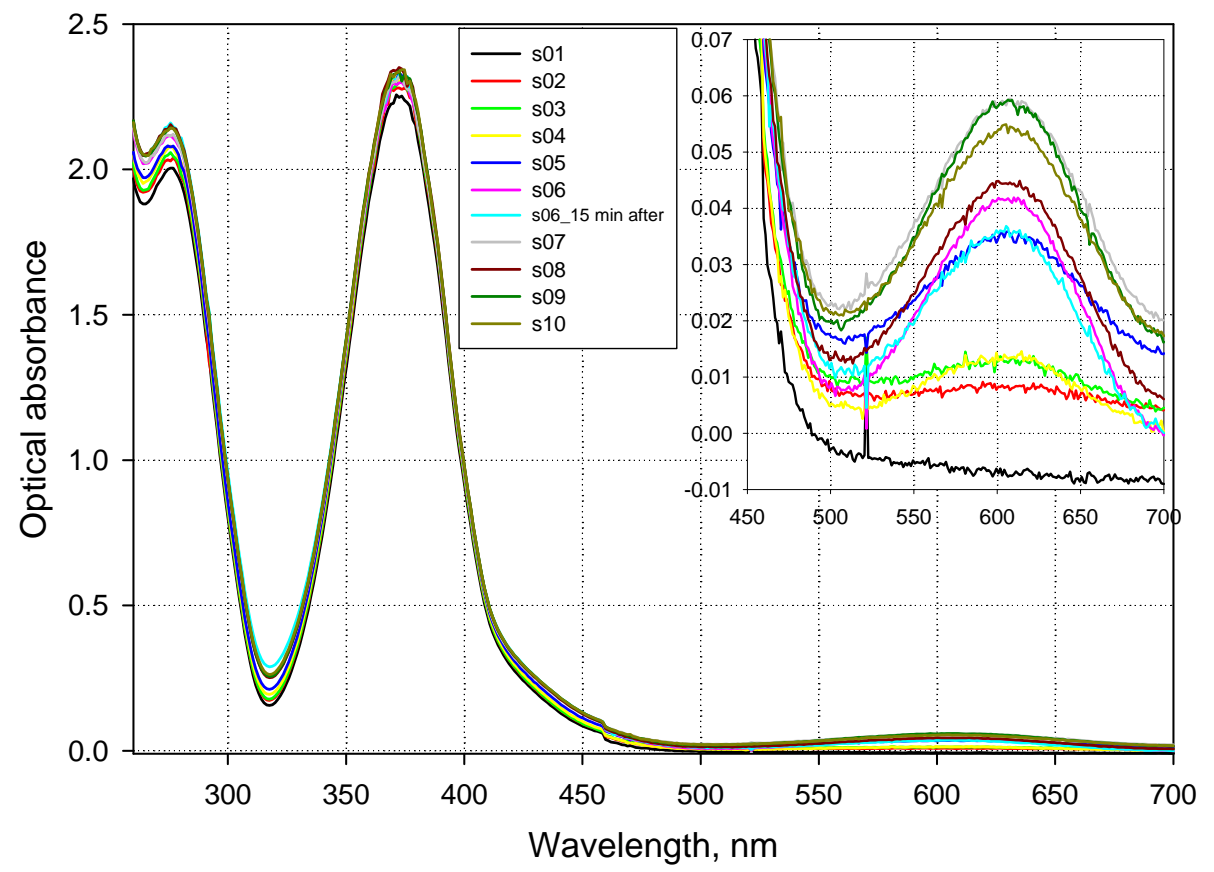

Figure 3.39. Oxidative Leaching of $\mathrm{Fe}(\mathrm{OH})_{3} / \mathrm{Cr}(\mathrm{OH})_{3} / \mathrm{Pu}(\mathrm{OH})_{4}$ Sludge Simulant with Excessive Amount of Permanganate. The permanganate to $\mathrm{Cr}$ (III) molar ratio is as follows: $1: 1$, $1.033: 1 ; 1.05: 1 ; 1.066: 1 ; 1.083: 1$, and $1.117: 1$ for samples s01, s02, s03, s04, s05, and s06, respectively. Samples s07 to s10 represent the kinetics of oxidative leaching at the 1.117:1 molar ratio with a 30-min sampling frequency. 
In total, 10 leachate samples were collected, acidified, and analyzed by liquid scintillation counting. In all samples, no statistically significant difference between the observed counting rate and the background counting rate was found. The calculated percentage of $\mathrm{Pu}$ dissolution is less than $1.8 \%$, which corresponds to less than $0.018 \times 5.6=0.10 \mu \mathrm{M}$ of soluble $\mathrm{Pu}$ in the leachate.

In summary, oxidative-leaching tests at $0.25 \mathrm{M} \mathrm{NaOD}$ resulted in very low concentrations of solubilized $\mathrm{Pu}$ in the leachates (less than $0.1 \mu \mathrm{M}$ ), which are below the detection limit of $\mathrm{Pu}(\mathrm{VI})$ in this medium by OAS. Therefore, no attempt to apply LWCC detection for identifying the oxidation state of soluble $\mathrm{Pu}$ was made. No evidence of additional solubilization of $\mathrm{Pu}$ with longer contact times of the sludge stimulant with an excess of the oxidizer was found. The results obtained in this study are consistent with prior results of Pacific Northwest National Laboratory (PNNL) oxidative-alkaline leaching with washed Hanford tank sludges using permanganate in $0.1 \mathrm{M} \mathrm{NaOH}$ medium (Rapko et al. 2004). In those tests, the average fraction of $\mathrm{Pu}$ removed from the sludges was found to be $0.44 \pm 0.40 \%$ (based on results of eight tests). The average fraction of $\mathrm{Cr}$ removed for the same tests was determined to be $70 \pm 30 \%$, which is about $1 / 3$ lower than the practically quantitative leaching of $\mathrm{Cr}$ observed in this project for $1: 1$ and higher Mn(VII)-to-Cr(III) molar ratios.

\subsubsection{Leaching in $3 \mathrm{M}$ NaOD Solution}

PNNL oxidative-alkaline leaching tests performed with permanganate at a $3 \mathrm{M} \mathrm{NaOH}$ concentration with washed Hanford tank sludges (Rapko et al. 2004) showed much higher levels of dissolved Pu (from 2 to $69 \%$ of Pu removed; with an average value of $24 \pm 25 \%$ ) and a higher efficiency of $\mathrm{Cr}$ removal (from $45 \%$ to $99.6 \%$ with an average value of $88 \pm 18 \%$ ). Therefore, in this project, it was decided to run several oxidative-leaching experiments at this higher level of alkalinity to see to what extent the enhanced leaching of $\mathrm{Pu}$ could be reproduced with simplified sludge simulant and to examine the kinetic features of this process.

Experimental conditions used for this group of tests (amount of sludge, liquid to solid ratio, stirring speed, etc.) were essentially the same as with leaching tests at $0.25 \mathrm{M} \mathrm{NaOD}$.

\section{Superstoichiometric Amount of Permanganate}

Three superstoichiometic ratios of $\mathrm{Mn}$ (VII) to $\mathrm{Cr}$ (III) in the sludge were studied. The 1.15:1 ratio was tested initially (using the 3-week-old simulant) followed by two more experiments with a higher excess of oxidant run in parallel 7 days later (4-week-old simulant from the same main batch). The results of these tests are shown in Figure 3.40. All three tests demonstrate the very unexpected trend of decreasing the yield of solubilized $\mathrm{Pu}$ with time for the first $4.5 \mathrm{hr}$ of contact time. The same tendency is observed in the 1.15:1 curve for much longer contact times (up to 6 days). The highest concentration of dissolved $\mathrm{Pu}$ in all three tests was achieved just 3 minutes after simulant agitation in the presence of permanganatecontaining solution and was found to be $1.8 \mu \mathrm{M}, 2.0 \mu \mathrm{M}$, and $2.0 \mu \mathrm{M}$ for the tests with a $15 \%, 28 \%$, and $45 \%$ excess of permanganate, respectively. In 2 to 2.5 hours, it drops down to $1.0 \mu \mathrm{M}, 1.2 \mu \mathrm{M}$, and $1.3 \mu \mathrm{M}$ of dissolved $\mathrm{Pu}$, respectively. An analysis of the technical literature indicates that the decrease in concentration of dissolved plutonium was observed before in some tests with oxidative-alkaline leaching of real Hanford tank sludges using washed SX-101 sludge solids (see Figure 3.13 in Rapko et al. [2004]).

The Cr(III)-dissolution efficiency curve (data not shown) indicates practically complete dissolution of $\mathrm{Cr}(\mathrm{OH})_{3}$ from the simulant for the very first kinetic point (3 minutes after contact) regardless of the 
Mn(VII)-to-Cr(III) molar ratio followed by the same level of chromate concentration in leachate solutions in subsequent measurements. The leachate color in these tests after filtration was always green-yellow as opposed to the tests at a $0.25 \mathrm{M} \mathrm{NaOH}$ concentration where it was purple-yellow for $\mathrm{Mn}(\mathrm{VII}) / \mathrm{Cr}(\mathrm{III})$ ratios greater than 1:1. The greenish color at $3 \mathrm{M}$ of $\mathrm{NaOD}$ corresponds to the conversion of unreacted permanganate to manganate under these conditions. The manganate absorbance peak intensity was found to decrease with time for all three series, indicating partial reduction of $\mathrm{Mn}$ (VI) to insoluble $\mathrm{Mn}(\mathrm{IV})$. It is likely that additional removal of soluble $\mathrm{Pu}$ from the solution with time is related to the formation of additional $\mathrm{MnO}_{2}$ in the process of oxidative leaching and co-precipitation of $\mathrm{Pu}(\mathrm{VI})$ with manganese dioxide. More experiments are needed to verify this hypothesis.

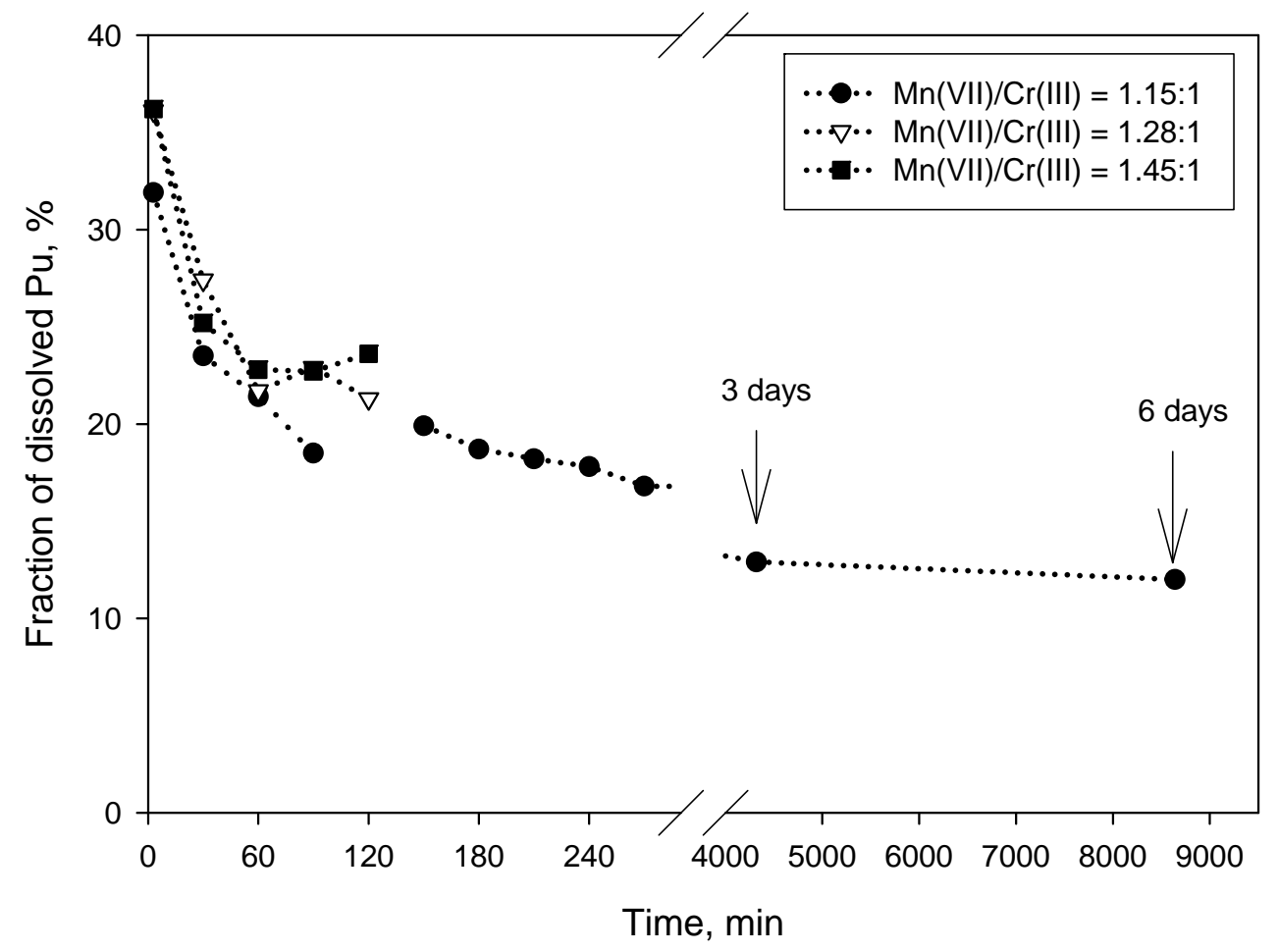

Figure 3.40. The Kinetics of Oxidative Leaching of $\mathrm{Fe}(\mathrm{OH})_{3} / \mathrm{Cr}(\mathrm{OH})_{3} / \mathrm{Pu}(\mathrm{OH})_{4}$ Sludge Simulant with Excessive Amount of Permanganate. The 120-min point for the 1.15:1 curve showed an abnormally high leaching percentage both for $\mathrm{Cr}(\mathrm{III})$ and $\mathrm{Pu}(\mathrm{VI})$ (most likely associated with a pipetting error) and is not included in the plot.

\section{Substoichiometric to Stoichiometric Amount of Permanganate}

Three series of oxidative alkaline leaching were performed with molar ratios of $\mathrm{Mn}$ (VII) to $\mathrm{Cr}$ (III) set at $0.66: 1,0.83: 1$, and 1:1. Only two kinetic points were measured in these experiments: 3 minutes after mixing and 30 minutes after mixing. No additional increase in the level of $\mathrm{Cr}(\mathrm{VI})$ concentration in leachate was found between these two points within each series. In all three cases, the filtrate color was yellow, indicating complete consumption of $\mathrm{Mn}(\mathrm{VII})$ [and $\mathrm{Mn}(\mathrm{VI})$ ] in the process of $\mathrm{Cr}$ (III) conversion to $\mathrm{Cr}(\mathrm{VI})$. Liquid scintillation counting (LSC) data showed no signs of Pu solubilization for all three ratios studied $(<1.8 \%$ of potentially soluble plutonium present in the leachates). Table 3.7 summarizes the results of these tests. 
Table 3.7. Concentrations of $\mathrm{Cr}(\mathrm{VI})$ and Soluble $\mathrm{Pu}$ in the $3 \mathrm{M}$ NaOD Leachates with Substoichiometric to Stoichiometric Addition of Mn(VII)

\begin{tabular}{|c|c|c|c|c|c|c|c|}
\hline \multirow[b]{2}{*}{$\begin{array}{c}\text { Mn(VII)/Cr(III) } \\
\text { Molar Ratio }\end{array}$} & \multirow{2}{*}{$\begin{array}{c}\mathrm{C}_{\mathrm{Cr}(\mathrm{VI})} \\
\text { Expected, } \\
\mathbf{M}^{(\mathrm{a})}\end{array}$} & \multirow{2}{*}{$\begin{array}{c}\mathbf{C}_{\mathrm{Cr}(\mathrm{VI})} \\
\text { Actually } \\
\text { Measured, } \\
\mathbf{M}^{(\mathbf{b})}\end{array}$} & \multirow{2}{*}{$\begin{array}{l}\text { Calculated } \\
\text { Volume of } \\
\text { Interstitial } \\
\text { Liquid in the } \\
\text { Sludge, mL }\end{array}$} & \multicolumn{2}{|c|}{$C_{P u \text { in leachate }}, \mu M$} & \multicolumn{2}{|c|}{$\begin{array}{c}\text { Fraction of } \mathrm{Pu} \\
\text { Removed from the } \\
\text { Sludge, } \%\end{array}$} \\
\hline & & & & $3 \mathrm{~min}$ & $30 \mathrm{~min}$ & $3 \mathrm{~min}$ & $30 \mathrm{~min}$ \\
\hline $0.66: 1$ & 0.100 & 0.085 & 0.62 & $<0.102$ & $<0.102$ & $<1.8$ & $<1.8$ \\
\hline $0.83: 1$ & 0.123 & 0.104 & 0.64 & $<0.102$ & $<0.102$ & $<1.8$ & $<1.8$ \\
\hline $1.00: 1$ & 0.144 & 0.124 & 0.57 & $<0.102$ & $<0.102$ & $<1.8$ & $<1.8$ \\
\hline
\end{tabular}

\subsubsection{Quenching of Excessive Manganate in the Leachates with Weakly Acidic Solution of Cr(III)}

As follows from the results of oxidative alkaline leaching tests of the sludge simulant in $3 \mathrm{M} \mathrm{NaOD}$, appreciable solubilization of $\mathrm{Pu}$ from the sludge (in the 1.5- to $2-\mu \mathrm{M}$ range) can be achieved only with an excessive amount of oxidizer in terms of the $\mathrm{Mn}(\mathrm{VII}) / \mathrm{Cr}(\mathrm{III})$ molar ratio. The leachate produced in these tests always had a green color of varied intensity due to the presence of unreacted oxidant as manganate. Manganate absorbs strongly in the red region of the spectrum and (see Section 3.9.1) obscures weak spectral features of $\mathrm{Pu}(\mathrm{V})$ and $\mathrm{Pu}(\mathrm{VI})$ by its own absorbance in the 550- to 770-nm range when both $\mathrm{Pu}$ and $\mathrm{Mn}(\mathrm{VI})$ are present in comparable concentrations. In the solutions produced by the oxidative leaching of the $\mathrm{Fe}(\mathrm{OH})_{3} / \mathrm{Cr}(\mathrm{OH})_{3} / \mathrm{Pu}(\mathrm{OH})_{4}$ sludge simulant with $15 \%$ molar excess of permanganate, the residual manganate was found to be present approximately at the $0.018 \mathrm{M}$ level of concentration, which represents $0.018: 2 \times 10^{-6}=9000$-fold excess with respect to the concentration of soluble $\mathrm{Pu}$. This enormous ratio makes the application of LWCC for detecting Pu spectra in undiluted solution impossible, simply due to a huge attenuation of light, not only in the region of the major absorbance band of Mn(VII) at $603 \mathrm{~nm}$, but in all of the usable range of solvent transparency (550 to $960 \mathrm{~nm}$ ). One possible way to decrease the level of manganate in the leachate solution is to add a reducing agent to convert soluble $\mathrm{Mn}(\mathrm{VI})$ to insoluble $\mathrm{MnO}_{2}$. Several reductants were considered, but it was concluded that the solution of $\mathrm{Cr}$ (III) nitrate would be the best choice for practical application because the $\mathrm{Cr}$ (III) in the process of $\mathrm{Mn}(\mathrm{VI})$ reduction gets oxidized to $\mathrm{Cr}(\mathrm{VI})$, which is already present in the leachate solution and (as was shown earlier) does not interfere with $\mathrm{Pu}(\mathrm{V})$ and $\mathrm{Pu}(\mathrm{VI})$ spectra in the 550- to 960-nm range. Before applying the $\mathrm{Cr}$ (III) to the Pu-containing solution, it was tested in a cold experiment with manganate to establish reaction stoichiometry between these species.

Verification of the Reaction Stoichiometry in the Process of Manganate Reduction with $\mathrm{Cr}(\mathrm{OH})_{4}{ }^{-}$

A solution of sodium manganate was prepared by the spontaneous reduction of permanganate by water in $2.5 \mathrm{M}$ of $\mathrm{NaOD}$. This reaction was performed in a glass vial and was observed to proceed slowly as it did not go to completion even after 9 weeks, as shown in Figure 3.41 (black trace [s00] showing several finely structured peaks of residual permanganate with the most prominent ones at 528 and $546 \mathrm{~nm}$ ). 
Therefore, Cr(III) addition was performed in several increments with the first addition made to convert all residual permanganate to manganate (this step is not shown as a separate spectral trace in the figure).

Each subsequent time after adding Cr(III), the solution became less greenish and turbid because of $\mathrm{Mn}(\mathrm{VI})$ conversion to $\mathrm{Mn}(\mathrm{IV})$. The turbidity was eliminated by centrifuging the sample before spectral measurement to remove colloidal $\mathrm{MnO}_{2}$ from the beam propagation zone and to measure the manganate peak intensity more precisely. Three more additions of $\mathrm{Cr}$ (III) resulted in significant discoloration of the reaction mixture (dark red, green, and pink spectral traces). A decrease in the 603-nm peak intensity between the second and the third addition of $\mathrm{Cr}(\mathrm{III})\left(\Delta \mathrm{A}_{603}=1.95-1.41=0.54\right)$ corresponded to a reduction of $0.3375 \mathrm{mM}$ of manganate with $0.222 \mathrm{mM}$ of $\mathrm{Cr}(\mathrm{III})$. The ratio between these two numbers is $1.52: 1$, which is very close to the theoretically expected ratio of $3: 2$. Therefore, the process of Mn(VI) quenching with $\mathrm{Cr}$ (III) can be described by the following chemical reaction:

$$
3 \mathrm{MnO}_{4}{ }^{2-}+2 \mathrm{Cr}^{3+}+4 \mathrm{OH}^{-}=3 \mathrm{MnO}_{2}+2 \mathrm{CrO}_{4}{ }^{2-}+2 \mathrm{H}_{2} \mathrm{O}
$$

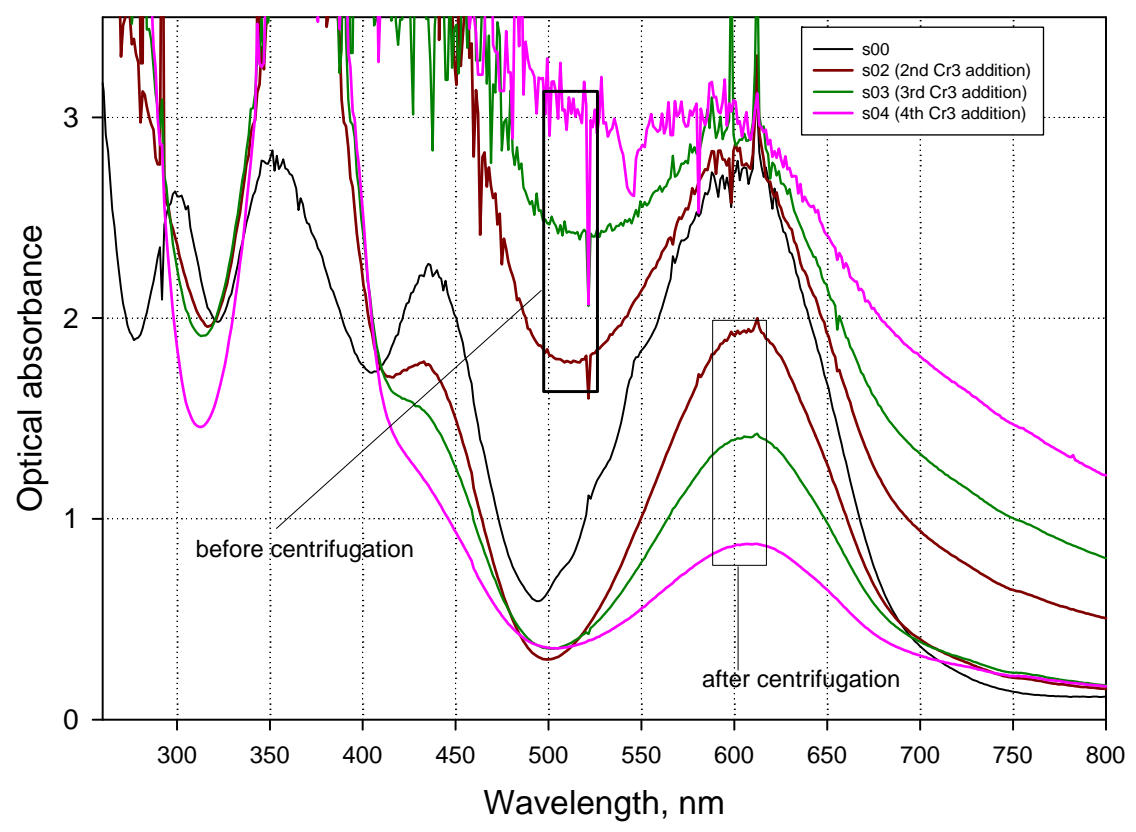

Figure 3.41. Cold Experiment on Stepwise Reduction of Manganate by $\mathrm{Cr}(\mathrm{OH})_{4}{ }^{-}$in $2.5 \mathrm{M} \mathrm{NaOD}$. The spectral trace $\mathrm{s} 00$ represents the starting solution of manganate with a small admixture of remaining permanganate.

\section{Application of Soluble Cr(III) Treatment to Leachate from Oxidative-Leaching Test with 15\% Molar Excess of Permanganate in $3 \mathrm{M} \mathrm{NaOD}$}

After the reaction stoichiometry between $\mathrm{Cr}(\mathrm{III})$ and $\mathrm{Mn}(\mathrm{VI})$ was established, an attempt was made to treat the $\mathrm{Pu}$-containing leachate solution from the experiment on sludge simulant leaching with a $15 \%$ excess of permanganate in $3 \mathrm{M} \mathrm{NaOD}$. All 6 days before this experiment was conducted, the leachate had been stored in the original oxidative-leaching container without separation from the undissolved fraction of the sludge simulant and newly formed $\mathrm{MnO}_{2}$. As follows from Figure 3.41 (11 points curve with filled circles), during this storage period, the percentage of leached Pu decreased from $32 \%$ to $12 \%$, which 
corresponds to the remaining concentration of soluble plutonium at $1.8 \times 12 / 32=0.68 \mu \mathrm{M}$. At the same time, the manganate peak intensity at $603 \mathrm{~nm}$ dropped down from 0.071 to 0.058 absorbance units (data not shown) because of the partial conversion of $\mathrm{Mn}(\mathrm{VI})$ to insoluble $\mathrm{MnO}_{2}$. This indicates that the spontaneous decomposition of manganate in the leachate with time was accompanied by an additional removal of soluble $\mathrm{Pu}$ from the solution, presumably due to the co-precipitation of $\mathrm{Pu}(\mathrm{VI})$ with newly formed $\mathrm{MnO}_{2}$.

To eliminate manganate completely from solution, five additions of near-neutral $\mathrm{Cr}\left(\mathrm{NO}_{3}\right)_{3}$ solution were made with 30-min intervals between consecutive additions. The spectral data corresponding to separate steps of $\mathrm{Cr}$ (III) addition are shown in Figure 3.42, plot a). After each addition of $\mathrm{Cr}$ (III) a small portion of the solution was sampled and acidified for determination of the remaining concentration of soluble Pu. Plot b) in the same Figure shows the concentration profile of soluble plutonium at various stages of elimination of $\mathrm{Mn}(\mathrm{VI})$. One can see that complete removal of manganate from solution is accompanied by a decrease in $\mathrm{Pu}$ concentration to less than $0.04 \mu \mathrm{M}$. This level of $\mathrm{Pu}$ concentration can not be probed by LWCC. The effect of significant drop of $\mathrm{Pu}$ concentration at the very last $\mathrm{Cr}$ (III) addition stage can be partially related to coprecipitation of soluble $\mathrm{Pu}$ with $\mathrm{Cr}(\mathrm{OH})_{3}$ formed when excess of $\mathrm{Cr}^{3+}$ was added to the solution

\subsubsection{Comparison of Oxidative Alkaline Leaching of Pu from Sludge Simulant with Other Studies}

Enhanced solubilization of Pu after oxidative alkaline leaching of Hanford tank waste sludge simulants by permanganate at $3.0 \mathrm{M} \mathrm{NaOH}$ concentration were recently reported by Nash and colleagues (Nash et al. 2005). The leaching efficiency of $\mathrm{Pu}$ was found to be a non-linear function of the initial level of $\mathrm{MnO}_{4}{ }^{-}$ concentration in contact with simulants. Fractions of $\mathrm{Pu}$ leached at the highest tested concentration of $\mathrm{MnO}_{4}{ }^{-}$of $0.1 \mathrm{M}$ amounted to $35 \%, 72 \%$, and $80 \%$ for the $\mathrm{BiPO}_{4}$, plutonium-uranium extraction (PUREX), and REDOX sludge simulants, respectively. The way these simulants were prepared [adding $\mathrm{Pu}(\mathrm{IV})$ or $\mathrm{Pu}(\mathrm{VI})$ hydroxycarbonato complex to the bulk of non-radioactive sludge simulant matrix], in our opinion, did not result in homogeneous distribution of $\mathrm{Pu}$ traces within the simulant matrix and does not simulate the creation of sludge in Hanford waste neutralization processes. For this reason, we believe that leaching results obtain by Nash and colleagues (2005) significantly overestimate the dissolution efficiency of $\mathrm{Pu}$ compared with homogeneously distributed samples studied in this project.

A drastic difference observed in this work between the extent of Pu solubilization from the sludge simulant by an excess of permanganate at $0.25 \mathrm{M}$ and $3 \mathrm{M}$ concentrations of $\mathrm{NaOD}$ is consistent with results of a study on the co-precipitation of $\mathrm{Pu}(\mathrm{VI}, \mathrm{V})$ from alkaline solution with manganese dioxide produced by reduction of permanganate by the method of appearing reagents (Krot et al. 1998). These researchers found that "coefficients of decontamination" $\left(\mathrm{K}_{\mathrm{d}}\right)$ of $\mathrm{NaOH}$ solutions from $\mathrm{Pu}(\mathrm{VI})$ by precipitation of $\mathrm{MnO}_{2}$ obtained by $\mathrm{MnO}_{4}^{-}$reduction with hydrogen peroxide are a sensitive function of $\mathrm{NaOH}$ concentration. There is practically no difference between $\mathrm{K}_{\mathrm{d}}$ values in the 0.5 - to 1-M concentration range of $\mathrm{NaOH}$ and a very significant loss of $\mathrm{Pu}(\mathrm{VI})$ affinity to $\mathrm{MnO}_{2}$ between a 1- and 2$\mathrm{M}$ concentration of $\mathrm{NaOH}$. 


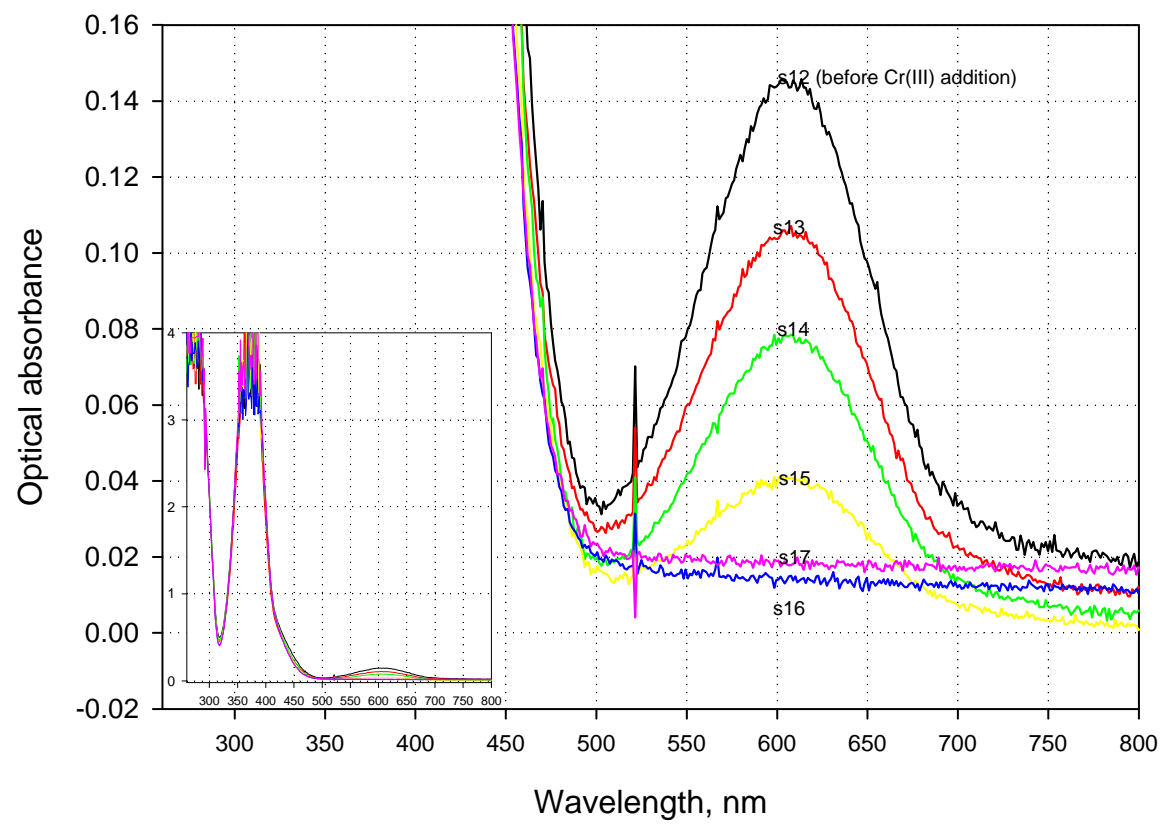

a)

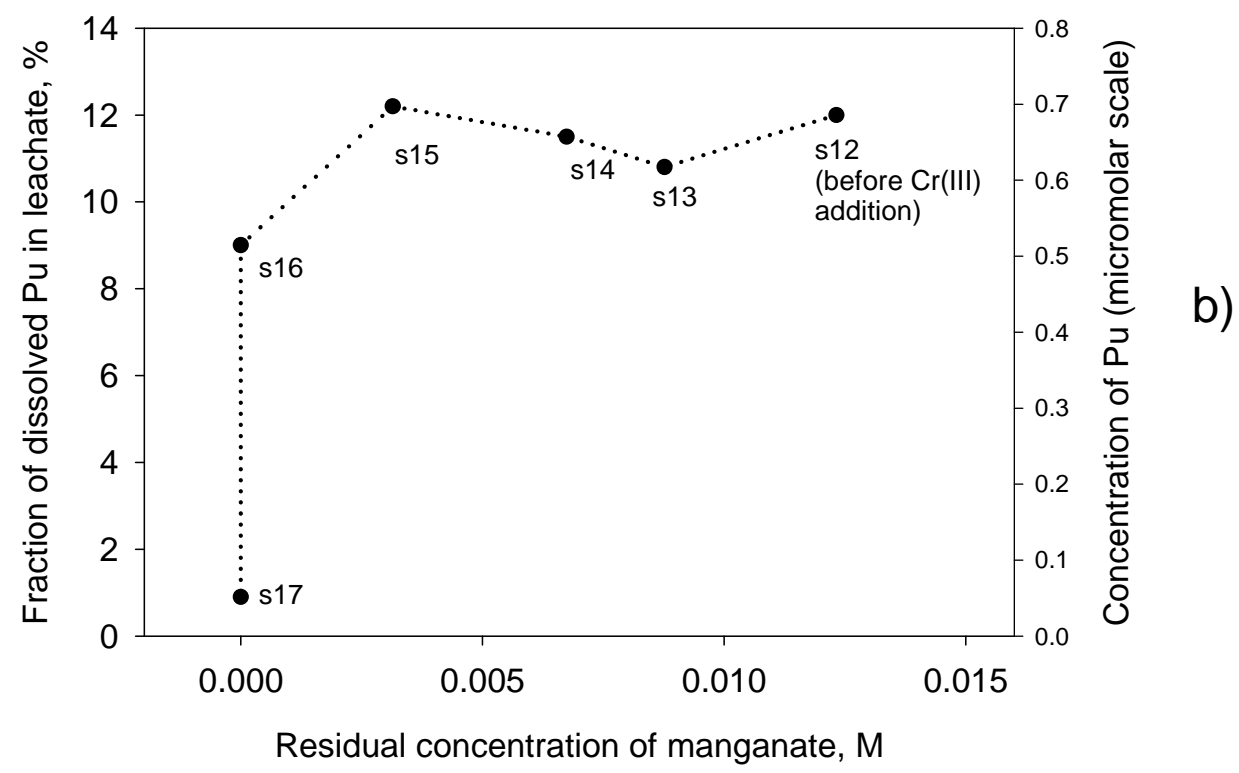

Figure 3.42. Quenching of Excessive $\mathrm{Mn}(\mathrm{VI})$ with Soluble $\mathrm{Cr}(\mathrm{III})$ Nitrate in $3 \mathrm{M}$ NaOD Leachate 6 Days After Oxidative Treatment of $\mathrm{Fe}(\mathrm{OH})_{3} / \mathrm{Cr}(\mathrm{OH})_{3} / \mathrm{Pu}(\mathrm{OH})_{4}$ Sludge Simulant with $15 \%$ Molar Excess of $\mathrm{Mn}(\mathrm{VI})$ : a) $\mathrm{Mn}(\mathrm{VI})$ peak intensity decrease with increasing amount of $\mathrm{Cr}(\mathrm{III})$ added; b) concentration profile of soluble plutonium at various stages of elimination of $\mathrm{Mn}(\mathrm{VI})$ from solution. 


\subsection{Conclusions}

This section describes findings of the project tests, including spectral ranges and signatures, redox stability, detection limits, and oxidation and redox potentials. There is also a summary of the dissolution of $\mathrm{Pu}(\mathrm{OH})_{4}$ (solid) in alkaline permanganate and manganate solutions as well as a summary of the oxidative leaching of $\mathrm{Fe}(\mathrm{OH})_{3}+\mathrm{Cr}(\mathrm{OH})_{3}+\mathrm{Pu}(\mathrm{OH})_{4}$ sludge simulant.

- A spectral range of 500-cm long LWCC in alkaline chromate containing solutions is found to be 560 to $700 \mathrm{~nm}$ and 560 to $960 \mathrm{~nm}$ in $\mathrm{H}_{2} \mathrm{O}$ and $\mathrm{D}_{2} \mathrm{O}$ solvents, respectively.

- Spectral signatures and the redox stability of $\mathrm{Pu}(\mathrm{V})$ and $\mathrm{Pu}(\mathrm{VI})$ in the $0.1-$ to $1-\mathrm{M} \mathrm{NaOD} / \mathrm{D}_{2} \mathrm{O}$ solutions at low micromolar $\mathrm{Pu}$ concentrations are established:

o A detection limit of $\mathrm{Pu}(\mathrm{VI})$ at $625 \mathrm{~nm}$ is found to be $0.5 \pm 0.04 \mu \mathrm{M}$ both for $0.1-$ and $1-\mathrm{M}$ NaOD solutions.

o At $1 \mathrm{M}$ alkalinity, an initially pure $\mathrm{Pu}(\mathrm{VI})$ solution shows partial conversion to $\mathrm{Pu}(\mathrm{V})$ with time (up to $12 \%$ in 3 days).

o Detection limits of $\mathrm{Pu}(\mathrm{V})$ at $653 \mathrm{~nm}$ and $809 \mathrm{nM}$ are found to be $0.24 \mu \mathrm{M}$ and $0.38 \mu \mathrm{M}$, respectively, in a $1 \mathrm{M} \mathrm{NaOD}$ solution in the concentration range of $\mathrm{Pu}(\mathrm{V})$ up to $23 \mu \mathrm{M}$.

- $\mathrm{Pu}(\mathrm{V})$ in $0.25 \mathrm{M}$ of $\mathrm{NaOD}$ is not stable and undergoes disproportionation to $\mathrm{Pu}(\mathrm{IV})$ and $\mathrm{Pu}(\mathrm{VI})$. A limited linearity of the calibration curve is established up to $1.6 \mu \mathrm{M}$ concentration of $\mathrm{Pu}(\mathrm{V})$.

- $\mathrm{Pu}(\mathrm{IV})$ in $0.25 \mathrm{M} \mathrm{NaOD}$ solution does not show any clearly identifiable spectral signatures because of the low solubility of $\mathrm{Pu}(\mathrm{IV})(0.022 \pm 0.005 \mu \mathrm{M})$.

- The redox behavior of $\mathrm{Pu}(\mathrm{V})$ in $\mathrm{NaOD}$ does not change in the presence of chromate.

- The effect of carbonate on the spectral characteristics of $\mathrm{Pu}(\mathrm{VI}, \mathrm{V}$, and IV) is determined:

- $\mathrm{A} \mathrm{Pu}(\mathrm{VI})$ mixed hydroxy-carbonate complex formation manifests itself in the 860- to 870 -nm spectral range with an exact peak position being a function of the $\mathrm{NaOD}$ concentration and the $\mathrm{CO}_{3}{ }^{2-} / \mathrm{OD}^{-}$ratio.

o The effect of carbonate on the $\mathrm{Pu}(\mathrm{V})$ spectra is the most clearly seen in the 725- to $775-\mathrm{nm}$ range in addition to the red shift of the major peak of $\mathrm{Pu}(\mathrm{V})$ from $809 \mathrm{~nm}$ to $825 \mathrm{~nm}$.

o Solubility enhancement for $\mathrm{Pu}(\mathrm{IV})$ solutions in $0.25 \mathrm{M}$ of $\mathrm{NaOD}$ in the presence of carbonate is related to the partial oxidation of $\mathrm{Pu}(\mathrm{IV})$ to $\mathrm{Pu}(\mathrm{V})$ (weak spectral signatures at $653 \mathrm{~nm}$ and $825 \mathrm{~nm}$ ).

- Formal oxidation potentials of $\mathrm{Pu}(\mathrm{VI}) / \mathrm{Pu}(\mathrm{V})$ were measured in a series of $\mathrm{NaOD}$ solutions from 0.25 - to 1-M hydroxide concentration. 
- Redox potentials of the $\mathrm{Mn}(\mathrm{VII}) / \mathrm{Mn}(\mathrm{VI})$ couple were measured in 0.25- to 1-M NaOD solutions with a wide variation of permanganate-to-manganate ratios, including pure manganate solutions.

- Ionic forms of $\mathrm{Pu}(\mathrm{IV})$ and $\mathrm{Pu}(\mathrm{V})$ in a $0.25 \mathrm{M} \mathrm{NaOD}$ solution undergo rapid oxidation to $\mathrm{Pu}(\mathrm{VI})$ in the presence of $\mathrm{Mn}(\mathrm{VII})$ and $\mathrm{Mn}(\mathrm{VI})$.

- $\mathrm{Pu}(\mathrm{OH})_{4}$ (solid) interacts with an alkaline solution of $\mathrm{Mn}(\mathrm{VII})$, not only as a catalyst of $\mathrm{Mn}(\mathrm{VII})$ to $\mathrm{Mn}(\mathrm{VI})$ reduction by water, but also as a reducing agent itself with significant solubilization of $\mathrm{Pu}$ via oxidation of $\mathrm{Pu}(\mathrm{IV})$ to $\mathrm{Pu}(\mathrm{VI})$, even at a low molar excess of $\mathrm{Mn}(\mathrm{VII})$.

- The technique of acidic strike of initially alkaline plutonium-containing solution in the presence of $\mathrm{Cr}(\mathrm{VI})$ and $\mathrm{Mn}$ (VII) causes significant perturbation of lower oxidation states of $\mathrm{Pu}$ with very fast oxidation of $\mathrm{Pu}(\mathrm{V})$ by $\mathrm{Cr}(\mathrm{VI})$ alone and rapid oxidation of $\mathrm{Pu}(\mathrm{IV})$ by mixture of $\mathrm{Cr}(\mathrm{VI})$ and $\mathrm{Mn}(\mathrm{VII})$.

\subsection{Summary of Dissolution of $\mathrm{Pu}(\mathrm{OH})_{4}$ (solid) in Alkaline Permanganate and Manganate Solutions}

- Evidence of significant dissolution of $\mathrm{Pu}(\mathrm{OH})_{4}$ by alkaline solution of $\mathrm{Mn}(\mathrm{VII})$ was obtained [up to $53 \%$ at $3.4: 1$ molar ratio of $\mathrm{Mn}(\mathrm{VII})$ to $\mathrm{Pu}(\mathrm{IV})$ in $0.25 \mathrm{M} \mathrm{NaOH}$ ].

- $\mathrm{Mn}(\mathrm{VI})$ is a much less efficient dissolving agent (6 to $15 \%$ of $\mathrm{Pu}(\mathrm{OH})_{4}$ dissolved under identical conditions) than is $\mathrm{Mn}(\mathrm{VII})$.

- The consumption of permanganate in experiments with aged $\mathrm{Pu}(\mathrm{OH})_{4}$ exceeds the expected 2:1 stoichiometry for the $\mathrm{Pu}(\mathrm{IV})+2 \mathrm{Mn}(\mathrm{VII})=\mathrm{Pu}(\mathrm{VI})+2 \mathrm{Mn}(\mathrm{VI})$ reaction. This gives evidence of catalytic reduction of $\mathrm{Mn}(\mathrm{VII})$ by water in the presence of undissolved $\mathrm{Pu}(\mathrm{IV})$ hydroxide.

- A 3:1 oxidative reaction stoichiometry is found with in situ formed $\mathrm{Pu}(\mathrm{OH})_{4}$ in an alkaline solution of Mn(VII).

\subsection{Summary of Oxidative Leaching of $\mathrm{Fe}(\mathrm{OH})_{3}+\mathrm{Cr}(\mathrm{OH})_{3}+\mathrm{Pu}(\mathrm{OH})_{4}$ Sludge Simulant}

Note: This work appears to be the first reported study in which plutonium-containing sludge simulant for the REDOX Process Hanford tank sludge was prepared by neutralizing an initially homogeneous solution of $\mathrm{Fe}\left(\mathrm{NO}_{3}\right)_{3}+\mathrm{Cr}\left(\mathrm{NO}_{3}\right)_{3}+\mathrm{Pu}\left(\mathrm{NO}_{3}\right)_{4}$ from an acidic medium as opposed to spiking a $\mathrm{Pu}(\mathrm{IV})$ solution into a heterogenous mixture of $\mathrm{Fe}(\mathrm{OH})_{3}+\mathrm{Cr}(\mathrm{OH})_{3}$ in an alkaline medium.

- Oxidative leaching of sludge simulant in $0.25 \mathrm{M}$ of $\mathrm{NaOH}$

o The quantitative dissolution of $\mathrm{Cr}(\mathrm{OH})_{3}$ by $\mathrm{NaMnO}_{4}$ occurs in the first 3 minutes after $\mathrm{Mn}(\mathrm{VII})$ addition with stirring, starting from a 1:1 $\mathrm{Mn}(\mathrm{VII}) / \mathrm{Cr}(\mathrm{III})$ molar ratio.

o No detectable $\mathrm{Pu}$ concentration was found in the leachate at $0.25 \mathrm{M}$ of $\mathrm{NaOH}$ regardless of contact time (up to 3 days) and a molar excess of $\mathrm{Mn}$ (VII) with respect to $\mathrm{Cr}$ (III) (the dissolved fraction of $\mathrm{Pu}$ is less than $1.8 \%$; the estimated soluble $\mathrm{Pu}$ concentration is less than $0.1 \mu \mathrm{M}$ ). Excess oxidant remains in the leachate solution as permanganate. 
- Oxidative leaching of sludge simulant in $3.0 \mathrm{M}$ of $\mathrm{NaOH}$

o The dissolution of $\mathrm{Cr}(\mathrm{OH})_{3}$ is very fast and quantitative if a sufficient amount of permanganate is added.

o $32 \%$ of $\mathrm{Pu}$ is present in the leachate in the first 3 minutes after oxidant addition at a $1.15: 1 \mathrm{Mn}(\mathrm{VII}) / \mathrm{Cr}(\mathrm{III})$ molar ratio $\left(\mathrm{C}_{\mathrm{Pu}}=1.5 \mu \mathrm{M}\right)$.

o A higher excess of oxidant (up to $1.45: 1$ ) does not increase the percentage of dissolved $\mathrm{Pu}$.

- The dissolved fraction of $\mathrm{Pu}$ in the leachate in contact with metathesized sludge and an excess of manganate decreases with time $\left(32 \%_{3 \mathrm{~min}} \rightarrow 21 \%_{1 \mathrm{hr}} \rightarrow 18 \%_{4.5 \mathrm{hr}} \rightarrow 13 \%_{3}\right.$ days $\rightarrow 12 \%$ d days).

o There is no detectable $\mathrm{Pu}$ in the leachate at a substoichiometric $\mathrm{Mn}(\mathrm{VII}) / \mathrm{Cr}(\mathrm{III})$ molar ratio.

o Excess oxidant in the leachate solution is present as manganate.

o The quenching of excess oxidant with $\mathrm{Cr}(\mathrm{III})$ nitrate $\left(3 \mathrm{MnO}_{4}{ }^{2-}+2 \mathrm{Cr}^{3+}+4 \mathrm{OH}^{-} \rightarrow 3 \mathrm{MnO}_{2}\right.$ $+2 \mathrm{CrO}_{4}{ }^{2-}+2 \mathrm{H}_{2} \mathrm{O}$ ) results in additional $95 \%$ removal of $\mathrm{Pu}$ from the leachate. As result of this treatment, the dissolved $\mathrm{Pu}$ concentration decreases from $0.67 \mu \mathrm{M}$ to $0.032 \mu \mathrm{M}$. 
PNNL-16844

WTP-RPT-165, Rev 0

\section{Distribution}

No. of

Copies

OFFSITE

$1 \quad$ Savannah River National Laboratory

Richard Edwards

Savannah River National Laboratory

Westinghouse SA

Aiken, SC 29808-0001
No. of

Copies

ONSITE

$7 \quad$ Pacific Northwest National Laboratory

C.H. Delegard

P7-25

D. E. Kurath

P7-28

G.J. Lumetta

$\mathrm{P} 7-22$

B.M. Rapko

P7-25

S. I. Sinkov

P7-25

Project Office (2)

P7-28

2 Bechtel National, Inc.

D. Alford (2)

H4-02

Distr. 1 